\title{
High Flux Isotope Reactor Low-Enriched Uranium Low Density Silicide Fuel Design Parameters
}

\section{Approved for public release.} Distribution is unlimited.
Benjamin R. Betzler

David Chandler

Jin Whan Bae

Germina Ilas

Jennifer L. Meszaros

March 22, 2021 


\section{DOCUMENT AVAILABILITY}

Reports produced after January 1, 1996, are generally available free via US Department of Energy (DOE) SciTech Connect.

Website: http://www.osti.gov/

Reports produced before January 1, 1996, may be purchased by members of the public from the following source:

National Technical Information Service

5285 Port Royal Road

Springfield, VA 22161

Telephone: 703-605-6000 (1-800-553-6847)

TDD: 703-487-4639

Fax: 703-605-6900

E-mail: info@ntis.gov

Website: http://classic.ntis.gov/

Reports are available to DOE employees, DOE contractors, Energy Technology Data Exchange representatives, and International Nuclear Information System representatives from the following source:

Office of Scientific and Technical Information

PO Box 62

Oak Ridge, TN 37831

Telephone: $865-576-8401$

Fax: 865-576-5728

E-mail: report@osti.gov

Website: http://www.osti.gov/contact.html

This report was prepared as an account of work sponsored by an agency of the United States Government. Neither the United States Government nor any agency thereof, nor any of their employees, makes any warranty, express or implied, or assumes any legal liability or responsibility for the accuracy, completeness, or usefulness of any information, apparatus, product, or process disclosed, or represents that its use would not infringe privately owned rights. Reference herein to any specific commercial product, process, or service by trade name, trademark, manufacturer, or otherwise, does not necessarily constitute or imply its endorsement, recommendation, or favoring by the United States Government or any agency thereof. The views and opinions of authors expressed herein do not necessarily state or reflect those of the United States Government or any agency thereof. 


\title{
HIGH FLUX ISOTOPE REACTOR LOW-ENRICHED URANIUM LOW DENSITY SILICIDE FUEL DESIGN PARAMETERS
}

\author{
Benjamin R. Betzler \\ David Chandler \\ Jin Whan Bae \\ Germina Ilas \\ Jennifer L. Meszaros
}

March 22, 2021

Prepared by

OAK RIDGE NATIONAL LABORATORY

Oak Ridge, TN 37831-6283

managed by

UT-Battelle, LLC

for the

US DEPARTMENT OF ENERGY

under contract DE-AC05-00OR22725 



\section{CONTENTS}

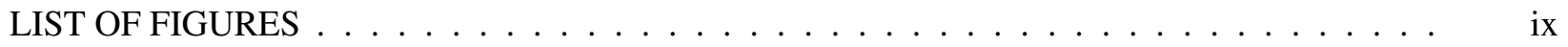

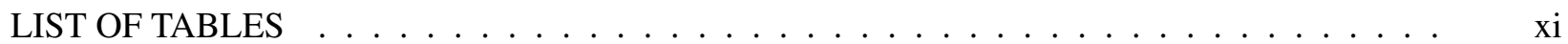

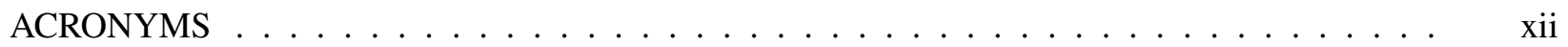

ACKNOWLEDGMENTS . . . . . . . . . . . . . . . . . . . xiii

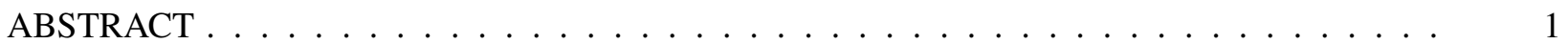

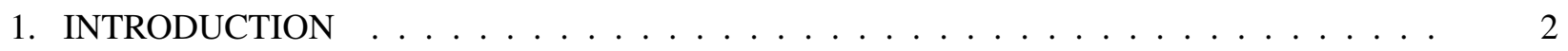

2. FUEL ELEMENT GEOMETRY $\ldots \ldots \ldots \ldots \ldots \ldots \ldots \ldots \ldots$

3. SILICIDE DISPERSION FUEL $\ldots \ldots \ldots \ldots \ldots \ldots \ldots \ldots \ldots$

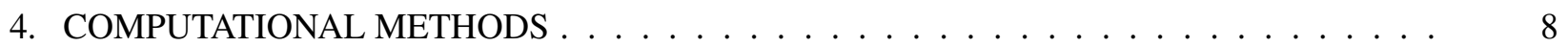

4.1 Neutronics Mesh . . . . . . . . . . . . . . . . . . . . . . . . . 8

4.2 Depletion Modeling . . . . . . . . . . . . . . . . . . . . . . 9

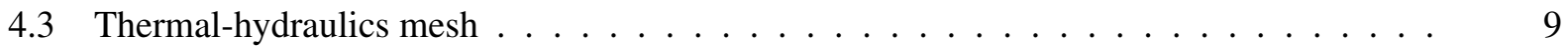

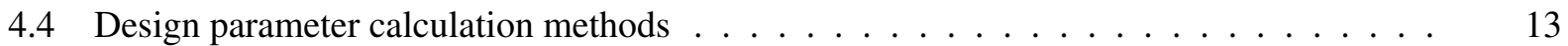

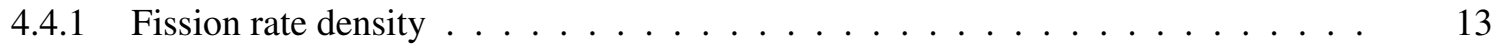

4.4 .2 Cumulative fission density . . . . . . . . . . . . . . . . . . 13

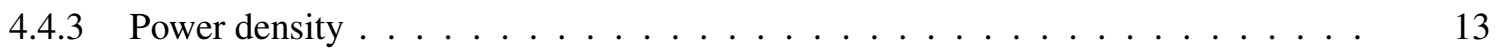

4.4.4 Heat flux . . . . . . . . . . . . . . . . . . . . . 13

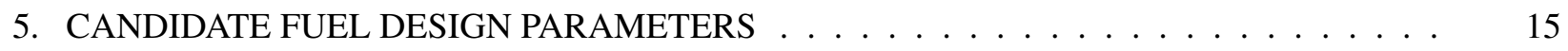

6. OVERVIEW OF METRICS . . . . . . . . . . . . . . . . . . . . . . . . . 19

6.1 DESCRIPTION OF METRICS . . . . . . . . . . . . . . . . . . . . . . . . . . . . . . 19

6.1 .1 Cf Production Rate . . . . . . . . . . . . . . . . . . . . . . . . . 19

6.1 .2 Cycle Length . . . . . . . . . . . . . . . . . . . . . 20

6.1 .3 Cold Source Flux and Ratio _ . . . . . . . . . . . . . . . . 20

6.1 .4 Flux Trap Fast Flux and Ratio $\ldots \ldots \ldots \ldots$

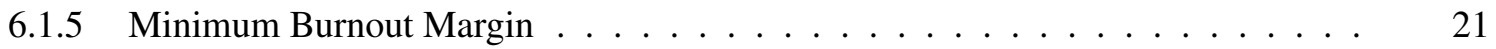

6.1.6 Reflector Fast Flux and Ratio . . . . . . . . . . . . . . . . . . . . . 21

$6.1 .7{ }^{235} \mathrm{U}$ Loading and Utilization . . . . . . . . . . . . . . . . . . . . . . . . 21

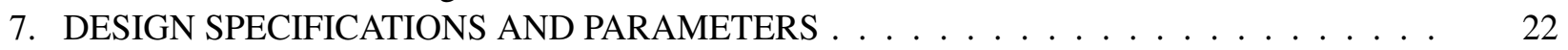

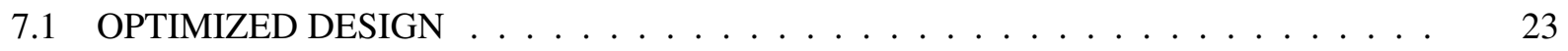

7.1 .1 Fuel Meat Shape . . . . . . . . . . . . . . . . . . . . . 24

7.1 .2 Fission Rate Density . . . . . . . . . . . . . . . . . . . 26

7.1 .3 Power Density . . . . . . . . . . . . . . . . . . . . . . 27

7.1 .4 Heat Flux . . . . . . . . . . . . . . . . . . . . . . . . . . . 28

7.1.5 Cumulative Fission Density . . . . . . . . . . . . . . . . . . . 29

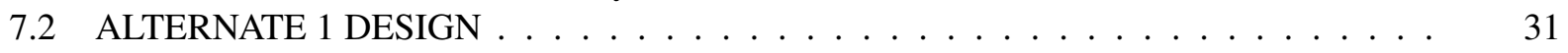

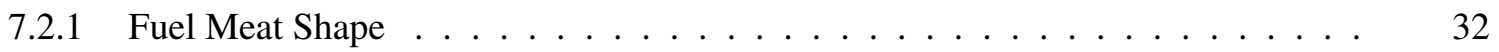

7.2 .2 Fission Rate Density . . . . . . . . . . . . . . . . . . . . . . . 34

7.2 .3 Power Density . . . . . . . . . . . . . . . . . . . . . . 35

7.2 .4 Heat Flux . . . . . . . . . . . . . . . . . . . . . . . . 36

7.2 .5 Cumulative Fission Density _ . . . . . . . . . . . . . . . 37

7.3 ALTERNATE 2 DESIGN . . . . . . . . . . . . . . . . . . . . . . . . . . . . 39

7.3 .1 Fuel Meat Shape . . . . . . . . . . . . . . . . . . . . 40

7.3 .2 Fission Rate Density . . . . . . . . . . . . . . . . . . . . 41

7.3 .3 Power Density . . . . . . . . . . . . . . . . . . . . . 43 
7.3 .4 Heat Flux . . . . . . . . . . . . . . . . . . . . . . . 44

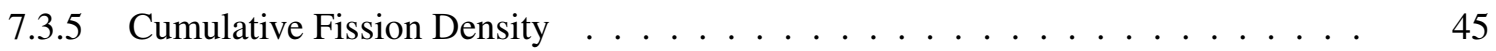

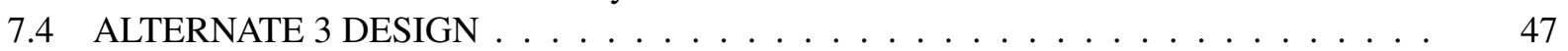

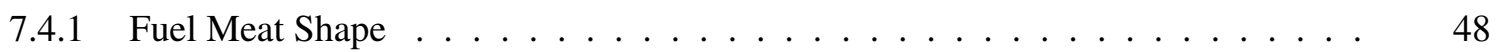

7.4 .2 Fission Rate Density . . . . . . . . . . . . . . . . . . . . . . . . . . 49

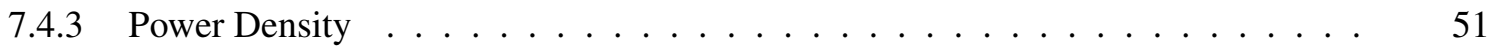

7.4 .4 Heat Flux . . . . . . . . . . . . . . . . . . . . . . 52

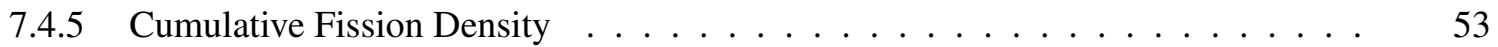

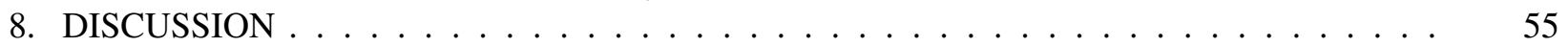

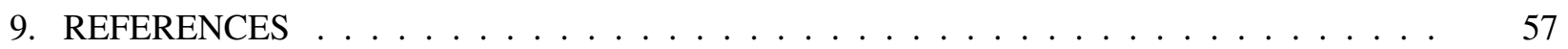

APPENDIX A. DISTRIBUTIONS FOR OPTIMIZED DESIGN $\ldots \ldots \ldots \ldots$. . . . . . . . . A - 1

APPENDIX A-1. FISSION RATE DENSITY DISTRIBUTIONS FOR OPTIMIZED DESIGN A - 1

APPENDIX A-2. CUMULATIVE FISSION DENSITY DISTRIBUTIONS FOR OPTIMIZED

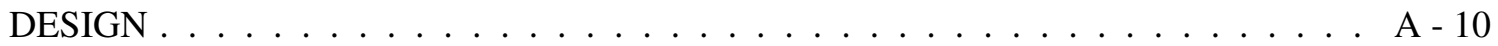

APPENDIX A-3. POWER DENSITY DISTRIBUTIONS FOR OPTIMIZED DESIGN $\ldots$. . A - 16 APPENDIX A-4. HEAT FLUX DISTRIBUTIONS FOR OPTIMIZED DESIGN . . . . . . A - 25 APPENDIX B. DISTRIBUTIONS FOR ALTERNATE 1 DESIGN . . . . . . . . . . . . . . . B - 1 APPENDIX B-1. FISSION RATE DENSITY DISTRIBUTIONS FOR ALTERNATE 1 DESIGN B - 1 APPENDIX B-2. CUMULATIVE FISSION DENSITY DISTRIBUTIONS FOR

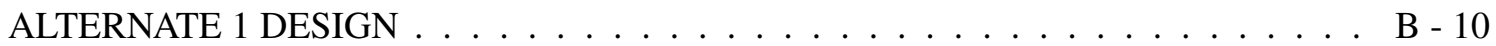

APPENDIX B-3. POWER DENSITY DISTRIBUTIONS FOR ALTERNATE 1 DESIGN . . . B - 16 APPENDIX B-4. HEAT FLUX DISTRIBUTIONS FOR ALTERNATE 1 DESIGN . . . . . . B - 25 APPENDIX C. DISTRIBUTIONS FOR ALTERNATE 2 DESIGN . . . . . . . . . . . . . . C - 1 APPENDIX C-1. FISSION RATE DENSITY DISTRIBUTIONS FOR ALTERNATE 2 DESIGN C - 1 APPENDIX C-2. CUMULATIVE FISSION DENSITY DISTRIBUTIONS FOR

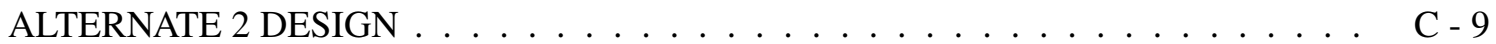
APPENDIX C-3. POWER DENSITY DISTRIBUTIONS FOR ALTERNATE 2 DESIGN . . . C - 15 APPENDIX C-4. HEAT FLUX DISTRIBUTIONS FOR ALTERNATE 2 DESIGN $\ldots \ldots$. . . C - 23 APPENDIX D. DISTRIBUTIONS FOR ALTERNATE 3 DESIGN . . . . . . . . . . . . . . D - 1 APPENDIX D-1. FISSION RATE DENSITY DISTRIBUTIONS FOR ALTERNATE 3 DESIGN D - 1 APPENDIX D-2. CUMULATIVE FISSION DENSITY DISTRIBUTIONS FOR

ALTERNATE 3 DESIGN . . . . . . . . . . . . . . . . . . . . . D - 10 APPENDIX D-3. POWER DENSITY DISTRIBUTIONS FOR ALTERNATE 3 DESIGN . . . D - 16 APPENDIX D-4. HEAT FLUX DISTRIBUTIONS FOR ALTERNATE 3 DESIGN . . . . . . D - 25 


\section{LIST OF FIGURES}

1 High Flux Isotope Reactor (HFIR) inner and outer fuel elements. . . . . . . . . . . . . 3

2 Fuel element HFIR Steady State Heat Transfer Code (HSSHTC) nodes (black circles) superimposed on neutronics mesh (black lines). . . . . . . . . . . . . . . . 12

3 Python HFIR Analysis and Measurement Engine (PHAME)-generated MCNP file

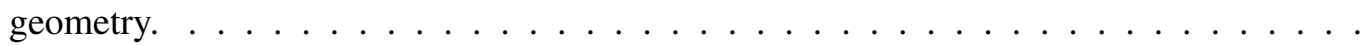

4 The top image shows the center and symmetric fuel, where the layers are clad-filler-fuel-filler-clad. The middle image shows the off-center and asymmetric fuel, where the layers are clad-fuel-filler-clad. The bottom images shows the axial contour of the center and symmetric fuel, where the fuel thickness is reduced to $200 \mu \mathrm{m}$. These images are for illustration only. . . . . . . . . . . . . . . . . . 18 Interpretation of fuel plate plots with Alternate Design 1 IFE illustrated. . . . . . . . . . 22

6 Fuel meat shape for the optimized design. . . . . . . . . . . . . . . . . . . . . 24

7 Fuel bottom meat shape for the optimized design. The axial gradient increases the minimum safety margin, which usually occurs at the bottom of the core. . . . . . . . . 25

8 Optimized design maximum fission density during operation. . . . . . . . . . . . 26

9 Optimized design maximum power density during operation. . . . . . . . . . . . . . 27

10 Optimized design maximum heat flux during operation. . . . . . . . . . . . . . . 28

11 Optimized design maximum cumulative fission density during operation. . . . . . . . . . 29

12 Optimized design fission rate density variation with cumulative fission density during

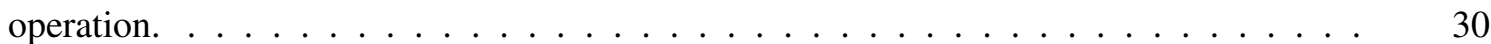

13 Fuel meat shape for the alternate 1 design. . . . . . . . . . . . . . . . . . 32

14 Fuel bottom meat shape for the alternate 1 design. The axial gradient increases the minimum safety margin, which usually occurs at the bottom of the core. . . . . . . . . . 33

15 Alternate 1 design maximum fission density during operation. . . . . . . . . . . . . 34

16 Alternate 1 design maximum power density during operation. . . . . . . . . . . . . . . 35

17 Alternate 1 design maximum heat flux during operation. . . . . . . . . . . . . . . . . 36

18 Alternate 1 design maximum cumulative fission density during operation. . . . . . . . . 37

19 Alternate 1 design fission rate density variation with cumulative fission density during

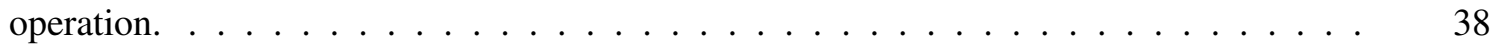

20 Fuel meat shape for the alternate 2 design. . . . . . . . . . . . . . . . 40

21 Alternate 2 design maximum fission density during operation. . . . . . . . . . . . . . . . 41

22 Alternate 2 design maximum power density during operation. . . . . . . . . . . . . . 43

23 Alternate 2 design maximum heat flux during operation. . . . . . . . . . . . . . . 44

24 Alternate 2 design maximum cumulative fission density during operation. . . . . . . . . . 45

25 Alternate 2 design fission rate density variation with cumulative fission density during

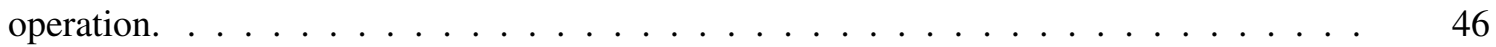

26 Fuel meat shape for the alternate 3 design. . . . . . . . . . . . . . . . . . 48

27 Alternate 3 design maximum fission density during operation. . . . . . . . . . . . . 49

28 Alternate 3 design maximum power density during operation. . . . . . . . . . . . . . . . 51

29 Alternate 3 design maximum heat flux during operation. . . . . . . . . . . . . . . 52

30 Alternate 3 design maximum cumulative fission density during operation. . . . . . . . . 53

31 Alternate 3 design fission rate density variation with cumulative fission density during operation. . . . . . . . . . . . . . . . . . . . . 
32 Fission rate density distribution for optimized design IFE region on day 0 (see Section

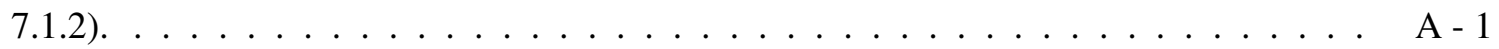

33 Fission rate density distribution for optimized design IFE region on day 1 (see Section

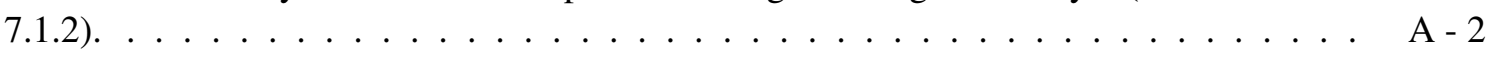

34 Fission rate density distribution for optimized design IFE region on day 15 (see Section

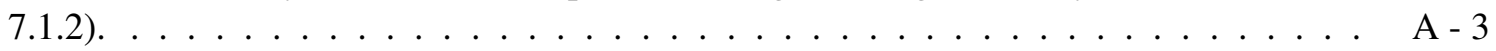

35 Fission rate density distribution for optimized design IFE region on day 27 (see Section

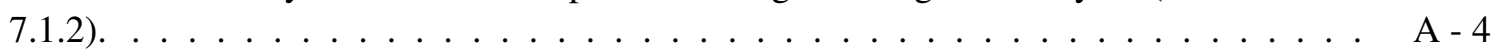

36 Fission rate density distribution for optimized design OFE region on day 0 (see Section

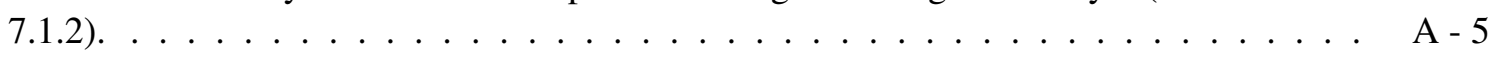

37 Fission rate density distribution for optimized design OFE region on day 1 (see Section

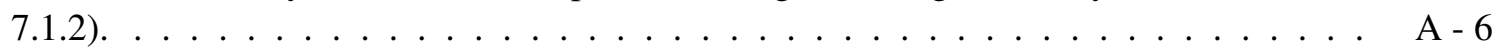

38 Fission rate density distribution for optimized design OFE region on day 2 (see Section

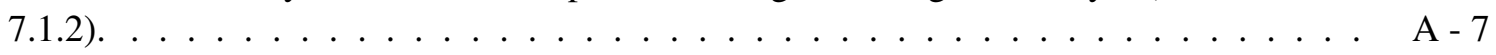

39 Fission rate density distribution for optimized design OFE region on day 15 (see Section

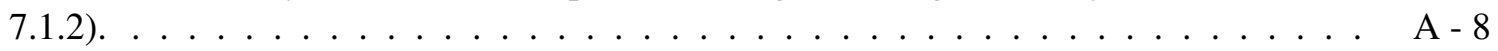

40 Fission rate density distribution for optimized design OFE region on day 27 (see Section $7.1 .2 \ldots \ldots \ldots \ldots \ldots \ldots \ldots \ldots \ldots \ldots$ A $-\ldots \ldots \ldots \ldots \ldots$

41 Cumulative fission density distribution for optimized design IFE region on day 1 (see

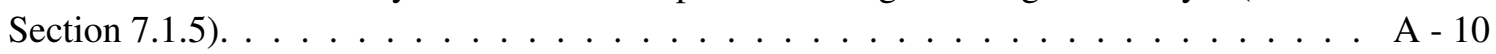

42 Cumulative fission density distribution for optimized design IFE region on day 15 (see

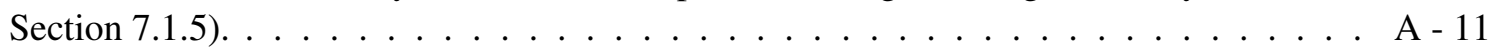

43 Cumulative fission density distribution for optimized design IFE region on day 27 (see

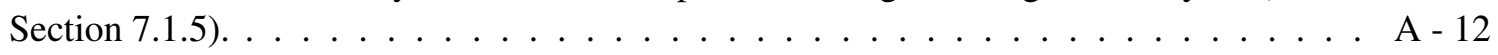

44 Cumulative fission density distribution for optimized design OFE region on day 1 (see

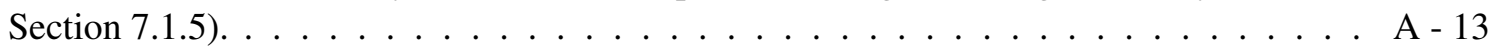

45 Cumulative fission density distribution for optimized design OFE region on day 15 (see Section 7.1.5) . . . . . . . . . . . . . . . . . . . . A -14

46 Cumulative fission density distribution for optimized design OFE region on day 27 (see

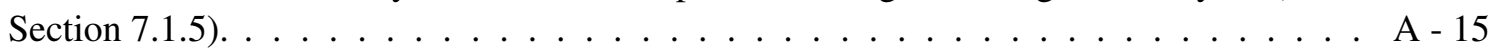

47 Power density distribution for optimized design IFE region on day 0 (see Section 7.1.3). . A - 16

48 Power density distribution for optimized design IFE region on day 1 (see Section 7.1.3). . A - 17

49 Power density distribution for optimized design IFE region on day 15 (see Section 7.1.3). A - 18

50 Power density distribution for optimized design IFE region on day 27 (see Section 7.1.3). A - 19

51 Power density distribution for optimized design OFE region on day 0 (see Section 7.1.3). A - 20

52 Power density distribution for optimized design OFE region on day 1 (see Section 7.1.3). A - 21

53 Power density distribution for optimized design OFE region on day 2 (see Section 7.1.3). A - 22

54 Power density distribution for optimized design OFE region on day 15 (see Section 7.1.3). A - 23

55 Power density distribution for optimized design OFE region on day 27 (see Section 7.1.3). A - 24

56 Heat flux distribution for optimized design IFE region on day 0 (see Section 7.1.4). . . . A - 25

57 Heat flux distribution for optimized design IFE region on day 1 (see Section 7.1.4). . . . A - 26

58 Heat flux distribution for optimized design IFE region on day 15 (see Section 7.1.4). . . A - 27

59 Heat flux distribution for optimized design IFE region on day 27 (see Section 7.1.4). . . A - 28

60 Heat flux distribution for optimized design OFE region on day 0 (see Section 7.1.4). . . A - 29

61 Heat flux distribution for optimized design OFE region on day 1 (see Section 7.1.4). . . A - 30 
62 Heat flux distribution for optimized design OFE region on day 2 (see Section 7.1.4). . . A - 31

63 Heat flux distribution for optimized design OFE region on day 15 (see Section 7.1.4). . . A - 32

64 Heat flux distribution for optimized design OFE region on day 27 (see Section 7.1.4). . . A - 33

65 Fission rate density distribution for alternate 1 design IFE region on day 0 (see Section

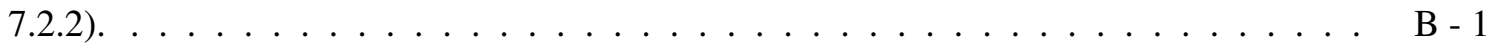

66 Fission rate density distribution for alternate 1 design IFE region on day 1 (see Section

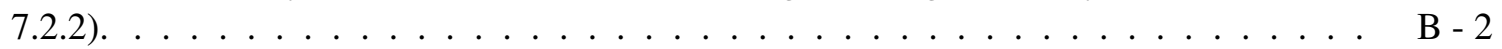

67 Fission rate density distribution for alternate 1 design IFE region on day 15 (see Section $7.2 .2 \ldots \ldots \ldots \ldots \ldots \ldots \ldots \ldots \ldots$

68 Fission rate density distribution for alternate 1 design IFE region on day 27 (see Section

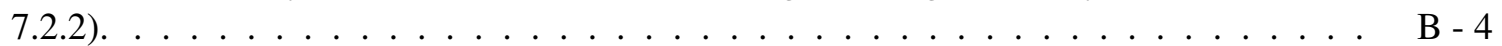

69 Fission rate density distribution for alternate 1 design OFE region on day 0 (see Section

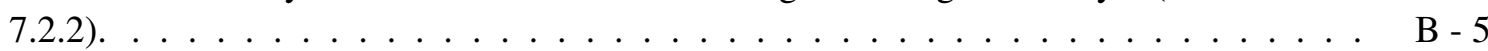

70 Fission rate density distribution for alternate 1 design OFE region on day 1 (see Section

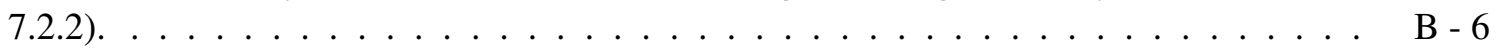

71 Fission rate density distribution for alternate 1 design OFE region on day 2 (see Section

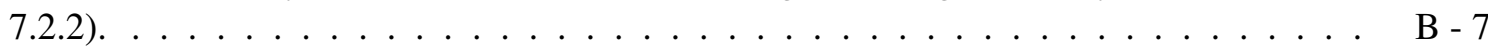

72 Fission rate density distribution for alternate 1 design OFE region on day 15 (see Section

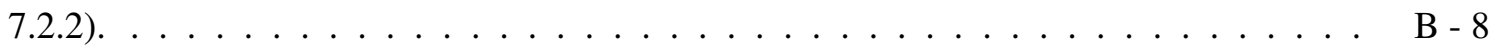

73 Fission rate density distribution for alternate 1 design OFE region on day 27 (see Section

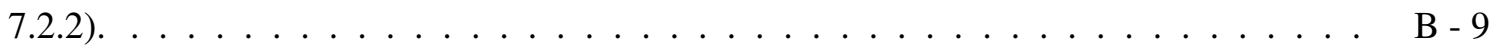

74 Cumulative fission density distribution for alternate 1 design IFE region on day 1 (see Section 7.2.5) . . . . . . . . . . . . . . . . . . . B - 10

75 Cumulative fission density distribution for alternate 1 design IFE region on day 15 (see

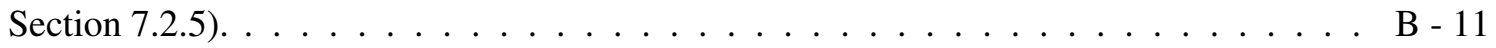

76 Cumulative fission density distribution for alternate 1 design IFE region on day 27 (see Section 7.2.5) . . . . . . . . . . . . . . . . . . . . B - 12

77 Cumulative fission density distribution for alternate 1 design OFE region on day 1 (see

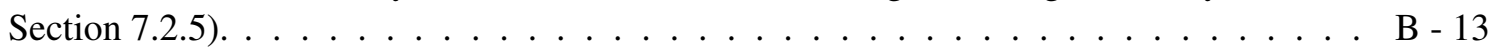

78 Cumulative fission density distribution for alternate 1 design OFE region on day 15 (see

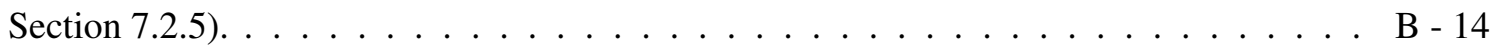

79 Cumulative fission density distribution for alternate 1 design OFE region on day 27 (see

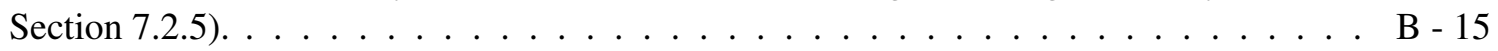

80 Power density distribution for alternate 1 design IFE region on day 0 (see Section 7.2.3).

81 Power density distribution for alternate 1 design IFE region on day 1 (see Section 7.2.3).

B - 16

82 Power density distribution for alternate 1 design IFE region on day 15 (see Section 7.2.3). B - 18

83 Power density distribution for alternate 1 design IFE region on day 27 (see Section 7.2.3). B - 19

84 Power density distribution for alternate 1 design OFE region on day 0 (see Section 7.2.3). B - 20

85 Power density distribution for alternate 1 design OFE region on day 1 (see Section 7.2.3). B - 21

86 Power density distribution for alternate 1 design OFE region on day 2 (see Section 7.2.3). B - 22

87 Power density distribution for alternate 1 design OFE region on day 15 (see Section 7.2.3). B - 23

88 Power density distribution for alternate 1 design OFE region on day 27 (see Section 7.2.3). B - 24

89 Heat flux distribution for alternate 1 design IFE region on day 0 (see Section 7.2.4). . . B - 25

90 Heat flux distribution for alternate 1 design IFE region on day 1 (see Section 7.2.4). . . B - 26

91 Heat flux distribution for alternate 1 design IFE region on day 15 (see Section 7.2.4). . . B - 27 
92 Heat flux distribution for alternate 1 design IFE region on day 27 (see Section 7.2.4). . . B - 28

93 Heat flux distribution for alternate 1 design OFE region on day 0 (see Section 7.2.4). . . B - 29

94 Heat flux distribution for alternate 1 design OFE region on day 1 (see Section 7.2.4). . . B - 30

95 Heat flux distribution for alternate 1 design OFE region on day 2 (see Section 7.2.4). . . B - 31

96 Heat flux distribution for alternate 1 design OFE region on day 15 (see Section 7.2.4). . B - 32

97 Heat flux distribution for alternate 1 design OFE region on day 27 (see Section 7.2.4). . B - 33

98 Fission rate density distribution for alternate 2 design IFE region on day 0 (see Section

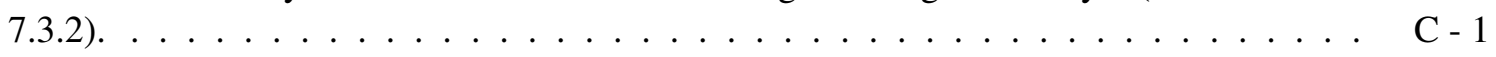

99 Fission rate density distribution for alternate 2 design IFE region on day 1 (see Section

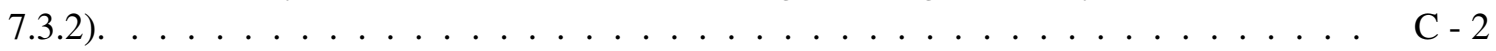

100 Fission rate density distribution for alternate 2 design IFE region on day 15 (see Section

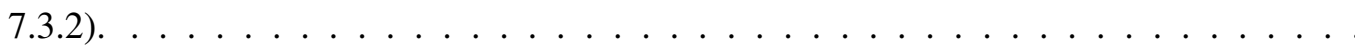

101 Fission rate density distribution for alternate 2 design IFE region on day 27 (see Section

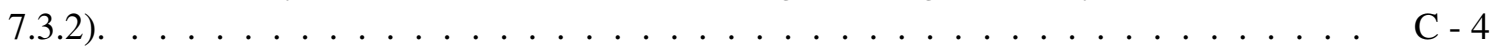

102 Fission rate density distribution for alternate 2 design OFE region on day 0 (see Section

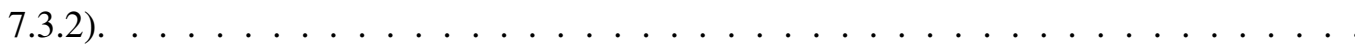

103 Fission rate density distribution for alternate 2 design OFE region on day 1 (see Section

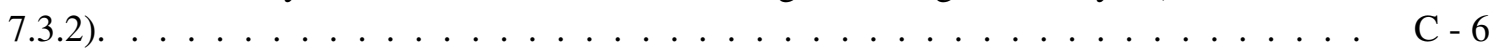

104 Fission rate density distribution for alternate 2 design OFE region on day 15 (see Section

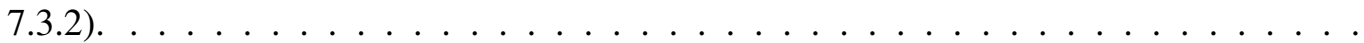

105 Fission rate density distribution for alternate 2 design OFE region on day 27 (see Section

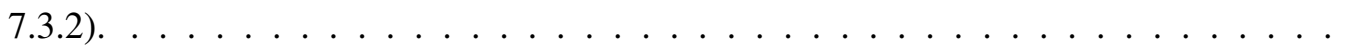

Cumulative fission density distribution for alternate 2 design IFE region on day 1 (see

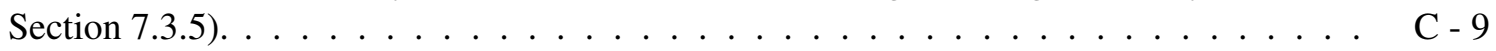

107 Cumulative fission density distribution for alternate 2 design IFE region on day 15 (see

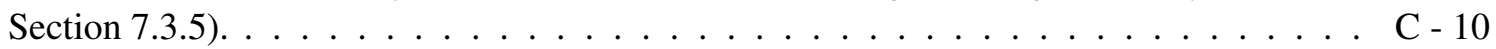

108 Cumulative fission density distribution for alternate 2 design IFE region on day 27 (see

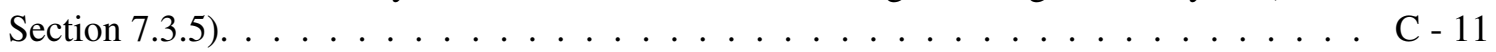

109 Cumulative fission density distribution for alternate 2 design OFE region on day 1 (see

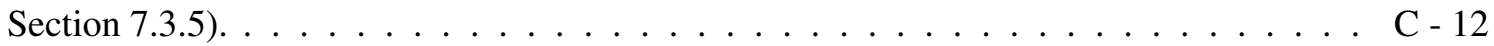

110 Cumulative fission density distribution for alternate 2 design OFE region on day 15 (see

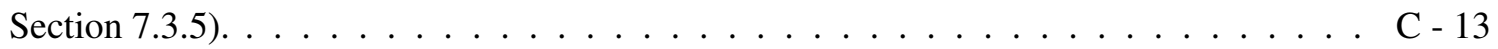

111 Cumulative fission density distribution for alternate 2 design OFE region on day 27 (see

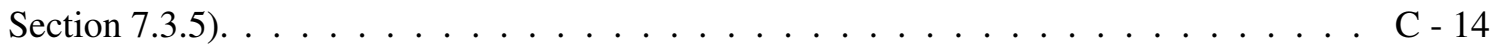

112 Power density distribution for alternate 2 design IFE region on day 0 (see Section 7.3.3). C - 15

113 Power density distribution for alternate 2 design IFE region on day 1 (see Section 7.3.3). C - 16

114 Power density distribution for alternate 2 design IFE region on day 15 (see Section 7.3.3). C - 17

115 Power density distribution for alternate 2 design IFE region on day 27 (see Section 7.3.3). C - 18

116 Power density distribution for alternate 2 design OFE region on day 0 (see Section 7.3.3). C - 19

117 Power density distribution for alternate 2 design OFE region on day 1 (see Section 7.3.3). C - 20

118 Power density distribution for alternate 2 design OFE region on day 15 (see Section 7.3.3). C - 21

119 Power density distribution for alternate 2 design OFE region on day 27 (see Section 7.3.3). C - 22

120 Heat flux distribution for alternate 2 design IFE region on day 0 (see Section 7.3.4). . C - 23

121 Heat flux distribution for alternate 2 design IFE region on day 1 (see Section 7.3.4). . . C - 24

122 Heat flux distribution for alternate 2 design IFE region on day 15 (see Section 7.3.4). . . C - 25 
123 Heat flux distribution for alternate 2 design IFE region on day 27 (see Section 7.3.4). . . C - 26

124 Heat flux distribution for alternate 2 design OFE region on day 0 (see Section 7.3.4). . . C - 27

125 Heat flux distribution for alternate 2 design OFE region on day 1 (see Section 7.3.4). . . C - 28

126 Heat flux distribution for alternate 2 design OFE region on day 15 (see Section 7.3.4). . C - 29

127 Heat flux distribution for alternate 2 design OFE region on day 27 (see Section 7.3.4). . C - 30

128 Fission rate density distribution for alternate 3 design IFE region on day 0 (see Section

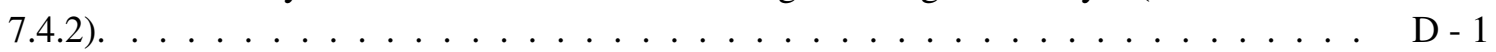

129 Fission rate density distribution for alternate 3 design IFE region on day 1 (see Section

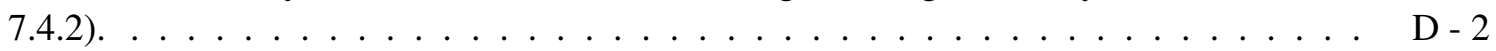

130 Fission rate density distribution for alternate 3 design IFE region on day 15 (see Section

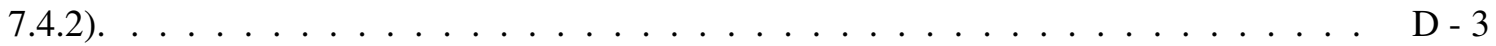

131 Fission rate density distribution for alternate 3 design IFE region on day 27 (see Section

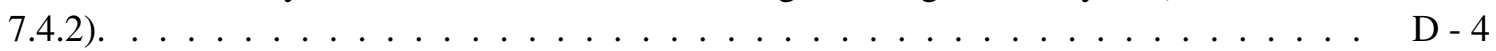

132 Fission rate density distribution for alternate 3 design OFE region on day 0 (see Section

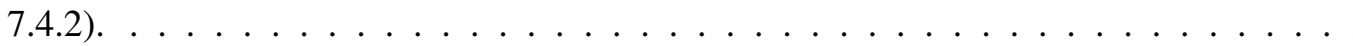

133 Fission rate density distribution for alternate 3 design OFE region on day 1 (see Section 7.4.2)

Fission rate density distribution for alternate 3 design OFE region on day 2 (see Section

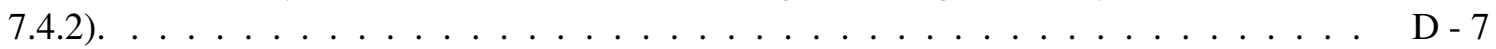

135 Fission rate density distribution for alternate 3 design OFE region on day 15 (see Section

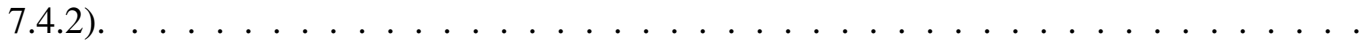

136 Fission rate density distribution for alternate 3 design OFE region on day 27 (see Section

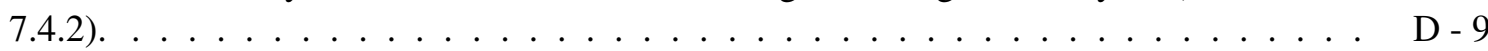

137 Cumulative fission density distribution for alternate 3 design IFE region on day 1 (see

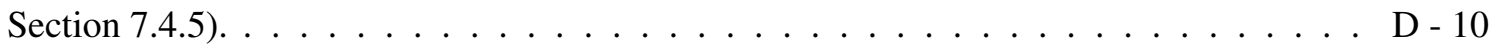

138 Cumulative fission density distribution for alternate 3 design IFE region on day 15 (see

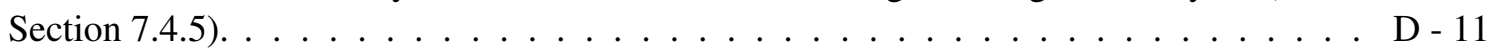

139 Cumulative fission density distribution for alternate 3 design IFE region on day 27 (see

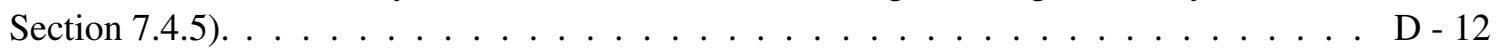

140 Cumulative fission density distribution for alternate 3 design OFE region on day 1 (see

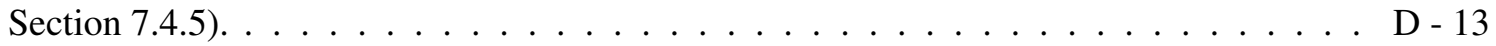

141 Cumulative fission density distribution for alternate 3 design OFE region on day 15 (see Section 7.4.5) . . . . . . . . . . . . . . . . . . . . . . D - 14

142 Cumulative fission density distribution for alternate 3 design OFE region on day 27 (see

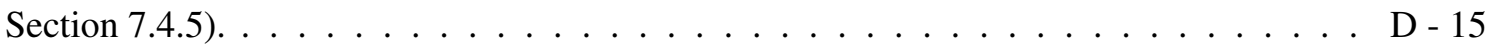

143 Power density distribution for alternate 3 design IFE region on day 0 (see Section 7.4.3). D - 16

144 Power density distribution for alternate 3 design IFE region on day 1 (see Section 7.4.3). D - 17

145 Power density distribution for alternate 3 design IFE region on day 15 (see Section 7.4.3). D - 18

146 Power density distribution for alternate 3 design IFE region on day 27 (see Section 7.4.3). D - 19

147 Power density distribution for alternate 3 design OFE region on day 0 (see Section 7.4.3). D - 20

148 Power density distribution for alternate 3 design OFE region on day 1 (see Section 7.4.3). D - 21

149 Power density distribution for alternate 3 design OFE region on day 2 (see Section 7.4.3). D - 22

150 Power density distribution for alternate 3 design OFE region on day 15 (see Section 7.4.3). D - 23

151 Power density distribution for alternate 3 design OFE region on day 27 (see Section 7.4.3). D - 24

152 Heat flux distribution for alternate 3 design IFE region on day 0 (see Section 7.4.4). . . D - 25 
153 Heat flux distribution for alternate 3 design IFE region on day 1 (see Section 7.4.4). . . D - 26

154 Heat flux distribution for alternate 3 design IFE region on day 15 (see Section 7.4.4). . . D - 27

155 Heat flux distribution for alternate 3 design IFE region on day 27 (see Section 7.4.4). . . D - 28

156 Heat flux distribution for alternate 3 design OFE region on day 0 (see Section 7.4.4). . . D - 29

157 Heat flux distribution for alternate 3 design OFE region on day 1 (see Section 7.4.4). . . D - 30

158 Heat flux distribution for alternate 3 design OFE region on day 2 (see Section 7.4.4). . . D - 31

159 Heat flux distribution for alternate 3 design OFE region on day 15 (see Section 7.4.4). . D - 32

160 Heat flux distribution for alternate 3 design OFE region on day 27 (see Section 7.4.4). . D - 33 



\section{LIST OF TABLES}

1 Key HFIR highly enriched uranium (HEU) geometry and operational parameters. . . . . 5

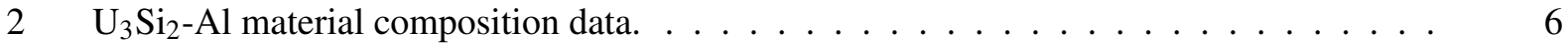

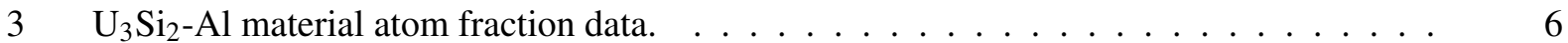

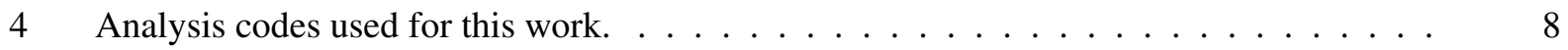

5 Radii of the inner fuel element (IFE) fuel regions in the neutronics model. . . . . . . . . . 9

6 Radii of the outer fuel element (OFE) fuel regions in the neutronics model. . . . . . . . 10

7 Axial mesh for fuel regions in the neutronics model. . . . . . . . . . . . . . . 10

8 Radii of the fuel nodes in the HSSHTC model. . . . . . . . . . . . . . . . . . 11

9 Axial mesh for fuel nodes in the HSSHTC model. . . . . . . . . . . . . . . . . . . 11

10 Key HFIR low-enriched uranium (LEU) geometry and operational parameters common to all presented designs. . . . . . . . . . . . . . . . . . . . . . 16

11 Complex fuel design features and benefits. . . . . . . . . . . . . . . 17

12 Currently analyzed silicide designs that meet the performance and safety metrics. Case numbers denote different fuel shapes. . . . . . . . . . . . . . . . . .

13 Metrics used to measure the performance and safety of the LEU core. . . . . . . . . . .

14 The performance and safety metrics for the new low density LEU designs need to meet or exceed HEU metrics. All the designs in this study meet or exceed HEU metrics minus the cold source cold flux ratio, minimum burnout margin, and uranium utilization. . . . . . . 20

15 Key optimized design geometry and operational parameters. . . . . . . . . . . . 23

16 Fuel shape polynomial coefficients for optimized design. . . . . . . . . . . . . . 25

17 Minimum and maximum fission rate densities in the optimized design. . . . . . . . . . 26

18 Minimum and maximum power densities in the optimized design. . . . . . . . . . . . . . 27

19 Minimum and maximum heat fluxes in the optimized design. . . . . . . . . . . . . 28

20 Minimum and maximum cumulative fission density values in the optimized design. . . . 29

21 Key alternate 1 design geometry and operational parameters. . . . . . . . . . . . 31

22 Fuel shape polynomial coefficients for alternate 1 design. . . . . . . . . . . . . 33

23 Minimum and maximum fission rate densities in the alternate 1 design. . . . . . . . . . 34

24 Minimum and maximum power densities in the alternate 1 design. . . . . . . . . . . . . . . 35

25 Minimum and maximum heat fluxes in the alternate 1 design. . . . . . . . . . . 36

26 Minimum and maximum cumulative fission density values in the alternate 1 design. . . 37

27 Key alternate 2 design geometry and operational parameters. . . . . . . . . . . . . . . 39

28 Fuel shape polynomial coefficients for alternate 2 design. . . . . . . . . . . . . . 41

29 Minimum and maximum fission rate densities in the alternate 2 design. . . . . . . . . . . 42

30 Minimum and maximum power densities in the alternate 2 design. . . . . . . . . . . . . 43

31 Minimum and maximum heat fluxes in the alternate 2 design. . . . . . . . . . . . . . 44

32 Minimum and maximum cumulative fission density values in the alternate 2 design. . . 45

33 Key alternate 3 design geometry and operational parameters. . . . . . . . . . . . . . 47

34 Fuel shape polynomial coefficients for alternate 3 design. . . . . . . . . . . . . . 49

35 Minimum and maximum fission rate densities in the alternate 3 design. . . . . . . . . 50

36 Minimum and maximum power densities in the alternate 3 design. . . . . . . . . . . . 51

37 Minimum and maximum heat fluxes in the alternate 3 design. . . . . . . . . . . . . 52

38 Minimum and maximum cumulative fission density values in the alternate 3 design. . . . 53

39 Summary of maximum parameters for each low density $\mathrm{U}_{3} \mathrm{Si}_{2}-\mathrm{Al}$ design. . . . . . . . 56 
BOC beginning-of-cycle

CE control element

DOE Department of Energy

EOC end-of-cycle

HEU highly enriched uranium

HFIR High Flux Isotope Reactor

HPC high-performance computing

HSSHTC HFIR Steady State Heat Transfer Code

IAEA International Atomic Energy Agency

IFE inner fuel element

LEU low-enriched uranium

MCNP Monte Carlo N-Particle code

MOC middle-of-cycle

NNSA National Nuclear Security Administration

OFE outer fuel element

ORNL Oak Ridge National Laboratory

PHAME Python HFIR Analysis and Measurement Engine

USHPRR US High Performance Research Reactor 


\section{ACKNOWLEDGEMENTS}

This work is supported by the National Nuclear Security Administration Office of Material Management and Minimization, US Department of Energy. Reviews of the manuscript by Emilian Popov and Kara Godsey at Oak Ridge National Laboratory are appreciated. 


\begin{abstract}
High Flux Isotope Reactor (HFIR) highly enriched uranium (HEU) to low-enriched uranium (LEU) conversion activities are ongoing as part of the Department of Energy (DOE) National Nuclear Security Administration (NNSA)'s nuclear nonproliferation mission. Design activities studying the conversion of HFIR from HEU to LEU fuel explored different fuel design features and shapes with a low density uranium-silicide dispersion $\left(\mathrm{U}_{3} \mathrm{Si}_{2}-\mathrm{Al}\right)$ fuel, which has a uranium density of $4.8 \mathrm{gU} / \mathrm{cm}^{3}$. The goal of these studies is to generate several HFIR LEU fuel designs of varying fuel fabrication complexity that meet the current HEU performance metrics and safety requirements. The documented designs will serve as references for fuel fabrication and qualification activities.

Recent advancements in modeling and simulation tools enable quick prototyping of fuel designs. Shift, a Monte Carlo neutron transport and depletion tool optimized for high-performance computing (HPC) architectures, is used for efficient fuel cycle and performance metrics calculations. The HFIR Steady State Heat Transfer Code (HSSHTC) is used to vet the thermal safety margin. Also, a new automation tool that connects all fuel design analysis steps, named Python HFIR Analysis and Measurement Engine (PHAME), has been developed to expedite the design study in an efficient and reproducible manner. Leveraging these tools, several candidate fuel designs were selected for varying fabrication complexity.

This report provides design feature details for four selected HFIR LEU low density $\mathrm{U}_{3} \mathrm{Si}_{2}$-Al fuel designs and their corresponding performance and safety metrics. Nominal, best-estimate design parameters and irradiation conditions, including fission rate densities, power densities, heat fluxes, and cumulative fission densities are provided for candidate fuel designs relevant to framing irradiation experiments to support fuel qualification efforts. Simulations show that the low density $\mathrm{U}_{3} \mathrm{Si}_{2}-\mathrm{Al}$, with design features to enhance safety, can meet HEU core performance metrics and safety requirements if the reactor power is increased from $85 \mathrm{MW}$ (HEU) to $95 \mathrm{MW}$ (LEU) and if the active fuel length is increased from $50.80 \mathrm{~cm}$ (HEU) to $55.88 \mathrm{~cm}$ (LEU).
\end{abstract}




\section{INTRODUCTION}

The HFIR is a US Department of Energy (DOE) Office of Science User Facility that is operated at the Oak Ridge National Laboratory (ORNL). HFIR is a versatile research reactor that provides one of the highest steady-state neutron fluxes of any reactor in the world for neutron scattering experiments focused on fundamental and applied research on the structure and dynamics of matter, as well as materials irradiation studies and production of medical, industrial, and research isotopes.

ORNL is funded by the US DOE National Nuclear Security Administration (NNSA)'s Office of Material Management and Minimization $\left(\mathrm{M}^{3}\right)$ to perform HFIR conversion activities such as design studies presented herein. US High Performance Research Reactor (USHPRR)s, including HFIR, the Advanced Test Reactor, the National Institute of Standards and Technology Research Reactor, the Massachusetts Institute of Technology Research Reactor, and the University of Missouri Research Reactor, are providing research on potential LEU alternatives in support of NNSA's nonproliferation mission.

Initial studies to convert HFIR from its current HEU dispersion fuel to LEU fuel explored uranium-molybdenum (U-10Mo) monolithic alloy fuel because of its high uranium density [7, 23]. HFIR's proposed U-10Mo fuel design [7] consisted of radial and axial contoured fuel profiles. HFIR initiated fuel design studies with LEU uranium-silicide dispersion $\left(\mathrm{U}_{3} \mathrm{Si}_{2}-\mathrm{Al}\right)$ fuel in 2017 and officially rebaselined to $\mathrm{U}_{3} \mathrm{Si}_{2}-\mathrm{Al}$ in 2019 .

Current studies are focused on $\mathrm{U}_{3} \mathrm{Si}_{2}-\mathrm{Al}$ dispersion fuels with different uranium metal densities $[9,10,11,13]$. The goal of the HFIR conversion efforts is to design, qualify, fabricate, and deploy LEU HFIR fuel that will maintain or exceed current reactor performance metrics and safety requirements at an affordable cost [22]. Following the conversion of HFIR from HEU to LEU fuel, (1) the ability of HFIR to perform its scientific missions must be maintained or enhanced, (2) all safety requirements must be met, and (3) annual operating costs must not increase.

This report presents design characteristics and performance parameters for candidate low-density $\mathrm{U}_{3} \mathrm{Si}_{2}-\mathrm{Al}$ fuel (4.8 $\frac{\mathrm{gU}}{\mathrm{cm}^{3}}$ ) designs [9]. A similar design report details the performance of the high-density $\mathrm{U}_{3} \mathrm{Si}_{2}-\mathrm{Al}$ [1] fuel design. An optimization approach leveraging reactor physics and steady-state thermal hydraulics simulations yield optimal designs using this $\mathrm{U}_{3} \mathrm{Si}_{2}-\mathrm{Al}$ fuel $[3,4,5,6,8]$ and predefined conversion assumptions [22]. Multiple fuel designs are presented herein, as they represent designs with varying fabrication complexity; this provides fuel fabrication and fuel qualification options to be investigated. Designs presented in this report meet or exceed most HFIR HEU core performance metrics and safety requirements [19]. A quantitative, multivariate design down-selection will be performed after additional fabrication and irradiation testing are performed. At a minimum, the down-selection process must consider performance, safety, fabrication cost, and uranium utilization.

The set of design parameters highlighted in this report are:

1. fuel element and fuel plate geometry and features,

2. temporal fission rate density distributions,

3. temporal power density distributions,

4. temporal heat flux distributions, and

5. discharge cumulative fission density distributions. 


\section{FUEL ELEMENT GEOMETRY}

The HFIR core consists of concentric annular regions: a central flux trap containing vertical experimental targets; two fuel elements - inner fuel element (IFE) and outer fuel element (OFE) — separated by a thin water labyrinth region; a region containing two control elements (CEs); a beryllium reflector; and a water region up to the edge of the pressure vessel, which is located in a pool of water [14].

The fuel assembly consists of an integral two-element configuration; the IFE is designed to be seated within the OFE. The IFE and OFE are composed of numerous $1.27 \mathrm{~mm}$ thick involute-shaped fuel plates separated by $1.27 \mathrm{~mm}$ thick coolant channels (Figure 1). The fuel plate elements are composed of a fuel region (also known as fuel meat) and a filler region enclosed by an aluminum cladding. In the current HEU design, the fuel meat is a mixture of aluminum powder and $\mathrm{U}_{3} \mathrm{O}_{8}$ with $93 \mathrm{wt} \%{ }^{235} \mathrm{U}$. The fuel meat is contoured along the arc of the involute plate to reduce edge power peaking. The IFE fuel also contains $\mathrm{B}_{4} \mathrm{C}$ for reactivity hold-down and to control power distribution during operation. The fuel plates are inserted into slots located in the cylindrical aluminum side plates, and they extend into machine grooves where they are attached to the side plates via circumferential welds. Key geometry and operational parameters are provided in Table 1. More details of the fuel element geometry can be found in the work by Ilas et al. [20].

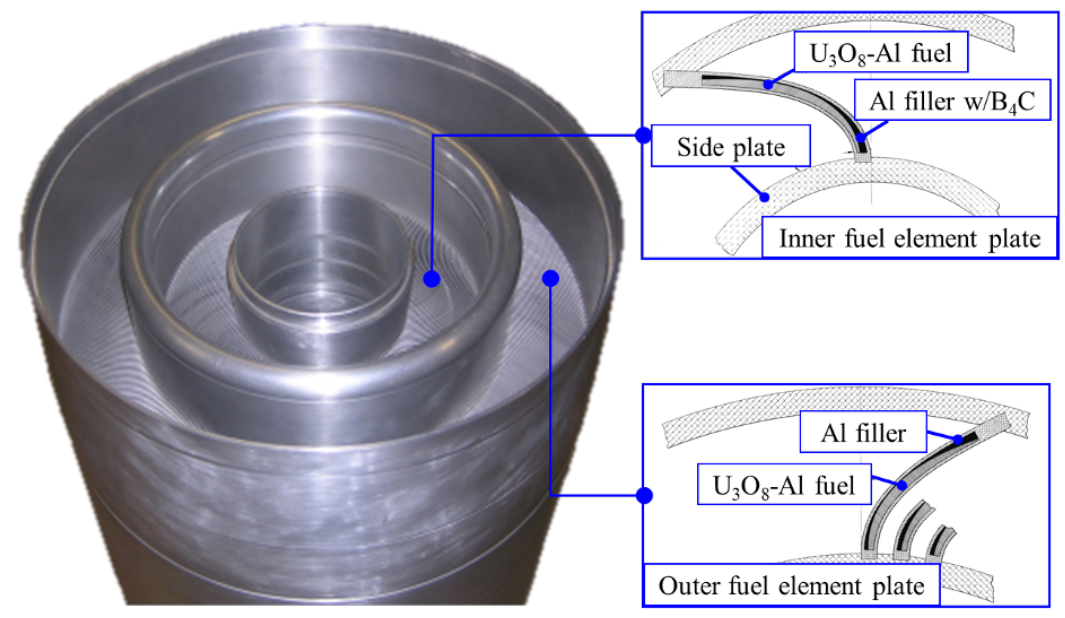

Figure 1. HFIR inner and outer fuel elements. 


\section{SILICIDE DISPERSION FUEL}

The study described in this report considered the $4.8 \mathrm{gU} / \mathrm{cm}^{3} \mathrm{U}_{3} \mathrm{Si}_{2}-\mathrm{Al}$ dispersion fuel with an enrichment of 19.75 wt. $\%{ }^{235} \mathrm{U} / \mathrm{U}$. According to the International Atomic Energy Agency (IAEA) [18], the $\mathrm{U}_{3} \mathrm{Si}_{2}$ density is $12.2 \mathrm{~g} / \mathrm{cm}^{3}$ and the corresponding silicon and uranium weight fractions are 0.075 and 0.925 , respectively. A typical aluminum density [18] of $2.7 \mathrm{~g} / \mathrm{cm}^{3}$ is also used. A summary of the $\mathrm{U}_{3} \mathrm{Si}_{2}-\mathrm{Al}$ material composition assumed for this study is provided in Table 2. This table provides the assumed Al, U, $\mathrm{Si}$, and porosity volume fractions and densities. With an assumed enrichment of $19.75 \mathrm{wt} . \%{ }^{235} \mathrm{U}$, the ${ }^{235} \mathrm{U}$ density in the $\mathrm{U}_{3} \mathrm{Si}_{2}-\mathrm{Al}$ fuel meat is $0.948 \mathrm{~g} / \mathrm{cm}^{3}$.

An enrichment of $19.75 \mathrm{wt} . \%{ }^{235} \mathrm{U} / \mathrm{U}$ is assumed for these studies because this is the enrichment that has been utilized for LEU conversion studies. The assumed weight percent for ${ }^{234} U,{ }^{236} U$, and ${ }^{238} U$ in $U$ are $0.18,0.09$, and 79.78 , respectively. The isotopic composition used in the neutron transport calculations is listed in Table 3. 
Table 1. Key HFIR HEU geometry and operational parameters.

\begin{tabular}{|c|c|c|c|}
\hline Parameter & Units & \multicolumn{2}{|c|}{ Value } \\
\hline Power & MW & \multicolumn{2}{|c|}{85} \\
\hline Cycle length & days & \multicolumn{2}{|c|}{$24-26$} \\
\hline Coolant & - & \multicolumn{2}{|c|}{ light water } \\
\hline Inlet coolant temperature & ${ }^{\circ} \mathrm{C}$ & \multicolumn{2}{|c|}{48.89} \\
\hline Inlet coolant pressure & $\mathrm{MPa}$ & \multicolumn{2}{|c|}{3.33} \\
\hline Primary flow rate & $\mathrm{m}^{3} / \mathrm{s}$ & \multicolumn{2}{|c|}{1.01} \\
\hline Number of fuel elements & - & \multicolumn{2}{|c|}{2} \\
\hline Fuel plate clad & - & \multicolumn{2}{|c|}{$\overline{\mathrm{Al}}$} \\
\hline Clad thickness & $\mu \mathrm{m}$ & \multicolumn{2}{|c|}{254} \\
\hline Fuel meat & - & \multicolumn{2}{|c|}{$\mathrm{U}_{3} \mathrm{O}_{8}-\mathrm{Al}$} \\
\hline Fuel plate filler & - & \multicolumn{2}{|c|}{$\mathrm{Al}\left(+\mathrm{B}_{4} \mathrm{C}\right.$ in IFE $)$} \\
\hline Fuel meat + filler thickness & $\mu \mathrm{m}$ & \multicolumn{2}{|c|}{762} \\
\hline Fuel plate thickness & $\mu \mathrm{m}$ & \multicolumn{2}{|c|}{1270} \\
\hline Coolant channel thickness & $\mu \mathrm{m}$ & \multicolumn{2}{|c|}{1270} \\
\hline Plate-to-water ratio & - & \multicolumn{2}{|c|}{1} \\
\hline${ }^{235} \mathrm{U}$ enrichment & wt. $\%{ }^{235} \mathrm{U} / \mathrm{U}$ & \multicolumn{2}{|c|}{93} \\
\hline${ }^{235}$ U loading & $\mathrm{kg}$ & \multicolumn{2}{|c|}{9.40} \\
\hline U loading & $\mathrm{kg}$ & \multicolumn{2}{|c|}{10.11} \\
\hline $\mathrm{U}_{3} \mathrm{O}_{8}$ density & $\mathrm{g} / \mathrm{cm}^{3}$ & \multicolumn{2}{|c|}{8.22} \\
\hline${ }^{235} \mathrm{U}$ density & $\mathrm{g}^{235} \mathrm{U} / \mathrm{cm}^{3} \mathrm{U}_{3} \mathrm{O}_{8}$ & \multicolumn{2}{|c|}{6.47} \\
\hline Active fuel meat length & $\mathrm{cm}$ & \multicolumn{2}{|c|}{50.80} \\
\hline Fuel plate length & $\mathrm{cm}$ & \multicolumn{2}{|c|}{60.96} \\
\hline Active fuel zone volume & $\mathrm{L}$ & \multicolumn{2}{|c|}{50.03} \\
\hline Average power density & $\mathrm{MW} / \mathrm{L}$ & \multicolumn{2}{|c|}{1.70} \\
\hline Fuel meat heat transfer area & $\mathrm{m}^{2}$ & & \\
\hline & & IFE & OFE \\
\hline Number of fuel plates & - & 171 & 369 \\
\hline${ }^{235} \mathrm{U}$ loading & $\mathrm{kg}$ & 2.60 & 6.80 \\
\hline${ }^{235}$ U loading & g/plate & 15.18 & 18.44 \\
\hline $\mathrm{U}_{3} \mathrm{O}_{8}$-to-Al mass split & wt. $\% \mathrm{U}_{3} \mathrm{O}_{8}$ & 30 & 40 \\
\hline Burnable poison in the filler & - & ${ }^{10} \mathrm{~B}$ in $\mathrm{B}_{4} \mathrm{C}$ & - \\
\hline${ }^{10} \mathrm{~B}$ loading & $\mathrm{g}$ & 2.70 & - \\
\hline${ }^{10} \mathrm{~B}$ density in filler & $\mathrm{mg} / \mathrm{cm}^{3}$ & 1.752 & - \\
\hline Involute radius * & $\mathrm{cm}$ & 6.91261 & 14.91742 \\
\hline Fuel plate arc length ${ }^{*}$ & $\mathrm{~cm}$ & 9.21004 & 8.09752 \\
\hline $\begin{array}{l}\text { Distance from inner plate edge to involute } \\
\text { origin* }\end{array}$ & $\mathrm{cm}$ & 0.29718 & 0.29464 \\
\hline Distance along involute to fuel meat start & $\mathrm{cm}$ & 0.23241 & 0.21336 \\
\hline Distance along involute to fuel meat end & $\mathrm{cm}$ & 8.02259 & 7.22884 \\
\hline Fuel meat arc length & $\mathrm{cm}$ & 7.79018 & 7.01548 \\
\hline Fuel meat heat transfer area & $\mathrm{m}^{2}$ & 13.53435 & 26.30132 \\
\hline Inner radius of fuel meat & $\mathrm{cm}$ & 7.11950 & 15.11586 \\
\hline Outer radius of fuel meat & $\mathrm{cm}$ & 12.53239 & 20.87073 \\
\hline Active fuel zone volume & $\mathrm{L}$ & 16.97643 & 33.05139 \\
\hline
\end{tabular}

${ }^{*}$ Visual depiction of fuel plate geometry in Figure 5 
Table 2. $\mathrm{U}_{3} \mathrm{Si}_{2}-\mathrm{Al}$ material composition data.

\begin{tabular}{|c|c|c|c|c|}
\hline Parameter & Unit & Symbol & Value & Source \\
\hline Al density & $\mathrm{g} / \mathrm{cm}^{3}$ & $\rho_{A l}$ & 2.7 & [18] \\
\hline $\mathrm{U}$ density in $\mathrm{U}_{3} \mathrm{Si}_{2}-\mathrm{Al}$ & $\mathrm{g} / \mathrm{cm}^{3}$ & $\rho_{U, M}$ & 4.8 & assumed based on [24] \\
\hline $\mathrm{U}_{3} \mathrm{Si}_{2}$ density & $\mathrm{g} / \mathrm{cm}^{3}$ & $\rho_{U 3 S i 2}$ & 12.2 & {$[18]$} \\
\hline $\mathrm{U}$ weight fraction in $\mathrm{U}_{3} \mathrm{Si}_{2}$ & - & $W_{U}$ & 0.925 & {$[18]$} \\
\hline $\mathrm{U}$ density in $\mathrm{U}_{3} \mathrm{Si}_{2}$ & $\mathrm{~g} / \mathrm{cm}^{3}$ & $\rho_{U, S}$ & 11.285 & $\rho_{U_{3} S i_{2}} \cdot\left(W_{U}\right)$ \\
\hline Si weight fraction in $\mathrm{U}_{3} \mathrm{Si}_{2}$ & - & $W_{S i}$ & 0.075 & {$[18]$} \\
\hline Si density in $\mathrm{U}_{3} \mathrm{Si}_{2}$ & $\mathrm{~g} / \mathrm{cm}^{3}$ & $\rho_{S i, S}$ & 0.915 & $\rho_{U_{3} S i_{2}} \cdot\left(W_{S i}\right)$ \\
\hline parameter "a" & $\mathrm{cm}^{3} / \mathrm{g}$ & $\mathrm{a}$ & 0.3118 & [18]; $\frac{1}{W_{U}}\left(\frac{1}{\rho_{A l}}-\frac{1}{\rho_{U_{3} S i_{2}}}\right)$ \\
\hline $\begin{array}{l}\mathrm{U}_{3} \mathrm{Si}_{2} \text { volume fraction in } \\
\mathrm{U}_{3} \mathrm{Si}_{2}-\mathrm{Al}\end{array}$ & - & $V_{f, M}$ & 0.4253 & {$[18] ; \frac{\rho_{U, M}\left(\frac{1}{\rho_{A l}}-a W_{U}\right)}{W_{U}}$} \\
\hline $\mathrm{U}_{3} \mathrm{Si}_{2}$ density in $\mathrm{U}_{3} \mathrm{Si}_{2}-\mathrm{Al}$ & $\mathrm{g} / \mathrm{cm}^{3}$ & $\rho_{U 3 S i 2, M}$ & 5.1892 & $V_{f, M} \cdot\left(\rho_{U_{3} S i_{2}}\right)$ \\
\hline Porosity volume fraction & - & $V_{P, M}$ & 0.0824 & $\begin{array}{l}{[18], \quad 0.072 V_{f, M}-} \\
0.275\left(V_{f, m}\right)^{2}+1.32\left(V_{f, M}\right)^{3}\end{array}$ \\
\hline Al matrix volume fraction & - & $V_{A l, M}$ & 0.4922 & $1-V_{f, M}-V_{P, M}$ \\
\hline $\mathrm{Al}$ density in $\mathrm{U}_{3} \mathrm{Si}_{2}-\mathrm{Al}$ & $\mathrm{g} / \mathrm{cm}^{3}$ & $\rho_{A l, M}$ & 1.3290 & $\rho_{A l}\left(V_{A l, M}\right)$ \\
\hline $\mathrm{U}_{3} \mathrm{Si}_{2}-\mathrm{Al}$ density & $\mathrm{g} / \mathrm{cm}^{3}$ & $\rho_{M}$ & 6.5181 & $\rho_{U 3 S i 2, M}+\rho_{A l, M}$ \\
\hline${ }^{235} \mathrm{U}$ enrichment & $\mathrm{g}^{235} \mathrm{U} / \mathrm{gU}$ & $e$ & 0.1975 & $\begin{array}{l}\text { assumed based on LEU } \\
\text { enrichment }\end{array}$ \\
\hline${ }^{235} \mathrm{U}$ density in $\mathrm{U}_{3} \mathrm{Si}_{2}$ & $\mathrm{~g} / \mathrm{cm}^{3}$ & $\rho_{U 5, S}$ & 2.2288 & $\rho_{U, S}(e)$ \\
\hline${ }^{235} \mathrm{U}$ density in $\mathrm{U}_{3} \mathrm{Si}_{2}-\mathrm{Al}$ & $\mathrm{g} / \mathrm{cm}^{3}$ & $\rho_{U 5, M}$ & 0.9480 & $\rho_{U, M}(e)$ \\
\hline
\end{tabular}

Table 3. $\mathbf{U}_{3} \mathbf{S i}_{2}-\mathbf{A l}$ material atom fraction data.

\begin{tabular}{ll}
\hline Isotope & Atom fraction \\
\hline${ }^{27} \mathrm{Al}^{13}$ & $5.91103 \mathrm{E}-01$ \\
${ }^{28} \mathrm{Si}^{14}$ & $1.53948 \mathrm{E}-01$ \\
${ }^{29} \mathrm{Si}^{14}$ & $7.55088 \mathrm{E}-03$ \\
${ }^{30} \mathrm{Si}^{14}$ & $4.81762 \mathrm{E}-03$ \\
${ }^{234} \mathrm{U}^{92}$ & $4.33147 \mathrm{E}-04$ \\
${ }^{235} \mathrm{U}^{92}$ & $4.83986 \mathrm{E}-02$ \\
${ }^{236} \mathrm{U}^{92}$ & $2.22055 \mathrm{E}-04$ \\
${ }^{238} \mathrm{U}^{92}$ & $1.93527 \mathrm{E}-01$ \\
\hline
\end{tabular}


As described in Section 3.3.1 of the US Nuclear Regulatory Commission's report [24], "the fuel particles in the core swell as a function of burnup to accommodate fission products, both solid and gaseous, that occupy a greater volume than the fissioning uranium." Fuel meat swelling causes plate thickness to increase, resulting in a reduced in-core coolant-to-moderator volume. The reduction in the volume of water adjacent to the fuel plates degrades reactor performance by introducing negative reactivity and therefore reducing cycle length. It also adversely affects the thermal safety margin by thinning the coolant channel.

The swelling rate of $\mathrm{U}_{3} \mathrm{Si}_{2}$ is $6.2 \%$ percent per $10^{21}$ fissions $/ \mathrm{cm}^{3}-\mathrm{U}_{3} \mathrm{Si}_{2}$ [24]. Thus, fuel particle swelling increases linearly as a function of burnup. As shown above, the volume fraction of $\mathrm{U}_{3} \mathrm{Si}_{2}$ in the fuel meat (i.e., $\mathrm{U}_{3} \mathrm{Si}_{2}$-Al) is 0.4253 , so the swelling rate can also be described as $2.637 \%$ per $10^{21}$ fissions $/ \mathrm{cm}^{3}$ - fuel meat. The impact of fuel swelling on cycle length was shown to be small in a preliminary study, so fuel swelling is not specifically modeled in the depletion simulations. However, fuel swelling is considered in the HSSHTC calculations to decrease the coolant channel thickness. 


\section{COMPUTATIONAL METHODS}

The computational design and analysis methods have been modernized to (1) decrease time of analysis, (2) decrease inconsistencies in the analysis, and (3) increase reproducibility [2, 25]. Tools used in this work are shown in Table 4.

Table 4. Analysis codes used for this work.

\begin{tabular}{lll}
\hline Name & Description & Reference \\
\hline Shift & $\begin{array}{l}\text { Monte Carlo radiation transport code. Sim- } \\
\text { ulates neutron transport in HFIR and deple- } \\
\text { tion of fuel and target isotopes. }\end{array}$ \\
& $\begin{array}{l}\text { Reads processed output from Shift to calcu- } \\
\text { late steady-state thermal hydraulic metrics } \\
\text { HSSHTC }\end{array}$ \\
& such as burnout margins steady-state tem- \\
& $\begin{array}{l}\text { perature. } \\
\text { Driver for the entire analysis process. Orga- } \\
\text { nizes and passes data between tools. Also } \\
\text { contains a visualization suite. }\end{array}$ \\
\hline
\end{tabular}

The analysis process is as follows:

1. Determine fuel design features (Table 11) and fuel shape (radial thickness profile)

2. Generate Monte Carlo N-Particle code (MCNP) geometry from analyst input (Figure 3)

3. Generate corresponding Shift input file

4. Run Shift with critical CE position search to determine critical CE position.

5. Parse Shift output to produce reactor physics performance metrics (h5 database)

6. Create HSSHTC input file from the produced database

7. Run HSSHTC

8. Parse HSSHTC output file to store thermal hydraulics metrics (h5 database)

9. Use visualization suite to produce plots and tables of analysis results

Except for the initial step, the entire analysis process is automated, which increases reproducibility and decreases probability of human error. A full HFIR Monte Carlo N-Particle code (MCNP) model with a representative loading is used to generate these metrics [12].

\subsection{Neutronics Mesh}

The involute fuel plates within the fuel elements are explicitly modeled using a set of hexahedra to approximately define the fuel meat, filler, and Al cladding of the fuel plates and the water coolant between the plates. The radial mesh used to define the hexahedra approximating the fuel meat shape is listed in Tables 5 and 6, respectively. A total of 21 radial mesh cells are used to define the IFE, primarily because it has a smaller involute radius and therefore more curvature than the OFE. The IFE and OFE axial meshes 
consist of 21 cells as described in Table 7. Nonuniform radial and axial mesh cells are defined to accurately capture the fuel shape and the flux gradients that occur at the axial and radial extremes of the fuel meat.

Table 5. Radii of the IFE fuel regions in the neutronics model.

\begin{tabular}{llll}
\hline No. & $r_{i}(\mathrm{~cm})^{*}$ & $r_{o}(\mathrm{~cm})$ & $\Delta r(\mathrm{~cm})$ \\
\hline 1 & 7.124378 & 7.20 & 0.08 \\
2 & 7.20 & 7.35 & 0.15 \\
3 & 7.35 & 7.50 & 0.15 \\
4 & 7.50 & 7.75 & 0.25 \\
5 & 7.75 & 8.00 & 0.25 \\
6 & 8.00 & 8.25 & 0.25 \\
7 & 8.25 & 8.50 & 0.25 \\
8 & 8.50 & 8.85 & 0.35 \\
9 & 8.85 & 9.20 & 0.35 \\
10 & 9.20 & 9.50 & 0.30 \\
11 & 9.50 & 9.85 & 0.35 \\
12 & 9.85 & 10.20 & 0.35 \\
13 & 10.20 & 10.50 & 0.30 \\
14 & 10.50 & 10.85 & 0.35 \\
15 & 10.85 & 11.20 & 0.35 \\
16 & 11.20 & 11.50 & 0.30 \\
17 & 11.50 & 11.75 & 0.25 \\
18 & 11.75 & 12.00 & 0.25 \\
19 & 12.00 & 12.20 & 0.20 \\
20 & 12.20 & 12.40 & 0.20 \\
21 & 12.40 & 12.54696 & 0.15 \\
\hline
\end{tabular}

$* r_{i}$ and $r_{o}$ are inner and outer radii; $\Delta r=r_{o}-r_{i}$

\subsection{Depletion Modeling}

For depletion modeling, the fully explicit transport-depletion coupling method is used, where a single transport calculation is done at the beginning of the time, and that result is used for all the depletion substeps. For this work, a timestep of a day is used, with 10 depletion substeps. [16] explains depletion modeling in Shift in detail.

\subsection{Thermal-hydraulics mesh}

The HSSHTC is a 2-D r-z steady-state heat transfer code represented as $(\mathrm{i}, \mathrm{j})$ nodes. The IFE and OFE radial mesh defining the fuel meat consists of 11 nodes each as shown in Table 8. The IFE and OFE axial mesh consists of 23 nodes as shown in Table 9. The HSSHTC node locations were selected based on the following guidelines: (1) $\sim 0.4 \mathrm{~cm} \Delta s$ (distance along arc length) at radial edges, (2) $0.5 \mathrm{~cm} \Delta z$ at axial edges, (3) internal fuel meat nodes approximately at neutronic s midpoints, (4) internal fuel nodes approximately at neutronic z midpoints, and (5) nodes at location optimized for energy conservation based on the power distribution. Very fine axial and radial meshes at the radial and axial extremes were not desired because HSSHTC does not conduct heat into the unfueled regions and a very fine mesh around the 
Table 6. Radii of the OFE fuel regions in the neutronics model.

\begin{tabular}{llll}
\hline No. & $r_{i}(\mathrm{~cm})^{*}$ & $r_{o}(\mathrm{~cm})$ & $\Delta r(\mathrm{~cm})$ \\
\hline 1 & 15.13905 & 15.30 & 0.16 \\
2 & 15.30 & 15.50 & 0.20 \\
3 & 15.50 & 16.00 & 0.50 \\
4 & 16.00 & 16.50 & 0.50 \\
5 & 16.50 & 17.00 & 0.50 \\
6 & 17.00 & 17.50 & 0.50 \\
7 & 17.50 & 18.00 & 0.50 \\
8 & 18.00 & 18.50 & 0.50 \\
9 & 18.50 & 19.00 & 0.50 \\
10 & 19.00 & 19.50 & 0.50 \\
11 & 19.50 & 20.00 & 0.50 \\
12 & 20.00 & 20.50 & 0.50 \\
13 & 20.50 & 20.75 & 0.25 \\
14 & 20.75 & 20.95536 & 0.21 \\
\hline$* r_{i}$ and $r_{o}$ are inner and outer radii; $\Delta r=r_{o}-r_{i}$
\end{tabular}

Table 7. Axial mesh for fuel regions in the neutronics model.

\begin{tabular}{llll}
\hline No. & $Z_{\text {upper }}(\mathrm{cm}){ }^{*}$ & $Z_{\text {lower }}(\mathrm{cm})$ & $\Delta z(\mathrm{~cm})$ \\
\hline 1 & 27.94 & 27.44 & 0.50 \\
2 & 27.44 & 26.94 & 0.50 \\
3 & 26.94 & 25.94 & 1.00 \\
4 & 25.94 & 24.94 & 1.00 \\
5 & 24.94 & 23.00 & 1.94 \\
6 & 23.00 & 18.00 & 5.00 \\
7 & 18.00 & 13.00 & 5.00 \\
8 & 13.00 & 8.00 & 5.00 \\
9 & 8.00 & 3.00 & 5.00 \\
10 & 3.00 & 1.00 & 2.00 \\
11 & 1.00 & -1.00 & 2.00 \\
12 & -1.00 & -3.00 & 2.00 \\
13 & -3.00 & -8.00 & 5.00 \\
14 & -8.00 & -13.00 & 5.00 \\
15 & -13.00 & -18.00 & 5.00 \\
16 & -18.00 & -23.00 & 5.00 \\
17 & -23.00 & -24.94 & 1.94 \\
18 & -24.94 & -25.94 & 1.00 \\
19 & -25.94 & -26.94 & 1.00 \\
20 & -26.94 & -27.44 & 0.50 \\
21 & -27.44 & -27.94 & 0.50
\end{tabular}

* Location is with respect to the core midplane (at axial location $0.0 \mathrm{~cm}$ ). 
frame of the fuel meat would result in additional conservatism. Figure 2 illustrates the HSSHTC nodes superimposed onto the neutronics mesh.

Table 8. Radii of the fuel nodes in the HSSHTC model.

\begin{tabular}{lll}
\hline $\mathrm{i}$ & IFE r $(\mathrm{cm})$ & OFE r $(\mathrm{cm})$ \\
\hline 3 & 7.124 & 15.139 \\
4 & 7.493 & 15.521 \\
5 & 7.820 & 15.837 \\
6 & 8.254 & 16.252 \\
7 & 9.014 & 17.007 \\
8 & 10.012 & 18.007 \\
9 & 11.011 & 19.007 \\
10 & 11.753 & 19.752 \\
11 & 12.119 & 20.279 \\
12 & 12.326 & 20.67 \\
13 & 12.547 & 20.955 \\
\hline
\end{tabular}

Table 9. Axial mesh for fuel nodes in the HSSHTC model.

\begin{tabular}{llll}
\hline $\mathrm{i}$ & $\mathrm{z}(\mathrm{cm})^{*}$ & $\mathrm{i}$ & $\mathrm{z}(\mathrm{cm})$ \\
\hline 3 & 27.94 & 15 & -2.00 \\
4 & 27.44 & 16 & -5.50 \\
5 & 26.94 & 17 & -10.50 \\
6 & 26.32 & 18 & -15.50 \\
7 & 25.44 & 19 & -20.50 \\
8 & 23.97 & 20 & -23.97 \\
9 & 20.50 & 21 & -25.44 \\
10 & 15.50 & 22 & -26.32 \\
11 & 10.50 & 23 & -26.94 \\
12 & 5.50 & 24 & -27.44 \\
13 & 2.00 & 25 & -27.94 \\
14 & 0.00 & & \\
\hline *Location is with respect to the core midplane at axial location $0.0 \mathrm{~cm}$.
\end{tabular}




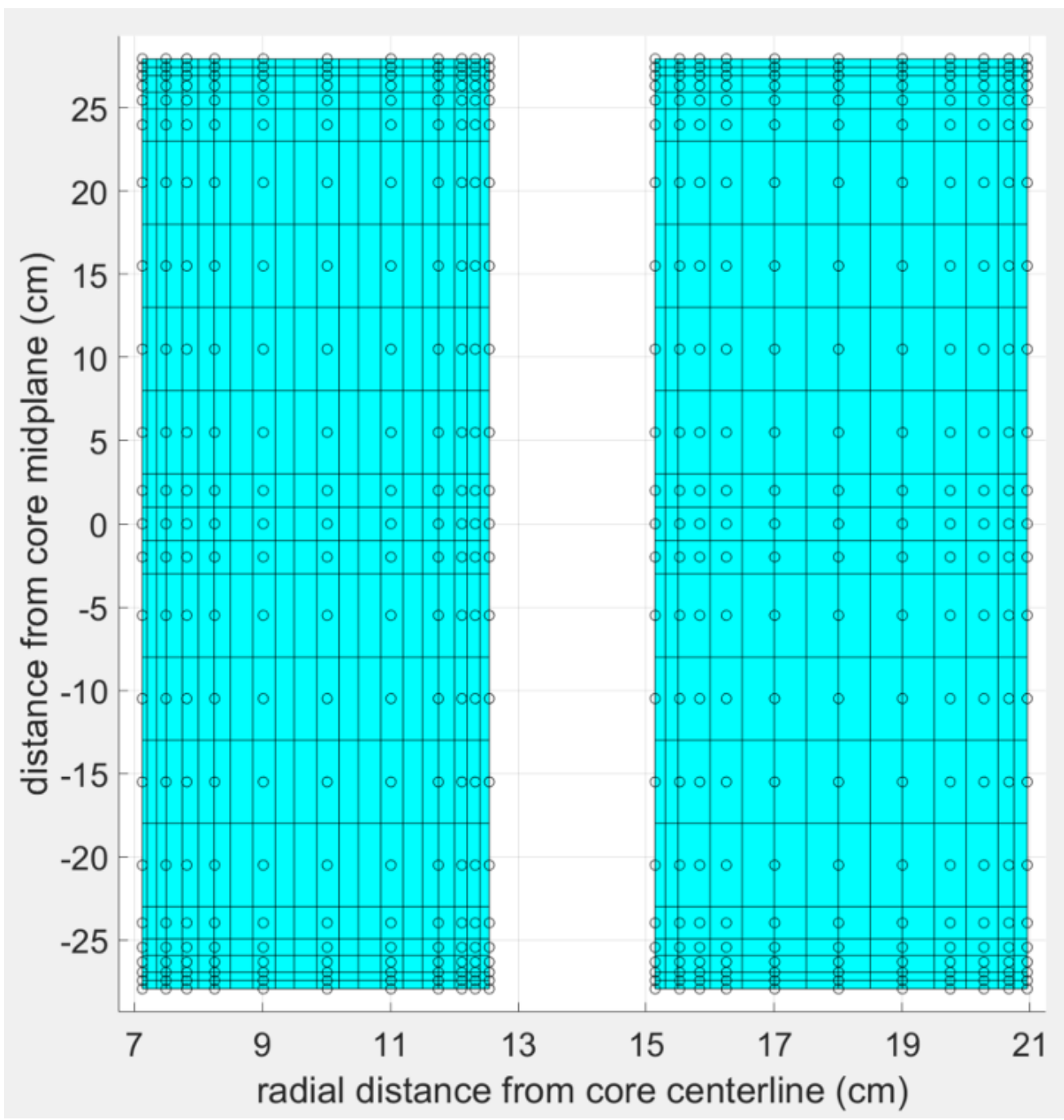

Figure 2. Fuel element HSSHTC nodes (black circles) superimposed on neutronics mesh (black lines). 


\subsection{Design parameter calculation methods}

\subsubsection{Fission rate density}

The fission rate density $f_{d}$ in a given fuel region is

$$
f_{d}=\frac{1}{V_{\text {fuel }}} \sum_{i}^{M} \int_{0}^{\infty} d E \int_{\partial V \in V_{\text {fuel }}} d V N_{i}(\mathbf{r}) \sigma_{i, f}(\mathbf{r}, E) \phi(\mathbf{r}, E)
$$

where $V_{\text {fuel }}$ is the volume of the given fuel region, $N_{i}$ is the number density of isotope $i, \sigma_{i, f}$ is the fission cross section of isotope $i, \phi$ is the scalar flux, and the sum is over the $M$ fissionable isotopes within the fuel region. The unit of $f_{d}$ is fissions per second per cubic $\mathrm{cm}$ of fuel particle.

\subsubsection{Cumulative fission density}

Cumulative fission density is calculated by taking the time integral of the fission rate density values.

$$
F_{d}\left(t_{f}\right)=\frac{1}{V_{\text {fuel }}} \sum_{i}^{M} \sum_{t}^{T} \int_{0}^{\infty} d E \int_{\partial V \in V_{\text {fuel }}} d V N_{i, t}(\mathbf{r}) \sigma_{i, f}(\mathbf{r}, E) \phi_{t}(\mathbf{r}, E) \Delta t
$$

The unit of $F_{d}$ is fissions per cubic $\mathrm{cm}$ of fuel particle. The maximum cumulative fission density in this report is an interpolated value between the last full cycle day and the next day. For example, if the cycle length is 26.7 days, then maximum cumulative fission density is at:

$$
F_{d}(26.7)=F_{d}(26)+\left(F_{d}(27)-F_{d}(26)\right) * 0.7
$$

\subsubsection{Power density}

Power density is calculated by multiplying the fission rate density by the average energy generated per fission $(200.7 \mathrm{MeV} *$ ). A conservative assumption is made that all energy generated by fission is deposited locally in the fuel meat.

$$
P_{d}=f_{d} * 200.7 \frac{\mathrm{MeV}}{\text { fission }} * \frac{1.60218 * 10^{-16} \mathrm{~kJ}}{1 \mathrm{MeV}}
$$

The unit of $P_{d}$ is $\mathrm{kW}$ per cubic cm of fuel particle.

\subsubsection{Heat flux}

Nominal heat fluxes are estimated using the following expression:

$$
q_{(r, z)}^{\prime \prime}\left(\frac{W}{c m^{2}}\right)=\overline{q^{\prime \prime}}\left(\frac{W}{c m^{2}}\right) \phi_{(r, z)}=\frac{P_{t o t}(W) f_{F E}}{A\left(c m^{2}\right)} \phi_{(r, z)}
$$

*This Q value of $200.7 \mathrm{Mev} /$ fission is a 'typical' Q value used in HFIR analyses close to the approximate cycle-averaged value that was recently calculated for the optimized silicide design. The BOC and EOC Q values were estimated to be 200.49 and 201.46 $\mathrm{MeV} /$ fission, respectively, givin the average Q value of $200.98 \mathrm{MeV} /$ fission [9]. 
where $q_{(r, z)}^{\prime \prime}$ is the nominal heat flux at $r, z$, and $\overline{q^{\prime \prime}}$ is the core average heat flux, $\phi_{(r, z)}$ is the relative fission density at $\mathrm{r}, \mathrm{z}, P_{t o t}$ is the total reactor power, $f_{F E}$ is the fraction of total heat deposited in the fuel element, and $A$ is the heat transfer area. A $f_{F E}$ value of 0.965 is assumed, and a heat transfer area of $4.3820 e^{5} \mathrm{~cm}^{2}$ is assumed for 22-inch fuel (Eq. 6). Symmetric heat transport through both sides of the fuel plates is assumed irrespective of the location of the fuel meat inside the plates (i.e., centered symmetric vs. off-centered asymmetric). The location of the fuel is taken into account by adjusting the uncertainty factors in the HSSHTC calculation.

$$
\begin{gathered}
A_{F E}=\left(\Delta s_{I F E} * N_{I F E}+\Delta s_{O F E} * N_{O F E}\right) *(H * 2) \\
\Delta s=\text { Length of fuel meat along involute } \\
N=\text { Number of fuel plates in region } \\
H=\text { Height of fuel plate }
\end{gathered}
$$




\section{CANDIDATE FUEL DESIGN PARAMETERS}

All four low density $\mathrm{U}_{3} \mathrm{Si}_{2}$ fuel designs share some key geometric and operational characteristics (Table 10). The fuel designs have different design features that impact manufacturing processes (Table 11). Table 12 shows the design features selected for the fuel design options explored in this effort. The fuel axial length had to be extended from $50.8 \mathrm{~cm}$ (20 inches) to $55.88 \mathrm{~cm}$ ( 22 inches) in order to meet cycle length standards.

The input generation script is set up so that the user can specify different combinations of design features. Figure 4 shows the MCNP geometry representations of these design features.

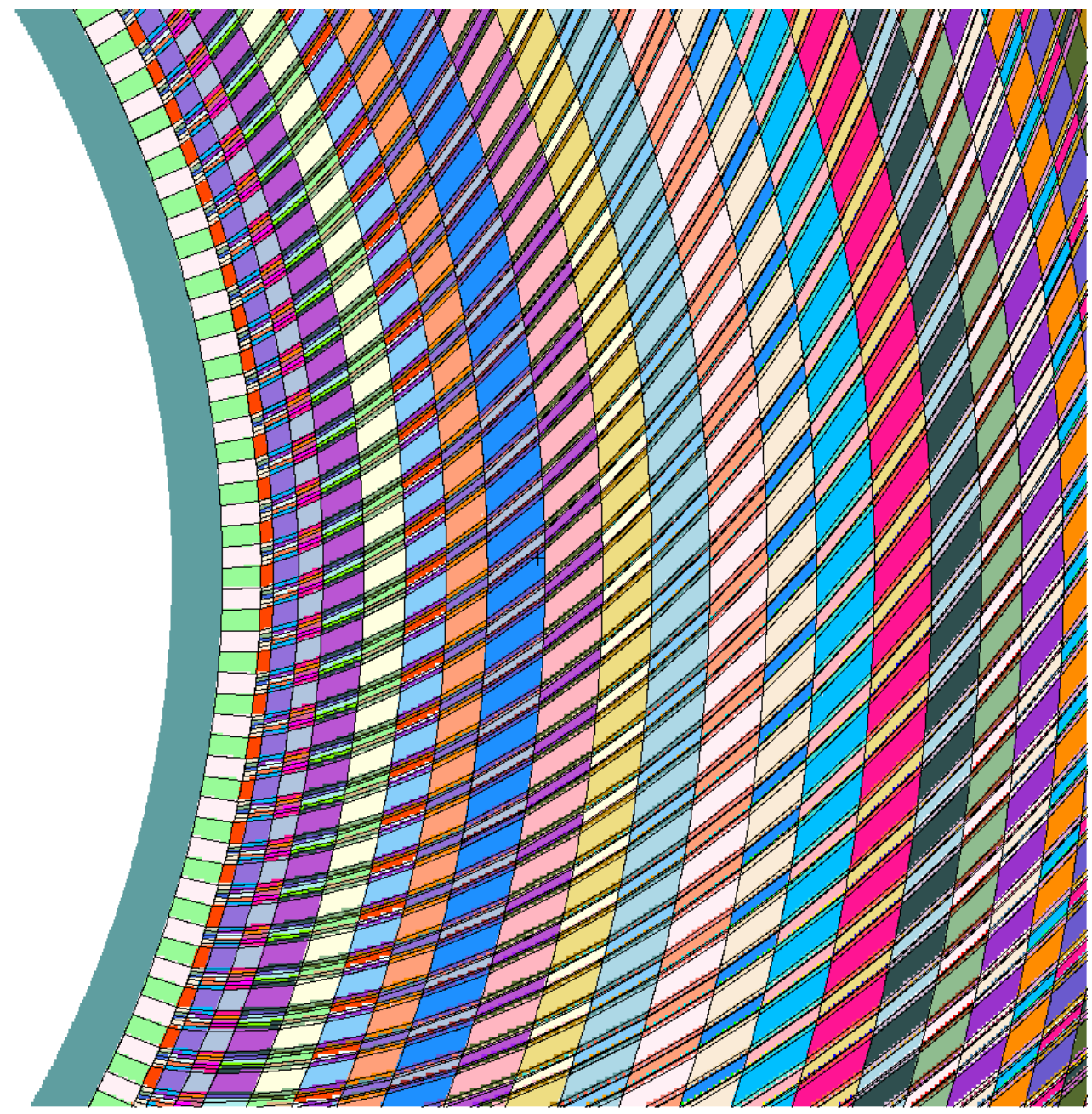

Figure 3. PHAME-generated MCNP file geometry. 
Table 10. Key HFIR LEU geometry and operational parameters common to all presented designs.

\begin{tabular}{|c|c|c|c|}
\hline Parameter & Units & \multicolumn{2}{|c|}{ Value } \\
\hline Power & MW & \multicolumn{2}{|c|}{95} \\
\hline Coolant & - & \multicolumn{2}{|c|}{ light water } \\
\hline Inlet coolant temperature & ${ }^{\circ} \mathrm{C}$ & \multicolumn{2}{|c|}{48.89} \\
\hline Inlet coolant pressure & $\mathrm{MPa}$ & \multicolumn{2}{|c|}{3.33} \\
\hline Primary flow rate & $\mathrm{m}^{3} / \mathrm{s}$ & \multicolumn{2}{|c|}{1.01} \\
\hline Number of fuel elements & - & \multicolumn{2}{|c|}{2} \\
\hline Clad thickness & $\mu \mathrm{m}$ & \multicolumn{2}{|c|}{254} \\
\hline Fuel meat + filler thickness & $\mu \mathrm{m}$ & \multicolumn{2}{|c|}{762} \\
\hline Fuel plate thickness & $\mu \mathrm{m}$ & \multicolumn{2}{|c|}{1270} \\
\hline Coolant channel thickness & $\mu \mathrm{m}$ & \multicolumn{2}{|c|}{1270} \\
\hline Plate-to-water ratio & - & \multicolumn{2}{|c|}{1} \\
\hline Active fuel meat length & $\mathrm{cm}$ & \multicolumn{2}{|c|}{55.88} \\
\hline Fuel plate length & $\mathrm{cm}$ & \multicolumn{2}{|c|}{60.96} \\
\hline Active fuel zone volume & $\mathrm{L}$ & \multicolumn{2}{|c|}{55.58} \\
\hline Average power density & MW/L & \multicolumn{2}{|c|}{1.71} \\
\hline \multirow[t]{2}{*}{ Fuel meat heat transfer area } & $\mathrm{m}^{2}$ & \multicolumn{2}{|c|}{44.13} \\
\hline & & IFE & OFE \\
\hline Number of fuel plates & - & 171 & 369 \\
\hline Involute radius* & $\mathrm{cm}$ & 6.91261 & 14.91742 \\
\hline Fuel plate arc length* & $\mathrm{cm}$ & 9.21004 & 8.09752 \\
\hline $\begin{array}{l}\text { Distance from inner plate edge to invo- } \\
\text { lute origin* }\end{array}$ & $\mathrm{cm}$ & 0.29718 & 0.29464 \\
\hline Distance along involute to fuel meat start & $\mathrm{cm}$ & 0.23114 & 0.23439 \\
\hline Distance along involute to fuel meat end & $\mathrm{cm}$ & 8.02706 & 7.32267 \\
\hline Fuel meat arc length & $\mathrm{cm}$ & 7.79592 & 7.08828 \\
\hline Fuel meat heat transfer area & $\mathrm{m}^{2}$ & 14.89875 & 29.23167 \\
\hline Inner radius of fuel meat & $\mathrm{cm}$ & 7.12438 & 15.13905 \\
\hline Outer radius of fuel meat & $\mathrm{cm}$ & 12.54696 & 20.95536 \\
\hline Active fuel zone volume & $\mathrm{L}$ & 18.72606 & 36.85477 \\
\hline
\end{tabular}

${ }^{*}$ Visual depiction of fuel plate geometry in Figure 5 
Table 11. Complex fuel design features and benefits.

\begin{tabular}{|c|c|c|}
\hline Design option & Description & Benefit \\
\hline Axial contour (i.e., toe) & $\begin{array}{l}\text { The lowest } 1 \mathrm{~cm} \text { of the fuel is linearly } \\
\text { interpolated from the top shape to a } \\
\text { radially flat fuel profile with reduced } \\
\text { thickness. }\end{array}$ & $\begin{array}{l}\text { Because the coolant flows from top } \\
\text { to bottom in HFIR, the location of } \\
\text { limiting thermal margin is at the bot- } \\
\text { tom (i.e., the outlet). By reducing } \\
\text { fuel mass on the bottom, outlet power } \\
\text { peaking is reduced. }\end{array}$ \\
\hline $\begin{array}{l}\text { Center and symmetric } \\
\text { fuel zone }\end{array}$ & $\begin{array}{l}\text { The fuel meat is centered and sym- } \\
\text { metric within the fuel plate thick- } \\
\text { ness and is surrounded by an equal } \\
\text { amount of filler material on each } \\
\text { side (plates consist of cladding, filler, } \\
\text { fuel, filler, and cladding instead of } \\
\text { cladding, fuel, filler, and cladding). }\end{array}$ & $\begin{array}{l}\text { Enhances heat transfer path from fuel } \\
\text { meat to coolant. The amount of heat } \\
\text { dissipated from the convex and con- } \\
\text { cave sides of the involute are equal. }\end{array}$ \\
\hline $\mathrm{Gd}_{2} \mathrm{O}_{3}$ in IFE filler & $\begin{array}{l}\text { Gadolinium is added in addition to } \\
\text { boron to suppress IFE power peaking } \\
\text { in the first few day(s) of operation. }\end{array}$ & $\begin{array}{l}\text { Provides for an increase in the total } \\
\text { fuel amount while maintaining safety } \\
\text { margins in the first few cycle days } \\
\text { when margins are typically smallest } \\
\text { for silicide designs. }\end{array}$ \\
\hline Boron strip underneath & $\begin{array}{l}\text { The lowest unfueled region (i.e., } \\
\text { clad) of the fuel contains a } 0.5 \text {-inch } \\
\text { boron strip in the form of borated alu- } \\
\text { minum powder. }\end{array}$ & $\begin{array}{l}\text { Because the coolant flows from top to } \\
\text { bottom in HFIR, the location of lim- } \\
\text { iting thermal margin is at the bottom } \\
\text { (i.e., the outlet). By placing boron on } \\
\text { the bottom, outlet power peaking is } \\
\text { suppressed. }\end{array}$ \\
\hline
\end{tabular}

Table 12. Currently analyzed silicide designs that meet the performance and safety metrics. Case numbers denote different fuel shapes.

\begin{tabular}{l|c|c|c|c}
\hline Name & Center-symmetric fuel & Axial contour & Gd in filler & Boron strip \\
\hline Optimized & $\mathrm{Y}$ & $\mathrm{Y}$ & - & - \\
Alternate 1 & - & $\mathrm{Y}$ & $\mathrm{Y}$ & - \\
Alternate 2 & $\mathrm{Y}$ & - & $\mathrm{Y}$ & - \\
Alternate 3 & - & - & - & $\mathrm{Y}$ \\
\hline
\end{tabular}




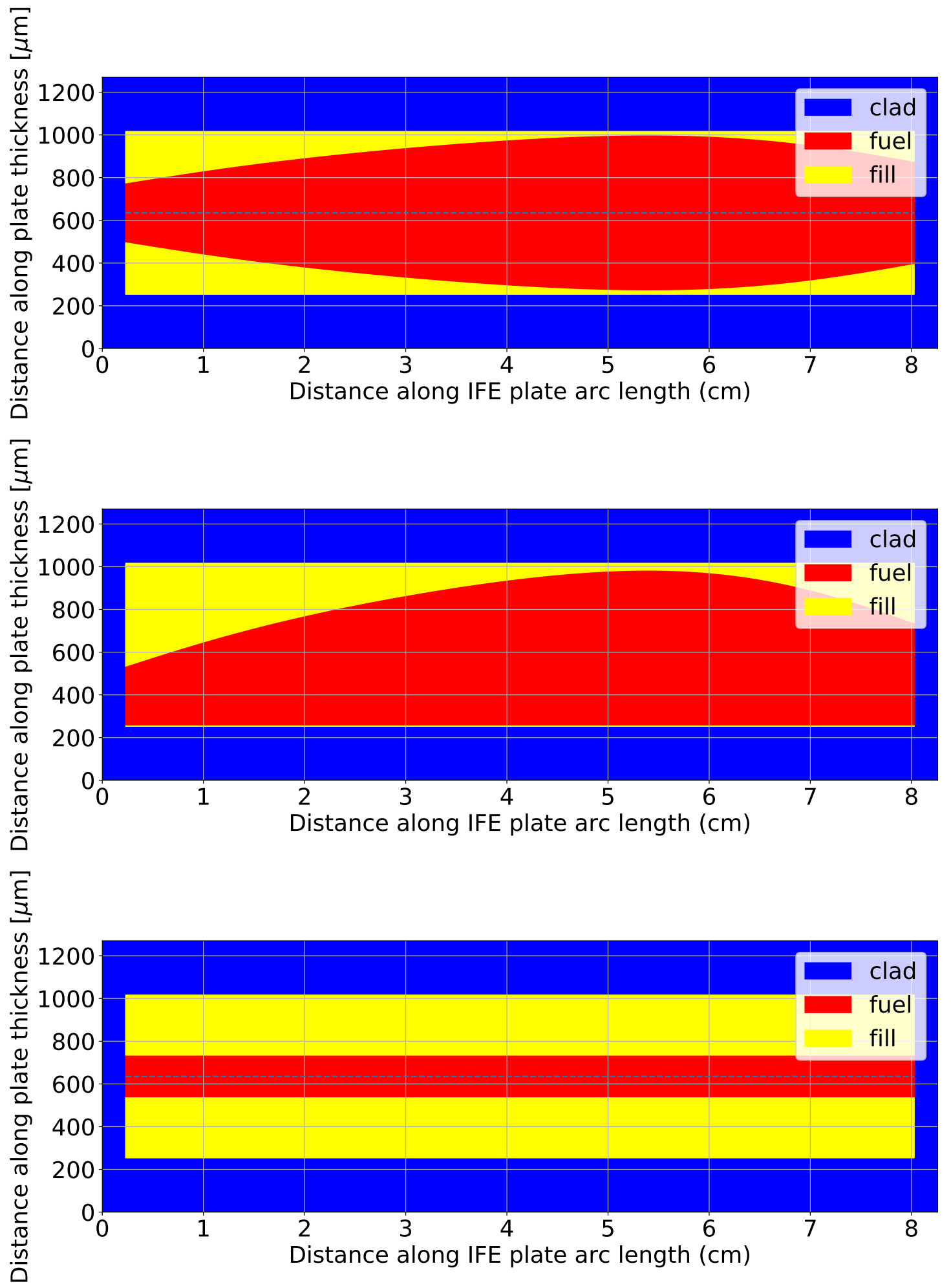

Figure 4. The top image shows the center and symmetric fuel, where the layers are clad-filler-fuelfiller-clad. The middle image shows the off-center and asymmetric fuel, where the layers are cladfuel-filler-clad. The bottom images shows the axial contour of the center and symmetric fuel, where the fuel thickness is reduced to $200 \mu \mathrm{m}$. These images are for illustration only. 


\section{OVERVIEW OF METRICS}

The metrics used to measure the LEU core performance and safety are shown in Table 13. The list of metrics used in this report is expanded from the list in Ilas et al. [19], to provide a more comprehensive set of metrics related to safety, performance, and resource utilization.

All the designs meet or exceed HEU metrics (Table 14) minus the cold source cold flux ratio, minimum burnout margin, and uranium utilization. The detailed explanations for these metrics are below. The most variation in performance between designs is seen in cycle length and $\mathrm{Cf}$ production rate.

\subsection{DESCRIPTION OF METRICS}

This section presents a brief description and the calculation method for each metric. All flux metrics are spatially and temporally averaged, so the single value denotes the average value across all radial, axial, and temporal (day) meshes.

\subsubsection{Cf Production Rate}

One of the primary missions of HFIR is isotope production, including the production of ${ }^{252} \mathrm{Cf}$, which is created within the curium-oxide targets inside the flux trap region through a complex absorption and decay

Table 13. Metrics used to measure the performance and safety of the LEU core.

\begin{tabular}{|c|c|c|c|}
\hline Metric & Type & Units & Description \\
\hline Cf production rate & Performance & $\mathrm{mg} /$ day & $\begin{array}{l}\text { Time-averaged mass of cal- } \\
\text { ifornium produced from the } \\
\text { curium targets }\end{array}$ \\
\hline $\mathrm{Cm}$ target thermal flux & Performance & $\frac{\mathrm{n}}{\mathrm{cm}^{2} \cdot \mathrm{s}}$ & $\begin{array}{l}\text { Thermal flux }(E<0.625 \mathrm{eV}) \text { in } \\
\text { the curium target }\end{array}$ \\
\hline $\begin{array}{l}\text { Cold source moderator vessel } \\
\text { cold flux ratio }\end{array}$ & Performance & - & $\begin{array}{l}\text { Ratio of cold flux }(E<0.103978 \\
\mathrm{eV}) \text { in cold source }\end{array}$ \\
\hline $\begin{array}{l}\text { Cold source moderator vessel } \\
\text { cold flux }\end{array}$ & Performance & $\frac{\text { neutrons }}{\mathrm{cm}^{2} \cdot \mathrm{s}}$ & $\begin{array}{l}\text { Cold flux }(E<0.103978 \mathrm{eV}) \text { in } \\
\text { the moderator vessel }\end{array}$ \\
\hline Cycle length & Performance & days & $\begin{array}{l}\text { Number of days the LEU core } \\
\text { can maintain criticality }\end{array}$ \\
\hline Flux trap fast flux & Performance & $\frac{\mathrm{n}}{\mathrm{cm}^{2} \cdot \mathrm{s}}$ & $\begin{array}{l}\text { Fast flux }(E>0.1 \mathrm{MeV}) \text { in flux } \\
\text { trap }\end{array}$ \\
\hline Flux trap fast flux ratio & Performance & - & $\begin{array}{l}\text { Ratio of fast flux }(E>0.1 \mathrm{MeV}) \\
\text { in flux trap }\end{array}$ \\
\hline Minimum burnout margin & Safety & - & Thermal safety margin \\
\hline Reflector fast flux & Performance & $\frac{\text { neutrons }}{\mathrm{cm}^{2} \cdot \mathrm{s}}$ & $\begin{array}{l}\text { Fast flux }(E>0.1 \mathrm{MeV}) \text { in re- } \\
\text { flector }\end{array}$ \\
\hline Reflector fast flux ratio & Performance & - & $\begin{array}{l}\text { Ratio of fast flux }(E>0.1 \mathrm{MeV}) \\
\text { in reflector }\end{array}$ \\
\hline${ }^{235} \mathrm{U}$ loading & Design & kg & Mass of ${ }^{235} \mathrm{U}$ in the fuel \\
\hline${ }^{235} \mathrm{U}$ utilization & Performance & day $/ \mathrm{kg}$ & $\begin{array}{l}\text { Cycle length divided by loaded } \\
{ }^{235} \mathrm{U}\end{array}$ \\
\hline
\end{tabular}


chain. This metric is calculated by obtaining the mass of ${ }^{252} \mathrm{Cf}$ at the end of the cycle and dividing by the cycle length.

\subsubsection{Cycle Length}

Cycle length denotes the number of days the core can maintain criticality. The critical element position search module determines positions throughout operation, ending when the core is subcritical, with the control elements fully withdrawn. From the control element position curve, an interpolation is made to estimate the cycle length. For example, if a core is subcritical with fully withdrawn control elements starting on day 27, then the cycle length would be $26 . N$ days, where $N$ is interpolated from the control element position curve.

\subsubsection{Cold Source Flux and Ratio}

The cold source flux magnitude and cold-to-total flux ratio are measures of the quality of the flux for cold neutron science. Increased brightness (i.e., greater magnitude) and reduced noise (i.e., higher cold-to-total flux ratio) are desired. Due to a hardened spectrum with LEU fuel relative to HEU, the cold-to-total flux ratio of these designs do not meet HEU metrics.

As the cold source neutron source region is radially external to the control elements, the cold source region flux is highly affected by the control element location. Therefore, designs with longer cycle lengths and associated slower control element withdrawals have a relatively lower average cold source flux.

\subsubsection{Flux Trap Fast Flux and Ratio}

The flux trap is the center region in HFIR that experiences the highest flux $\left(\sim 10^{15} \frac{\mathrm{neutrons}}{\mathrm{cm}^{2} \cdot \mathrm{s}}\right)$. The flux trap region is used for isotope production and materials irradiation testing. Fast flux in the flux trap is used for materials irradiation studies to accelerate damage testing. The fast flux and fast-to-total flux ratio metrics

Table 14. The performance and safety metrics for the new low density LEU designs need to meet or exceed HEU metrics. All the designs in this study meet or exceed HEU metrics minus the cold source cold flux ratio, minimum burnout margin, and uranium utilization.

\begin{tabular}{l|c|cccc}
\hline Metrics & HEU & Optimized & Alternate1 & Alternate2 & Alternate3 \\
\hline Cf production rate & 1.388 & 1.406 & 1.398 & 1.396 & 1.38 \\
Cm target flux & $>1.00 \mathrm{E}+15$ & $1.64 \mathrm{E}+15$ & $1.64 \mathrm{E}+15$ & $1.63 \mathrm{E}+15$ & $1.63 \mathrm{E}+15$ \\
Cold source cold flux ratio & 0.736 & 0.723 & 0.723 & 0.724 & 0.724 \\
Cold source flux & $4.48 \mathrm{E}+14$ & $4.63 \mathrm{E}+14$ & $4.64 \mathrm{E}+14$ & $4.65 \mathrm{E}+14$ & $4.65 \mathrm{E}+14$ \\
Cycle length & 26.2 & 27.464 & 27.452 & 27.117 & 27.121 \\
Flux trap fast flux & $1.07 \mathrm{E}+15$ & $1.15 \mathrm{E}+15$ & $1.15 \mathrm{E}+15$ & $1.14 \mathrm{E}+15$ & $1.14 \mathrm{E}+15$ \\
Flux trap fast flux ratio & 0.29 & 0.308 & 0.308 & 0.307 & 0.306 \\
Minimum burnout & 1.61 & 1.617 & 1.538 & 1.507 & 1.512 \\
Reflector fast flux & $2.89 \mathrm{E}+14$ & $3.22 \mathrm{E}+14$ & $3.22 \mathrm{E}+14$ & $3.23 \mathrm{E}+14$ & $3.23 \mathrm{E}+14$ \\
Reflector fast flux ratio & 0.192 & 0.198 & 0.198 & 0.197 & 0.197 \\
${ }^{235} \mathrm{U}$ loading & 9.4 & 13.95 & 13.95 & 13.933 & 13.951 \\
${ }^{235} \mathrm{U}$ utilization & 2.78 & 1.969 & 1.968 & 1.946 & 1.944 \\
\hline
\end{tabular}


are calculated by spatially averaging the fast fluxes in the material irradiation targets located in the flux trap. This results in a time-resolved quantity that is then averaged over the cycle.

\subsubsection{Minimum Burnout Margin}

Safety limit (SL) calculations must show that for cases in which a given process variable is at its SL, all other variables are at their limiting control settings (LCSs), and all uncertainties in the technical knowledge of the process have resolved unfavorably, then no hot spot burnout can occur. At each time step, HSSHTC determines the average temperatures and heat fluxes at the given power and then calculates the effects of uncertainties in reactor process conditions, tolerances and uncertainties in fuel manufacturing, and analysis/correlation uncertainties. At the last time step specified in the input, the reactor power is increased until the hot spot surface heat flux is equal to the surface heat flux predicted by the Gambill burnout heat flux correlation [17]. The burnout margin is defined as the burnout-to-nominal power ratio and the minimum burnout margin is the smallest ratio calculated over the cycle. Refer to [11] for more details regarding the safety limit calculation methods and the employed uncertainty factors for silicide fuel.

For the $95 \mathrm{MW}$ LEU core, a minimum burnout power of 129.2 MW is required to meet the current 1.36 flux-to-flow safety limit; however, a greater margin is required to render an LEU design option feasible because the minimum predicted HEU margin is 1.61 and the assumptions made for the LEU fuel uncertainty factors associated with manufacturing tolerances and physics correlations may need to be refined, making it prudent to favor a more conservative calculation in this analysis stage. It is desired to maintain the HEU-calculated margin (1.61), but a margin of 1.51 has been defined by the HFIR conversion team as the minimum margin to declare a LEU design feasible. This margin has been somewhat arbitrarily selected based on a previous safety limit and the difference between the safety limit and the calculated limit being $\approx 0.15$. The difference of 0.15 is then added to the current safety limit of 1.36 to get 1.51 .

A design that meets the HEU calculated 1.61 is preferred, but given the tight restraints on the design space, the 1.51 margin is adequate, as long as it notably pass the TSR SL of 1.36 and the reduced margin is offset by performance and fabrication improvements.

\subsubsection{Reflector Fast Flux and Ratio}

The removable beryllium reflector has eight large aluminum-lined irradiation positions, and one of these facilities is often used for materials irradiation purposes when large targets are to be irradiated. For the flux trap, these metrics are calculated by spatially averaging the fluxes in the 8 irradiation facilities $(1 \mathrm{~A}, 1 \mathrm{~B}$, 3A,3B, 5A, 5B, 7A, 7B) within the removable beryllium reflector region. This results in a time-resolved quantity that is then averaged over the cycle.

\subsection{7 $\quad{ }^{235} \mathrm{U}$ Loading and Utilization}

The ${ }^{235} \mathrm{U}$ loading metric denotes the total mass of ${ }^{235} \mathrm{U}$ in the fuel elements. The mass of fissile material is roughly proportional to the cycle length. The utilization metric is the cycle length divided by the initial ${ }^{235} \mathrm{U}$ mass loading. The HEU core has a lower ${ }^{235} \mathrm{U}$ loading and a higher utilization because it has a substantially lower amount of ${ }^{238} \mathrm{U}$, so it is impacted less by fuel parasitic neutron absorption. 


\section{DESIGN SPECIFICATIONS AND PARAMETERS}

This section presents the four candidate designs and their time-dependent, nominal maximum detailed design parameters (i.e., fission rate density, power density, heat flux, and cumulative fission density). The larger plots that show the spatially dependent values are provided in the appendix for readability. The reference numbers in each section are links to the plots in the document. Also, for these plots, only the beginning-of-cycle (BOC), first day, middle-of-cycle (MOC), and end-of-cycle (EOC) values are shown. The BOC and EOC state points are provided because they bound the cycle operations. Results at the first day into the cycle are provided because fission product poisons have approximately reached their equilibrium conditions, the control elements have rapidly withdrawn with respect to BOC, and the peak parameters at the outer radial edge of the OFE on the core midplane are observed. MOC conditions are provided because they approximately represent cycle average results.

The fuel plate geometry for each design is discussed in the following subsections for the four designs. Interpretation of the Alternate 1 design's IFE fuel plate is illustrated in Figure 5, with nominal dimensions shown. The fuel meat thickness $(\mathrm{t})$ profiles are defined as polynomial curves, $\mathrm{f}(\mathrm{x})$, where $\mathrm{x}$ is the arc distance from the origin of the involute generating radius. Thus, $x=0$ is the origin of the involute generating radius, which is 2.7215 inches $(6.91261 \mathrm{~cm})$ from the reactor core centerline for the IFE. The distance from the inner edge of the IFE plate to the origin of the involute is 0.117 inches $(0.29718 \mathrm{~cm})$. The distances from the origin of the involute to the fuel meat start and stop edges are taken as 0.091 inches $(0.23114 \mathrm{~cm})$ and 3.16026 inches $(8.02706 \mathrm{~cm})$. The nominal fuel plate arc length is 3.626 inches $(9.21004 \mathrm{~cm})$.

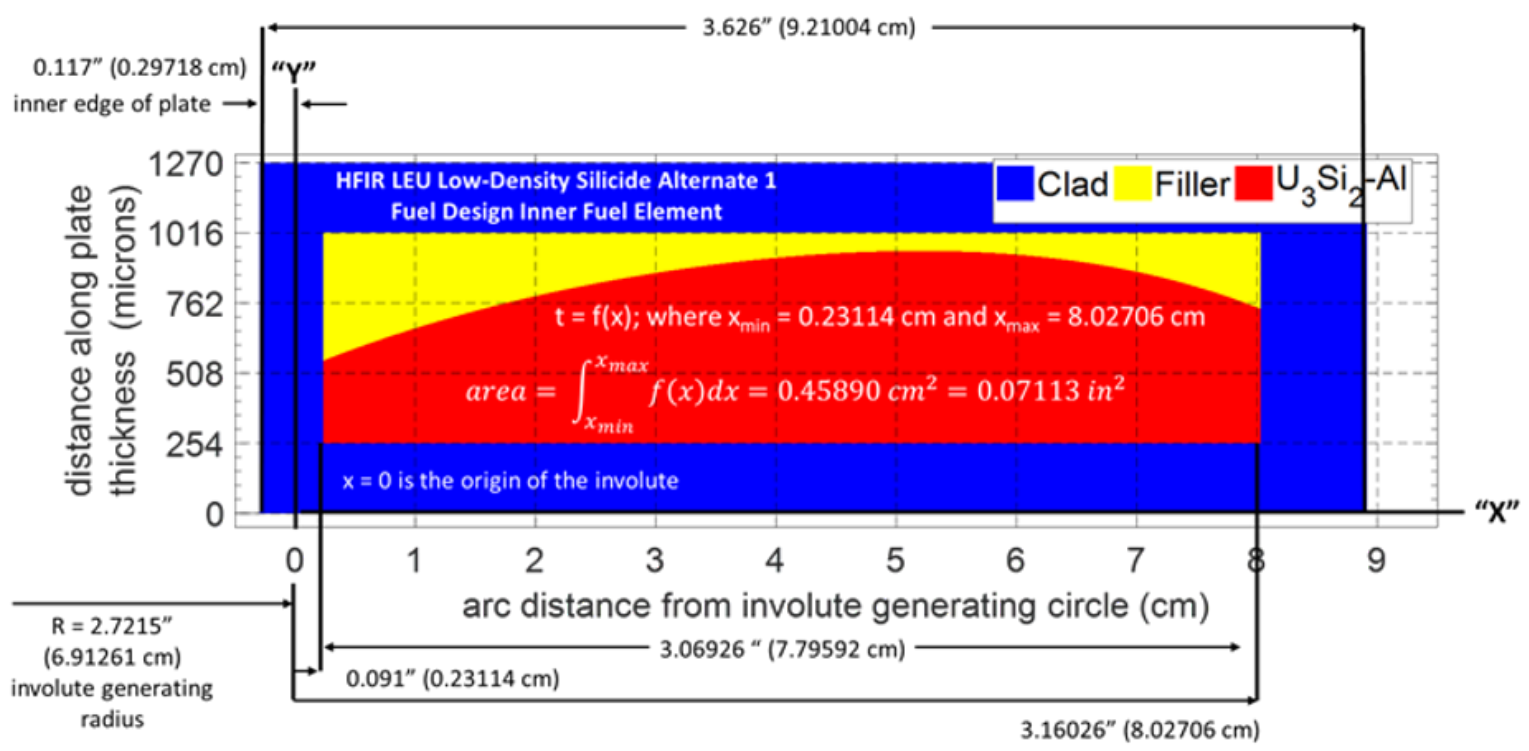

Figure 5. Interpretation of fuel plate plots with Alternate Design 1 IFE illustrated. 


\subsection{OPTIMIZED DESIGN}

The optimized design was generated by including center-symmetric fuel zones to promote heat transfer to the coolant and axial contours at the bottom of the fuel zones to reduce axial power peaking. Combining these two complex design features is advantageous, resulting in a design with a desirable thermal safety margin. The cycle length of this design is 27.46 days. The optimized fuel design specifications are presented in Table 15.

Table 15. Key optimized design geometry and operational parameters.

\begin{tabular}{llll}
\hline Parameter & Units & Value \\
\hline Center-symmetric fuel zone & - & yes \\
\hline Axial contour & - & yes \\
\hline $\mathrm{Gd}_{2} \mathrm{O}_{3}$ in IFE filler & - & no \\
\hline Boron strip below fuel & - & no \\
\hline U loading & $\mathrm{kg}$ & 70.6332 \\
\hline${ }^{235} \mathrm{U}$ loading & $\mathrm{kg}$ & 13.9501 \\
\hline & & $\mathrm{IFE}$ & OFE \\
\hline & $\mathrm{kg}$ & 4.0748 & 9.8753 \\
\hline${ }^{235} \mathrm{U}$ loading & $\mathrm{g} / \mathrm{plate}$ & 23.82924 & 26.76233 \\
\hline${ }^{235} \mathrm{U}$ loading per plate & - & $\mathrm{Al}+\mathrm{B}_{4} \mathrm{C}$ & $\mathrm{Al}$ \\
\hline Filler & $\mathrm{g}$ & 2.2025 & - \\
\hline${ }^{10} \mathrm{~B}$ loading in IFE filler & $\mathrm{mg} / \mathrm{cm}^{3}$ & 1.752 & - \\
\hline${ }^{10} \mathrm{~B}$ density in IFE filler & $\mathrm{mg}$ & 0.0 & 0.0 \\
\hline Gd loading in IFE filler & $\mathrm{mg} / \mathrm{cm}^{3}$ & 0.0 & 0.0 \\
\hline Gd density in IFE filler & & & \\
\hline
\end{tabular}




\subsubsection{Fuel Meat Shape}

The fuel meat thickness profile of the optimized design is described in Table 16, where $t(\mu \mathrm{m})$ is the fuel meat thickness and $\mathrm{s}(\mathrm{cm})$ is the distance from the origin of the involute generating radius. Illustrations of the IFE and OFE fuel meat shapes are shown in Figures 6 and 7.

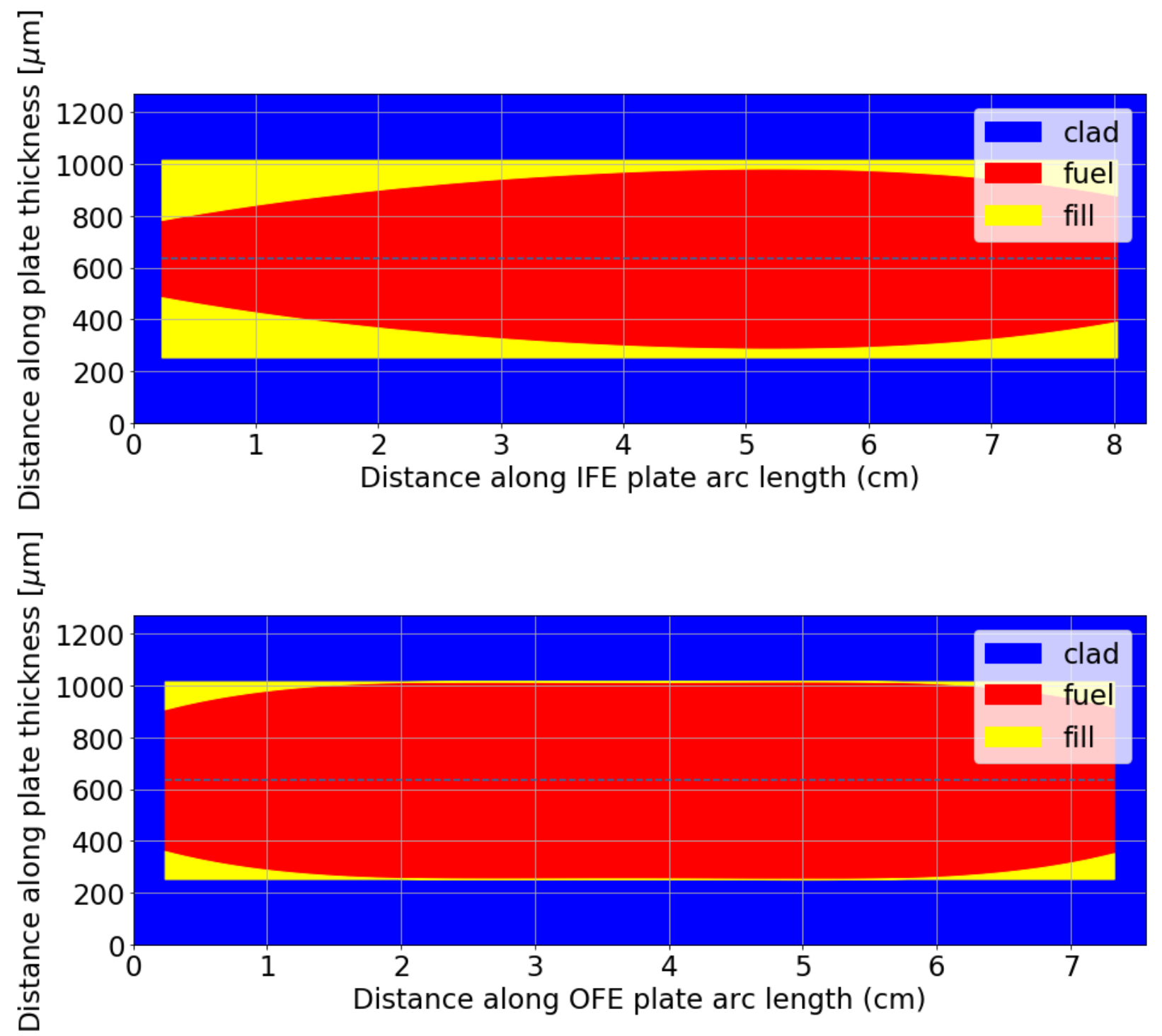

Figure 6. Fuel meat shape for the optimized design. 


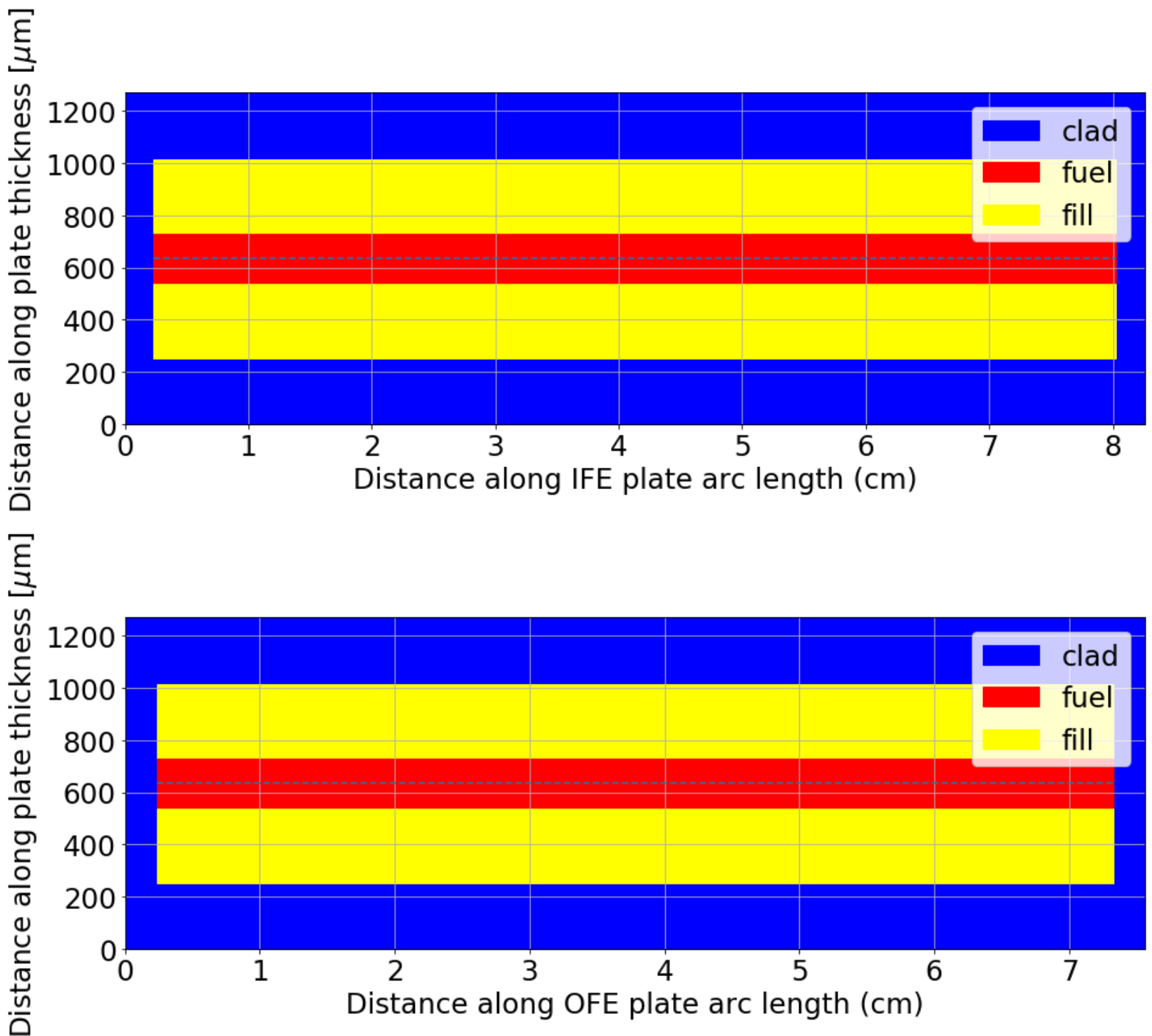

Figure 7. Fuel bottom meat shape for the optimized design. The axial gradient increases the minimum safety margin, which usually occurs at the bottom of the core.

Table 16. Fuel shape polynomial coefficients for optimized design.

\begin{tabular}{|c|c|c|c|c|c|c|c|}
\hline & \multicolumn{5}{|c|}{ Order } \\
\hline & $s_{i}(\mathrm{~cm})$ & $s_{f}(\mathrm{~cm})$ & 4 & 3 & 2 & 1 & 0 \\
\hline IFE & \multicolumn{2}{|c|}{ ALL } & $-2.23 \mathrm{E}-01$ & $2.88 \mathrm{E}+00$ & $-2.82 \mathrm{E}+01$ & $1.84 \mathrm{E}+02$ & $2.57 \mathrm{E}+02$ \\
\hline \multirow{3}{*}{ OFE } & 0.2343 & 1.696 & - & - & $-5.60 \mathrm{E}+01$ & $2.60 \mathrm{E}+02$ & $4.82 \mathrm{E}+02$ \\
\hline & 1.696 & 6.005 & - & - & - & - & $7.62 \mathrm{E}+02$ \\
\hline & 6.005 & 7.3226 & - & - & $-7.14 \mathrm{E}+01$ & $7.90 \mathrm{E}+02$ & $-1.41 \mathrm{E}+03$ \\
\hline
\end{tabular}




\subsubsection{Fission Rate Density}

Figure 8 shows the maximum fission rate density during operation for each fuel element. Table 17 lists the peak fission rate results and references to the figures in the appendix that illustrate the spatial fission rate density values for the four selected state points for each fuel element.

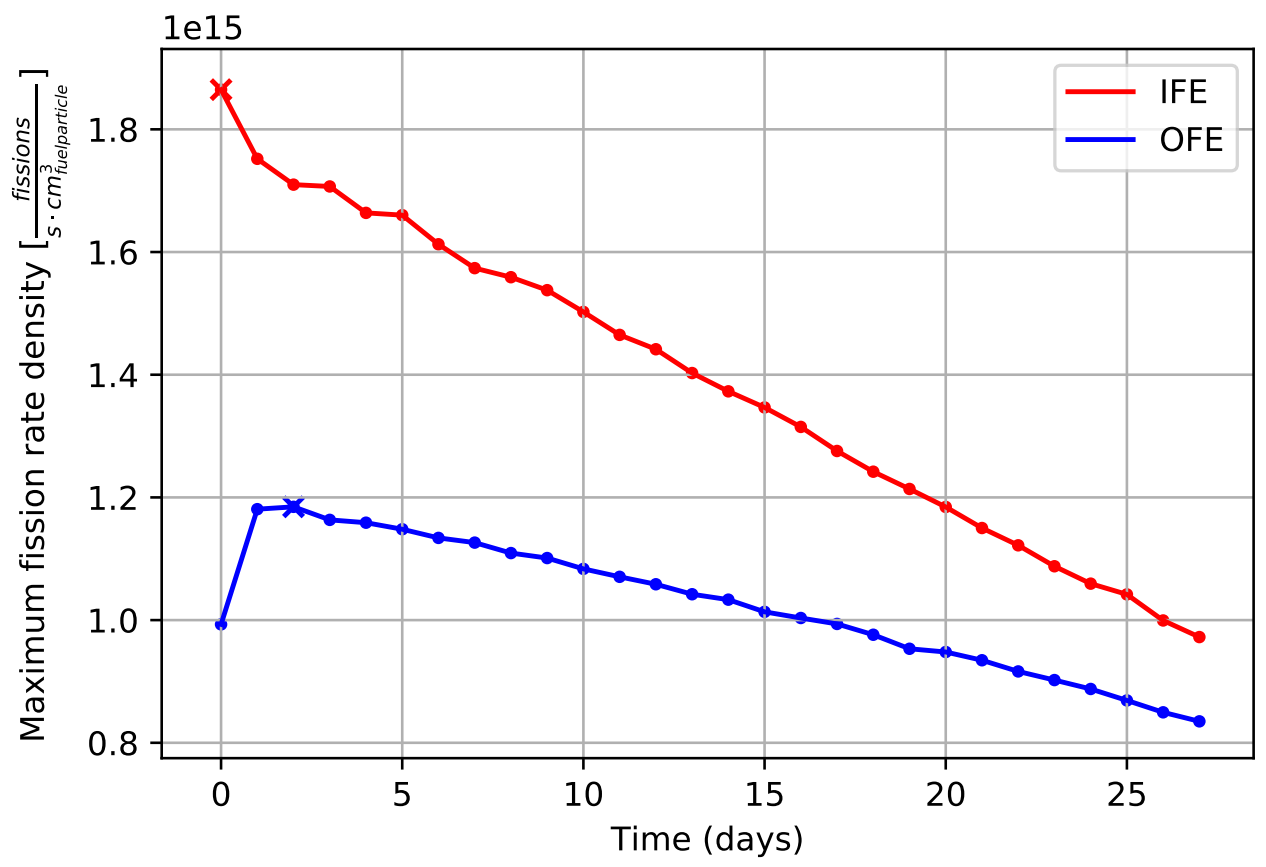

Figure 8. Optimized design maximum fission density during operation.

Table 17. Minimum and maximum fission rate densities in the optimized design.

\begin{tabular}{|c|c|c|c|c|c|}
\hline Day & Region & Minimum & Maximum & Unit & Ref. \\
\hline 0 & IFE & 3.2 & 18.65 & \multirow{9}{*}{$10^{14} \frac{\text { fissions }}{\mathrm{s} \cdot \mathrm{cc}_{\text {fuelparticle }}^{3}}$} & Fig. 32 \\
\hline 1 & IFE & 3.02 & 17.52 & & Fig. 33 \\
\hline 15 & IFE & 3.02 & 13.47 & & Fig. 34 \\
\hline 27 & IFE & 3.17 & 9.72 & & Fig. 35 \\
\hline 0 & OFE & 1.33 & 9.93 & & Fig. 36 \\
\hline 1 & OFE & 1.34 & 11.81 & & Fig. 37 \\
\hline 2 & OFE & 1.37 & 11.85 & & Fig. 38 \\
\hline 15 & OFE & 1.82 & 10.13 & & Fig. 39 \\
\hline 27 & OFE & 2.16 & 8.35 & & Fig. 40 \\
\hline
\end{tabular}




\subsubsection{Power Density}

The power density values are the fission rate density values multiplied by the average energy generated per fission. It is conservatively assumed that all energy generated by fission is deposited locally in the fuel meat. Therefore, the power density and fission rate density results have identical trends, and only the magnitudes of the results are different. Figure 9 shows the maximum local power density during operation for each fuel element. Table 18 lists the maximum power density results and references the figures in the appendix. Each plot in the appendix shows the spatial power density values for each of the four selected state points for each fuel element.

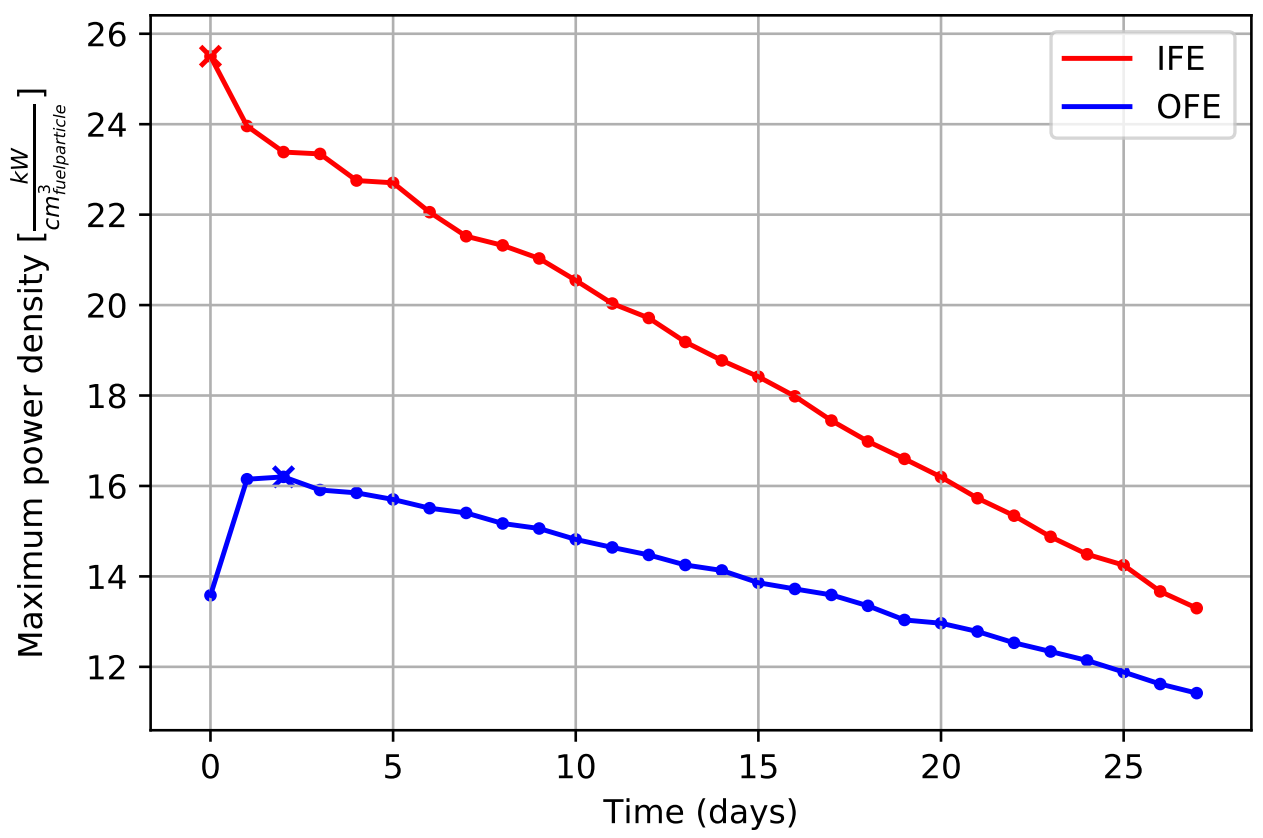

Figure 9. Optimized design maximum power density during operation.

Table 18. Minimum and maximum power densities in the optimized design.

\begin{tabular}{|c|c|c|c|c|c|}
\hline Day & Region & Minimum & Maximum & Unit & Ref. \\
\hline 0 & IFE & 4.37 & 25.5 & & Fig. 47 \\
\hline 1 & IFE & 4.13 & 23.96 & & Fig. 48 \\
\hline 15 & IFE & 4.12 & 18.42 & & Fig. 49 \\
\hline 27 & IFE & 4.34 & 13.3 & $\mathrm{~kW}$ & Fig. 50 \\
\hline 0 & OFE & 1.81 & 13.58 & $\mathrm{~cm}_{\text {fuelparticle }}^{3}$ & Fig. 51 \\
\hline 1 & OFE & 1.84 & 16.15 & & Fig. 52 \\
\hline 2 & OFE & 1.87 & 16.2 & & Fig. 53 \\
\hline 15 & OFE & 2.48 & 13.86 & & Fig. 54 \\
\hline 27 & OFE & 2.95 & 11.42 & & Fig. 55 \\
\hline
\end{tabular}




\subsubsection{Heat Flux}

Figure 10 shows the maximum heat flux during operation for each fuel element. Table 19 lists the maximum heat flux results and references to the figures in the appendix. Each plot in the appendix shows the spatial heat flux values for the four selected state points for each fuel element.

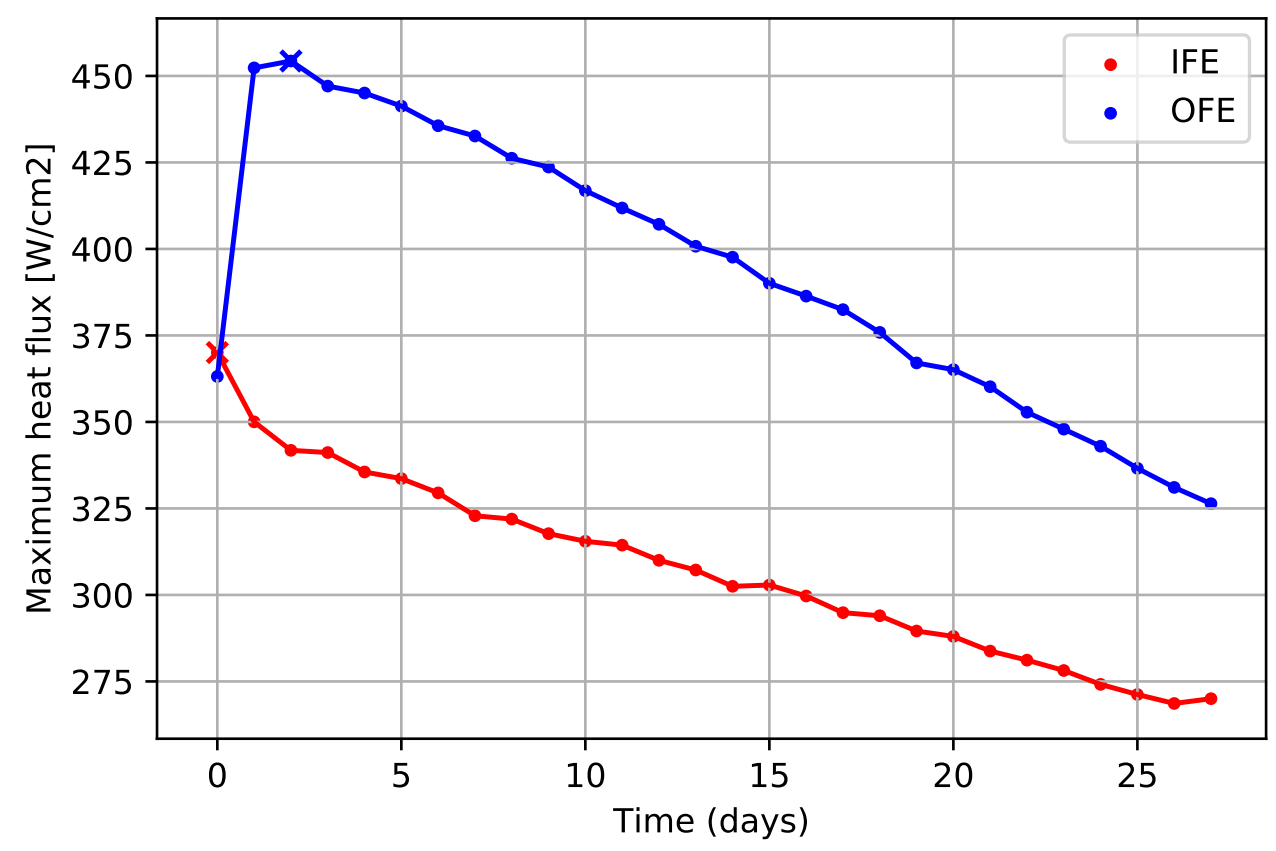

Figure 10. Optimized design maximum heat flux during operation.

Table 19. Minimum and maximum heat fluxes in the optimized design.

\begin{tabular}{|c|c|c|c|c|c|}
\hline Day & Region & Minimum & Maximum & Unit & Ref. \\
\hline 0 & IFE & 117.9 & 370.06 & & Fig. 56 \\
1 & IFE & 114.0 & 350.02 & & Fig. 57 \\
15 & IFE & 111.09 & 302.86 & & Fig. 58 \\
27 & IFE & 109.2 & 270.01 & $\underline{\mathrm{W}}$ & Fig. 59 \\
0 & OFE & 32.79 & 363.14 & $\mathrm{~cm}^{2}$ & Fig. 60 \\
1 & OFE & 33.43 & 452.33 & & Fig. 61 \\
2 & OFE & 33.91 & 454.31 & & Fig. 62 \\
15 & OFE & 42.28 & 390.07 & & Fig. 63 \\
27 & OFE & 71.77 & 326.38 & & Fig. 64 \\
\hline
\end{tabular}




\subsubsection{Cumulative Fission Density}

Figure 11 shows the maximum local cumulative fission density during operation for each fuel element, and Figure 12 illustrates the fission rate density variation with cumulative fission density for every spatial cell in the neutronics model. Table 20 lists the maximum cumulative fission density results and references to the figures in the appendix.

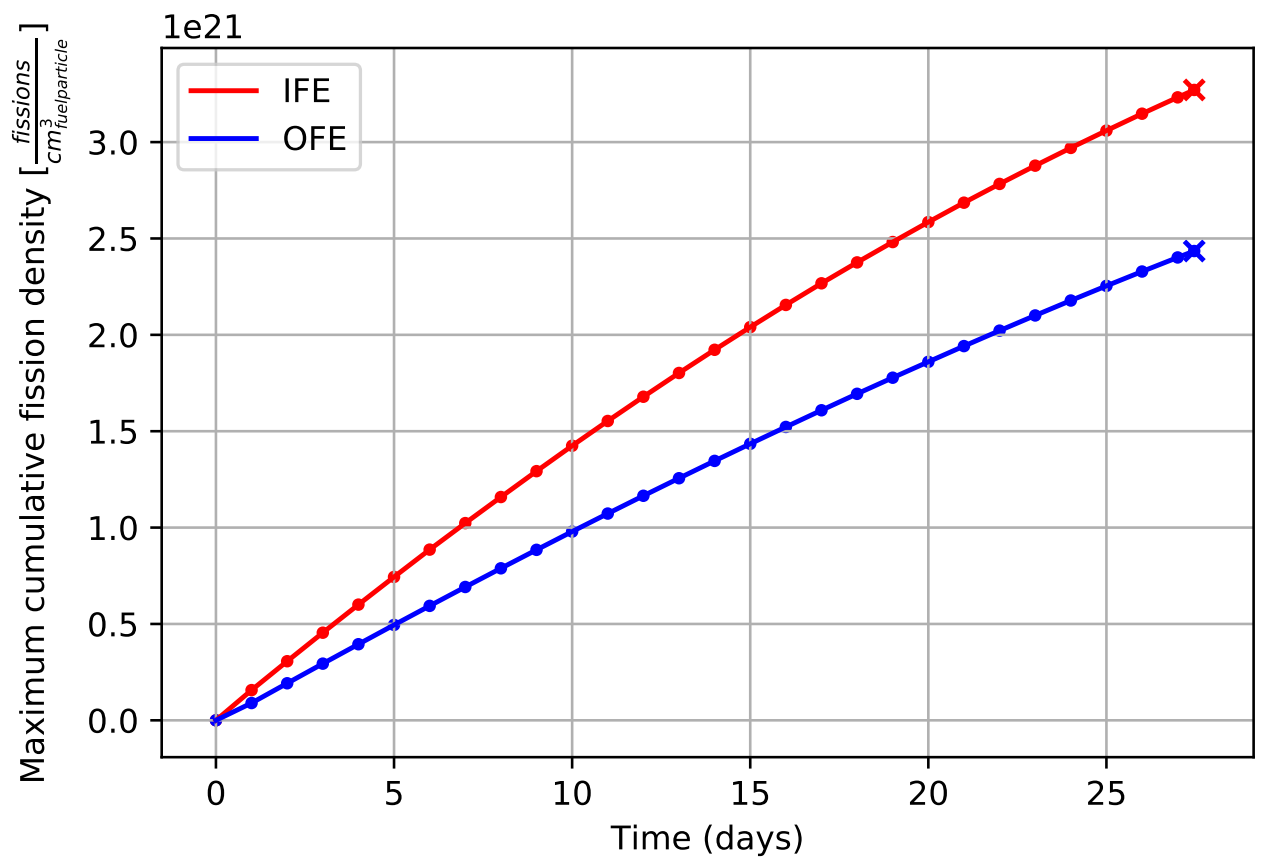

Figure 11. Optimized design maximum cumulative fission density during operation.

Table 20. Minimum and maximum cumulative fission density values in the optimized design.

\begin{tabular}{|c|c|c|c|c|c|}
\hline Day & Region & Minimum & Maximum & Unit & Ref. \\
\hline 1 & IFE & 0.27 & 1.57 & \multirow{6}{*}{$10^{20} \frac{\text { fissions }}{\mathrm{cm}_{\text {fuelparticle }}^{3}}$} & Fig. 41 \\
\hline 15 & IFE & 3.95 & 20.4 & & Fig. 42 \\
\hline 27 & IFE & 7.17 & 32.32 & & Fig. 43 \\
\hline 1 & OFE & 0.12 & 0.9 & & Fig. 44 \\
\hline 15 & OFE & 2.06 & 14.35 & & Fig. 45 \\
\hline 27 & OFE & 4.21 & 24.02 & & Fig. 46 \\
\hline
\end{tabular}




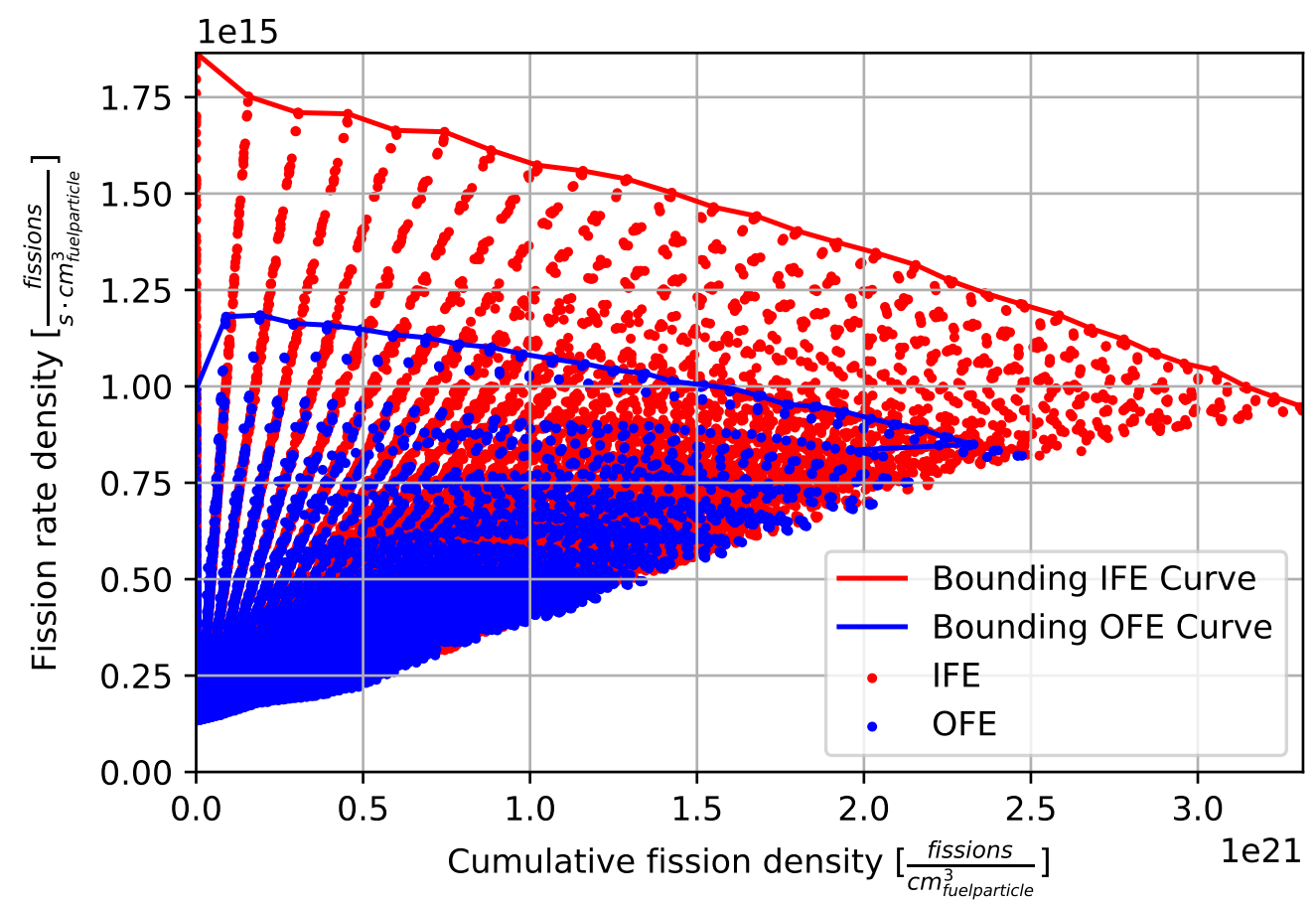

Figure 12. Optimized design fission rate density variation with cumulative fission density during operation. 


\subsection{ALTERNATE 1 DESIGN}

The alternate 1 design was generated by including axial contours at the bottom of the fuel zones to reduce axial power peaking and gadolinium oxide in the IFE filler to suppress power peaking in the IFE for the first few days. The cycle length of this design is 27.45 days. The alternate 1 fuel design specifications are presented in Table 21.

Table 21. Key alternate 1 design geometry and operational parameters.

\begin{tabular}{llll}
\hline Parameter & Units & Value \\
\hline Center-symmetric fuel zone & - & no \\
\hline Axial contour & - & yes \\
\hline $\mathrm{Gd}_{2} \mathrm{O}_{3}$ in IFE filler & - & yes \\
\hline Boron strip below fuel & - & no \\
\hline U loading & $\mathrm{kg}$ & 70.6332 \\
\hline${ }^{235} \mathrm{U}$ loading & $\mathrm{kg}$ & 13.9501 \\
\hline & & & OFE \\
\hline & $\mathrm{kg}$ & $\mathrm{IFE}$ & 9.8753 \\
\hline${ }^{235} \mathrm{U}$ loading & $\mathrm{g} / \mathrm{plate}$ & 4.0748 & 26.76233 \\
\hline${ }^{235} \mathrm{U}$ loading per plate & - & 23.82924 & $\mathrm{Al}$ \\
\hline Filler & $\mathrm{g}$ & $\mathrm{Al}+\mathrm{B}_{4} \mathrm{C}$ & - \\
\hline${ }^{10} \mathrm{~B}$ loading in IFE filler & $\mathrm{mg} / \mathrm{cm}^{3}$ & 2.2022 & - \\
\hline${ }^{10} \mathrm{~B}$ density in IFE filler & $\mathrm{mg}$ & 1.752 & 0.0 \\
\hline Gd loading in IFE filler & $\mathrm{mg} / \mathrm{cm}^{3}$ & 1.009 & 0.0 \\
\hline Gd density in IFE filler & & 0.80231 & \\
\hline
\end{tabular}




\subsubsection{Fuel Meat Shape}

The fuel meat thickness profile of the alternate 1 design is described in Table 22, where $t(\mu \mathrm{m})$ is the fuel meat thickness and $\mathrm{s}(\mathrm{cm})$ is the distance from the origin of the involute generating radius. Illustrations of the IFE and OFE fuel meat shapes are shown in Figures 13 and 14.

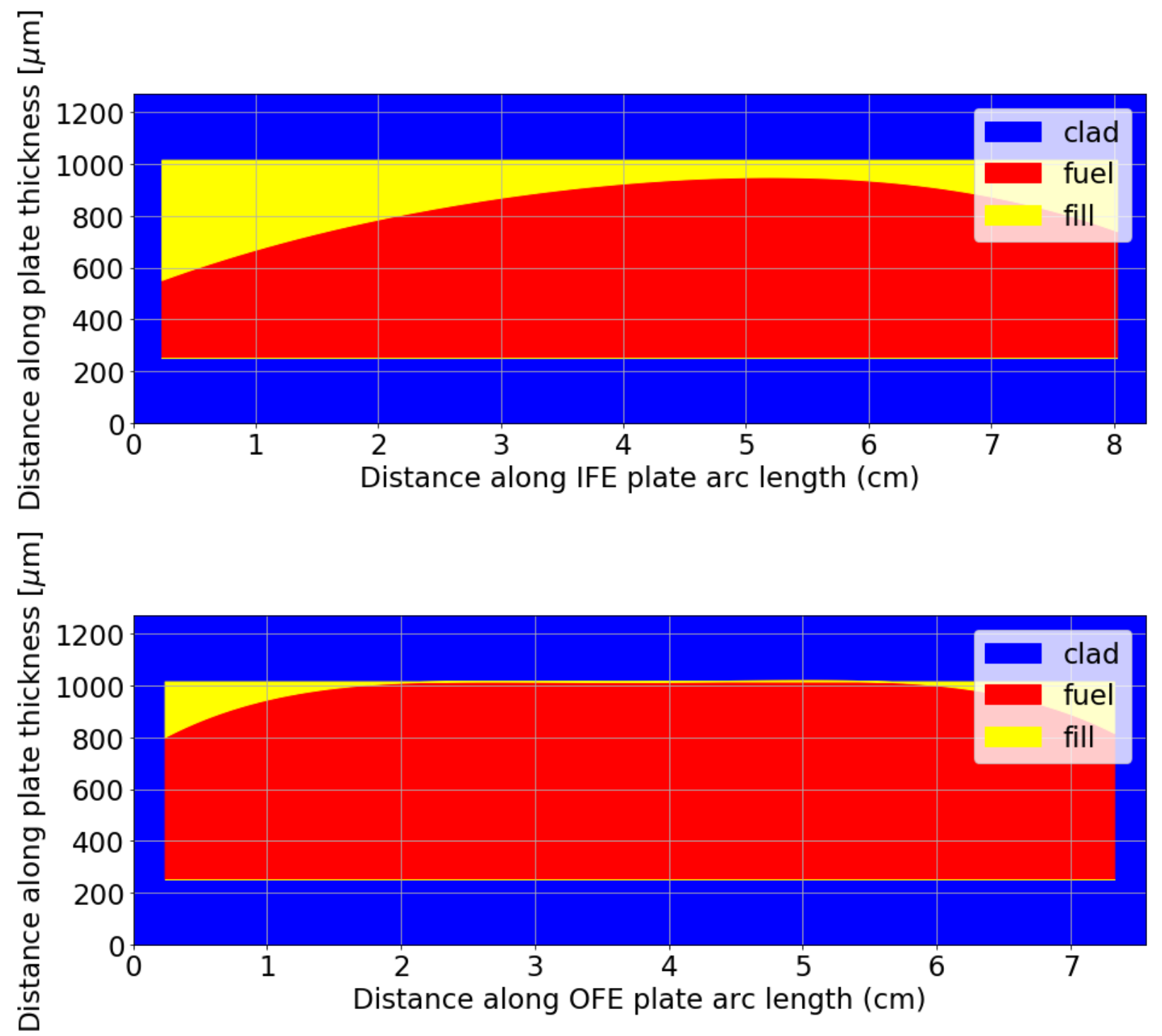

Figure 13. Fuel meat shape for the alternate 1 design. 


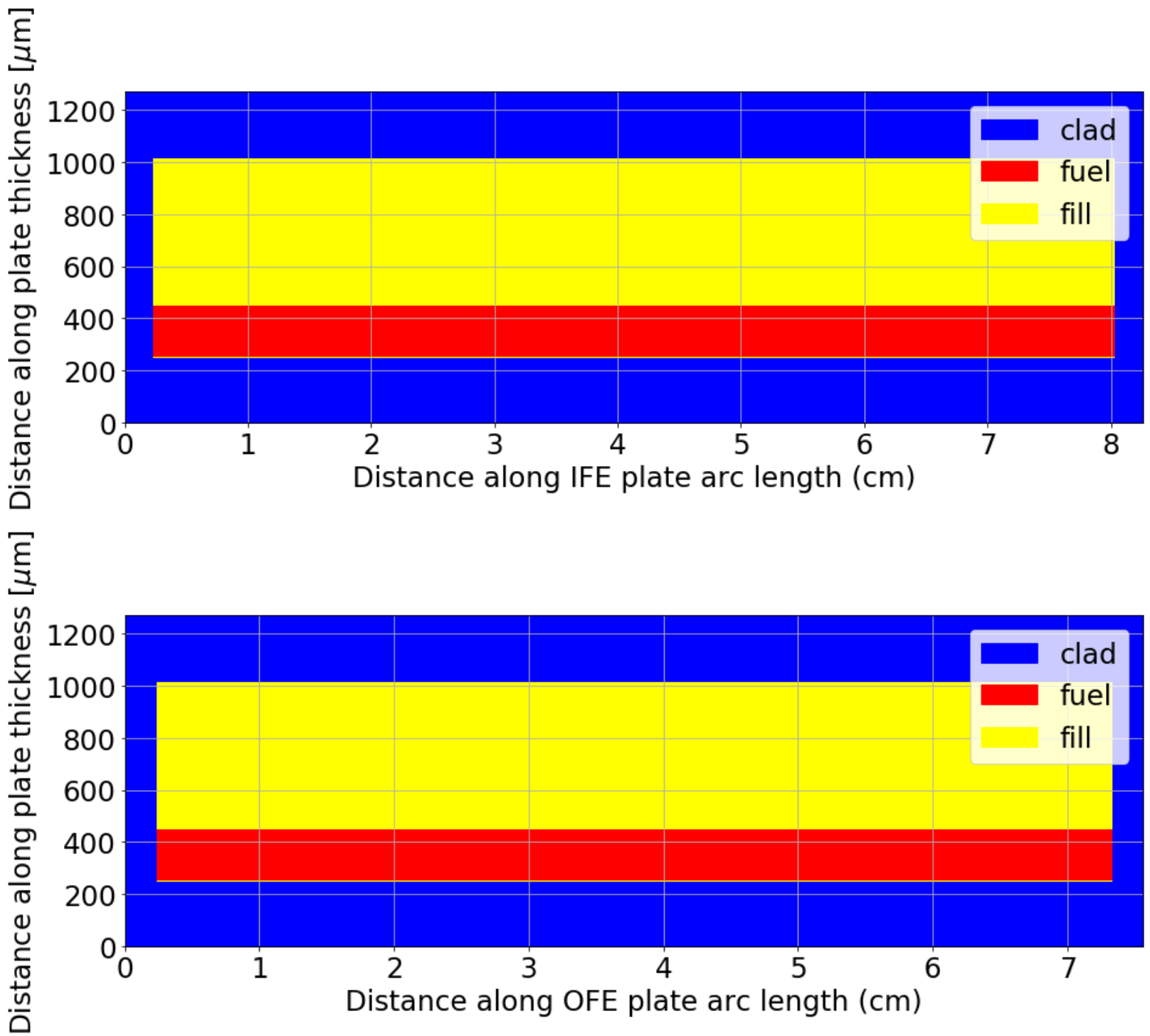

Figure 14. Fuel bottom meat shape for the alternate 1 design. The axial gradient increases the minimum safety margin, which usually occurs at the bottom of the core.

Table 22. Fuel shape polynomial coefficients for alternate 1 design.

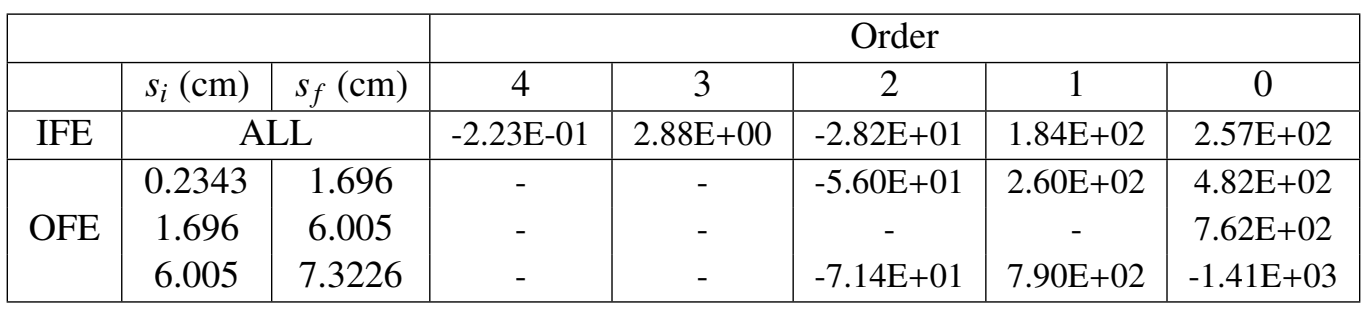




\subsubsection{Fission Rate Density}

Figure 15 shows the maximum fission rate density during operation for each fuel element. Table 23 lists the peak fission rate results and references to the figures in the appendix that illustrate the spatial fission rate density values for the four selected state points for each fuel element.

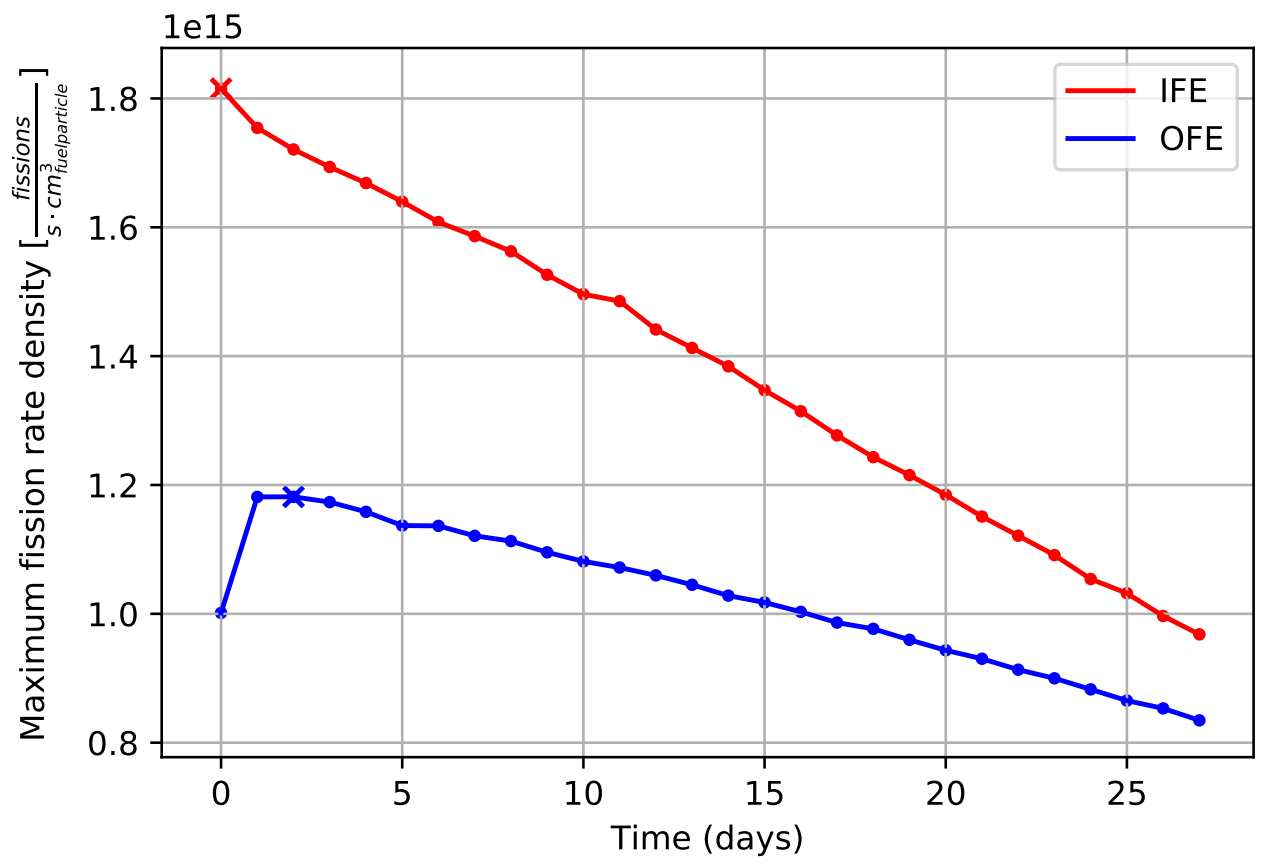

Figure 15. Alternate 1 design maximum fission density during operation.

Table 23. Minimum and maximum fission rate densities in the alternate 1 design.

\begin{tabular}{|c|c|c|c|c|c|}
\hline Day & Region & Minimum & Maximum & Unit & Ref. \\
\hline 0 & IFE & 3.1 & 18.15 & & Fig. 65 \\
1 & IFE & 2.97 & 17.54 & & Fig. 66 \\
15 & IFE & 3.08 & 13.47 & & Fig. 67 \\
27 & IFE & 3.17 & 9.68 & $10^{14} \frac{\text { fissions }^{3}}{\mathrm{scm}_{\text {fuelparticle }}^{3}}$ & Fig. 68 \\
0 & OFE & 1.31 & 10.01 & & Fig. 69 \\
1 & OFE & 1.36 & 11.82 & & Fig. 70 \\
2 & OFE & 1.38 & 11.82 & & Fig. 71 \\
15 & OFE & 1.8 & 10.18 & & Fig. 72 \\
27 & OFE & 2.15 & 8.35 & & Fig. 73 \\
\hline
\end{tabular}




\subsubsection{Power Density}

The power density values are the fission rate density values multiplied by the average energy generated per fission. It is conservatively assumed that all energy generated by fission is deposited locally in the fuel meat. Therefore, the power density and fission rate density results have identical trends, and only the magnitudes of the results are different. Figure 16 shows the maximum local power density during operation for each fuel element. Table 24 lists the maximum power density results and references the figures in the appendix. Each plot in the appendix shows the spatial power density values for each of the four selected state points for each fuel element.

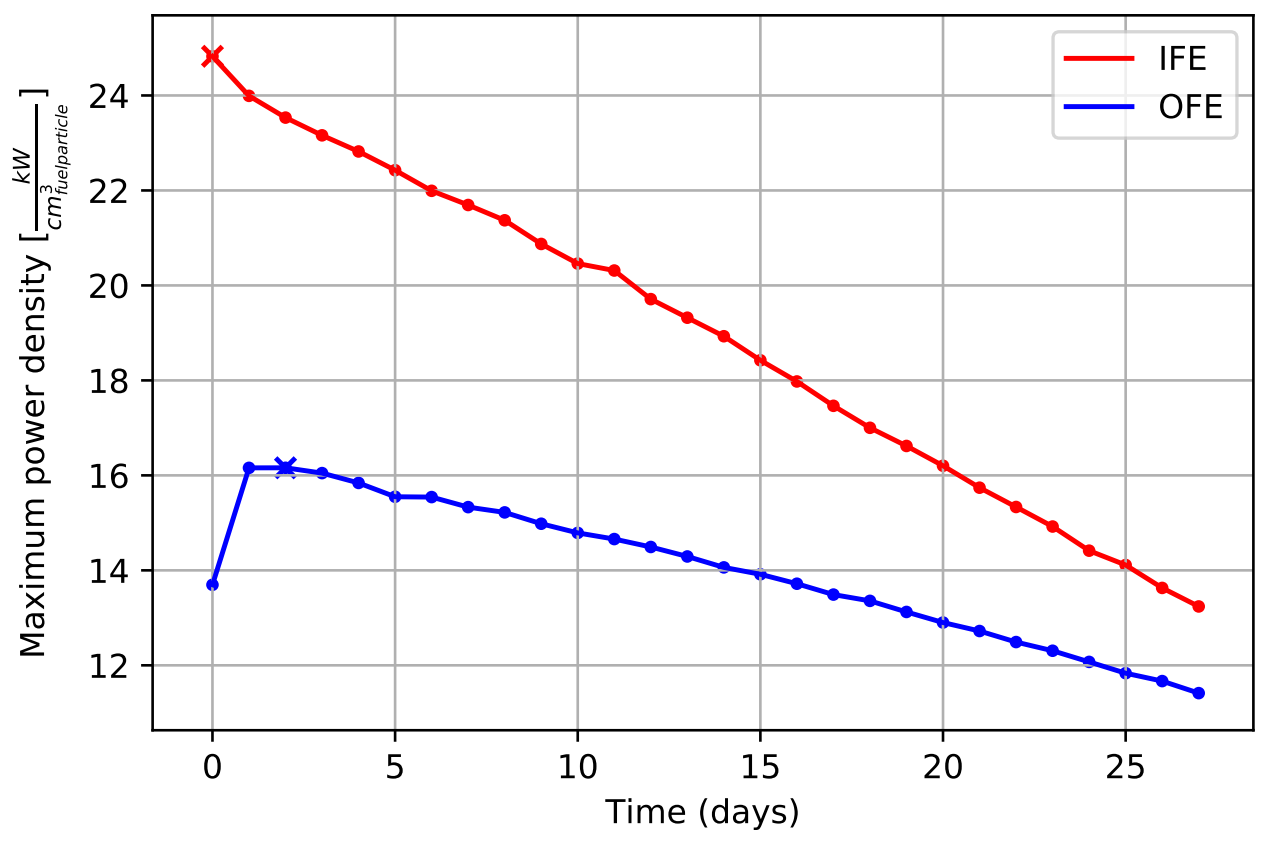

Figure 16. Alternate 1 design maximum power density during operation.

Table 24. Minimum and maximum power densities in the alternate 1 design.

\begin{tabular}{|c|c|c|c|c|c|}
\hline Day & Region & Minimum & Maximum & Unit & Ref. \\
\hline 0 & IFE & 4.24 & 24.82 & & Fig. 80 \\
\hline 1 & IFE & 4.06 & 23.99 & & Fig. 81 \\
\hline 15 & IFE & 4.21 & 18.42 & & Fig. 82 \\
\hline 27 & IFE & 4.33 & 13.24 & $\mathrm{~kW}$ & Fig. 83 \\
\hline 0 & OFE & 1.79 & 13.7 & $\mathrm{~cm}_{\text {fuelparticle }}^{3}$ & Fig. 84 \\
\hline 1 & OFE & 1.86 & 16.16 & & Fig. 85 \\
\hline 2 & OFE & 1.89 & 16.16 & & Fig. 86 \\
\hline 15 & OFE & 2.46 & 13.92 & & Fig. 87 \\
\hline 27 & OFE & 2.94 & 11.41 & & Fig. 88 \\
\hline
\end{tabular}




\subsubsection{Heat Flux}

Figure 17 shows the maximum heat flux during operation for each fuel element. Table 25 lists the maximum heat flux results and references to the figures in the appendix. Each plot in the appendix shows the spatial heat flux values for the four selected state points for each fuel element.

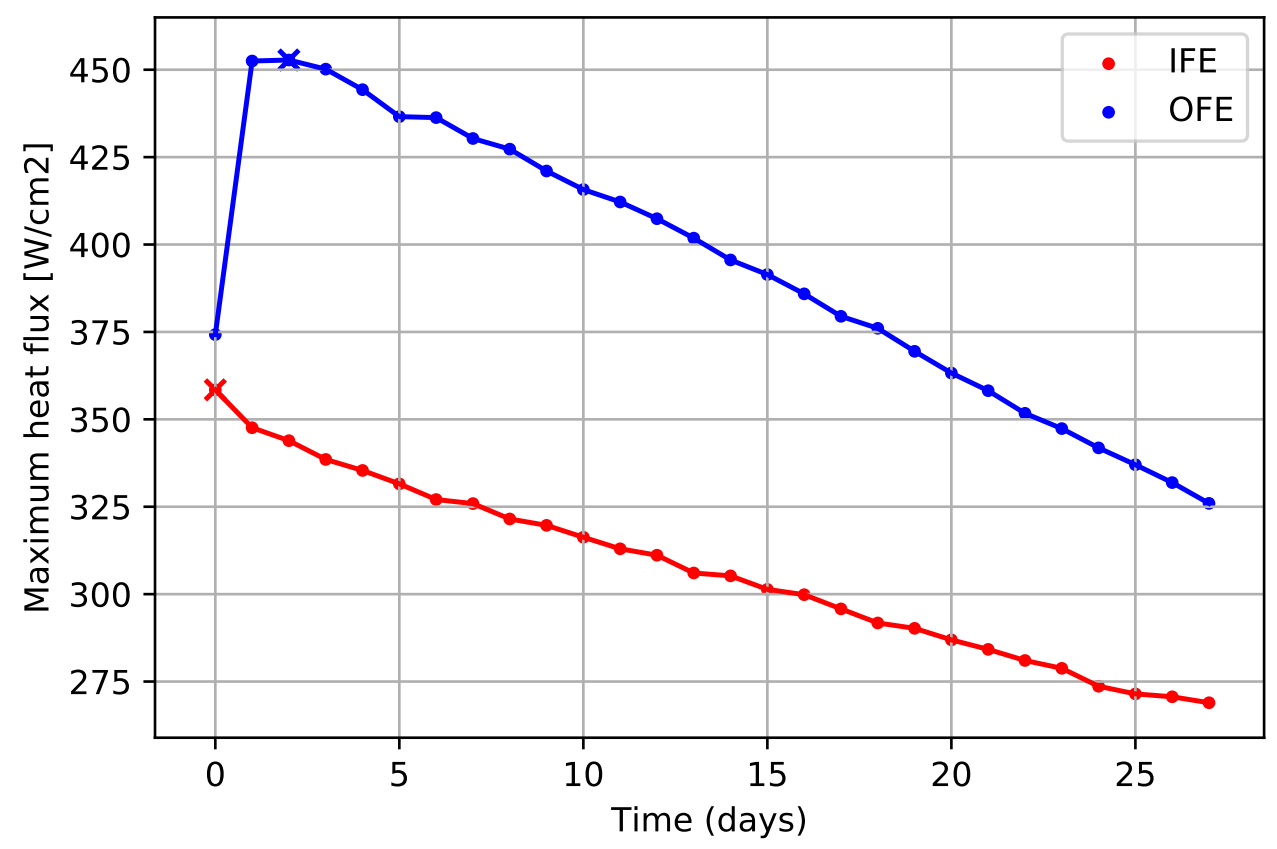

Figure 17. Alternate 1 design maximum heat flux during operation.

Table 25. Minimum and maximum heat fluxes in the alternate 1 design.

\begin{tabular}{|c|c|c|c|c|c|}
\hline Day & Region & Minimum & Maximum & Unit & Ref. \\
\hline 0 & IFE & 113.11 & 358.43 & & Fig. 89 \\
1 & IFE & 112.19 & 347.6 & & Fig. 90 \\
15 & IFE & 112.31 & 301.36 & & Fig. 91 \\
27 & IFE & 107.26 & 268.94 & $\underline{\mathrm{W}}$ & Fig. 92 \\
0 & OFE & 32.9 & 374.24 & $\mathrm{~cm}^{2}$ & Fig. 93 \\
1 & OFE & 32.82 & 452.49 & & Fig. 94 \\
2 & OFE & 32.86 & 452.78 & & Fig. 95 \\
15 & OFE & 42.05 & 391.41 & & Fig. 96 \\
27 & OFE & 70.87 & 325.96 & & Fig. 97 \\
\hline
\end{tabular}




\subsubsection{Cumulative Fission Density}

Figure 18 shows the maximum local cumulative fission density during operation for each fuel element, and Figure 19 illustrates the fission rate density variation with cumulative fission density for every spatial cell in the neutronics model. Table 26 lists the maximum cumulative fission density results and references to the figures in the appendix.

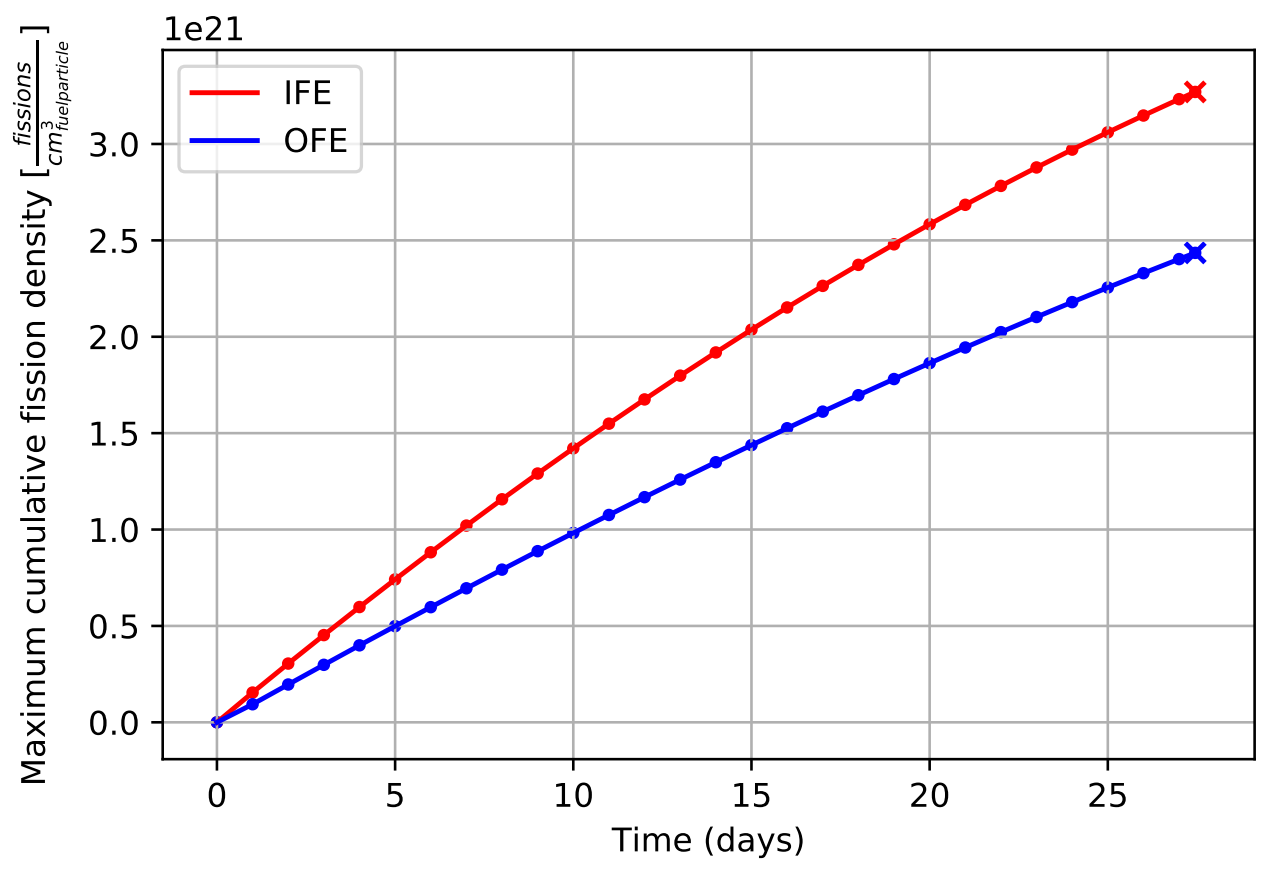

Figure 18. Alternate 1 design maximum cumulative fission density during operation.

Table 26. Minimum and maximum cumulative fission density values in the alternate 1 design.

\begin{tabular}{|c|c|c|c|c|c|}
\hline Day & Region & Minimum & Maximum & Unit & Ref. \\
\hline 1 & IFE & 0.26 & 1.54 & \multirow{6}{*}{$10^{20} \frac{\text { fissions }}{\mathrm{cm}_{\text {fuelparticle }}^{3}}$} & Fig. 74 \\
\hline 15 & IFE & 3.94 & 20.37 & & Fig. 75 \\
\hline 27 & IFE & 7.18 & 32.32 & & Fig. 76 \\
\hline 1 & OFE & 0.12 & 0.94 & & Fig. 77 \\
\hline 15 & OFE & 2.06 & 14.38 & & Fig. 78 \\
\hline 27 & OFE & 4.2 & 24.03 & & Fig. 79 \\
\hline
\end{tabular}




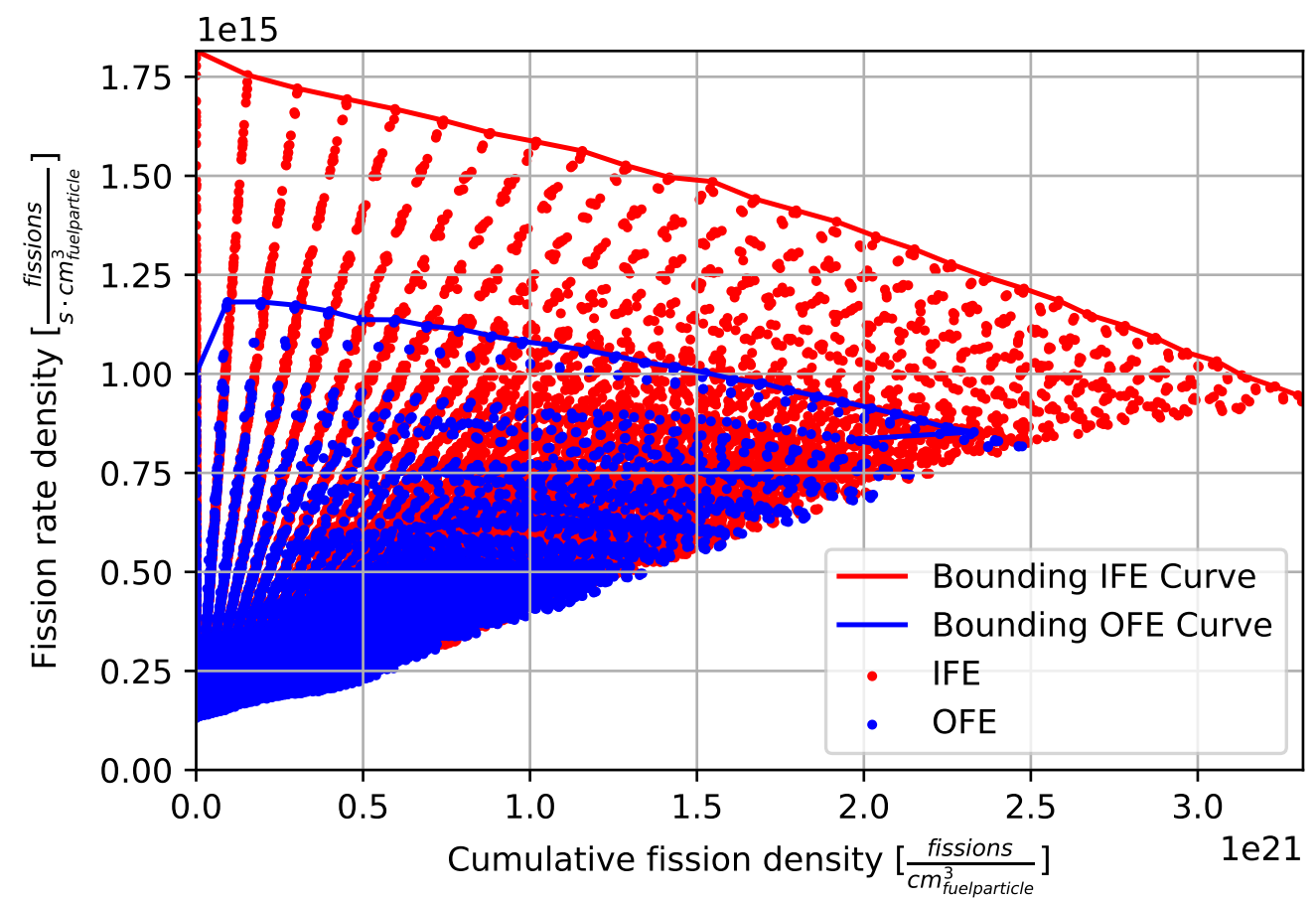

Figure 19. Alternate 1 design fission rate density variation with cumulative fission density during operation. 


\subsection{ALTERNATE 2 DESIGN}

The alternate 2 design was generated by including center-symmetric fuel zones to promote heat transfer to the coolant and gadolinium oxide in the IFE filler to suppress power peaking in the IFE for the first few days. The cycle length of this design is 27.12 days. The alternate 2 fuel design specifications are presented in Table 27.

Table 27. Key alternate 2 design geometry and operational parameters.

\begin{tabular}{llll}
\hline Parameter & Units & Value \\
\hline Center-symmetric fuel zone & - & yes \\
\hline Axial contour & - & no \\
\hline $\mathrm{Gd}_{2} \mathrm{O}_{3}$ in IFE filler & - & yes \\
\hline Boron strip below fuel & - & no \\
\hline U loading & $\mathrm{kg}$ & 70.5474 \\
\hline${ }^{235} \mathrm{U}$ loading & $\mathrm{kg}$ & 13.9331 \\
\hline & & $\mathrm{IFE}$ & OFE \\
\hline & $\mathrm{kg}$ & 3.9458 & 9.9873 \\
\hline${ }^{235} \mathrm{U}$ loading & $\mathrm{g} / \mathrm{plate}$ & 23.07485 & 27.06585 \\
\hline${ }^{235} \mathrm{U}$ loading per plate & - & $\mathrm{Al}+\mathrm{B}_{4} \mathrm{C}$ & $\mathrm{Al}$ \\
\hline Filler & $\mathrm{g}$ & 2.4406 & - \\
\hline${ }^{10} \mathrm{~B}$ loading in IFE filler & $\mathrm{mg} / \mathrm{cm}^{3}$ & 1.752 & - \\
\hline${ }^{10} \mathrm{~B}$ density in IFE filler & $\mathrm{mg}$ & 1.1182 & 0.0 \\
\hline Gd loading in IFE filler & $\mathrm{mg} / \mathrm{cm}^{3}$ & 0.80231 & 0.0 \\
\hline Gd density in IFE filler & &
\end{tabular}




\subsubsection{Fuel Meat Shape}

The fuel meat thickness profile of the alternate 2 design is described in Table 28 , where $\mathrm{t}(\mu \mathrm{m})$ is the fuel meat thickness and $\mathrm{s}(\mathrm{cm})$ is the distance from the origin of the involute generating radius. Illustrations of the IFE and OFE fuel meat shapes are shown in Figure 20.

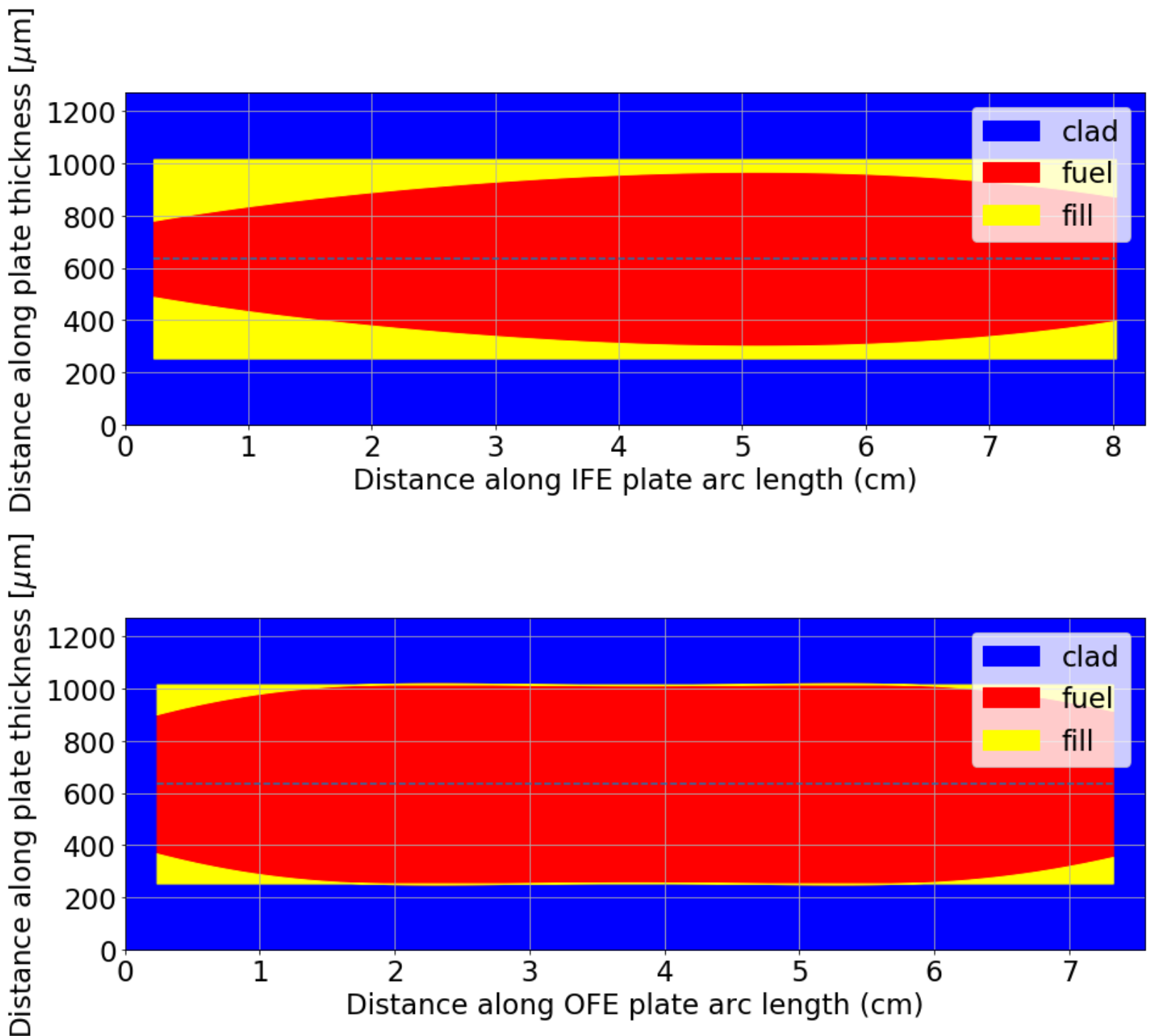

Figure 20. Fuel meat shape for the alternate 2 design. 
Table 28. Fuel shape polynomial coefficients for alternate 2 design.

\begin{tabular}{|c|c|c|c|c|c|c|c|c|c|}
\hline & & & \multicolumn{7}{|c|}{ Order } \\
\hline & $s_{i}(\mathrm{~cm})$ & $s_{f}(\mathrm{~cm})$ & 6 & 5 & 4 & 3 & 2 & 1 & 0 \\
\hline IFE & \multicolumn{2}{|c|}{ ALL } & $-3.06 \mathrm{E}-03$ & $8.76 \mathrm{E}-02$ & $-1.09 \mathrm{E}+00$ & $6.55 \mathrm{E}+00$ & $-3.32 E+01$ & $1.77 \mathrm{E}+02$ & $2.53 \mathrm{E}+02$ \\
\hline \multirow{3}{*}{ OFE } & 0.2343 & 1.696 & - & - & - & - & $-9.92 \mathrm{E}+01$ & $3.61 \mathrm{E}+02$ & $4.36 \mathrm{E}+02$ \\
\hline & 1.696 & 6.005 & - & - & - & - & - & - & $7.62 \mathrm{E}+02$ \\
\hline & 6.005 & 7.3226 & - & - & - & - & $-7.82 \mathrm{E}+01$ & $8.78 \mathrm{E}+02$ & $1.69 \mathrm{E}+03$ \\
\hline
\end{tabular}

\subsubsection{Fission Rate Density}

Figure 21 shows the maximum fission rate density during operation for each fuel element. Table 29 lists the peak fission rate results and references to the figures in the appendix that illustrate the spatial fission rate density values for the four selected state points for each fuel element.

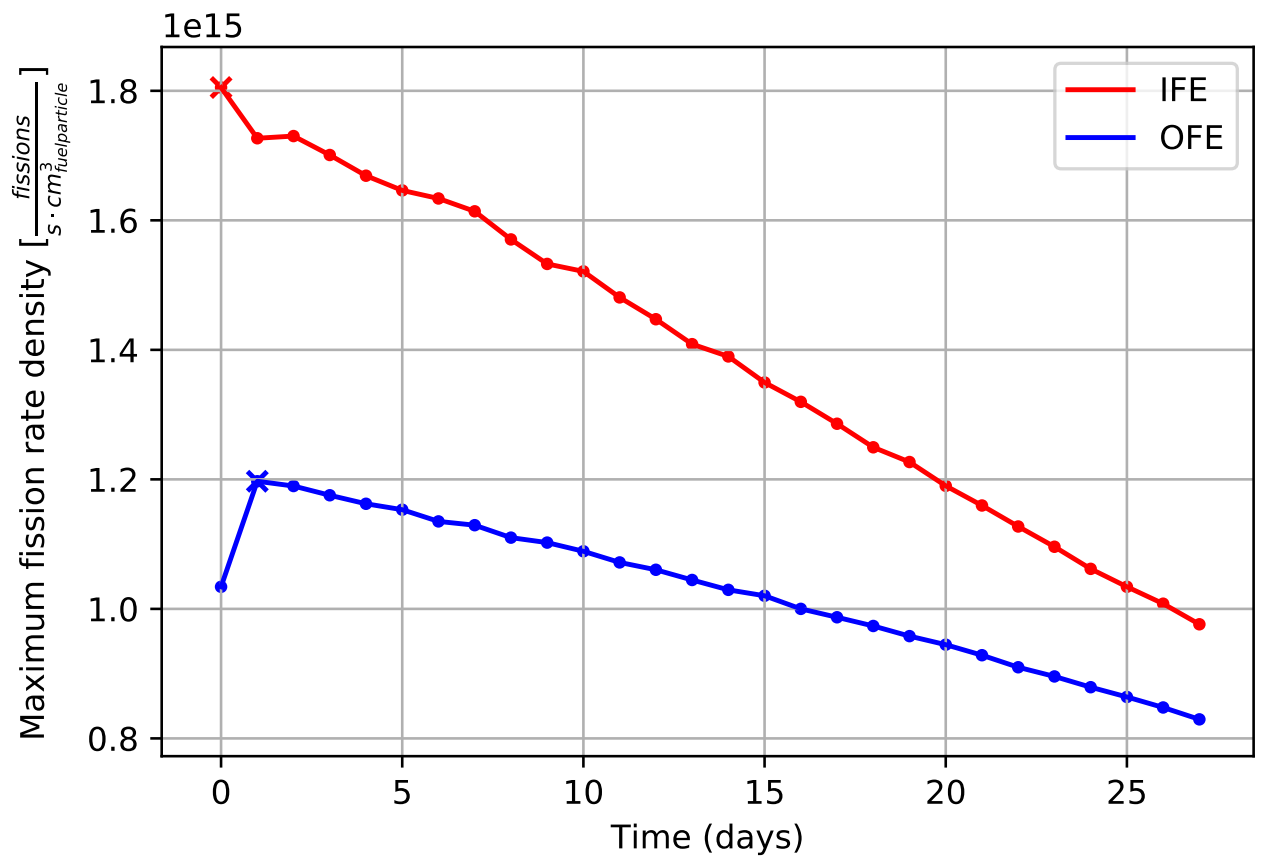

Figure 21. Alternate 2 design maximum fission density during operation. 
Table 29. Minimum and maximum fission rate densities in the alternate 2 design.

\begin{tabular}{|c|c|c|c|c|c|}
\hline Day & Region & Minimum & Maximum & Unit & Ref. \\
\hline 0 & IFE & 3.16 & 18.05 & & Fig. 98 \\
1 & IFE & 3.03 & 17.27 & & Fig. 99 \\
15 & IFE & 3.12 & 13.5 & & Fig. 100 \\
27 & IFE & 3.23 & 9.76 & $10^{14} \frac{\text { fissions }}{\text { s.cm }_{\text {fuelparticle }}^{3}}$ & Fig. 101 \\
0 & OFE & 1.27 & 10.34 & & Fig. 102 \\
1 & OFE & 1.34 & 11.97 & & Fig. 103 \\
15 & OFE & 1.75 & 10.2 & & Fig. 104 \\
27 & OFE & 2.16 & 8.29 & & Fig. 105 \\
\hline
\end{tabular}




\subsubsection{Power Density}

The power density values are the fission rate density values multiplied by the average energy generated per fission. It is conservatively assumed that all energy generated by fission is deposited locally in the fuel meat. Therefore, the power density and fission rate density results have identical trends, and only the magnitudes of the results are different. Figure 22 shows the maximum local power density during operation for each fuel element. Table 30 lists the maximum power density results and references the figures in the appendix. Each plot in the appendix shows the spatial power density values for each of the four selected state points for each fuel element.

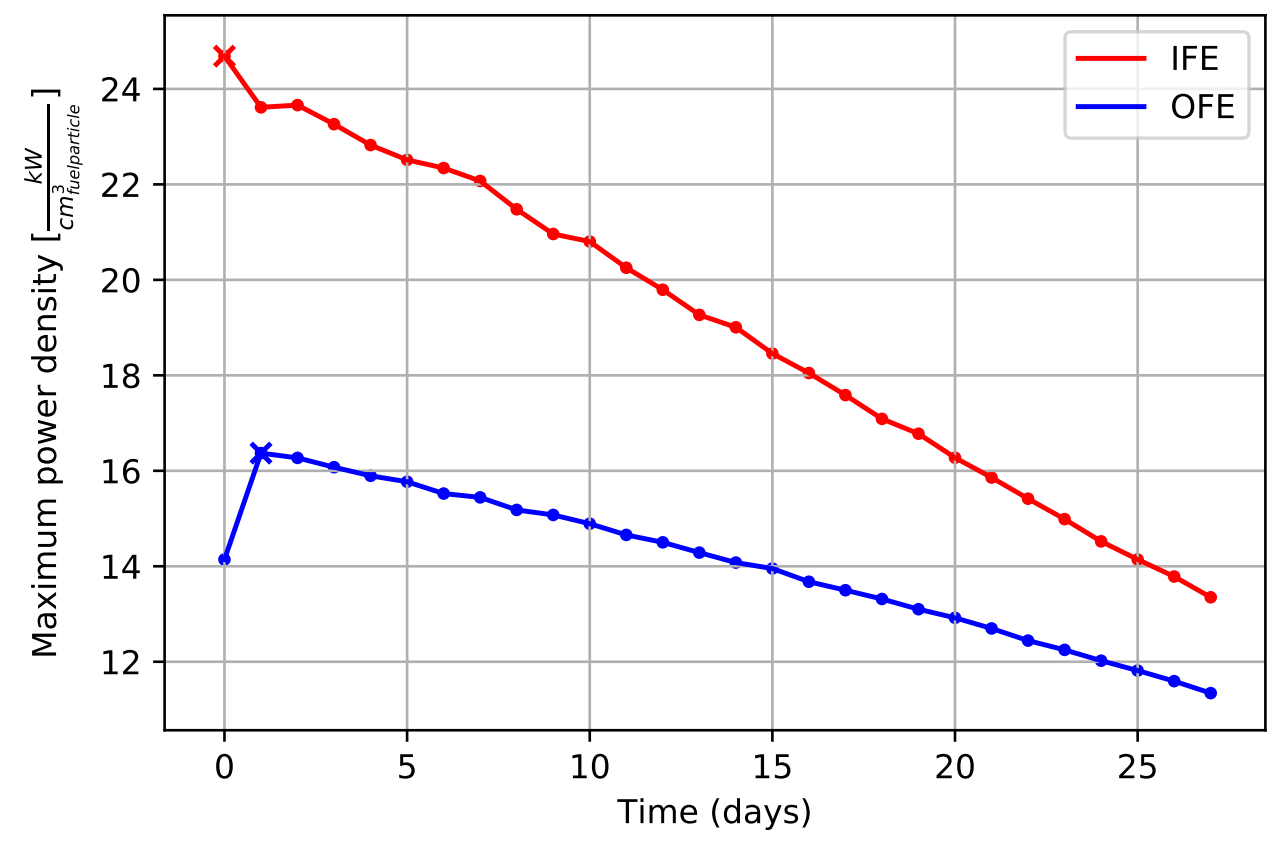

Figure 22. Alternate 2 design maximum power density during operation.

Table 30. Minimum and maximum power densities in the alternate 2 design.

\begin{tabular}{|c|c|c|c|c|c|}
\hline Day & Region & Minimum & Maximum & Unit & Ref. \\
\hline 0 & IFE & 4.32 & 24.69 & & Fig. 112 \\
1 & IFE & 4.14 & 23.61 & & Fig. 113 \\
15 & IFE & 4.26 & 18.46 & & Fig. 114 \\
27 & IFE & 4.42 & 13.35 & $\frac{\mathrm{kW}}{\mathrm{cm}_{\text {fuelparticle }}^{3}}$ & Fig. 115 \\
0 & FFig. 116 \\
1 & 1.74 & 14.14 & & Fig. 117 \\
15 & OFE & 1.83 & 16.37 & & Fig. 118 \\
27 & OFE & 2.39 & 13.95 & & Fig. 119 \\
\hline
\end{tabular}




\subsubsection{Heat Flux}

Figure 23 shows the maximum heat flux during operation for each fuel element. Table 31 lists the maximum heat flux results and references to the figures in the appendix. Each plot in the appendix shows the spatial heat flux values for the four selected state points for each fuel element.

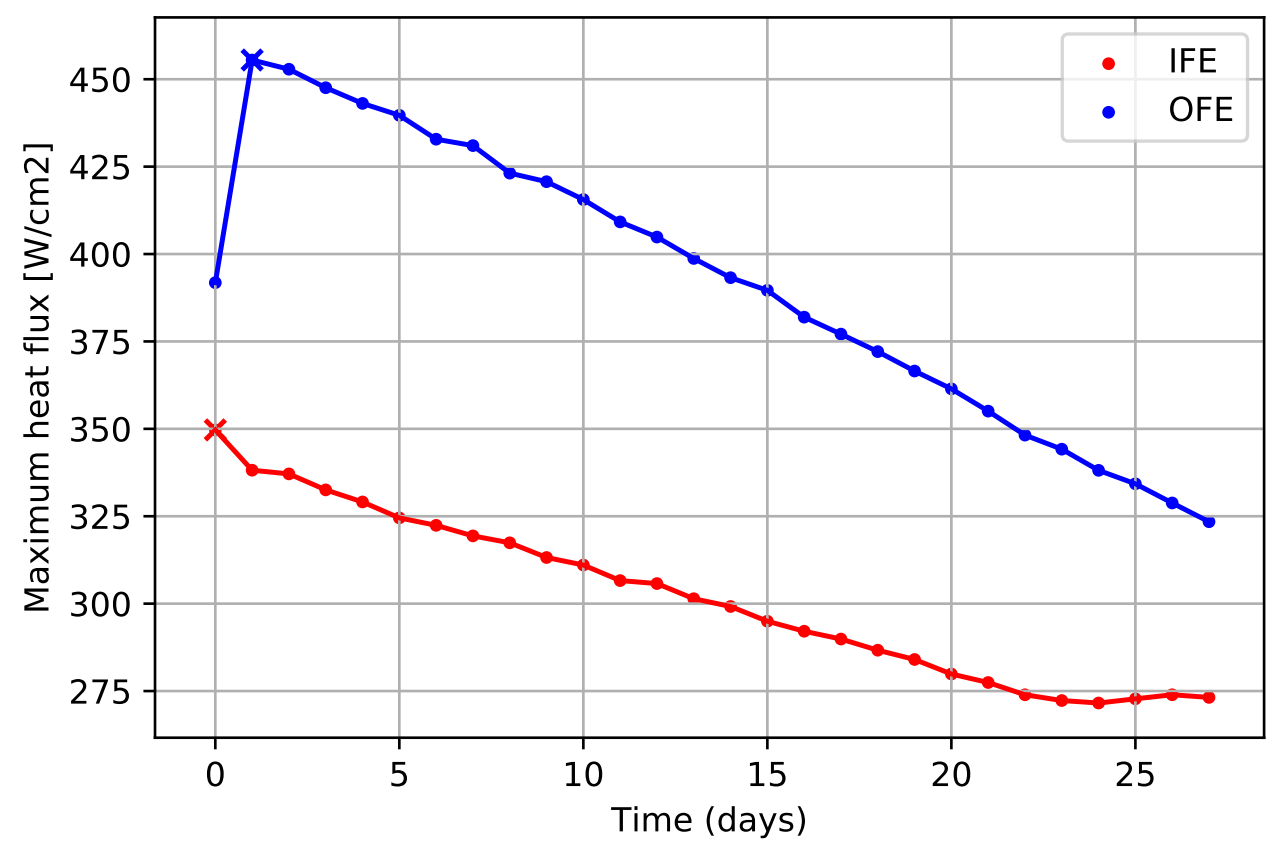

Figure 23. Alternate 2 design maximum heat flux during operation.

Table 31. Minimum and maximum heat fluxes in the alternate 2 design.

\begin{tabular}{|c|c|c|c|c|c|}
\hline Day & Region & Minimum & Maximum & Unit & Ref. \\
\hline 0 & IFE & 135.21 & 349.69 & & Fig. 120 \\
1 & IFE & 129.56 & 338.16 & & Fig. 121 \\
15 & IFE & 136.08 & 294.98 & & Fig. 122 \\
27 & IFE & 143.61 & 273.18 & $\mathrm{~W}$ & Fig. 123 \\
0 & OFE & 47.82 & 391.81 & $\frac{\mathrm{cm}^{2}}{}$ & Fig. 124 \\
1 & OFE & 50.34 & 455.5 & & Fig. 125 \\
15 & OFE & 87.76 & 389.62 & & Fig. 126 \\
27 & OFE & 110.09 & 323.43 & & Fig. 127 \\
\hline
\end{tabular}




\subsubsection{Cumulative Fission Density}

Figure 24 shows the maximum local cumulative fission density during operation for each fuel element, and Figure 25 illustrates the fission rate density variation with cumulative fission density for every spatial cell in the neutronics model. Table 32 lists the maximum cumulative fission density results and references to the figures in the appendix.

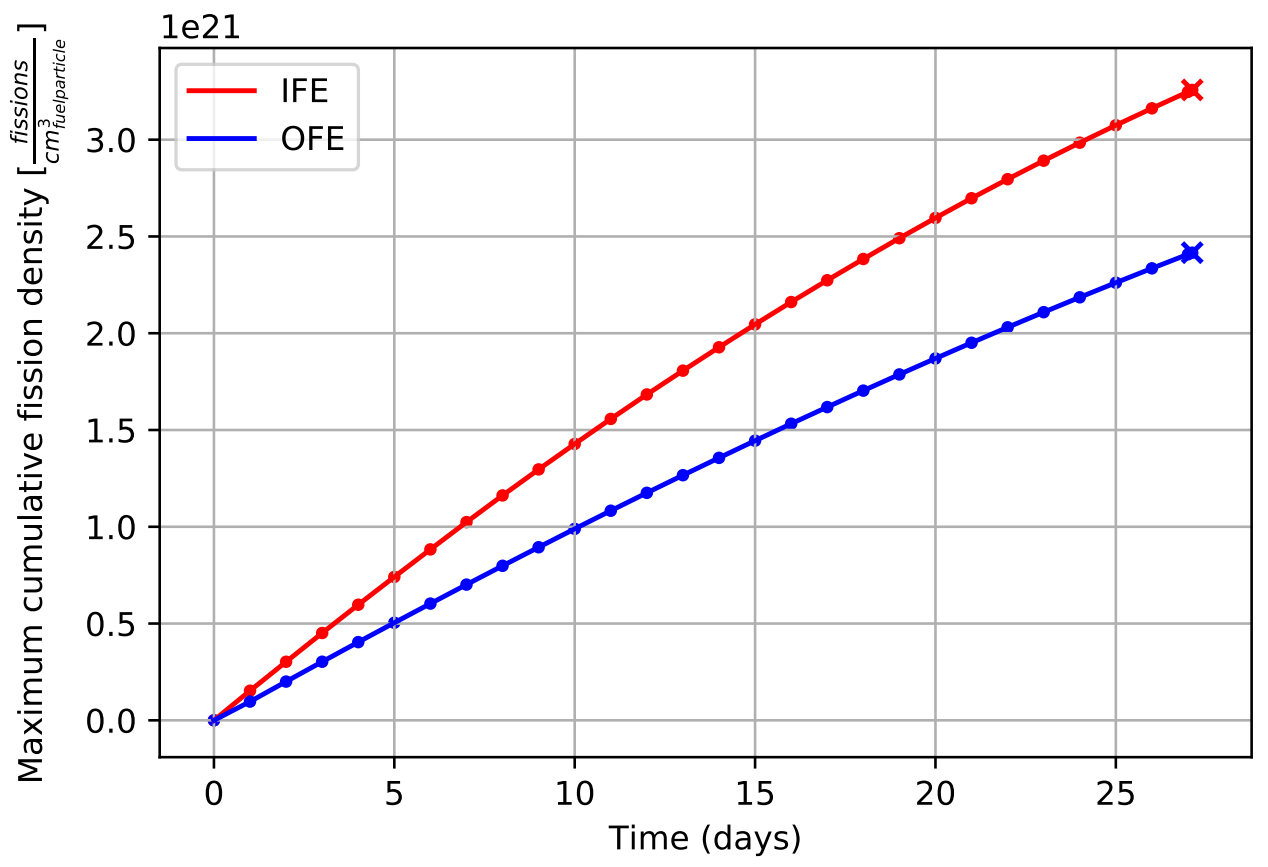

Figure 24. Alternate 2 design maximum cumulative fission density during operation.

Table 32. Minimum and maximum cumulative fission density values in the alternate 2 design.

\begin{tabular}{|c|c|c|c|c|c|}
\hline Day & Region & Minimum & Maximum & Unit & Ref. \\
\hline 1 & IFE & 0.27 & 1.53 & & Fig. 106 \\
15 & IFE & 4.0 & 20.46 & & Fig. 107 \\
27 & IFE & 7.33 & 32.47 & $10^{20} \frac{\text { fissions }}{\mathrm{cm}_{\text {fuelparticle }}^{3}}$ & Fig. 108 \\
1 & OFE & 0.11 & 0.97 & & Fig. 109 \\
15 & OFE & 2.03 & 14.45 & & Fig. 110 \\
27 & OFE & 4.07 & 24.08 & & Fig. 111 \\
\hline
\end{tabular}




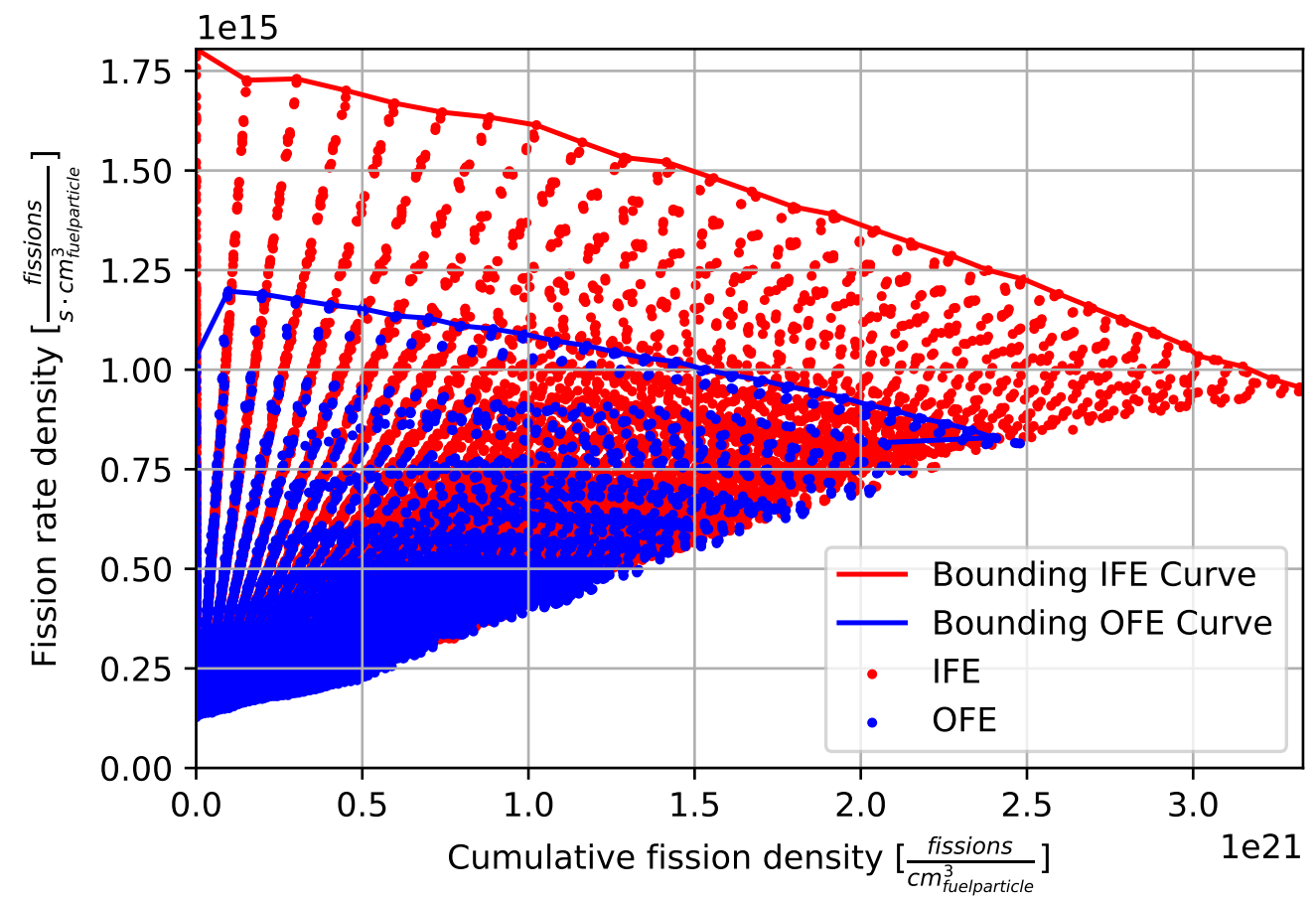

Figure 25. Alternate 2 design fission rate density variation with cumulative fission density during operation. 


\subsection{ALTERNATE 3 DESIGN}

The alternate 3 design was generated by including a 0.5 -inch boron strip in the form of a borated powder at the lowest unfueled region to increase thermal margins at the bottom of the fuel.

The cycle length of this design is 27.12 days. The alternate 3 fuel design specifications are presented in Table 33.

Table 33. Key alternate 3 design geometry and operational parameters.

\begin{tabular}{llll}
\hline Parameter & Units & Value \\
\hline Center-symmetric fuel zone & - & no \\
\hline Axial contour & - & no \\
\hline $\mathrm{Gd}_{2} \mathrm{O}_{3}$ in IFE filler & - & no \\
\hline Boron strip below fuel & - & yes \\
\hline U loading & $\mathrm{kg}$ & 70.6401 \\
\hline${ }^{235} \mathrm{U}$ loading & $\mathrm{kg}$ & 13.9514 \\
\hline & & & OFE \\
\hline${ }^{235} \mathrm{U}$ loading & $\mathrm{kg}$ & $\mathrm{IFE}$ & 9.9378 \\
\hline${ }^{235} \mathrm{U}$ loading per plate & $\mathrm{g} / \mathrm{plate}$ & 4.0136 & 26.93171 \\
\hline Filler & - & 23.47135 & $\mathrm{Al}$ \\
\hline${ }^{10} \mathrm{~B}$ loading in IFE filler & $\mathrm{g}$ & $\mathrm{Al}+\mathrm{B}_{4} \mathrm{C}$ & - \\
\hline${ }^{10} \mathrm{~B}$ density in IFE filler & $\mathrm{mg} / \mathrm{cm}^{3}$ & 2.3157 & - \\
\hline Gd loading in IFE filler & $\mathrm{mg}$ & 1.752 & 0.0 \\
\hline Gd density in IFE filler & $\mathrm{mg} / \mathrm{cm}^{3}$ & 0.0 & 0.0 \\
\hline
\end{tabular}




\subsubsection{Fuel Meat Shape}

The fuel meat thickness profile of the alternate 3 design is described in Table 34, where $\mathrm{t}(\mu \mathrm{m})$ is the fuel meat thickness and $\mathrm{s}(\mathrm{cm})$ is the distance from the origin of the involute generating radius. Illustrations of the IFE and OFE fuel meat shapes are shown in Figure 26.

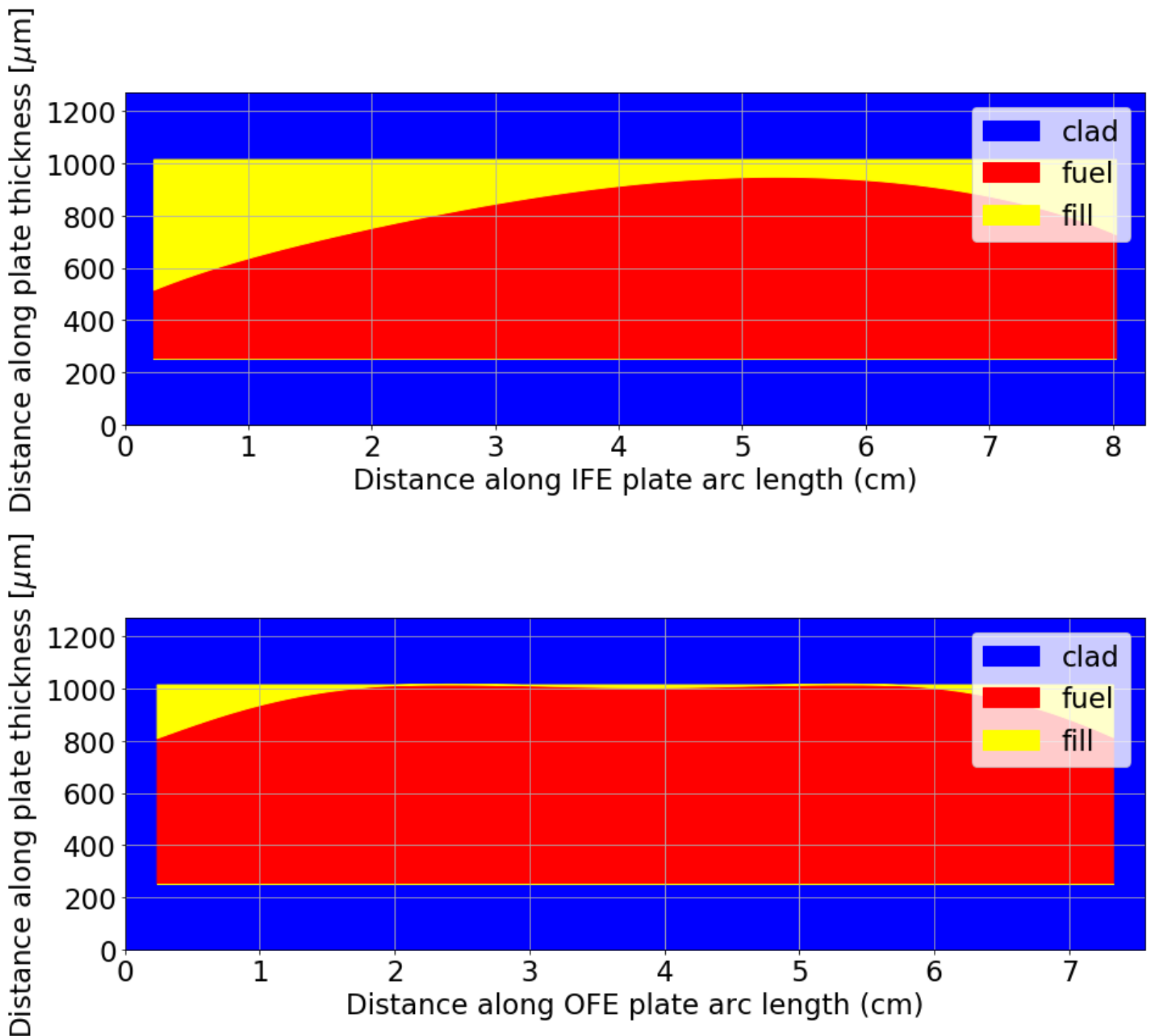

Figure 26. Fuel meat shape for the alternate 3 design. 
Table 34. Fuel shape polynomial coefficients for alternate 3 design.

\begin{tabular}{|c|c|c|c|c|c|c|c|c|c|}
\hline & & & \multicolumn{7}{|c|}{ Order } \\
\hline & $s_{i}(\mathrm{~cm})$ & $s_{f}(\mathrm{~cm})$ & 6 & 5 & 4 & 3 & 2 & 1 & 0 \\
\hline IFE & \multicolumn{2}{|c|}{ ALL } & $-1.93 \mathrm{E}-02$ & $4.96 \mathrm{E}-01$ & $-5.08 \mathrm{E}+00$ & $2.50 \mathrm{E}+01$ & $-7.30 \mathrm{E}+01$ & $2.22 \mathrm{E}+02$ & $2.15 \mathrm{E}+02$ \\
\hline \multirow{3}{*}{ OFE } & 0.2343 & 1.696 & - & - & - & - & $-5.60 \mathrm{E}+01$ & $2.53 \mathrm{E}+02$ & $4.89 \mathrm{E}+02$ \\
\hline & 1.696 & 6.005 & - & - & - & - & - & - & $7.57 \mathrm{E}+02$ \\
\hline & 6.005 & 7.3226 & - & - & - & - & $-8.52 \mathrm{E}+01$ & $9.75 E+02$ & $-2.02 \mathrm{E}+03$ \\
\hline
\end{tabular}

\subsubsection{Fission Rate Density}

Figure 27 shows the maximum fission rate density during operation for each fuel element. Table 35 lists the peak fission rate results and references to the figures in the appendix that illustrate the spatial fission rate density values for the four selected state points for each fuel element.

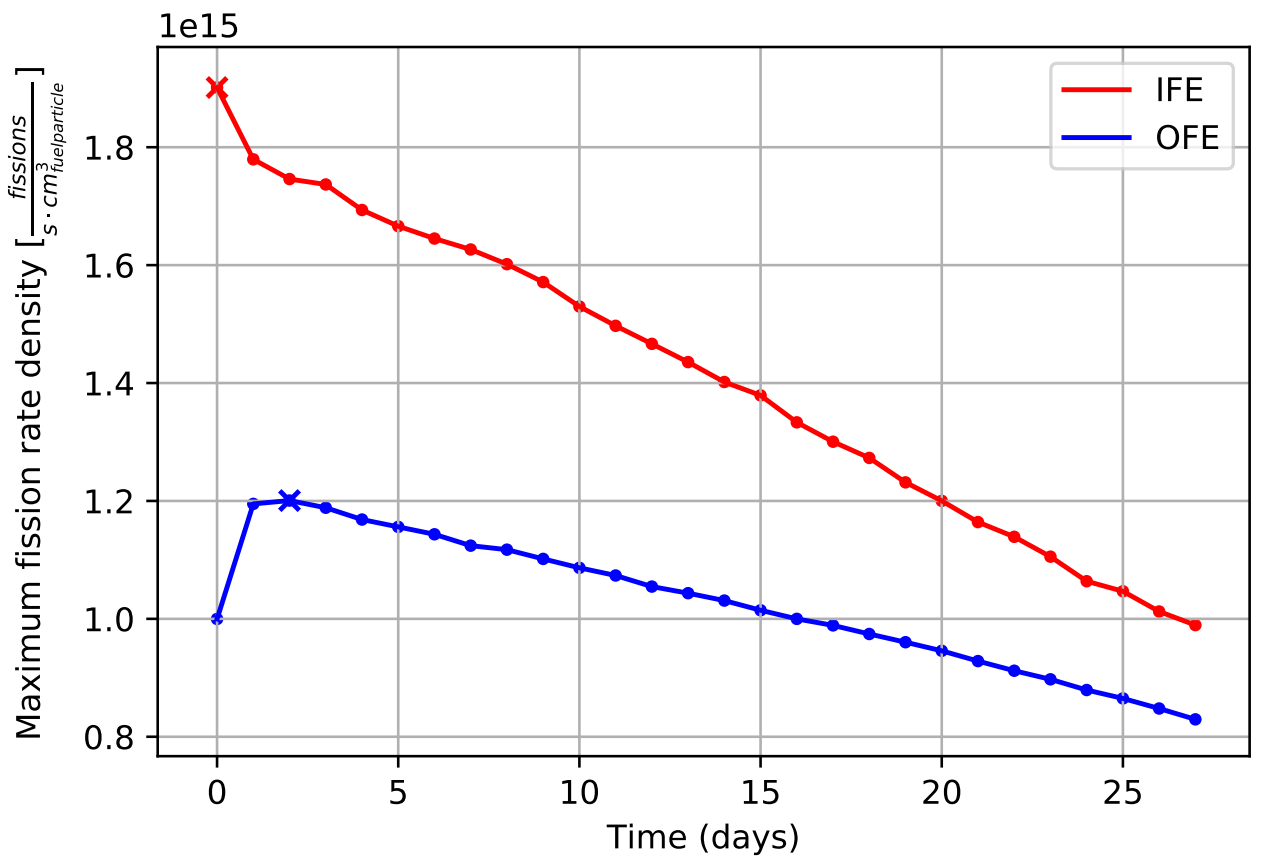

Figure 27. Alternate 3 design maximum fission density during operation. 
Table 35. Minimum and maximum fission rate densities in the alternate 3 design.

\begin{tabular}{|c|c|c|c|c|c|}
\hline Day & Region & Minimum & Maximum & Unit & Ref. \\
\hline 0 & IFE & 3.05 & 19.01 & & Fig. 128 \\
1 & IFE & 2.89 & 17.79 & & Fig. 129 \\
15 & IFE & 3.05 & 13.79 & & Fig. 130 \\
27 & IFE & 3.18 & 9.89 & $10^{14} \frac{\text { fissions }}{\text { s.c. }_{\text {fuelparticle }}^{3}}$ & Fig. 131 \\
0 & OFE & 1.25 & 10.0 & & \\
1 & OFE & 1.29 & 11.95 & & Fig. 132 \\
2 & OFE & 1.31 & 12.01 & & Fig. 134 \\
15 & OFE & 1.76 & 10.15 & & Fig. 135 \\
27 & OFE & 2.18 & 8.3 & & Fig. 136 \\
\hline
\end{tabular}




\subsubsection{Power Density}

The power density values are the fission rate density values multiplied by the average energy generated per fission. It is conservatively assumed that all energy generated by fission is deposited locally in the fuel meat. Therefore, the power density and fission rate density results have identical trends, and only the magnitudes of the results are different. Figure 28 shows the maximum local power density during operation for each fuel element. Table 36 lists the maximum power density results and references the figures in the appendix. Each plot in the appendix shows the spatial power density values for each of the four selected state points for each fuel element.

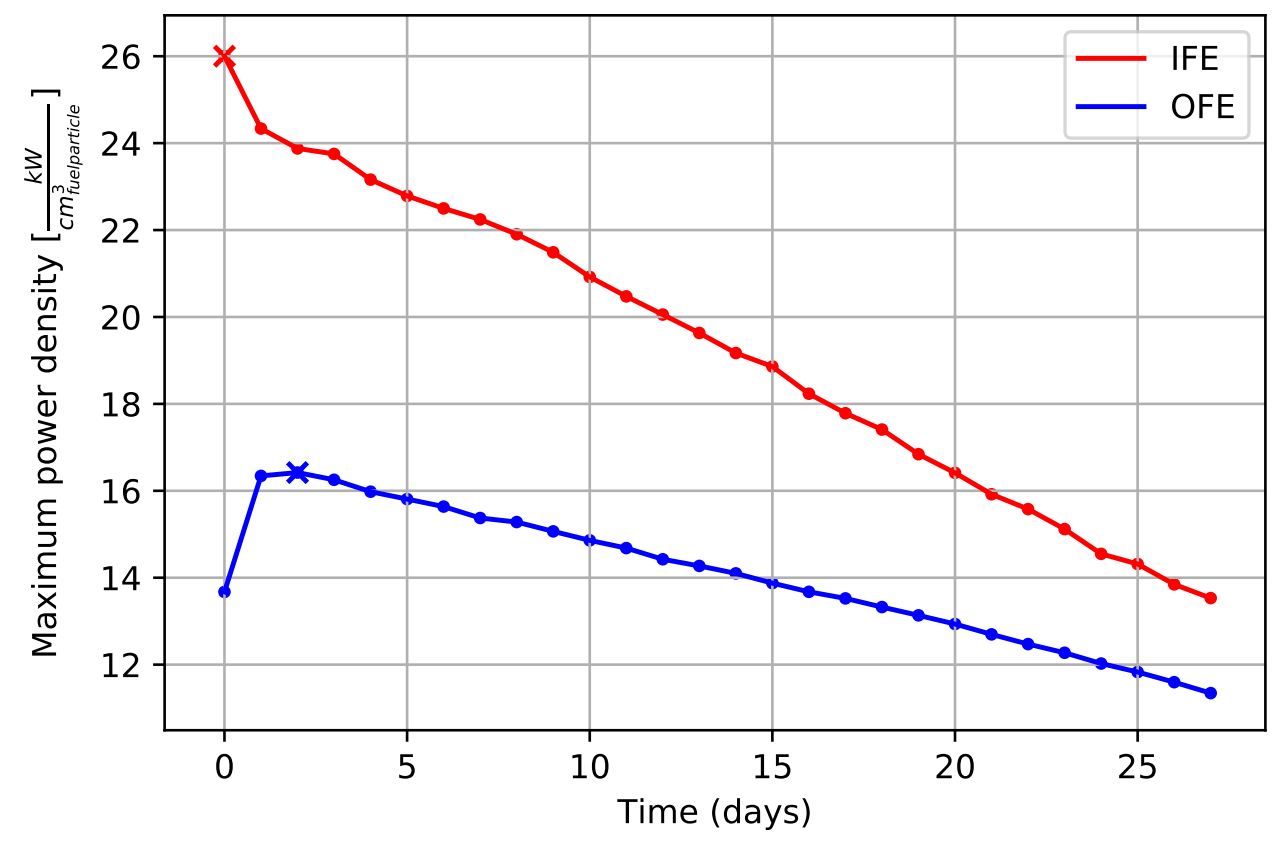

Figure 28. Alternate 3 design maximum power density during operation.

Table 36. Minimum and maximum power densities in the alternate 3 design.

\begin{tabular}{|c|c|c|c|c|c|}
\hline Day & Region & Minimum & Maximum & Unit & Ref. \\
\hline 0 & IFE & 4.17 & 26.0 & & Fig. 143 \\
1 & IFE & 3.96 & 24.34 & & Fig. 144 \\
15 & IFE & 4.17 & 18.86 & & Fig. 145 \\
27 & IFE & 4.35 & 13.53 & $\frac{\text { kW }}{\text { cm }_{\text {fuelparticle }}^{3}}$ & Fig. 146 \\
0 & Fig. 147 \\
1 & OFE & 1.71 & 13.67 & & Fig. 148 \\
2 & OFE & 1.76 & 16.34 & & Fig. 149 \\
15 & OFE & 2.4 & 16.42 & & Fig. 150 \\
27 & OFE & 2.98 & 11.88 & & Fig. 151 \\
\hline
\end{tabular}




\subsubsection{Heat Flux}

Figure 29 shows the maximum heat flux during operation for each fuel element. Table 37 lists the maximum heat flux results and references to the figures in the appendix. Each plot in the appendix shows the spatial heat flux values for the four selected state points for each fuel element.

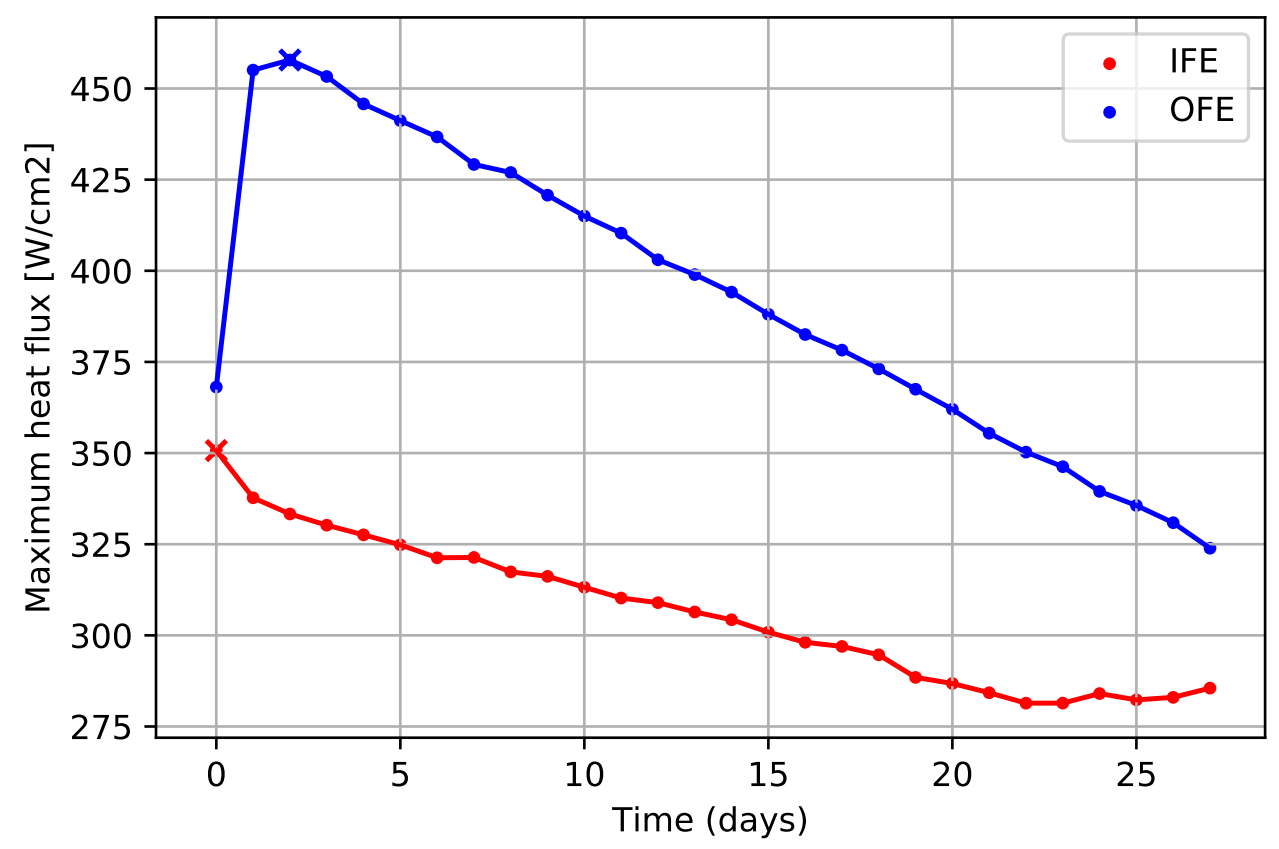

Figure 29. Alternate 3 design maximum heat flux during operation.

Table 37. Minimum and maximum heat fluxes in the alternate 3 design.

\begin{tabular}{|c|c|c|c|c|c|}
\hline Day & Region & Minimum & Maximum & Unit & Ref. \\
\hline 0 & IFE & 134.86 & 350.68 & & Fig. 152 \\
1 & IFE & 127.33 & 337.73 & & Fig. 153 \\
15 & IFE & 138.27 & 300.87 & & Fig. 154 \\
27 & IFE & 145.45 & 285.53 & $\underline{\mathrm{W}}$ & Fig. 155 \\
0 & OFE & 46.73 & 368.11 & $\frac{\mathrm{cm}^{2}}{}$ & Fig. 156 \\
1 & OFE & 48.26 & 455.05 & & Fig. 157 \\
2 & OFE & 49.89 & 457.81 & & Fig. 158 \\
15 & OFE & 86.63 & 388.06 & & Fig. 159 \\
27 & OFE & 109.87 & 323.9 & & Fig. 160 \\
\hline
\end{tabular}




\subsubsection{Cumulative Fission Density}

Figure 30 shows the maximum local cumulative fission density during operation for each fuel element, and Figure 31 illustrates the fission rate density variation with cumulative fission density for every spatial cell in the neutronics model. Table 38 lists the maximum cumulative fission density results and references to the figures in the appendix.

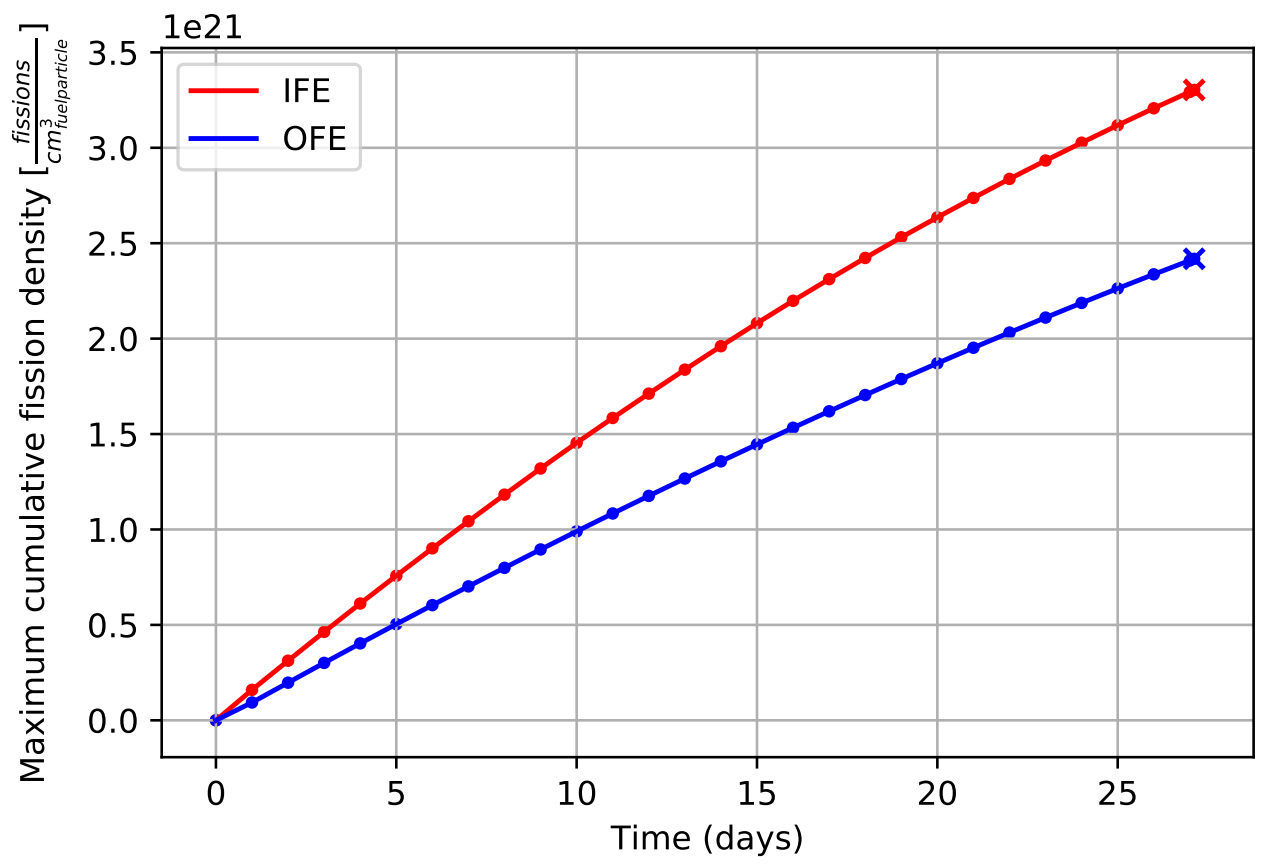

Figure 30. Alternate 3 design maximum cumulative fission density during operation.

Table 38. Minimum and maximum cumulative fission density values in the alternate 3 design.

\begin{tabular}{|c|c|c|c|c|c|}
\hline Day & Region & Minimum & Maximum & Unit & Ref. \\
\hline 1 & IFE & 0.26 & 1.6 & \multirow{6}{*}{$10^{20} \frac{\text { fissions }}{\mathrm{cm}_{\text {fuelparticle }}^{3}}$} & Fig. 137 \\
\hline 15 & IFE & 3.85 & 20.81 & & Fig. 138 \\
\hline 27 & IFE & 7.14 & 32.93 & & Fig. 139 \\
\hline 1 & OFE & 0.11 & 0.93 & & Fig. 140 \\
\hline 15 & OFE & 1.98 & 14.46 & & Fig. 141 \\
\hline 27 & OFE & 4.04 & 24.09 & & Fig. 142 \\
\hline
\end{tabular}




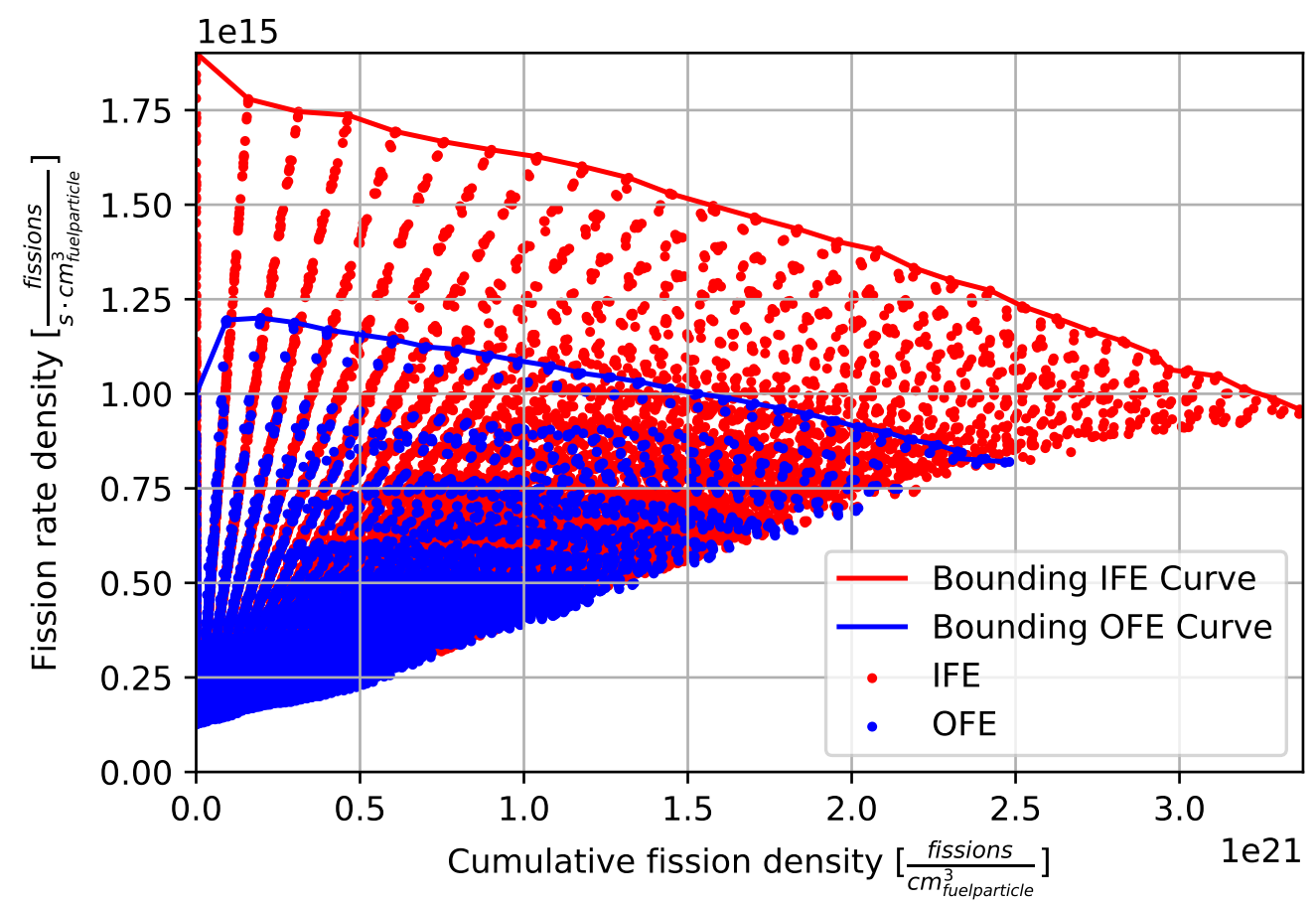

Figure 31. Alternate 3 design fission rate density variation with cumulative fission density during operation. 


\section{DISCUSSION}

Core design studies performed by Chandler et al. [9] resulted in four HFIR LEU $\mathrm{U}_{3} \mathrm{Si}_{2}$ - $\mathrm{Al}$ fuel designs with various design features that require additional fabrication $R \& D$ to determine their feasibility of fabrication. The design approach was initiated by first generating an optimized design with features known to result in excellent performance and safety. Alternate fuel designs were then generated by substituting a single design feature anticipated to be difficult to fabricate with one that would perform an analogous function [9]. With regards to the HEU core design, the LEU fuel designs require additional fabrication features primarily to reduce power peaking and increase thermal safety margin. Introduction of substantial amounts of ${ }^{238} \mathrm{U}$ into the core results in increased self-shielding due to the parasitic absorptions in the ${ }^{238} \mathrm{U}$ isotope. The reactor power must therefore be uprated from $85 \mathrm{MW}$ for the HEU core to $95 \mathrm{MW}$ for the LEU core to maintain performance. Consequently, additional power peaking mitigation features must be introduced to meet thermal safety requirements of the compact, high power density core.

This report provides detailed descriptions of these four fuel designs along with their performance and safety metrics and design parameters. All four fuel designs are presented herein, and all designs meet HEU key performance metrics. However the cold source cold-to-total flux ratio is slightly degraded due to the harder LEU fuel spectrum. The slightly increased fast flux down the beamlines, which acts as noise to the neutron scattering instruments, is not anticipated to adversely affect the neutron scattering mission. None of the designs have a greater thermal safety margin than the HEU core; however, they meet the minimum safety limit requirements. Some additional observations from this study are presented below.

- For the low density $\mathrm{U}_{3} \mathrm{Si}_{2}-\mathrm{Al}$ designs, having only center-symmetric fuel or an axial gradient feature requires Gd burnable poisons in the IFE filler in addition to boron burnable poison.

- The axial gradient design feature is more beneficial than the center and symmetric fuel design feature.

- A design feature to suppress power at the bottom of the fuel zone is required.

- The active fuel length must be increased relative to the HEU core design.

These four designs are presented to show (1) relevant operating conditions such as fission densities, power densities, and heat fluxes and (2) design flexibility for fuel fabrication in order to frame irradiation qualification needs and prioritize design feature R\&D efforts. The maximum parameters for each fuel element, for each of the four presented designs, are provided in Table 39. Given feedback from the fuel conversion pillars, a final design feature set will be chosen, and the selected fuel design will be further analyzed to assess additional performance and safety metrics with the fuel design. 
Table 39. Summary of maximum parameters for each low density $\mathrm{U}_{3} \mathrm{Si}_{2}$-Al design.

\begin{tabular}{llllll}
\hline & & Fis. rate density & Power density & Heat Flux & $\begin{array}{l}\text { Cumulative } \\
\text { fission density } \\
\left(\frac{f i s}{c m_{\text {fuelparticle }}^{3}}\right)\end{array}$ \\
\hline \multirow{2}{*}{ Optimized } & IFE & $1.86 \mathrm{E}+15$ & $2.55 \mathrm{E}+01$ & $3.70 \mathrm{E}+02$ & $3.27 \mathrm{E}+21$ \\
& OFE & $1.18 \mathrm{E}+15$ & $1.62 \mathrm{E}+01$ & $4.54 \mathrm{E}+02$ & $2.43 \mathrm{E}+21$ \\
\hline \multirow{2}{*}{ Alternate1 } & IFE & $1.82 \mathrm{E}+15$ & $2.48 \mathrm{E}+01$ & $3.58 \mathrm{E}+02$ & $3.27 \mathrm{E}+21$ \\
& OFE & $1.18 \mathrm{E}+15$ & $1.62 \mathrm{E}+01$ & $4.53 \mathrm{E}+02$ & $2.44 \mathrm{E}+21$ \\
\hline \multirow{2}{*}{ Alternate2 } & IFE & $1.81 \mathrm{E}+15$ & $2.47 \mathrm{E}+01$ & $3.50 \mathrm{E}+02$ & $3.26 \mathrm{E}+21$ \\
& OFE & $1.20 \mathrm{E}+15$ & $1.64 \mathrm{E}+01$ & $4.55 \mathrm{E}+02$ & $2.42 \mathrm{E}+21$ \\
\hline \multirow{2}{*}{ Alternate3 } & IFE & $1.90 \mathrm{E}+15$ & $2.60 \mathrm{E}+01$ & $3.51 \mathrm{E}+02$ & $3.30 \mathrm{E}+21$ \\
& OFE & $1.20 \mathrm{E}+15$ & $1.64 \mathrm{E}+01$ & $4.58 \mathrm{E}+02$ & $2.42 \mathrm{E}+21$ \\
\hline
\end{tabular}




\section{REFERENCES}

[1] J. Bae, B. R. Betzler, D. Chandler, G. Ilas, and M. J. L. High Flux Isotope Reactor Low-Enriched Uranium High Density Silicide Fuel Design Parameters. Technical Report ORNL/TM-2020-1799, United States, Apr. 2020.

[2] J. W. Bae, B. R. Betzler, D. Chandler, and G. Ilas. Automated Fuel Design Optimization for High Flux Isotope Reactor Low Enriched Uranium Neutronic and Thermal Hydraulic Core Design. In ,Proc. Intl. Conf. PHYSOR 2020, Cambridge, UK, 2020.

[3] B. R. Betzler, B. J. Ade, D. Chandler, G. Ilas, and E. E. Sunny. Optimization of Depletion Modeling and Simulation for the High Flux Isotope Reactor. In Proceedings of ANS Mathematics and Computational Topical Meeting, Nashville, Tennessee, USA, Apr. 2015.

[4] B. R. Betzler, D. Chandler, D. H. Cook, E. E. Davidson, and G. Ilas. Design Optimization Methods for High-performance Research Reactor Core Design. Nuclear Engineering and Design, 352, Oct. 2019.

[5] B. R. Betzler, D. Chandler, D. H. Cook, E. E. Davidson (née Sunny), and G. Ilas. High Flux Isotope Reactor Low-Enriched Uranium Core Design Optimization Studies. In ,Proc. Intl. Conf. PHYSOR 2018, Cancun, Mexico, Apr. 2018.

[6] B. R. Betzler, D. Chandler, E. E. Davidson, and G. Ilas. Design Optimization Studies for a High Flux Isotope Reactor Low-Enriched Uranium Core. Trans. Am. Nucl. Soc., 117, 2017.

[7] B. R. Betzler, D. Chandler, E. E. Davidson, and G. Ilas. High-Fidelity Modeling and Simulation for a High Flux Isotope Reactor Low-Enriched Uranium Core Design. Nuclear Science and Engineering, 187(1):81-99, July 2017.

[8] B. R. Betzler, D. Chandler, E. E. Davidson, and G. Ilas. Optimized Design Performance Analysis Tools for a High Flux Isotope Reactor Low-Enriched Uranium Core. Trans. Am. Nucl. Soc., 119, 2018.

[9] D. Chandler, B. R. Betzler, J. W. Bae, D. H. Cook, and G. Ilas. Conceptual Fuel Element Design Candidates for Conversion of High Flux Isotope Reactor with Low-Enriched Uranium Silicide Dispersion Fuel. In ,Proc. Intl. Conf. PHYSOR 2020, Cambridge, UK, 2020.

[10] D. Chandler, B. R. Betzler, D. H. Cook, G. Ilas, and D. G. Renfro. Neutronic and Thermal-Hydraulic Feasibility Studies for High Flux Isotope Reactor Conversion to Low-Enriched Uranium U3Si2-Al Fuel. In ,Proc. Intl. Conf. PHYSOR 2018, Cancun, Mexico, Apr. 2018.

[11] D. Chandler, B. R. Betzler, D. H. Cook, G. Ilas, and D. G. Renfro. Neutronic and Thermal-hydraulic Feasibility Studies for High Flux Isotope Reactor Conversion to Low-enriched Uranium Silicide Dispersion Fuel. Annals of Nuclear Energy, 130:277-292, Aug. 2019.

[12] D. Chandler, B. R. Betzler, G. J. Hirtz, G. Ilas, and E. E. Sunny. Modeling and Depletion Simulations for a High Flux Isotope Reactor Cycle with a Representative Experiment Loading. Technical Report ORNL/TM-2016/23, Oak Ridge National Laboratory, United States, Sept. 2016.

[13] D. Chandler, B. R. Betzler, P. K. Jain, J. W. Bae, D. H. Cook, V. D. Fudurich, T. K. Howard, C. J. Hurt, G. Ilas, J. L. Meszaros, and E. L. Popov. High Flux Isotope Reactor Conversion from 
High-Enriched to Low-Enriched Uranium Fuel - a 2019 Progress Update. In Proceedings of RERTR 2019, Zagreb, Croatia, Oct. 2019.

[14] R. D. Cheverton and T. M. Sims. HFIR CORE NUCLEAR DESIGN. Technical Report ORNL-4621, Oak Ridge National Lab., Tenn., Jan. 1971.

[15] T. Cole, L. Parsly, and W. Thomas. Revisions to the HFIR Steady States Heat Transfer Analysis Code. Technical Report ORNL/CF-86/68, Oak Ridge National Laboratory, Apr. 1986.

[16] G. G. Davidson, T. M. Pandya, S. R. Johnson, T. M. Evans, A. E. Isotalo, C. A. Gentry, and W. A. Wieselquist. Nuclide depletion capabilities in the Shift Monte Carlo code. Annals of Nuclear Energy, 114:259-276, Apr. 2018.

[17] W. Gambill. Design Curves for Burnout Heat Flux in Forced-Convection Subcooled Light Water Systems. Number ORNL-TM-2421. U.S. Atomic Energy Commission, Nov. 1968.

[18] IAEA. Research Reactor Core Conversion Guidebook, Volume 4: Fuels (Appendices I-K). Number 643/4 in TECDOC Series. International Atomic Energy Agency, Vienna, 1992.

[19] G. Ilas, B. R. Betzler, D. Chandler, D. G. Renfro, and E. E. Davidson. Key Metrics for HFIR HEU and LEU Models. Technical Report ORNL/TM-2016/581, Oak Ridge National Laboratory, United States, Oct. 2016.

[20] G. Ilas, D. Chandler, B. J. Ade, E. E. Sunny, B. R. Betzler, and D. L. Pinkston. Modeling and Simulations for the High Flux Isotope Reactor Cycle 400. Technical Report ORNL/TM-2015/36, Oak Ridge National Laboratory, United States, Mar. 2015.

[21] T. M. Pandya, S. R. Johnson, T. M. Evans, G. G. Davidson, S. P. Hamilton, and A. T. Godfrey. Implementation, Capabilities, and Benchmarking of Shift, a Massively Parallel Monte Carlo Radiation Transport Code. Journal of Computational Physics, 308:239-272, Mar. 2016.

[22] R. T. Primm, R. J. Ellis, J. C. Gehin, D. L. Moses, J. L. Binder, and N. Xoubi. Assumptions and Criteria for Performing a Feasability Study of the Conversion of the High Flux Isotope Reactor Core to Use Low-Enriched Uranium Fuel. Technical Report ORNL/TM-2005/269, Oak Ridge National Laboratory (ORNL), Oak Ridge, TN, Feb. 2006.

[23] D. Renfro, D. Chandler, D. Cook, G. Ilas, P. Jain, and J. Valentine. Preliminary Evaluation of Alternate Designs for HFIR Low-Enriched Uranium Fuel. Technical Report ORNL/TM-2014/154, Oak Ridge National Lab. (ORNL), Oak Ridge, TN (United States), Oct. 2014.

[24] USNRC. Safety Evaluation Report Related to the Evaluation of Low-Enriched Uranium Silicide-Aluminum Dispersion Fuel for Use in Non-Power Reactors. page 220, July 1988.

[25] I. Variansyah, J. W. Bae, B. R. Betzler, and G. Ilas. Metaheuristic Optimization Tool. Technical Report ORNL/TM-2019/1443, Oak Ridge National Laboratory, Oak Ridge, Tennessee, USA, Mar. 2020. 


\section{APPENDIX A. DISTRIBUTIONS FOR OPTIMIZED DESIGN}

\section{APPENDIX A-1. FISSION RATE DENSITY DISTRIBUTIONS FOR OPTIMIZED \\ DESIGN}

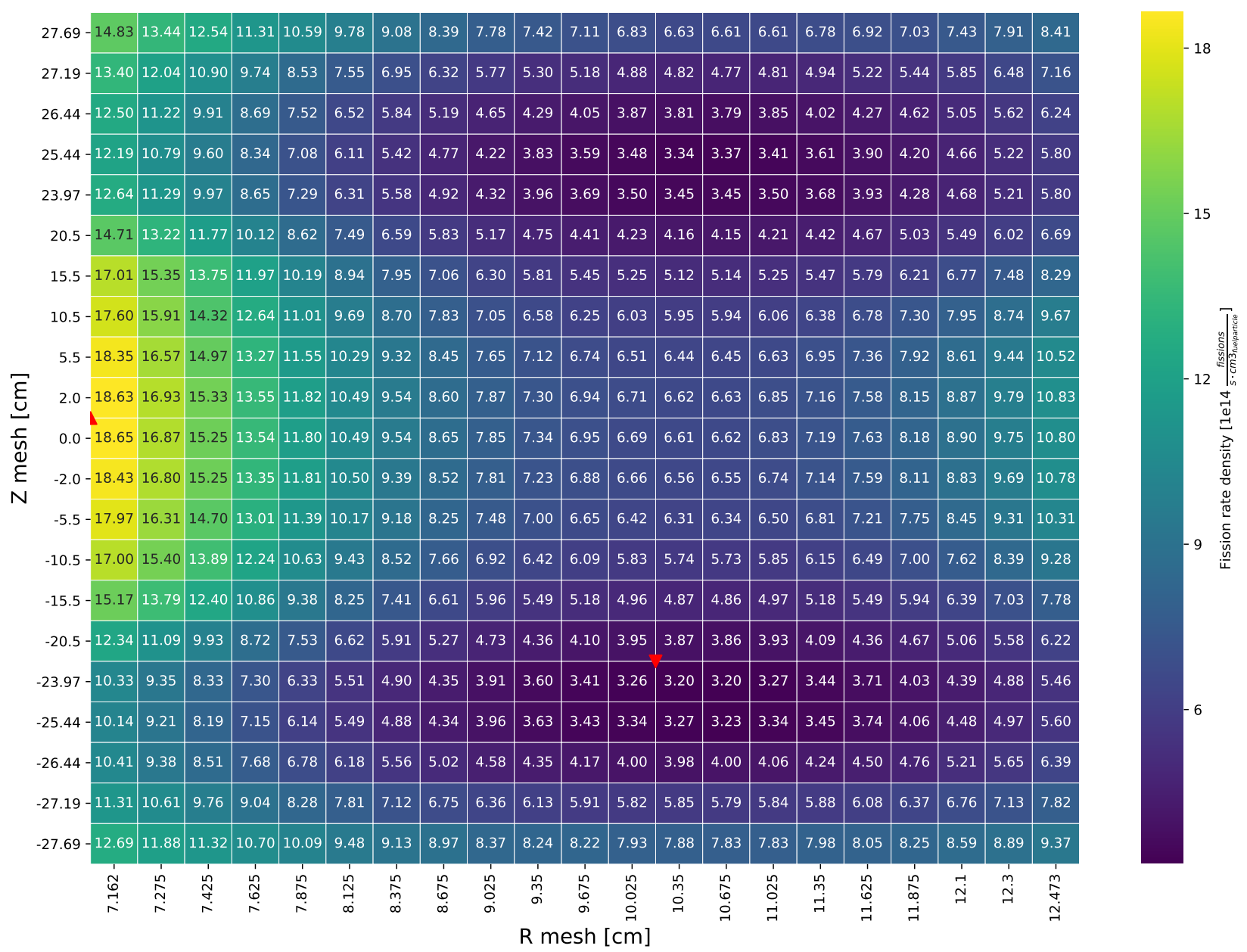

Figure 32. Fission rate density distribution for optimized design IFE region on day 0 (see Section 7.1.2). 


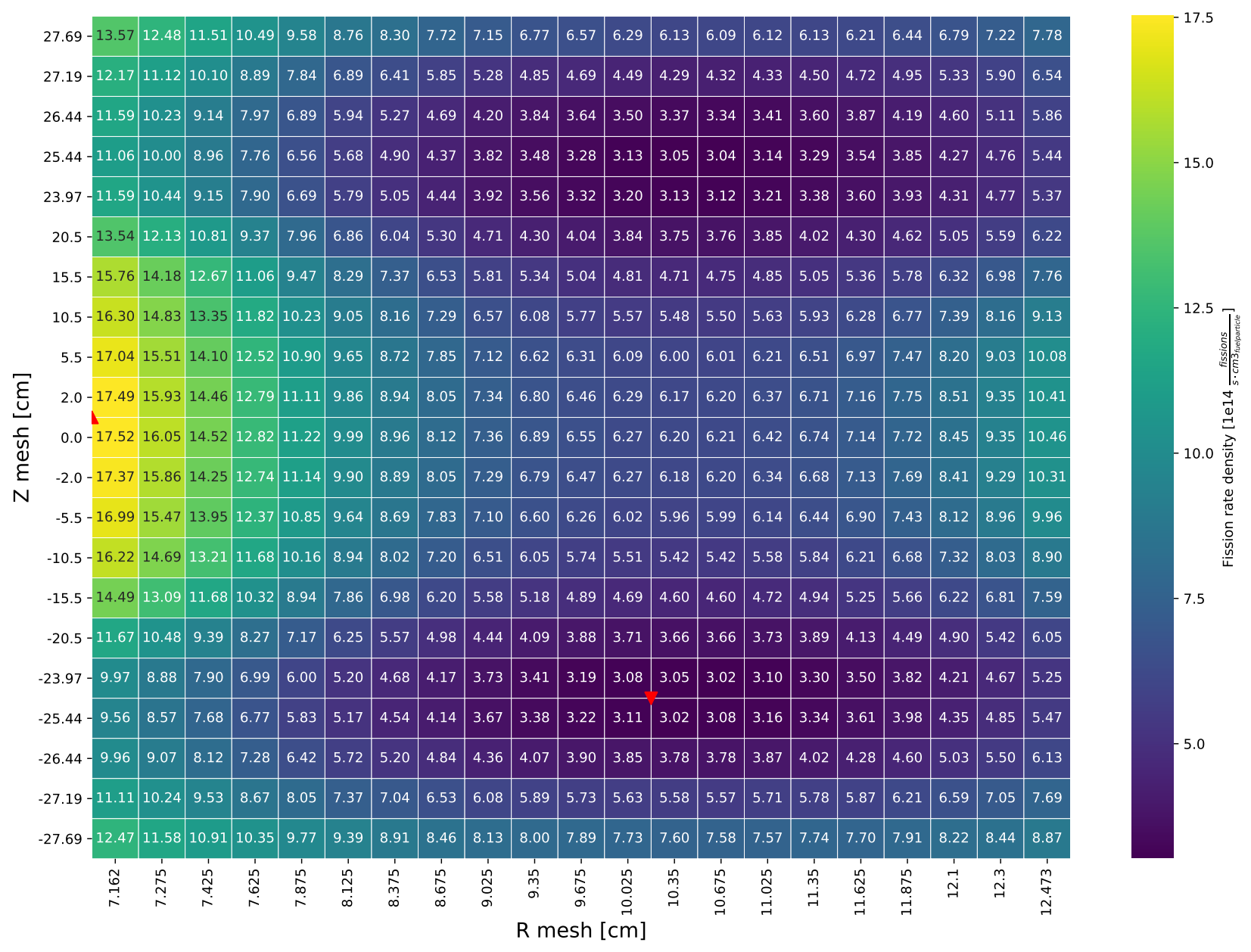

Figure 33. Fission rate density distribution for optimized design IFE region on day 1 (see Section 7.1.2). 


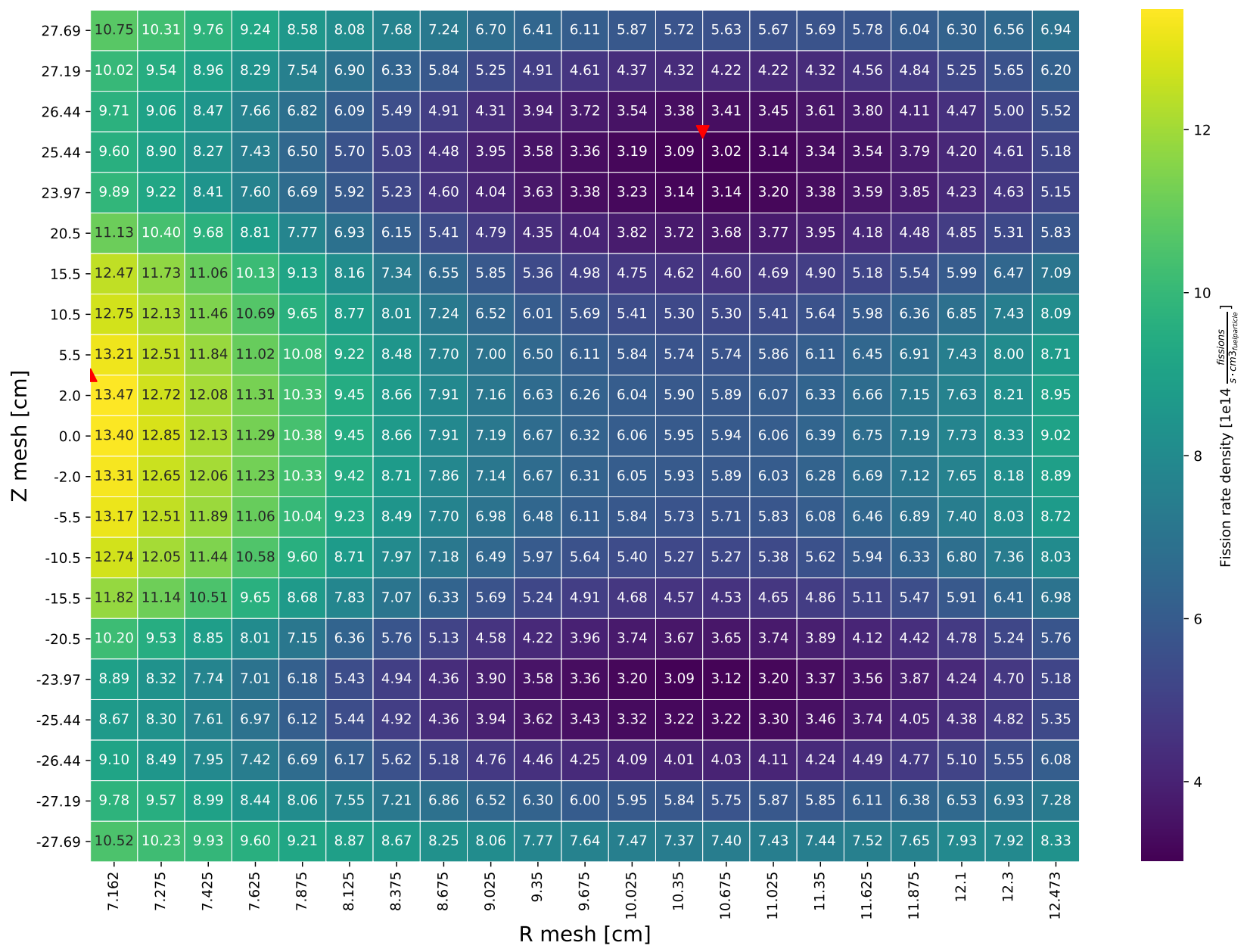

Figure 34. Fission rate density distribution for optimized design IFE region on day 15 (see Section 7.1.2). 


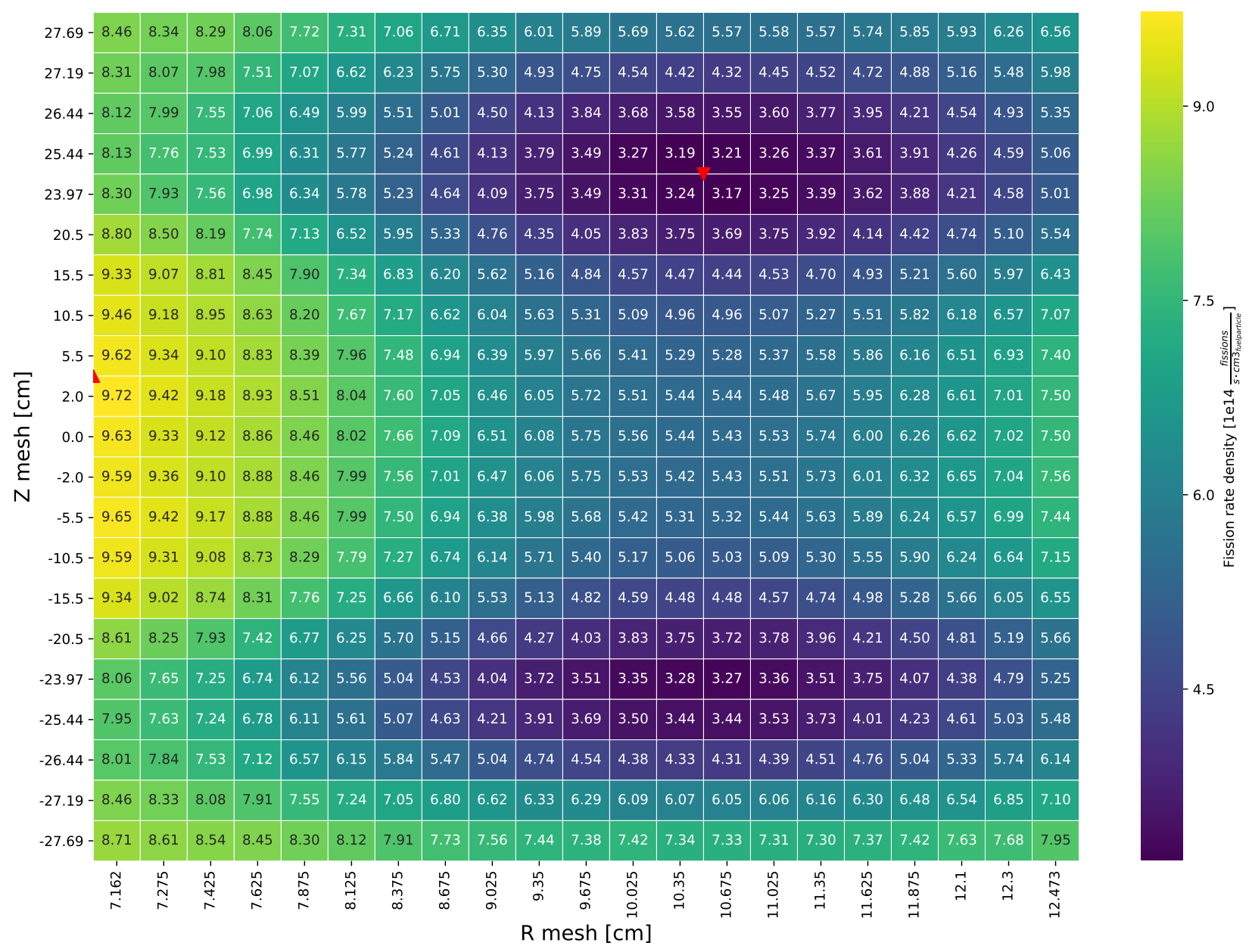

Figure 35. Fission rate density distribution for optimized design IFE region on day 27 (see Section 7.1.2). 


\begin{tabular}{|c|c|c|c|c|c|c|c|c|c|c|c|c|c|c|c|}
\hline $27.69-$ & 7.48 & 6.78 & 5.96 & 5.14 & 4.71 & 4.39 & 4.08 & 3.82 & 3.61 & 3.32 & 3.13 & 2.97 & 2.88 & 2.91 & \multirow[b]{3}{*}{-9.0} \\
\hline 27.19 & 6.49 & 5.70 & 4.71 & 3.86 & 3.42 & 3.13 & 2.88 & 2.72 & 2.53 & 2.41 & 2.27 & 2.25 & 2.33 & 2.46 & \\
\hline 26.44 & 5.65 & 4.92 & 3.99 & 3.18 & 2.73 & 2.46 & 2.29 & 2.12 & 2.00 & 1.94 & 1.89 & 1.92 & 2.04 & 2.19 & \\
\hline 25.44 & 5.25 & 4.56 & 3.72 & 2.92 & 2.48 & 2.25 & 2.08 & 1.94 & 1.83 & 1.80 & 1.78 & 1.82 & 1.95 & 2.12 & \multirow{4}{*}{7.5} \\
\hline 23.97 & 5.31 & 4.59 & 3.77 & 3.03 & 2.60 & 2.34 & 2.17 & 2.04 & 1.94 & 1.87 & 1.86 & 1.89 & 2.00 & 2.17 & \\
\hline 20.5 & 6.08 & 5.34 & 4.44 & 3.63 & 3.15 & 2.85 & 2.65 & 2.51 & 2.39 & 2.31 & 2.27 & 2.33 & 2.47 & 2.64 & \\
\hline 15.5 & 7.56 & 6.67 & 5.56 & 4.58 & 3.99 & 3.65 & 3.41 & 3.25 & 3.14 & 3.10 & 3.11 & 3.28 & 3.59 & 3.94 & \\
\hline 10.5 & 8.82 & 7.84 & 6.53 & 5.38 & 4.75 & 4.35 & 4.11 & 3.99 & 3.97 & 4.04 & 4.30 & 4.96 & 5.88 & 6.81 & \multirow{7}{*}{ 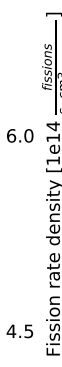 } \\
\hline 5.5 & 9.68 & 8.54 & 7.14 & 5.91 & 5.21 & 4.81 & 4.57 & 4.46 & 4.46 & 4.63 & 5.03 & 5.91 & 7.14 & 8.36 & \\
\hline 2.0 & 9.92 & 8.83 & 7.35 & 6.10 & 5.37 & 4.95 & 4.73 & 4.62 & 4.62 & 4.82 & 5.25 & 6.21 & 7.55 & 8.91 & \\
\hline $0.0-$ & 9.93 & 8.76 & 7.38 & 6.07 & 5.39 & 4.97 & 4.74 & 4.60 & 4.62 & 4.79 & 5.25 & 6.24 & 7.55 & 8.89 & \\
\hline-2.0 & 9.84 & 8.75 & 7.29 & 6.03 & 5.30 & 4.88 & 4.65 & 4.55 & 4.57 & 4.72 & 5.11 & 6.03 & 7.27 & 8.41 & \\
\hline-5.5 & 9.44 & 8.34 & 7.00 & 5.78 & 5.10 & 4.69 & 4.44 & 4.33 & 4.32 & 4.44 & 4.81 & 5.60 & 6.68 & 7.77 & \\
\hline-10.5 & 8.50 & 7.50 & 6.25 & 5.14 & 4.51 & 4.15 & 3.91 & 3.77 & 3.72 & 3.78 & 4.03 & 4.63 & 5.46 & 6.26 & \\
\hline-15.5 & 7.12 & 6.26 & 5.22 & 4.25 & 3.67 & 3.33 & 3.10 & 2.92 & 2.77 & 2.65 & 2.57 & 2.56 & 2.64 & 2.74 & \\
\hline-20.5 & 5.62 & 4.91 & 4.05 & 3.27 & 2.83 & 2.54 & 2.33 & 2.17 & 2.03 & 1.90 & 1.79 & 1.70 & 1.66 & 1.67 & \\
\hline-23.97 & 4.90 & 4.27 & 3.47 & 2.76 & 2.36 & 2.10 & 1.92 & 1.76 & 1.64 & 1.53 & 1.44 & 1.38 & 1.35 & 1.37 & \\
\hline-25.44 & 5.09 & 4.41 & 3.59 & 2.85 & 2.42 & 2.14 & 1.94 & 1.78 & 1.64 & 1.53 & 1.42 & 1.35 & 1.33 & 1.33 & \\
\hline-26.44 & 5.87 & 5.11 & 4.21 & 3.48 & 3.03 & 2.73 & 2.50 & 2.29 & 2.10 & 1.89 & 1.74 & 1.60 & 1.52 & 1.51 & \\
\hline$-27.19-$ & 7.41 & 6.63 & 5.86 & 5.07 & 4.59 & 4.20 & 3.89 & 3.50 & 3.20 & 2.89 & 2.60 & 2.28 & 2.06 & 1.93 & \\
\hline \multirow[t]{2}{*}{$-27.69-$} & 8.52 & 8.06 & 7.44 & 6.78 & 6.13 & 5.65 & 5.20 & 4.77 & 4.32 & 3.86 & 3.41 & 2.92 & 2.60 & 2.32 & -1.5 \\
\hline & 15.22 & 15.4 & 15.75 & 16.25 & 16.75 & 17.25 & $\begin{array}{r}17.75 \\
\mathrm{R} \text { me }\end{array}$ & $\begin{array}{l}18.25 \\
{[\mathrm{~cm}]}\end{array}$ & 18.75 & 19.25 & 19.75 & 20.25 & 20.625 & 20.853 & \\
\hline
\end{tabular}

Figure 36. Fission rate density distribution for optimized design OFE region on day 0 (see Section 7.1.2). 


\begin{tabular}{|c|c|c|c|c|c|c|c|c|c|c|c|c|c|c|}
\hline 27.69 & 6.95 & 6.25 & 5.48 & 4.78 & 4.38 & 4.07 & 3.84 & 3.60 & 3.37 & 3.16 & 2.91 & 2.81 & 2.76 & 2.80 \\
\hline 27.19 & 5.86 & 5.13 & 4.31 & 3.55 & 3.15 & 2.89 & 2.66 & 2.55 & 2.38 & 2.28 & 2.19 & 2.16 & 2.24 & 2.37 \\
\hline 26.44 & 5.26 & 4.58 & 3.67 & 2.91 & 2.50 & 2.28 & 2.13 & 2.03 & 1.90 & 1.84 & 1.81 & 1.82 & 1.99 & 2.17 \\
\hline 25.44 & 4.93 & 4.25 & 3.43 & 2.69 & 2.31 & 2.08 & 1.92 & 1.83 & 1.75 & 1.71 & 1.70 & 1.75 & 1.89 & 2.07 \\
\hline 23.97 & 4.87 & 4.29 & 3.48 & 2.82 & 2.42 & 2.18 & 2.03 & 1.93 & 1.86 & 1.80 & 1.79 & 1.88 & 2.05 & 2.24 \\
\hline 20.5 & 5.68 & 5.00 & 4.14 & 3.39 & 2.95 & 2.70 & 2.54 & 2.44 & 2.38 & 2.38 & 2.46 & 2.73 & 3.11 & 3.51 \\
\hline 15.5 & 7.15 & 6.28 & 5.23 & 4.32 & 3.80 & 3.52 & 3.33 & 3.25 & 3.23 & 3.31 & 3.57 & 4.16 & 4.96 & 5.80 \\
\hline 10.5 & 8.38 & 7.39 & 6.19 & 5.13 & 4.51 & 4.17 & 3.98 & 3.90 & 3.94 & 4.10 & 4.48 & 5.31 & 6.48 & 7.64 \\
\hline 5.5 & 9.23 & 8.17 & 6.83 & 5.68 & 5.04 & 4.69 & 4.50 & 4.46 & 4.56 & 4.86 & 5.52 & 6.86 & 8.65 & 10.42 \\
\hline 2.0 & 9.49 & 8.38 & 7.04 & 5.89 & 5.22 & 4.87 & 4.74 & 4.72 & 4.85 & 5.20 & 5.97 & 7.51 & 9.61 & 11.61 \\
\hline 0.0 & 9.60 & 8.53 & 7.11 & 5.91 & 5.25 & 4.88 & 4.73 & 4.73 & 4.88 & 5.26 & 6.01 & 7.62 & 9.73 & 11.81 \\
\hline-2.0 & 9.60 & 8.47 & 7.07 & 5.86 & 5.21 & 4.86 & 4.69 & 4.68 & 4.82 & 5.18 & 5.94 & 7.51 & 9.67 & 11.71 \\
\hline-5.5 & 9.16 & 8.09 & 6.79 & 5.62 & 4.98 & 4.61 & 4.44 & 4.41 & 4.51 & 4.81 & 5.46 & 6.79 & 8.59 & 10.39 \\
\hline-10.5 & 8.19 & 7.28 & 6.06 & 5.01 & 4.41 & 4.07 & 3.88 & 3.78 & 3.79 & 3.93 & 4.26 & 5.00 & 5.99 & 6.98 \\
\hline-15.5 & 6.89 & 6.07 & 5.07 & 4.18 & 3.66 & 3.37 & 3.18 & 3.09 & 3.05 & 3.11 & 3.35 & 3.86 & 4.59 & 5.30 \\
\hline-20.5 & 5.46 & 4.80 & 3.96 & 3.23 & 2.80 & 2.54 & 2.38 & 2.26 & 2.17 & 2.14 & 2.16 & 2.32 & 2.56 & 2.81 \\
\hline-23.97 & 4.77 & 4.15 & 3.36 & 2.69 & 2.28 & 2.04 & 1.88 & 1.73 & 1.63 & 1.53 & 1.47 & 1.43 & 1.42 & 1.45 \\
\hline-25.44 & 4.99 & 4.28 & 3.42 & 2.70 & 2.30 & 2.03 & 1.87 & 1.71 & 1.60 & 1.50 & 1.41 & 1.35 & 1.34 & 1.38 \\
\hline-26.44 & 5.65 & 4.92 & 4.05 & 3.34 & 2.90 & 2.60 & 2.38 & 2.21 & 2.03 & 1.88 & 1.71 & 1.59 & 1.53 & 1.54 \\
\hline-27.19 & 7.02 & 6.49 & 5.69 & 4.98 & 4.36 & 4.03 & 3.75 & 3.39 & 3.08 & 2.82 & 2.54 & 2.24 & 2.06 & 1.95 \\
\hline \multirow[t]{2}{*}{-27.69} & 8.21 & 7.86 & 7.19 & 6.51 & 5.94 & 5.54 & 5.03 & 4.64 & 4.28 & 3.81 & 3.37 & 2.91 & 2.58 & 2.37 \\
\hline & 15.22 & 15.4 & 15.75 & 16.25 & 16.75 & 17.25 & $\begin{array}{r}17.75 \\
\mathrm{Re}\end{array}$ & $\begin{array}{l}18.25 \\
{[\mathrm{~cm}]}\end{array}$ & 18.75 & 19.25 & 19.75 & 20.25 & 20.625 & 20.853 \\
\hline
\end{tabular}

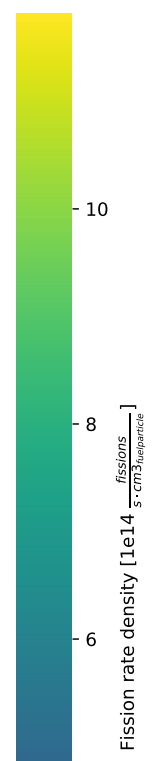

Figure 37. Fission rate density distribution for optimized design OFE region on day 1 (see Section 7.1.2). 


\begin{tabular}{|c|c|c|c|c|c|c|c|c|c|c|c|c|c|c|}
\hline $27.69-$ & 6.87 & 6.25 & 5.44 & 4.76 & 4.28 & 4.07 & 3.78 & 3.56 & 3.32 & 3.13 & 2.96 & 2.80 & 2.79 & 2.84 \\
\hline $27.19-$ & 5.95 & 5.19 & 4.28 & 3.54 & 3.14 & 2.88 & 2.66 & 2.54 & 2.40 & 2.25 & 2.17 & 2.16 & 2.26 & 2.42 \\
\hline 26.44 & 5.24 & 4.55 & 3.63 & 2.91 & 2.50 & 2.28 & 2.10 & 1.98 & 1.88 & 1.80 & 1.79 & 1.83 & 1.99 & 2.17 \\
\hline 25.44 & 4.85 & 4.19 & 3.40 & 2.70 & 2.32 & 2.06 & 1.91 & 1.81 & 1.74 & 1.70 & 1.69 & 1.76 & 1.95 & 2.14 \\
\hline $23.97-$ & 4.85 & 4.24 & 3.45 & 2.78 & 2.41 & 2.18 & 2.02 & 1.92 & 1.86 & 1.84 & 1.86 & 1.94 & 2.15 & 2.35 \\
\hline 20.5 & 5.64 & 4.98 & 4.12 & 3.37 & 2.95 & 2.68 & 2.53 & 2.44 & 2.40 & 2.43 & 2.55 & 2.86 & 3.30 & 3.78 \\
\hline 15.5 & 7.06 & 6.22 & 5.18 & 4.27 & 3.76 & 3.47 & 3.30 & 3.20 & 3.20 & 3.29 & 3.53 & 4.09 & 4.90 & 5.68 \\
\hline 10.5 & 8.25 & 7.31 & 6.11 & 5.07 & 4.47 & 4.14 & 3.97 & 3.90 & 3.94 & 4.10 & 4.52 & 5.40 & 6.60 & 7.77 \\
\hline 5.5 & 9.14 & 8.09 & 6.79 & 5.65 & 4.99 & 4.66 & 4.49 & 4.47 & 4.58 & 4.91 & 5.60 & 7.00 & 8.90 & 10.74 \\
\hline $2.0-$ & 9.42 & 8.36 & 7.00 & 5.85 & 5.20 & 4.88 & 4.72 & 4.70 & 4.83 & 5.20 & 5.98 & 7.57 & 9.69 & 11.72 \\
\hline 0.0 & 9.43 & 8.39 & 7.04 & 5.86 & 5.22 & 4.86 & 4.73 & 4.72 & 4.85 & 5.22 & 6.02 & 7.62 & 9.77 & 11.85 \\
\hline$-2.0-$ & 9.40 & 8.31 & 7.01 & 5.83 & 5.16 & 4.83 & 4.67 & 4.64 & 4.78 & 5.18 & 5.99 & 7.59 & 9.70 & 11.79 \\
\hline$-5.5-$ & 9.05 & 8.03 & 6.73 & 5.56 & 4.95 & 4.61 & 4.45 & 4.42 & 4.54 & 4.89 & 5.58 & 7.02 & 8.91 & 10.78 \\
\hline-10.5 & 8.13 & 7.22 & 6.02 & 4.98 & 4.38 & 4.05 & 3.86 & 3.78 & 3.80 & 3.95 & 4.31 & 5.08 & 6.15 & 7.19 \\
\hline-15.5 & 6.86 & 6.05 & 5.06 & 4.14 & 3.64 & 3.34 & 3.17 & 3.08 & 3.05 & 3.12 & 3.32 & 3.81 & 4.51 & 5.17 \\
\hline-20.5 & 5.46 & 4.79 & 3.98 & 3.22 & 2.79 & 2.54 & 2.38 & 2.28 & 2.22 & 2.21 & 2.30 & 2.53 & 2.87 & 3.24 \\
\hline-23.97 & 4.78 & 4.14 & 3.35 & 2.68 & 2.27 & 2.05 & 1.89 & 1.76 & 1.65 & 1.57 & 1.51 & 1.48 & 1.50 & 1.56 \\
\hline-25.44 & 4.91 & 4.21 & 3.42 & 2.71 & 2.30 & 2.08 & 1.89 & 1.73 & 1.63 & 1.54 & 1.44 & 1.37 & 1.38 & 1.39 \\
\hline-26.44 & 5.57 & 4.88 & 4.04 & 3.31 & 2.89 & 2.60 & 2.35 & 2.18 & 2.03 & 1.86 & 1.73 & 1.62 & 1.55 & 1.55 \\
\hline-27.19 & 7.03 & 6.42 & 5.62 & 4.86 & 4.44 & 4.00 & 3.74 & 3.42 & 3.17 & 2.84 & 2.56 & 2.29 & 2.09 & 1.97 \\
\hline \multirow[t]{2}{*}{$-27.69-$} & 8.28 & 7.75 & 7.10 & 6.39 & 5.94 & 5.48 & 5.01 & 4.62 & 4.23 & 3.79 & 3.39 & 2.91 & 2.56 & 2.39 \\
\hline & 15.22 & 15.4 & 15.75 & 16.25 & 16.75 & 17.25 & $\begin{array}{r}17.75 \\
\mathrm{R} \text { me }\end{array}$ & $\begin{array}{l}18.25 \\
{[\mathrm{~cm}]}\end{array}$ & 18.75 & 19.25 & 19.75 & 20.25 & 20.625 & 20.853 \\
\hline
\end{tabular}

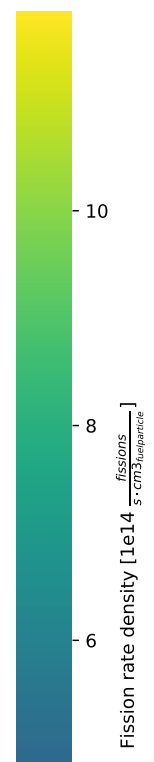

Figure 38. Fission rate density distribution for optimized design OFE region on day 2 (see Section 7.1.2). 


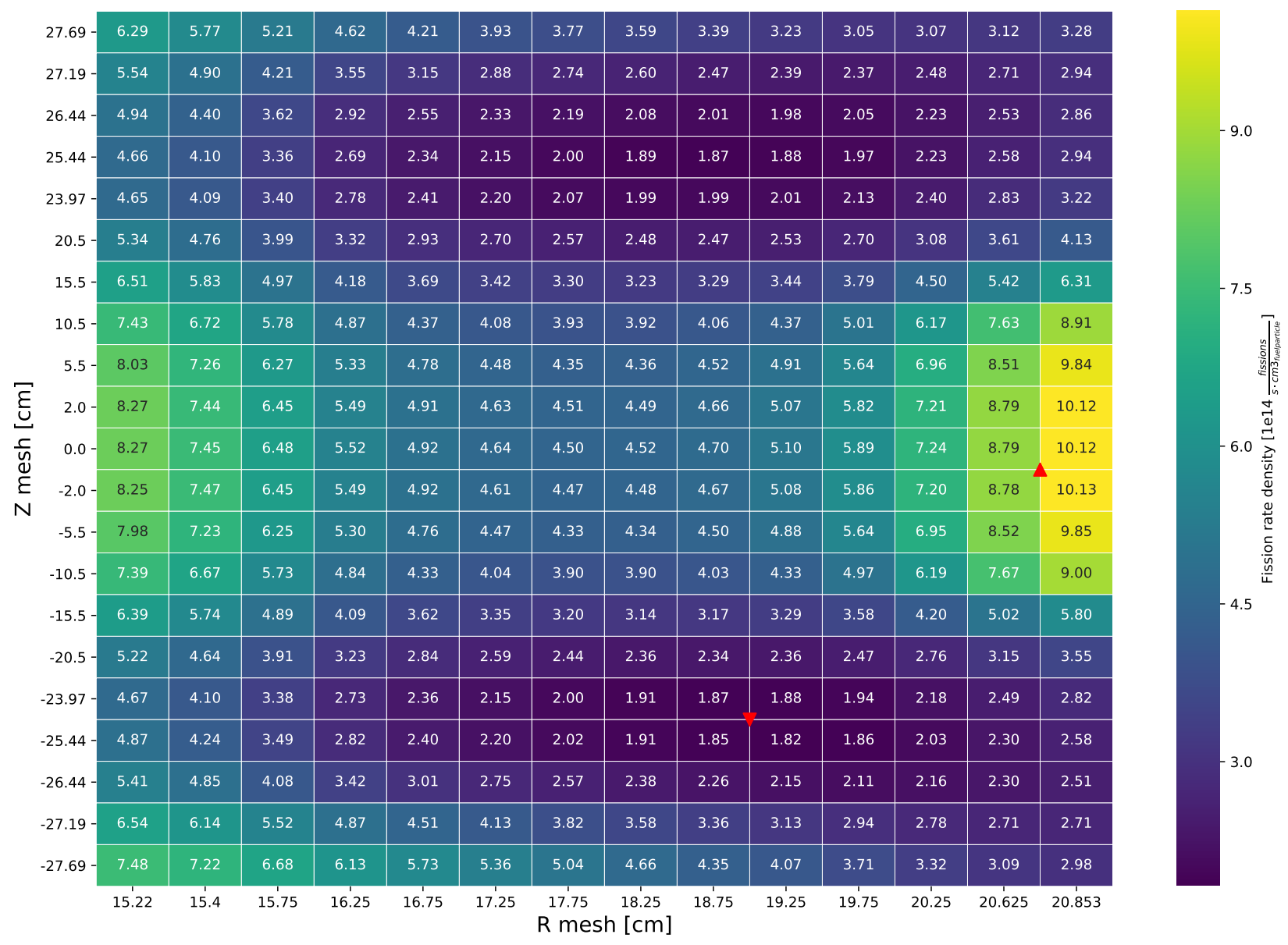

Figure 39. Fission rate density distribution for optimized design OFE region on day 15 (see Section 7.1.2). 


\begin{tabular}{|c|c|c|c|c|c|c|c|c|c|c|c|c|c|c|c|}
\hline 27.69 & 6.08 & 5.71 & 5.22 & 4.73 & 4.47 & 4.27 & 4.13 & 4.03 & 3.96 & 3.89 & 3.93 & 4.11 & 4.41 & 4.82 & \multirow{4}{*}{-7.5} \\
\hline 27.19 & 5.48 & 4.96 & 4.35 & 3.75 & 3.41 & 3.15 & 3.08 & 3.00 & 2.94 & 2.92 & 3.04 & 3.43 & 3.94 & 4.38 & \\
\hline 26.44 & 4.91 & 4.42 & 3.77 & 3.13 & 2.76 & 2.56 & 2.45 & 2.40 & 2.38 & 2.44 & 2.63 & 3.11 & 3.74 & 4.33 & \\
\hline 25.44 & 4.65 & 4.15 & 3.48 & 2.87 & 2.52 & 2.32 & 2.21 & 2.16 & 2.21 & 2.33 & 2.58 & 3.14 & 3.87 & 4.59 & \\
\hline 23.97 & 4.62 & 4.11 & 3.49 & 2.90 & 2.54 & 2.37 & 2.27 & 2.26 & 2.34 & 2.50 & 2.86 & 3.56 & 4.46 & 5.32 & \\
\hline 20.5 & 5.09 & 4.61 & 3.98 & 3.38 & 3.03 & 2.83 & 2.75 & 2.76 & 2.87 & 3.13 & 3.63 & 4.55 & 5.72 & 6.79 & \\
\hline 15.5 & 5.94 & 5.42 & 4.73 & 4.08 & 3.68 & 3.45 & 3.36 & 3.39 & 3.55 & 3.87 & 4.48 & 5.58 & 6.84 & 7.92 & \\
\hline 10.5 & 6.52 & 6.02 & 5.28 & 4.59 & 4.13 & 3.90 & 3.80 & 3.85 & 4.02 & 4.39 & 5.04 & 6.16 & 7.34 & 8.29 & \\
\hline 5.5 & 6.88 & 6.34 & 5.62 & 4.88 & 4.42 & 4.17 & 4.08 & 4.13 & 4.31 & 4.69 & 5.38 & 6.46 & 7.51 & 8.29 & \\
\hline 2.0 & 7.01 & 6.44 & 5.74 & 5.01 & 4.52 & 4.28 & 4.17 & 4.20 & 4.39 & 4.79 & 5.49 & 6.57 & 7.59 & 8.33 & \\
\hline 0.0 & 7.05 & 6.49 & 5.76 & 5.00 & 4.52 & 4.28 & 4.18 & 4.20 & 4.41 & 4.81 & 5.51 & 6.57 & 7.61 & 8.34 & \\
\hline-2.0 & 6.99 & 6.43 & 5.72 & 4.98 & 4.52 & 4.28 & 4.15 & 4.21 & 4.38 & 4.80 & 5.52 & 6.60 & 7.62 & 8.32 & \\
\hline$-5.5-$ & 6.92 & 6.36 & 5.62 & 4.87 & 4.42 & 4.19 & 4.08 & 4.12 & 4.32 & 4.71 & 5.41 & 6.48 & 7.53 & 8.32 & \\
\hline-10.5 & 6.64 & 6.05 & 5.34 & 4.63 & 4.17 & 3.92 & 3.82 & 3.85 & 4.03 & 4.40 & 5.08 & 6.20 & 7.39 & 8.35 & \\
\hline-15.5 & 6.03 & 5.47 & 4.80 & 4.12 & 3.71 & 3.48 & 3.38 & 3.40 & 3.56 & 3.90 & 4.51 & 5.63 & 6.93 & 8.09 & \\
\hline-20.5 & 5.21 & 4.70 & 4.05 & 3.42 & 3.06 & 2.85 & 2.76 & 2.76 & 2.86 & 3.12 & 3.64 & 4.61 & 5.82 & 6.97 & \\
\hline-23.97 & 4.83 & 4.27 & 3.63 & 3.02 & 2.63 & 2.43 & 2.32 & 2.29 & 2.35 & 2.50 & 2.83 & 3.53 & 4.43 & 5.30 & \\
\hline-25.44 & 5.01 & 4.40 & 3.75 & 3.11 & 2.70 & 2.49 & 2.36 & 2.31 & 2.28 & 2.37 & 2.59 & 3.03 & 3.69 & 4.32 & \\
\hline-26.44 & 5.63 & 5.13 & 4.46 & 3.81 & 3.44 & 3.17 & 3.00 & 2.88 & 2.80 & 2.82 & 2.93 & 3.18 & 3.59 & 4.07 & 3.0 \\
\hline$-27.19-$ & 6.68 & 6.20 & 5.79 & 5.31 & 4.96 & 4.60 & 4.46 & 4.26 & 4.13 & 4.05 & 4.02 & 4.11 & 4.31 & 4.49 & \\
\hline$-27.69-$ & 7.34 & 7.08 & 6.77 & 6.38 & 6.08 & 5.84 & 5.63 & 5.44 & 5.22 & 5.14 & 5.02 & 4.97 & 4.90 & 5.01 & \\
\hline & 15.22 & 15.4 & 15.75 & 16.25 & 16.75 & 17.25 & $\begin{array}{r}17.75 \\
\mathrm{R} \text { me }\end{array}$ & $\begin{array}{l}18.25 \\
{[\mathrm{~cm}]}\end{array}$ & 18.75 & 19.25 & 19.75 & 20.25 & 20.625 & 20.853 & \\
\hline
\end{tabular}

Figure 40. Fission rate density distribution for optimized design OFE region on day 27 (see Section 7.1.2). 


\section{APPENDIX A-2. CUMULATIVE FISSION DENSITY DISTRIBUTIONS FOR OPTIMIZED DESIGN}

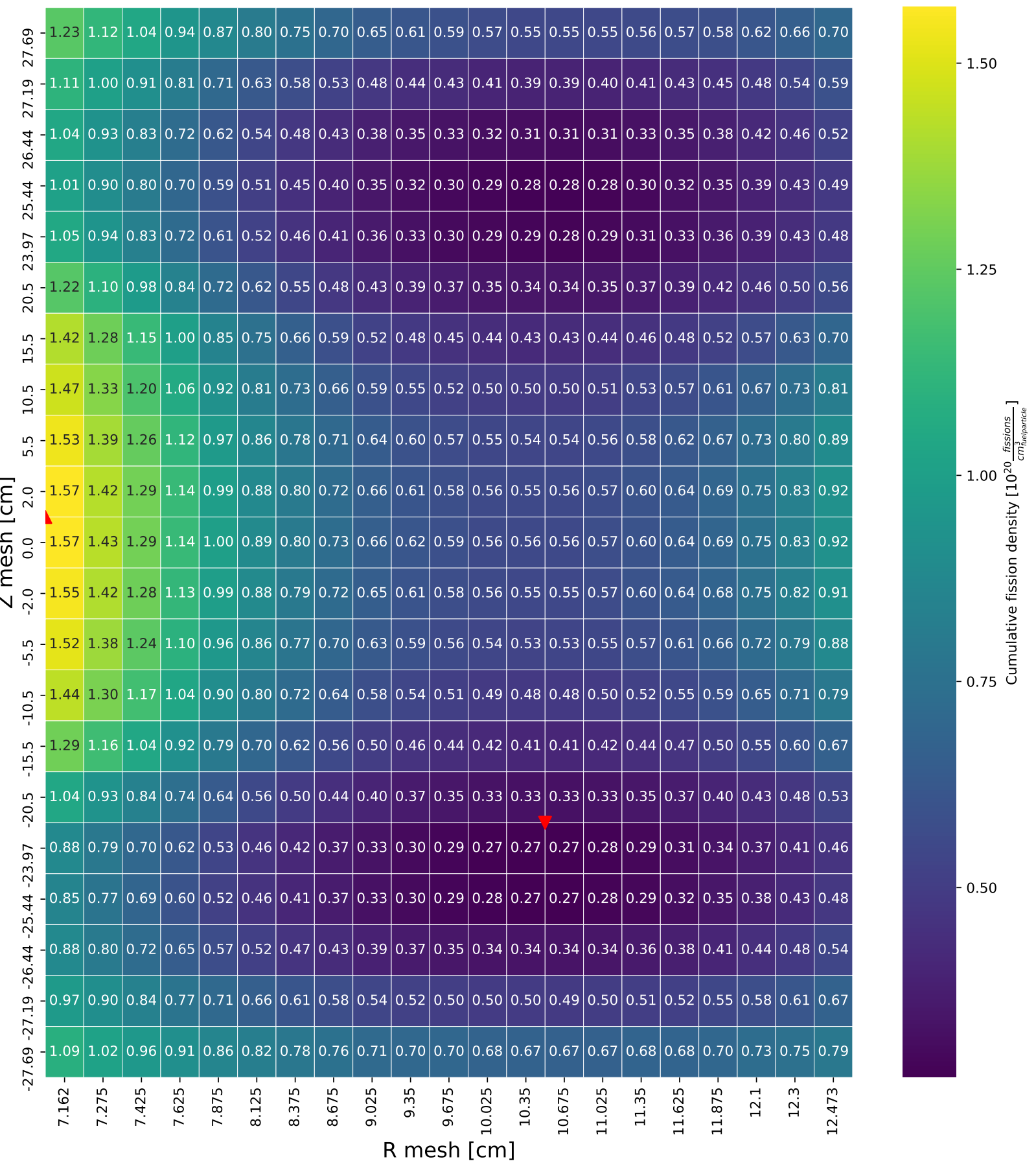

Figure 41. Cumulative fission density distribution for optimized design IFE region on day 1 (see Section 7.1.5). 


\section{$\stackrel{8}{\circ}-15.80$}

กิ

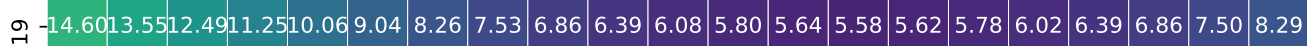

กิ

$-13.8712 .7011 .5410 .268 .92 \quad 7.87 \quad 7.03 \quad 6.25 \quad 5.58 \quad 5.11 \quad 4.78 \quad 4.58 \quad 4.45 \quad 4.42 \quad 4.49 \quad 4.70 \quad 5.01 \quad 5.42 \quad 5.92 \quad 6.57 \quad 7.37$

$\stackrel{\leftrightarrow}{\sim}$

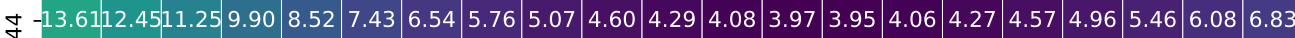

กั่

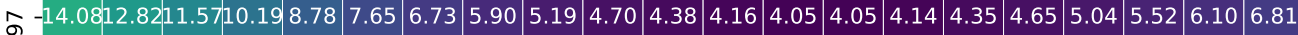

$\stackrel{m}{N}$

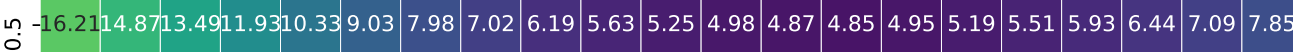
$\stackrel{\circ}{\text { ก }}$

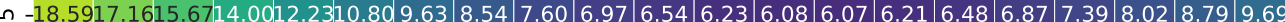
ก

เก $-19.1517 .8016 .4014 .7913 .1011 .7110 .589 .518 .55 \quad 7.92 \quad 7.47 \quad 7.16 \quad 7.02 \quad 7.03 \quad 7.20 \quad 7.558 .018 .609 .3410 .2011 .25$ 이

เก $-19.9318 .5517 .1815 .5513 .8512 .4411 .2810 .199 .22 \quad 8.578 .11 \quad 7.80 \quad 7.67 \quad 7.68 \quad 7.88 \quad 8.258 .77 \quad 9.4210 .2111 .1512 .27$ เก

Е 우 $-20.3518 .9617 .5615 .9114 .2012 .7511 .5810 .459 .48 \quad 8.828 .348 .03 \quad 7.90 \quad 7.918 .118 .509 .049 .7110 .5411 .5012 .65$ $\underline{\epsilon} \stackrel{\sim}{\sim}$

든 우 $-20.4019 .0217 .6115 .9414 .2312 .8011 .6110 .509 .518 .848 .378 .057 .91 \quad 7.938 .148 .549 .069 .7510 .5611 .5212 .67$ $\stackrel{\mathscr{N}}{\mathscr{\varepsilon}} \stackrel{\circ}{0}^{\circ}$

이 $-20.2818 .9017 .4815 .8514 .1412 .7211 .5510 .449 .468 .778 .338 .01 \quad 7.88 \quad 7.908 .108 .49 \quad 9.039 .6810 .5011 .4712 .62$ $N \stackrel{\circ}{i}$

เก $-19.8918 .5017 .1115 .4913 .8112 .4111 .2410 .149 .18 \quad 8.538 .08 \quad 7.76 \quad 7.627 .647 .84 \quad 8.208 .719 .3610 .1411 .0912 .21$

เก $-19.0317 .6616 .2714 .6913 .0011 .6010 .489 .418 .47 \quad 7.847 .40 \quad 7.106 .96 \quad 6.97 \quad 7.13 \quad 7.46 \quad 7.92 \quad 8.509 .2210 .0811 .10$ 우

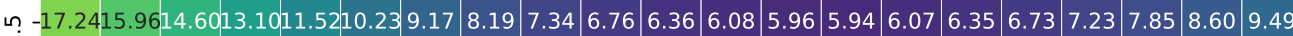
เก

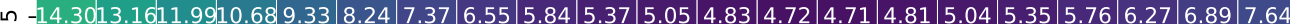

$\stackrel{\circ}{\Upsilon}$

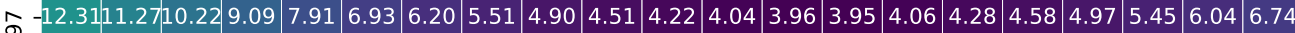

$\stackrel{m}{\sim}$

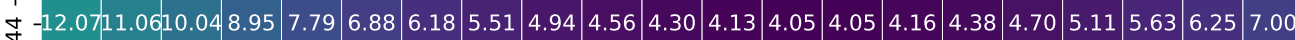

$\stackrel{\llcorner}{\sim}$

-12.5211.5610.649.59 8.56 7.72 $7.086 .47 \quad 5.925 .565 .305 .14 \quad 5.04 \quad 5.045 .155 .345 .64 \quad 6.04 \quad 6.54 \quad 7.167 .95$

$\stackrel{\bullet}{\oplus}$

윽-13.6712.8712.1311.2810.47 9.71 9.21 8.68 $8.22 \quad 7.90 \quad 7.657 .48 \quad 7.40 \quad 7.407 .47 \quad 7.60 \quad 7.84 \quad 8.178 .559 .039 .67$

i

ด.

ஸ

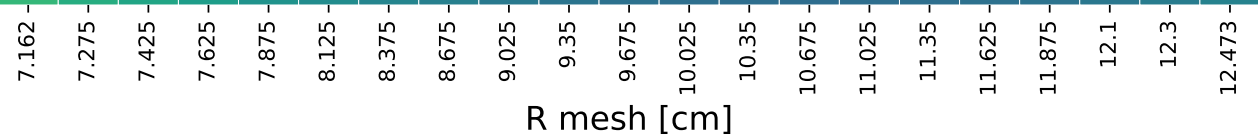

Figure 42. Cumulative fission density distribution for optimized design IFE region on day 15 (see Section 7.1.5). 
은 -24.1722 .7721 .3019 .5017 .6116 .0514 .7613 .5112 .3511 .5210 .9210 .4310 .1610 .0410 .1110 .3910 .8011 .4412 .2313 .2514 .50$

ڤ̆

L -29.8727 .9926 .0123 .6921 .1218 .9117 .0415 .2113 .5812 .4611 .6611 .1010 .8310 .7911 .0111 .4912 .1513 .0114 .0415 .2916 .75$ เก

เก -30.6828 .8927 .0324 .8422 .4120 .3218 .5216 .7515 .1214 .0113 .2112 .6512 .3912 .4012 .6813 .2514 .0114 .9916 .1617 .5319 .16$ $\stackrel{\circ}{\circ}$

ᄂn -31.7229 .9128 .0925 .9123 .5221 .4219 .6217 .8316 .2015 .0614 .2613 .6913 .4413 .4513 .7714 .3915 .2316 .2717 .5118 .9720 .70$

ह 。 -32.3030 .4528 .6326 .4424 .0421 .9020 .0918 .2716 .6315 .4814 .6414 .0813 .8213 .8314 .1514 .7815 .6516 .7318 .0019 .4821 .27$ $\underline{\varepsilon} \stackrel{i}{\sim}$

등 ㅇ․ -32.3230 .5128 .7026 .4824 .0721 .9720 .1518 .3416 .6815 .5314 .7014 .1313 .8513 .8714 .2014 .8515 .7016 .7718 .0519 .5421 .31$ $\stackrel{\mathscr{v}}{\varepsilon}$

$\varepsilon$ o -32.2330 .3928 .5726 .3723 .9921 .8820 .0718 .2616 .6215 .4514 .6514 .0713 .8113 .8314 .1514 .7915 .6516 .7117 .9719 .4621 .24$ $N \stackrel{\circ}{i}$

เก -31.7329 .9328 .0925 .9023 .5221 .4319 .6217 .8316 .1915 .0614 .2413 .6713 .4213 .4213 .7514 .3515 .1916 .2317 .4618 .9320 .66$

เก -30.6528 .8226 .9824 .7822 .3720 .2518 .4616 .6915 .0813 .9713 .1612 .6112 .3512 .3412 .6213 .1813 .9314 .9016 .0517 .4119 .02$ 운

in -28.2726 .4924 .6322 .4820 .1218 .1016 .3714 .7013 .2012 .1811 .4410 .9310 .6910 .6610 .8811 .3512 .0112 .8613 .8915 .1116 .56$ เก

เn $-24.0722 .4220 .7218 .7316 .6114 .8313 .3411 .9110 .649 .78 \quad 9.18 \quad 8.76 \quad 8.568 .538 .729 .129 .66 \quad 10.3911 .2612 .3113 .58$

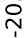

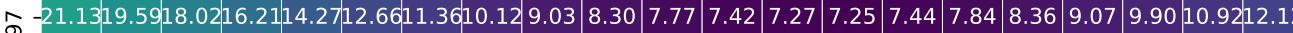

$\stackrel{4}{8}$

$\stackrel{\text { นก }}{1}$

\&

$\stackrel{\bullet}{\oplus}$

극 -23.2522.1321.0919.8218.5917.4716.6615.7915.0114.4714.0413.7213.5813.5313.6413.8914.2914.8115.4016.1517.14

ヘิ

ด.

ஸ

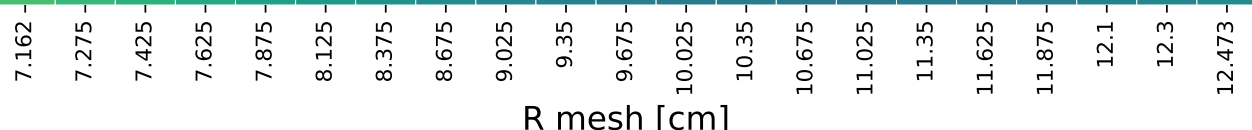

Figure 43. Cumulative fission density distribution for optimized design IFE region on day 27 (see Section 7.1.5). 


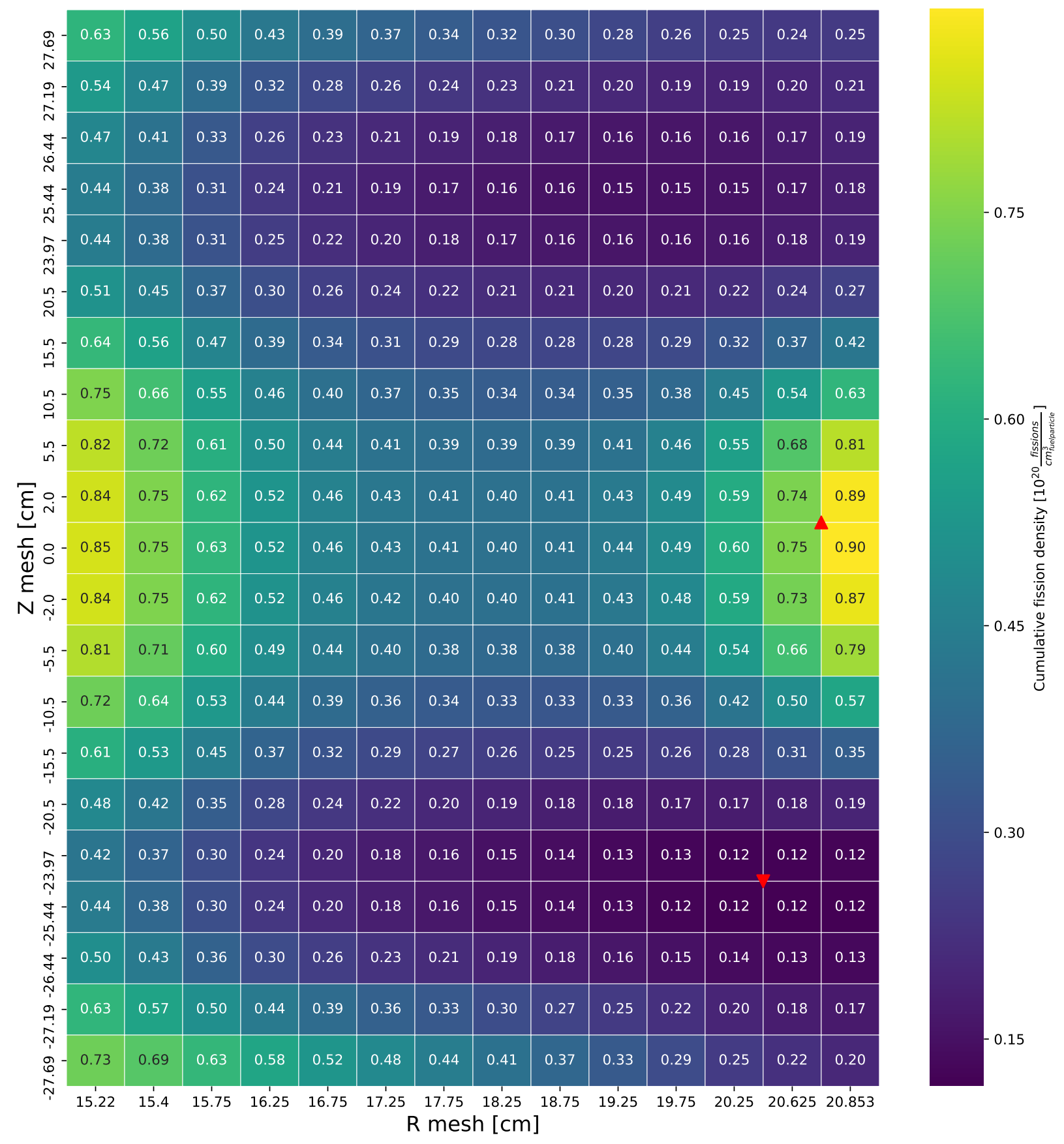

Figure 44. Cumulative fission density distribution for optimized design OFE region on day 1 (see Section 7.1.5). 


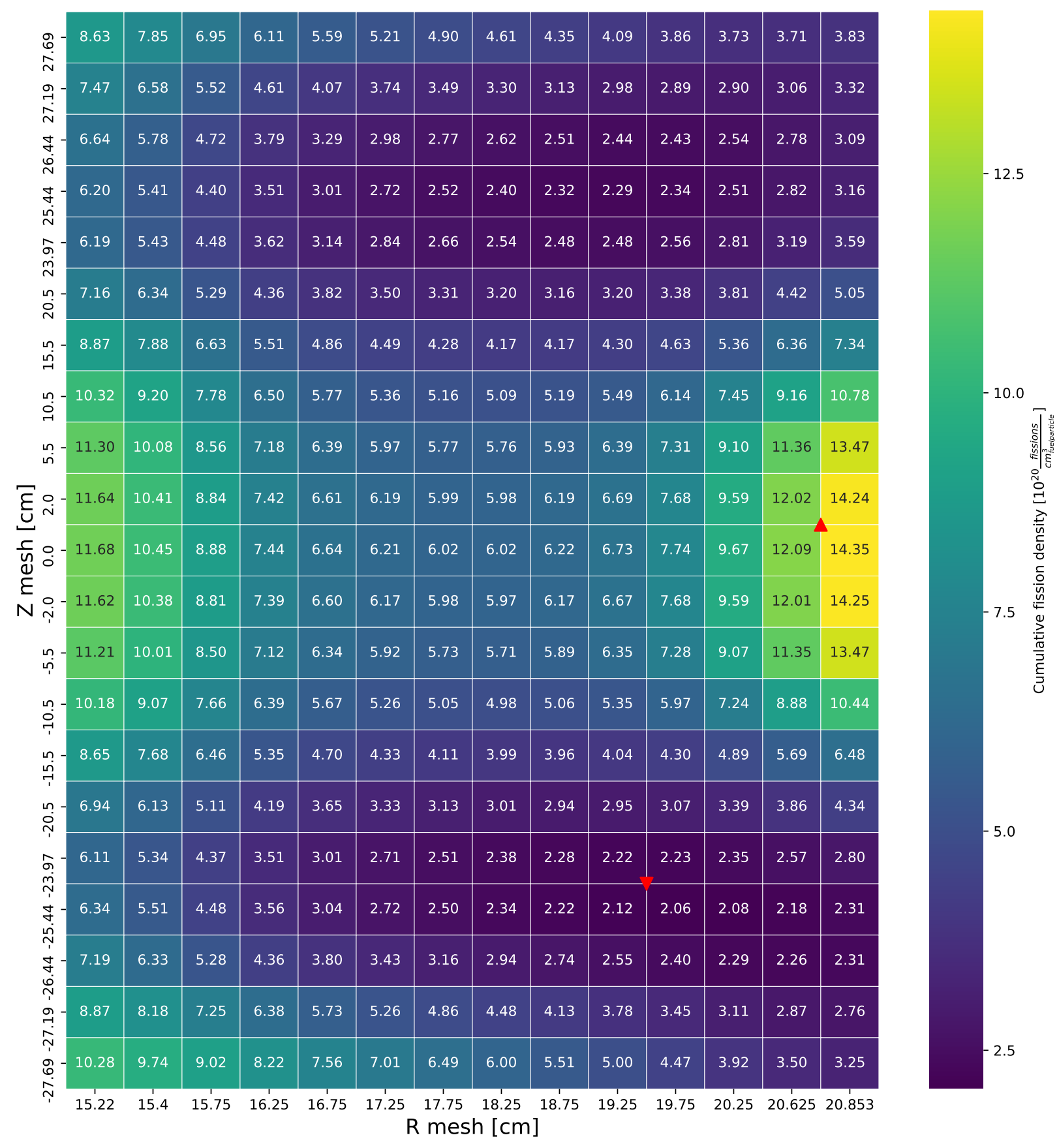

Figure 45. Cumulative fission density distribution for optimized design OFE region on day 15 (see Section 7.1.5). 


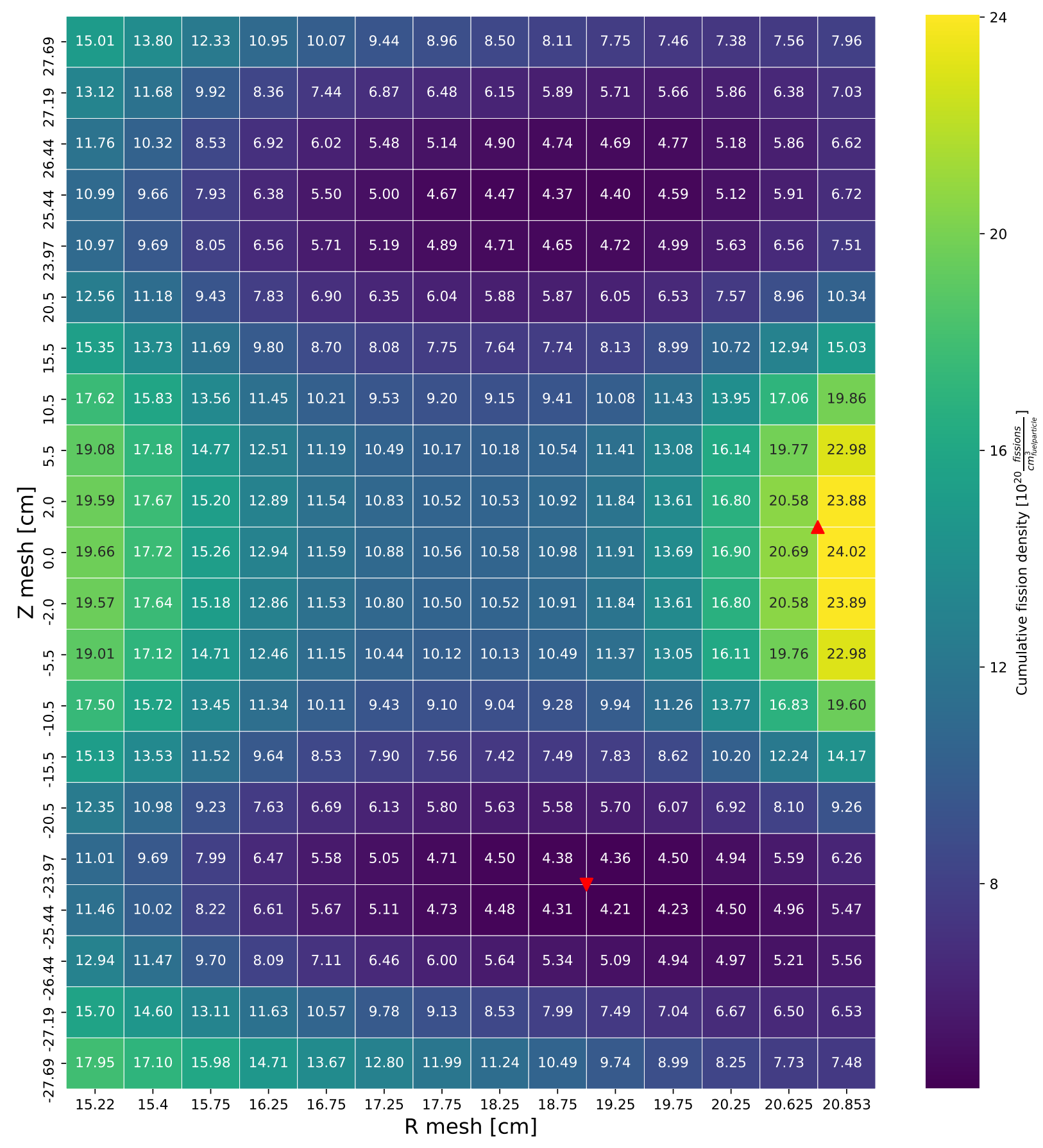

Figure 46. Cumulative fission density distribution for optimized design OFE region on day 27 (see Section 7.1.5). 


\section{APPENDIX A-3. POWER DENSITY DISTRIBUTIONS FOR OPTIMIZED DESIGN}

ดู

ก

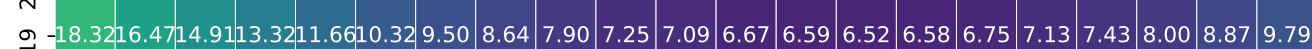$$
\text { a }
$$

$\stackrel{\dot{0}}{\mathrm{~N}}$

\&

กิ่

ติ

N

นกำ

นก -23.2720.9918.8116.3713.9412.2310.879.66 $8.617 .94 \quad 7.45 \quad 7.18 \quad 7.01 \quad 7.02 \quad 7.197 .48 \quad 7.92 \quad 8.50 \quad 9.2510 .2311 .33$ กั

เก -24.0721.7519.5817.2815.0613.2511.9010.719.64 $9.008 .558 .258 .148 .138 .298 .72 \quad 9.27 \quad 9.9810 .8811 .9513 .23$ 우

นกำ -25.0922 .6620 .4718 .1515 .8014 .0712 .7411 .5610 .469 .749 .228 .908 .808 .829 .079 .5010 .0610 .8411 .7812 .9114 .39$

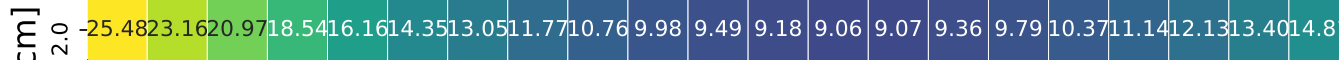
U

등 우 -25.5023 .0720 .8518 .5216 .1414 .3513 .0511 .8310 .7410 .049 .519 .159 .049 .069 .349 .8410 .4311 .1912 .1713 .3314 .77$ $\stackrel{\frac{\mathscr{U}}{\varepsilon}}{\varepsilon}$

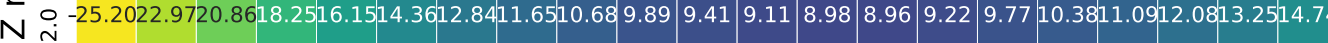

Ln $-24.5722 .3020 .1017 .8015 .5713 .9012 .5611 .2810 .239 .57 \quad 9.108 .78 \quad 8.628 .678 .899 .319 .87 \quad 10.6011 .5612 .7314 .10$ เก

ᄂ $-23.2521 .0618 .9916 .7414 .5312 .9011 .6510 .489 .478 .78 \quad 8.327 .98 \quad 7.85 \quad 7.848 .008 .418 .879 .5710 .4311 .4712 .69$

$\stackrel{ }{\rightarrow}$

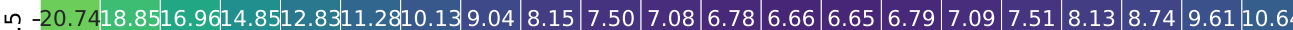

เก

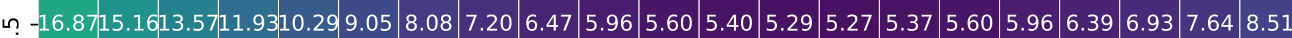

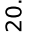

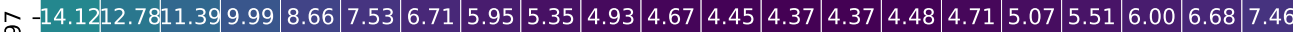

m

8

ஸे

\&

$\stackrel{\circ}{\circ}$

-15.4714.5013.3412.3711.3310.68 9.74 9.23 8.69 8.38 8.09 $7.978 .00 \quad 7.927 .98$ 8.04 8.31 8.71 9.25 9.75 10.69

ก

ตุ

กั

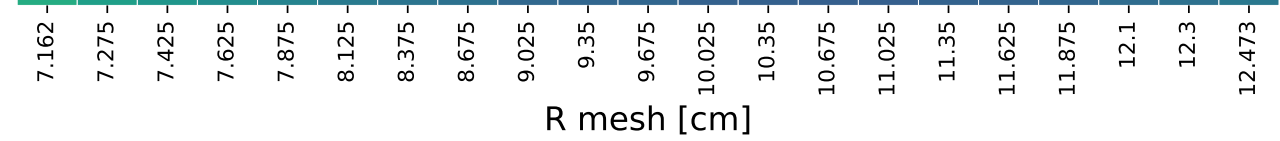

Figure 47. Power density distribution for optimized design IFE region on day 0 (see Section 7.1.3). 
$\stackrel{8}{i}$

ก

ᄀ?

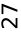

䒹

$\stackrel{\leftrightarrow}{i}$

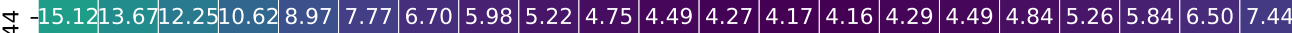

กั่

คิ

$\stackrel{\sim}{\sim}$

เก

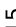

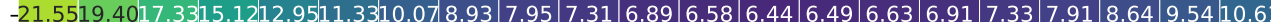

เก -22.2920.2718.2616.1613.9912.3711.169.97 $8.98 \quad 8.327 .897 .617 .50 \quad 7.53 \quad 7.70 \quad 8.118 .60 \quad 9.2510 .1111 .1612 .48$ 官

เn - -23.3021 .2219 .2817 .1214 .9113 .2011 .9210 .749 .739 .068 .638 .338 .208 .218 .498 .919 .5310 .2211 .2212 .3513 .79$

Е 우 $-23.9121 .7919 .7817 .4915 .1913 .4912 .2311 .0210 .039 .308 .838 .608 .448 .48 \quad 8.719 .179 .7910 .6011 .6312 .7814 .24$ $\underline{\mathrm{E}} \mathrm{i}$

등 ㅇ․ $-23.9621 .9519 .8617 .5315 .3413 .6612 .2511 .1010 .069 .428 .95 \quad 8.58 \quad 8.48 \quad 8.498 .78 \quad 9.22 \quad 9.77 \quad 10.5611 .5612 .7814 .30$ $\stackrel{\mathscr{v}}{\varepsilon}$ No. -23.7621 .6919 .4917 .4215 .2313 .5412 .1611 .009 .979 .298 .848 .578 .468 .478 .679 .149 .7510 .5211 .5012 .7014 .10$

in -23.2421 .1519 .0816 .9214 .8413 .1811 .8910 .719 .719 .038 .578 .248 .148 .198 .398 .819 .4410 .1711 .1012 .2513 .62$

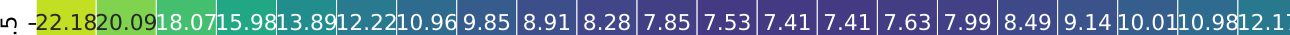
욱

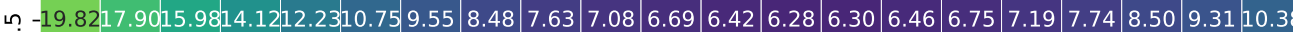
เั่

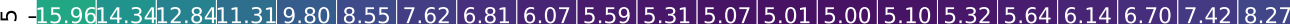

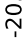

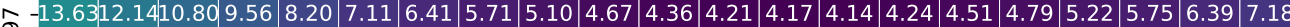

\&

$\stackrel{\text { กั่ }}{1}$

\&

\%

국.

N

ด

^

\begin{tabular}{|c|c|c|c|c|c|c|c|c|c|c|c|c|c|c|c|c|c|c|c|}
\hline 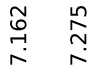 & $\stackrel{\stackrel{n}{\sim}}{\stackrel{5}{r}}$ & 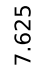 & $\begin{array}{l}\frac{n}{\infty} \\
\substack{n \\
r}\end{array}$ & $\begin{array}{l}\stackrel{\text { N }}{\underset{+}{\infty}} \\
\infty\end{array}$ & 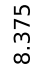 & $\begin{array}{l}\frac{n}{\widehat{0}} \\
\infty \\
\infty\end{array}$ & $\begin{array}{l}\stackrel{\text { N }}{0} \\
\text { å }\end{array}$ & $\stackrel{\stackrel{n}{m}}{\sigma}$ & $\begin{array}{l}\frac{n}{6} \\
6 \\
\sigma\end{array}$ & 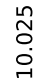 & $\begin{array}{l}\stackrel{\operatorname{m}}{m} \\
\stackrel{0}{+}\end{array}$ & $\begin{array}{l}\frac{n}{6} \\
6 \\
0 \\
-1\end{array}$ & $\begin{array}{l}\stackrel{\text { N }}{0} \\
\stackrel{-}{-}\end{array}$ & $\stackrel{\stackrel{n}{m}}{\stackrel{\sim}{r}}$ & $\begin{array}{l}\stackrel{\sim}{0} \\
\underset{-}{-1} \\
-1\end{array}$ & 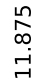 & $\underset{\sim}{\stackrel{-1}{\sim}}$ & $\underset{\sim}{\stackrel{M}{\sim}}$ & $\underset{\substack{m \\
\sim}}{\stackrel{m}{\sim}}$ \\
\hline
\end{tabular}

Figure 48. Power density distribution for optimized design IFE region on day 1 (see Section 7.1.3). 


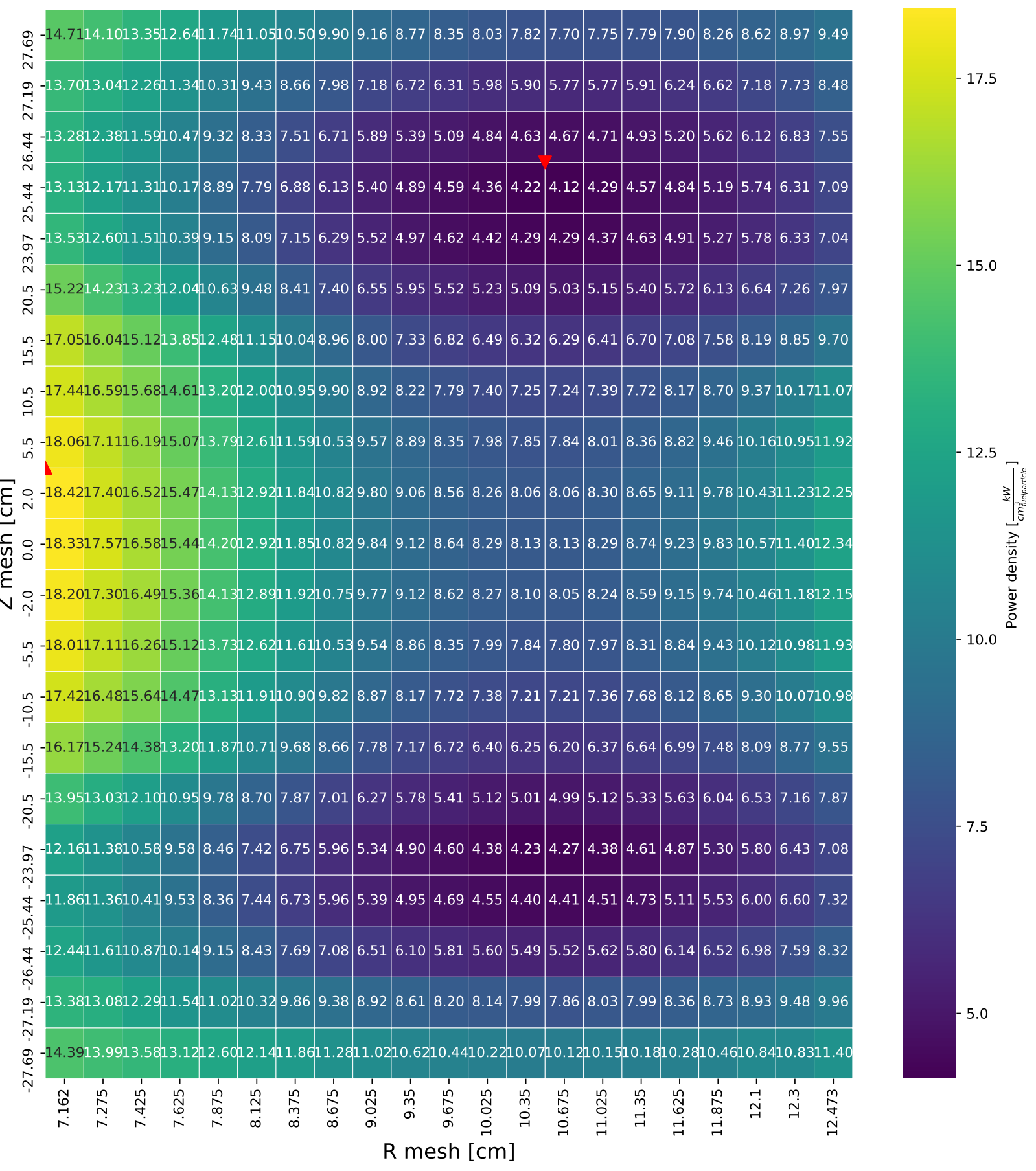

Figure 49. Power density distribution for optimized design IFE region on day 15 (see Section 7.1.3). 


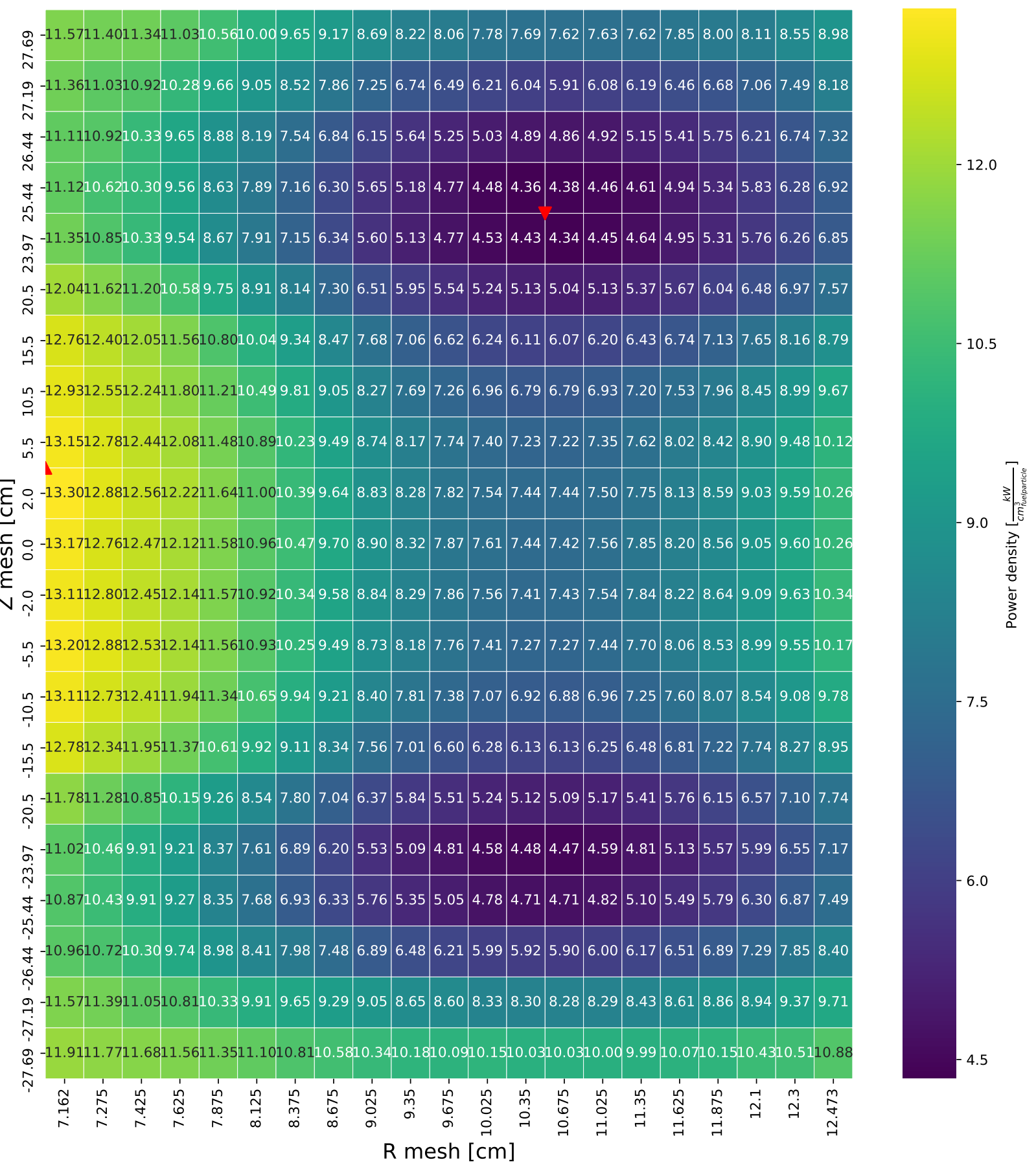

Figure 50. Power density distribution for optimized design IFE region on day 27 (see Section 7.1.3). 


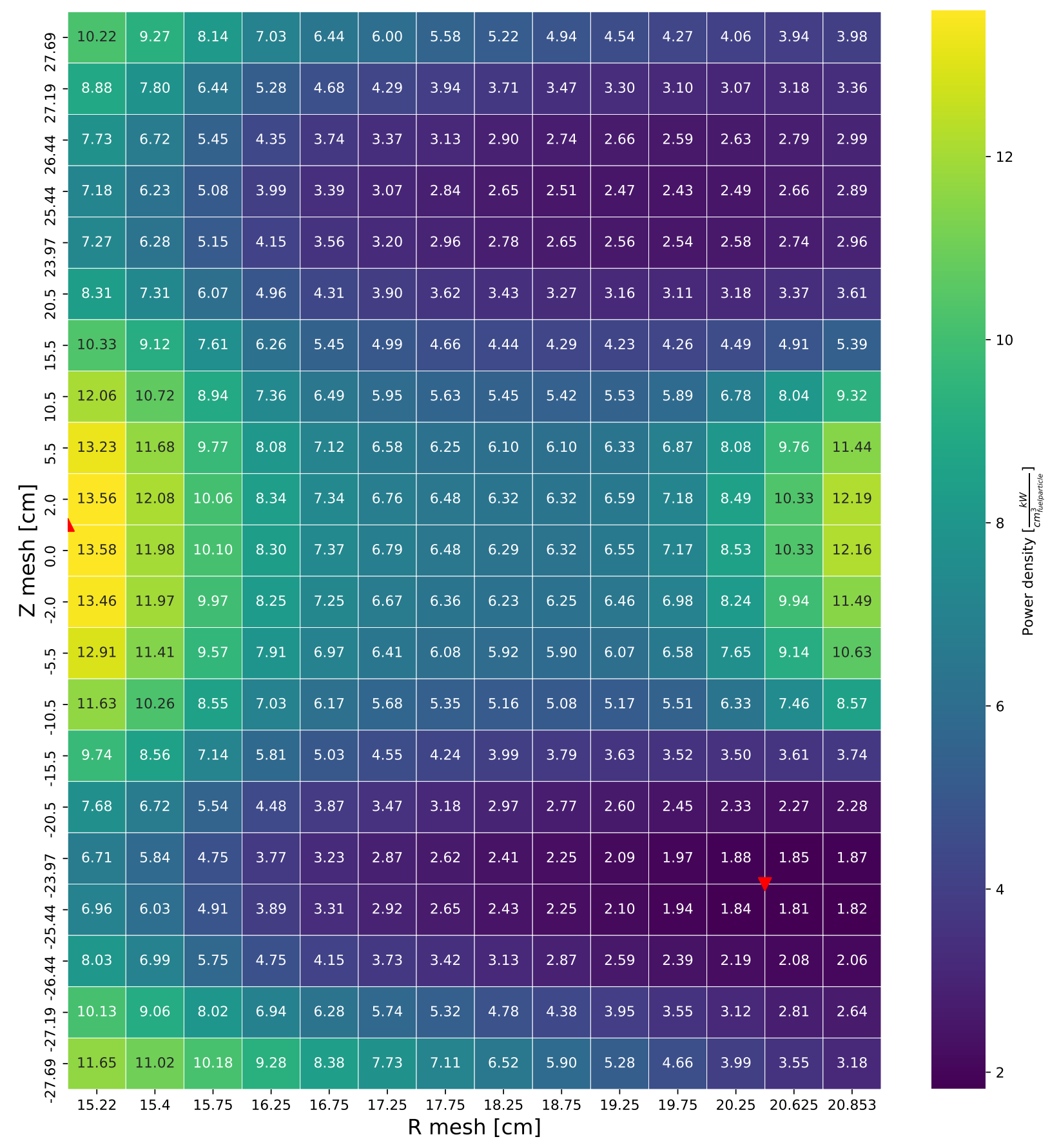

Figure 51. Power density distribution for optimized design OFE region on day 0 (see Section 7.1.3). 


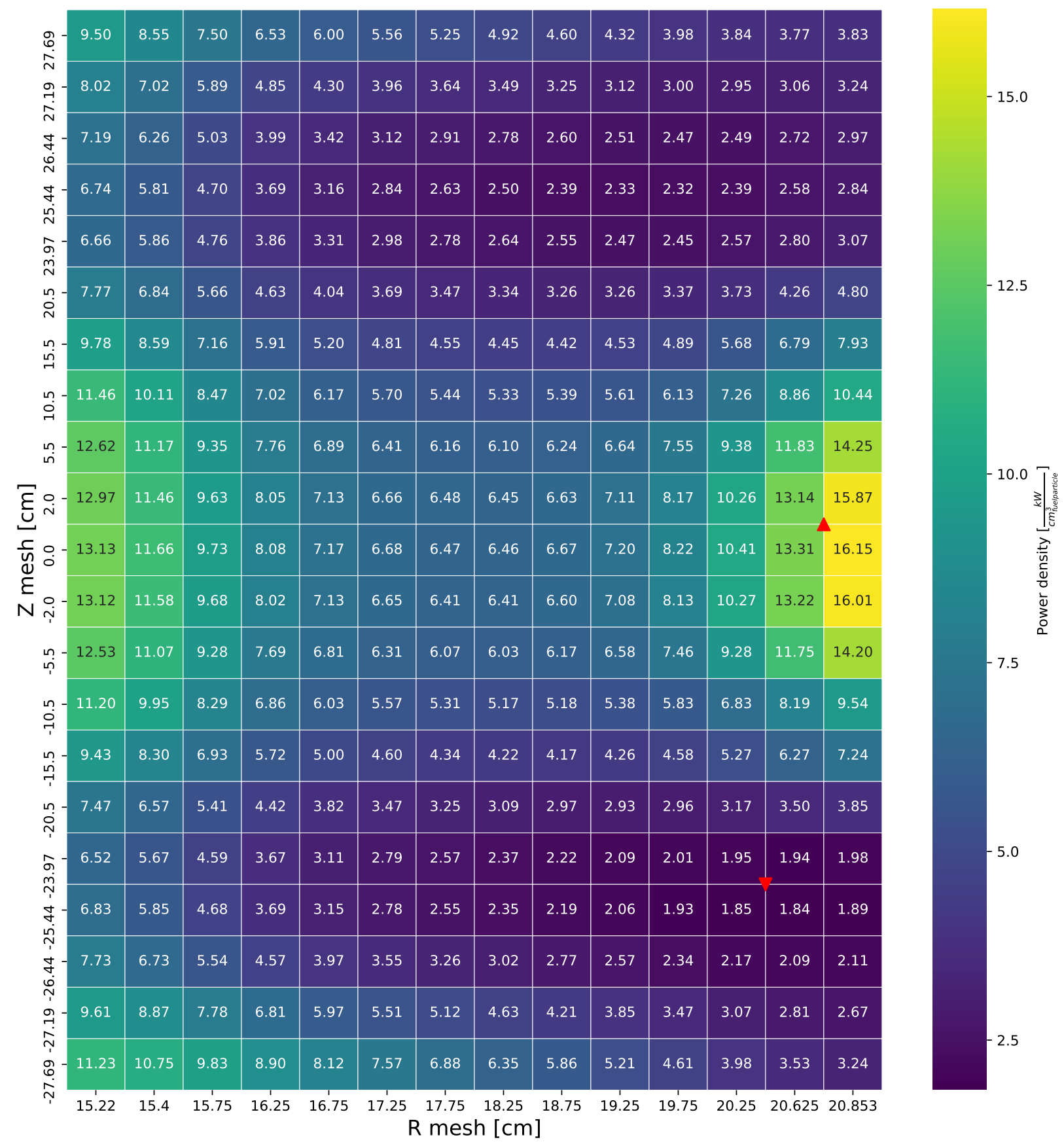

Figure 52. Power density distribution for optimized design OFE region on day 1 (see Section 7.1.3). 


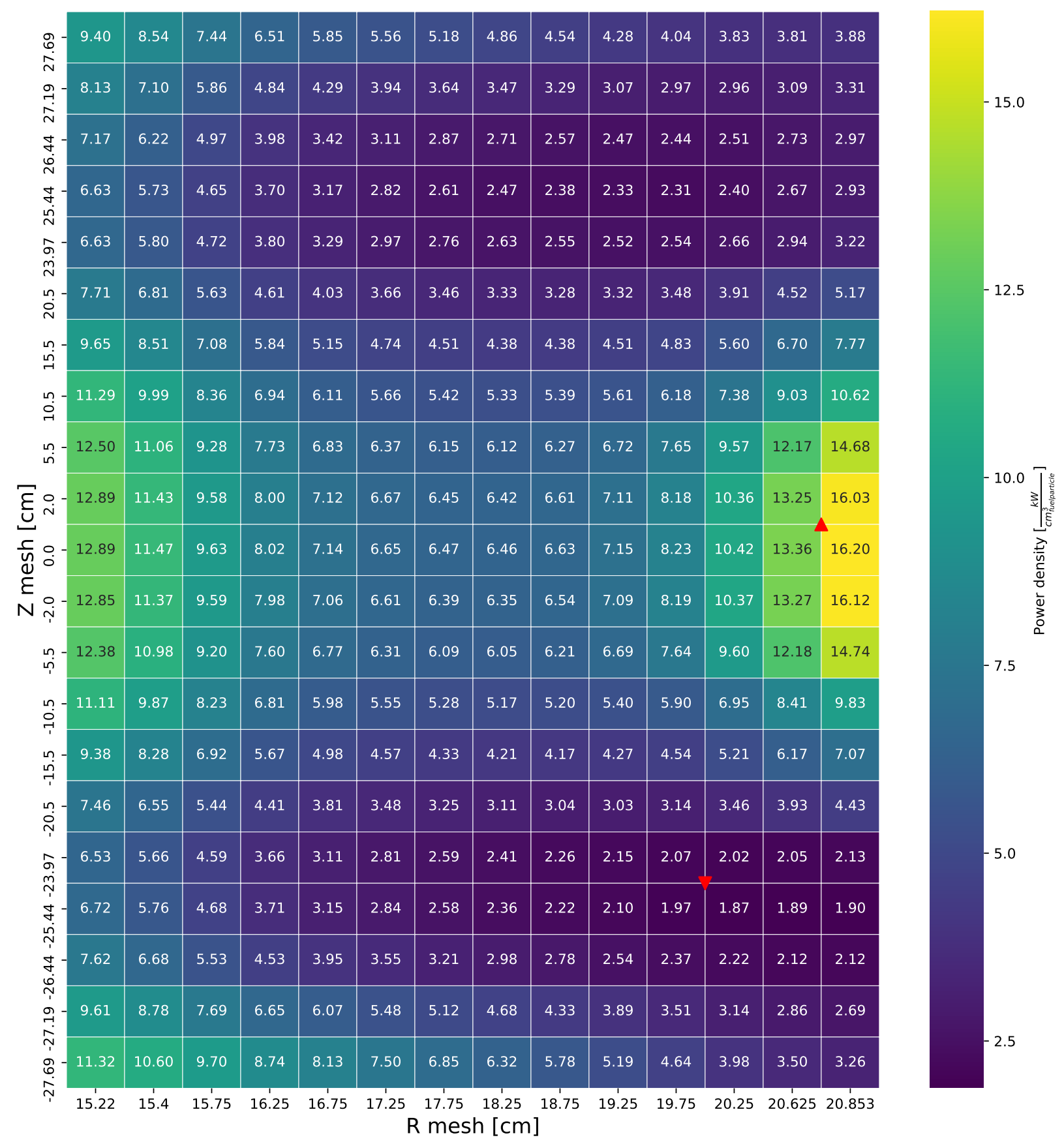

Figure 53. Power density distribution for optimized design OFE region on day 2 (see Section 7.1.3). 


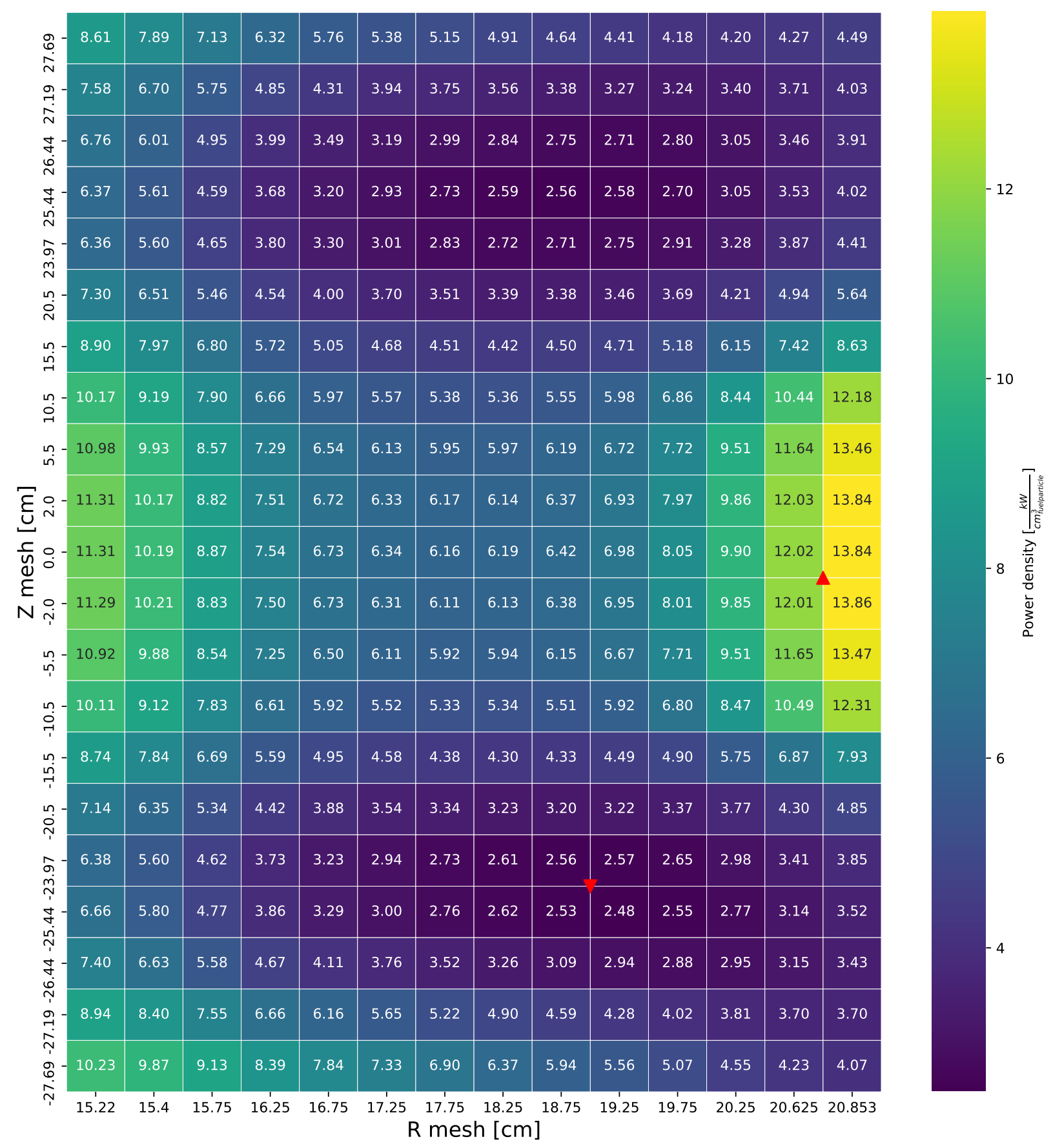

Figure 54. Power density distribution for optimized design OFE region on day 15 (see Section 7.1.3). 


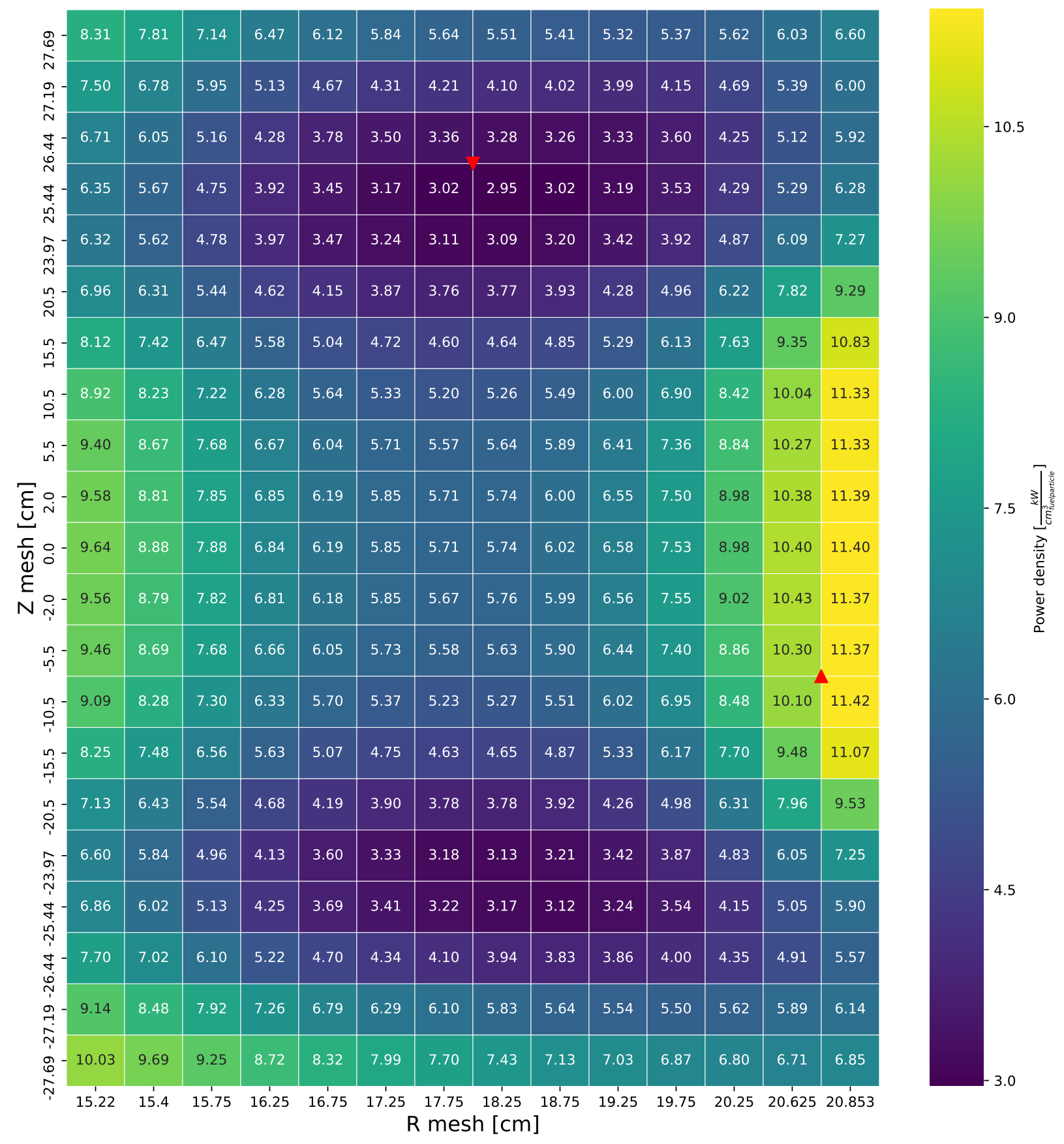

Figure 55. Power density distribution for optimized design OFE region on day 27 (see Section 7.1.3). 


\section{APPENDIX A-4. HEAT FLUX DISTRIBUTIONS FOR OPTIMIZED DESIGN}

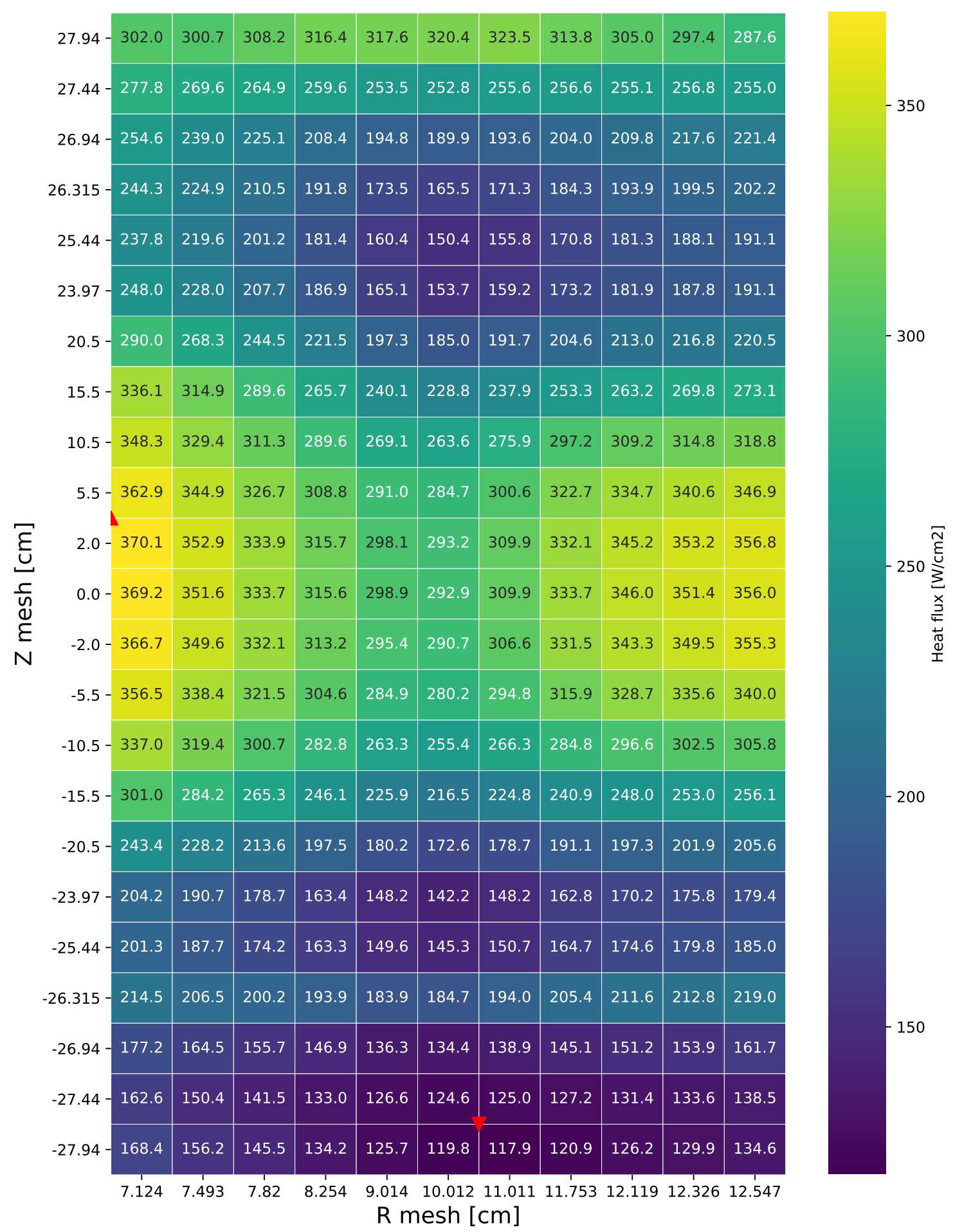

Figure 56. Heat flux distribution for optimized design IFE region on day 0 (see Section 7.1.4). 


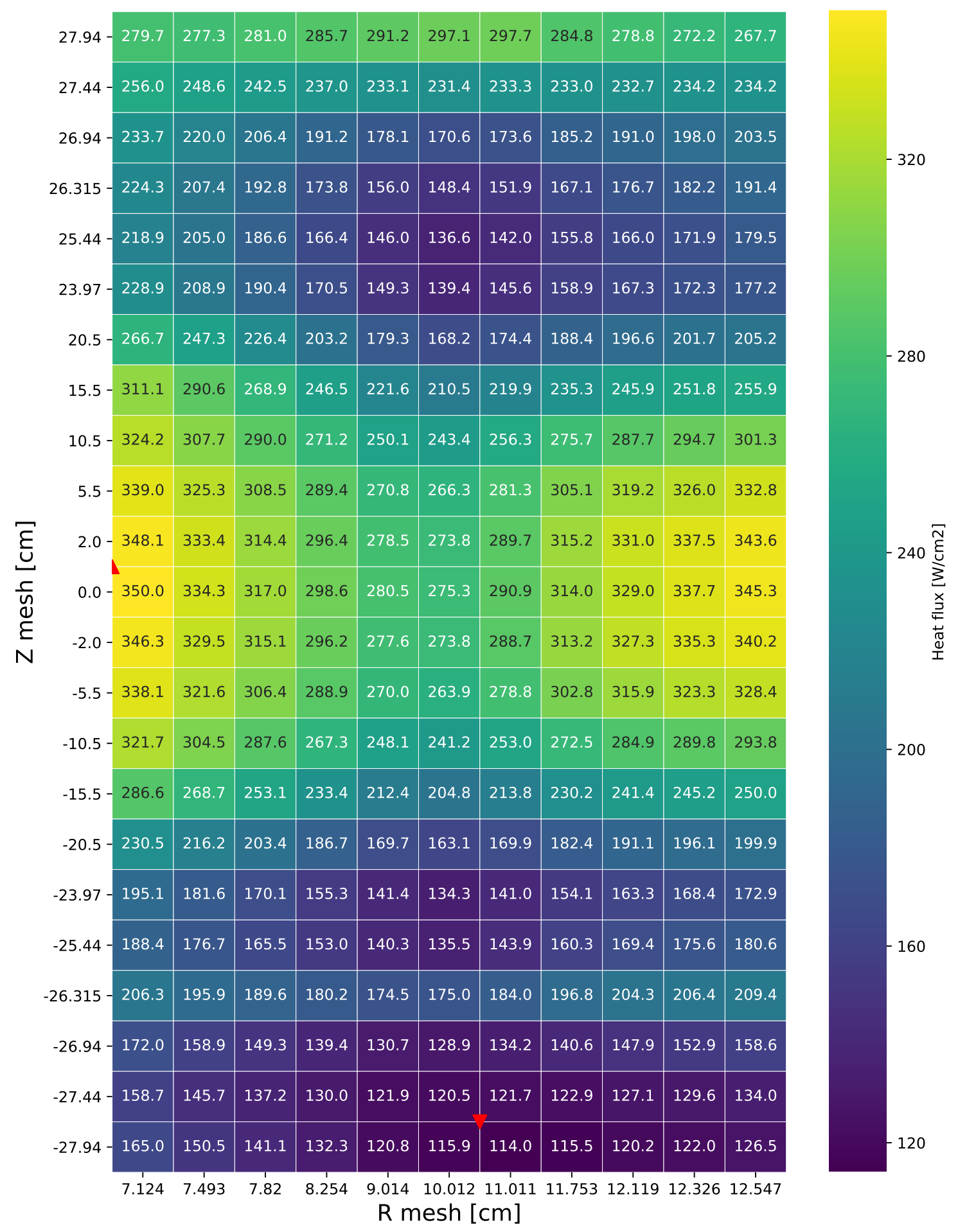

Figure 57. Heat flux distribution for optimized design IFE region on day 1 (see Section 7.1.4). 


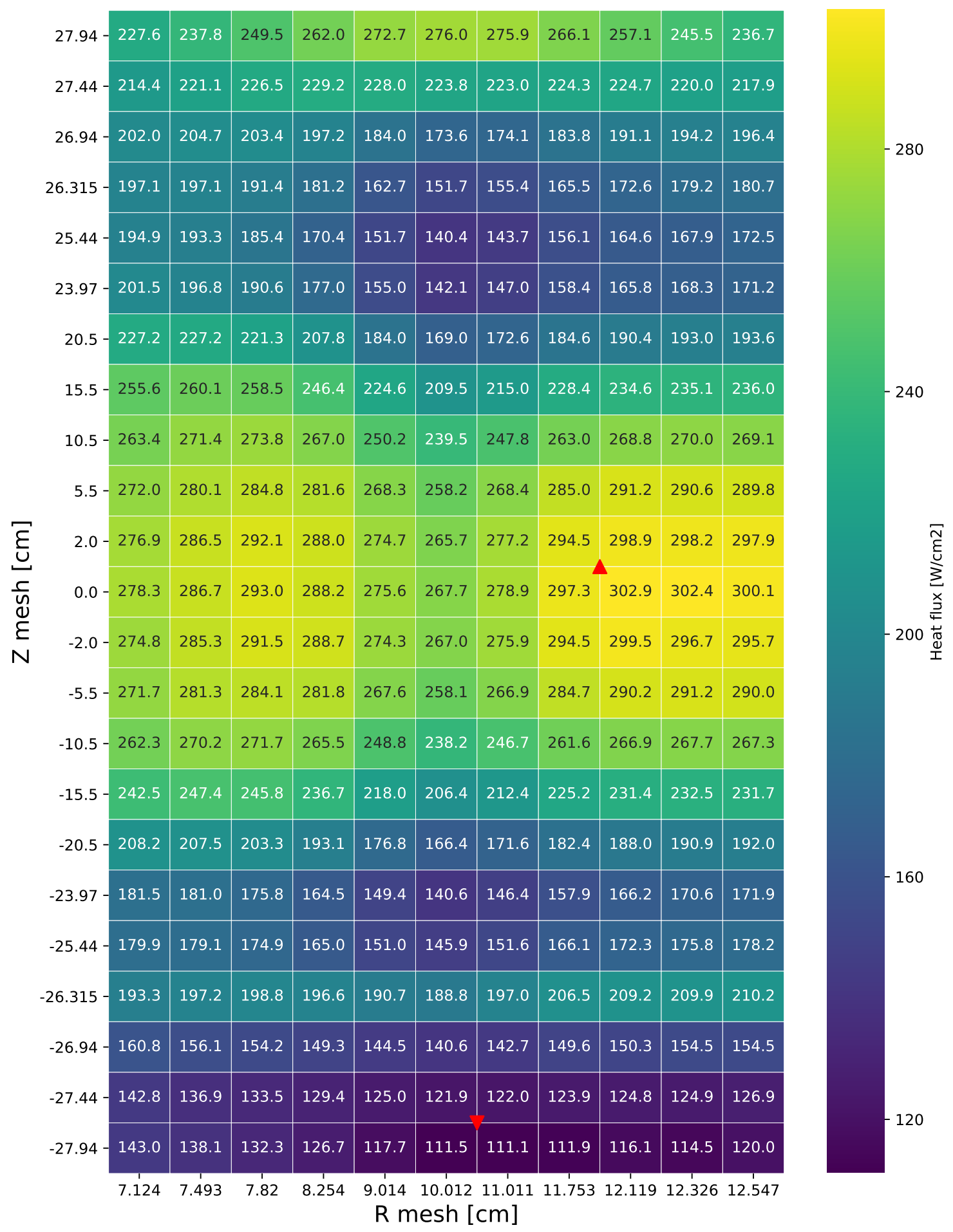

Figure 58. Heat flux distribution for optimized design IFE region on day 15 (see Section 7.1.4). 


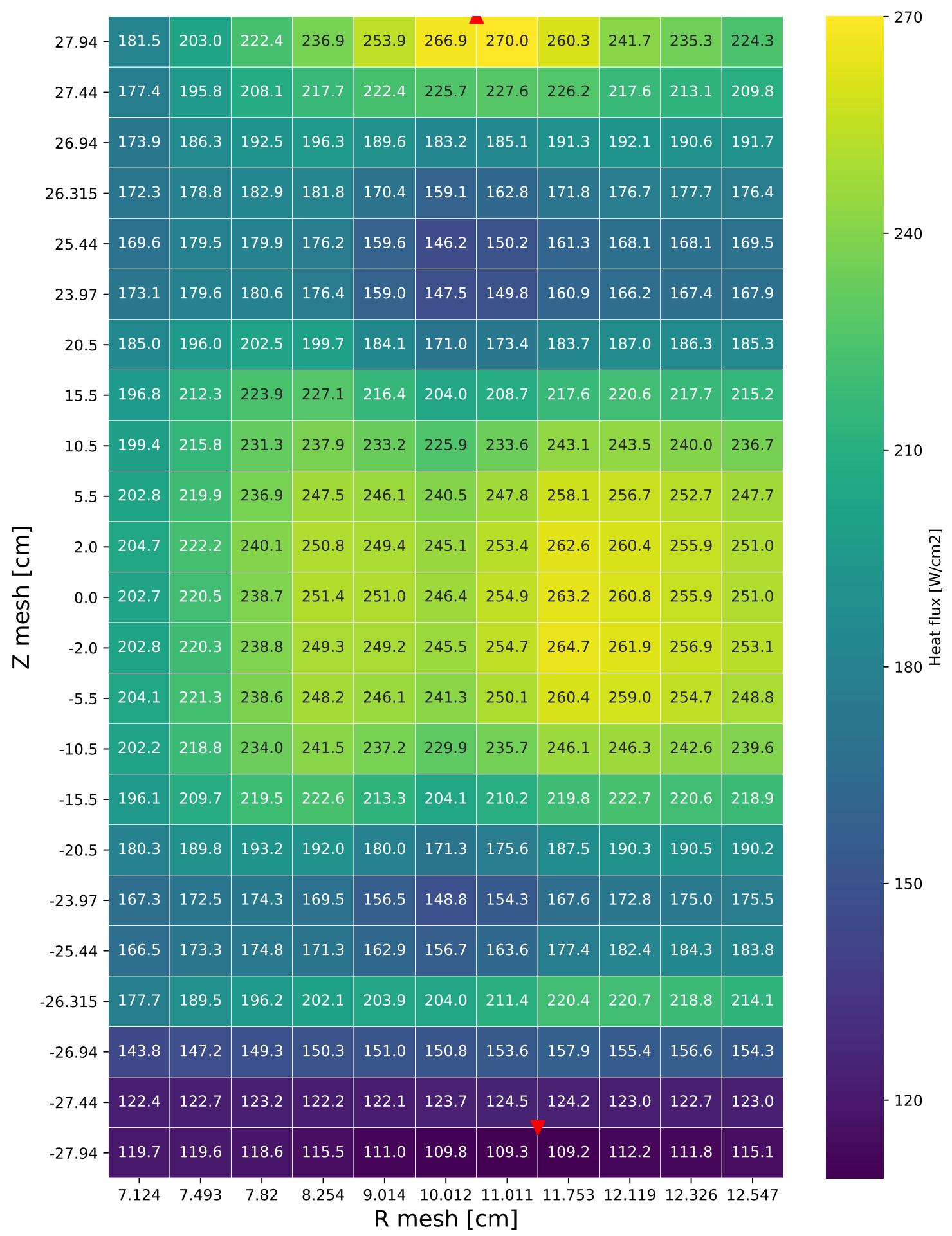

Figure 59. Heat flux distribution for optimized design IFE region on day 27 (see Section 7.1.4). 


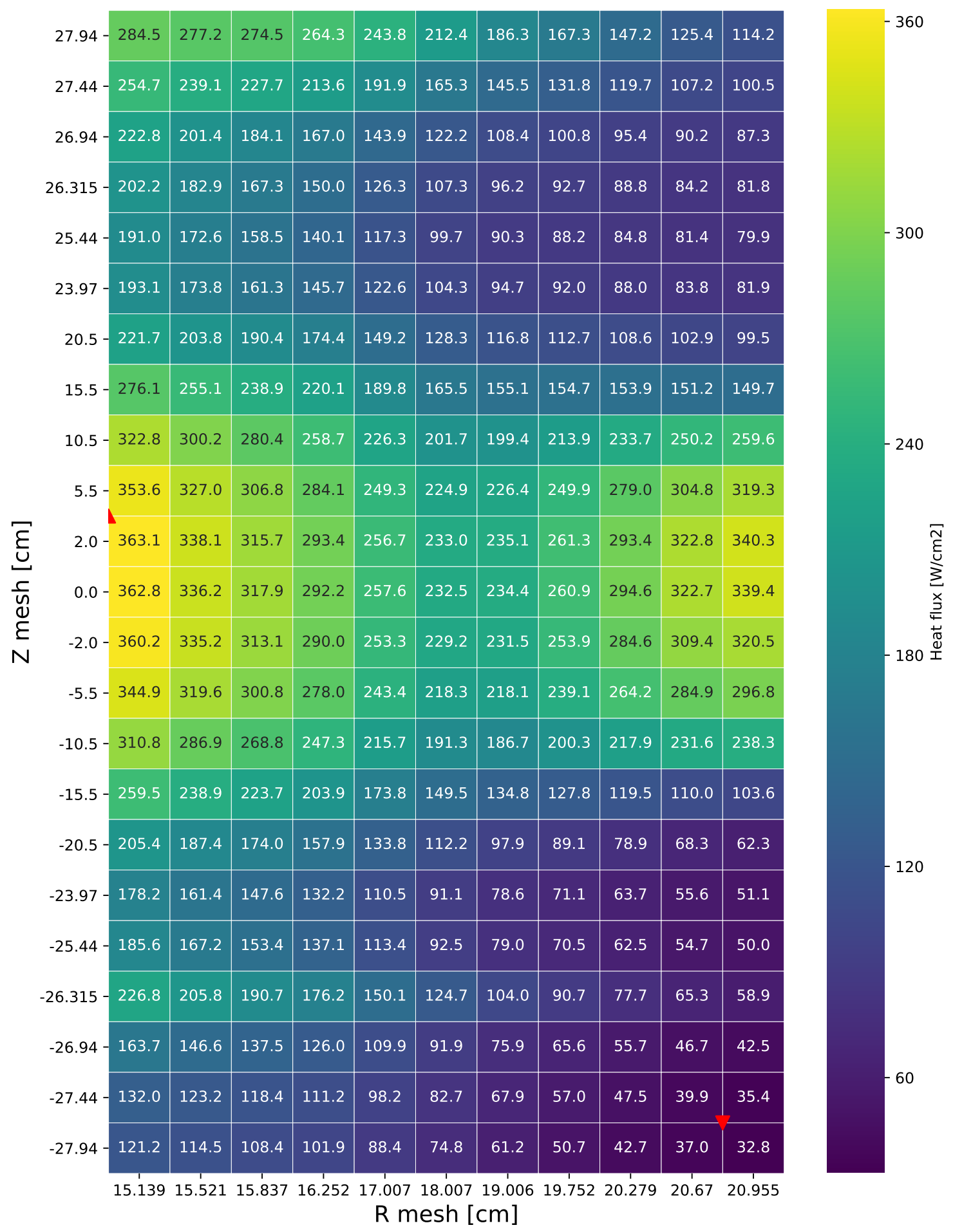

Figure 60. Heat flux distribution for optimized design OFE region on day 0 (see Section 7.1.4). 


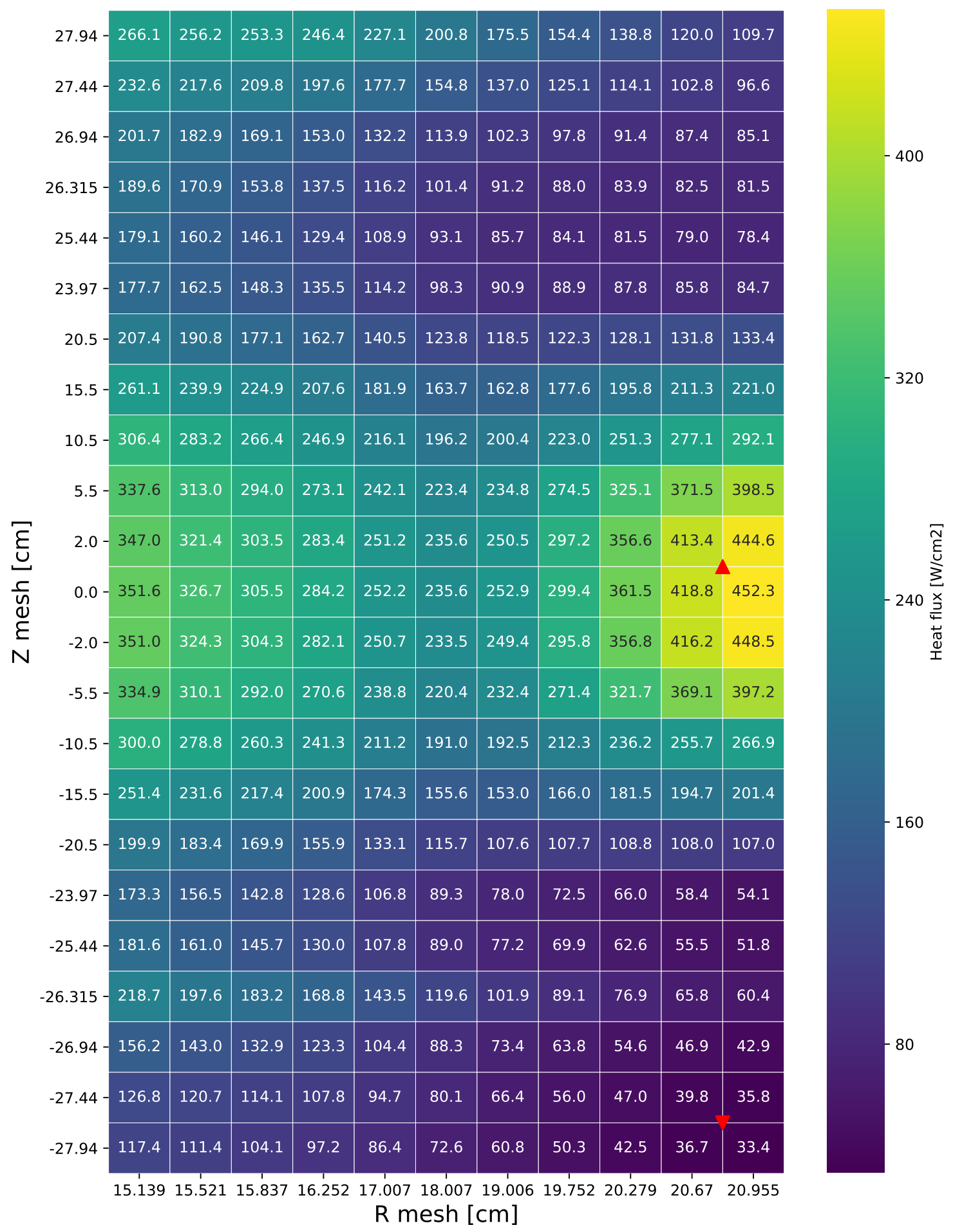

Figure 61. Heat flux distribution for optimized design OFE region on day 1 (see Section 7.1.4). 


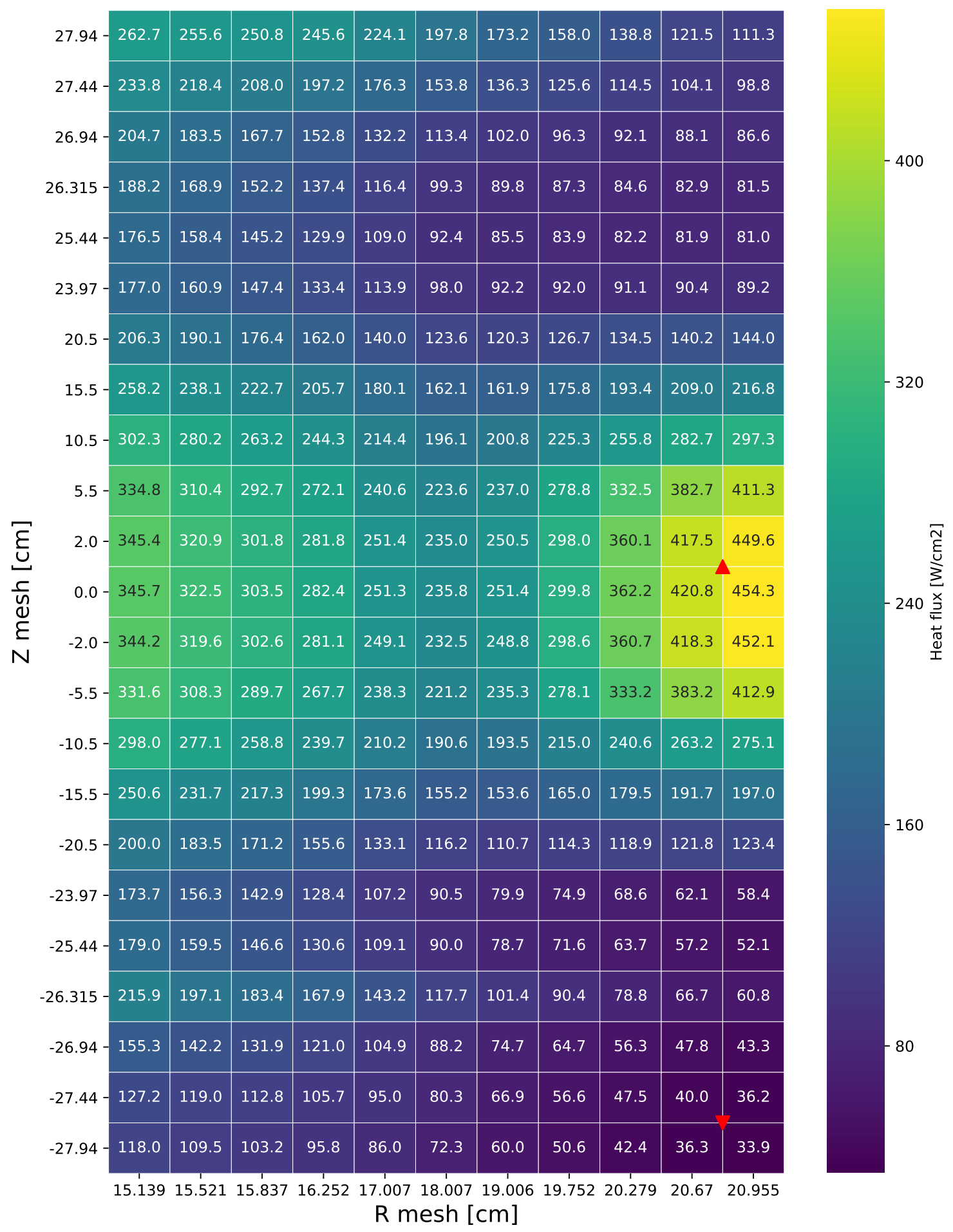

Figure 62. Heat flux distribution for optimized design OFE region on day 2 (see Section 7.1.4). 


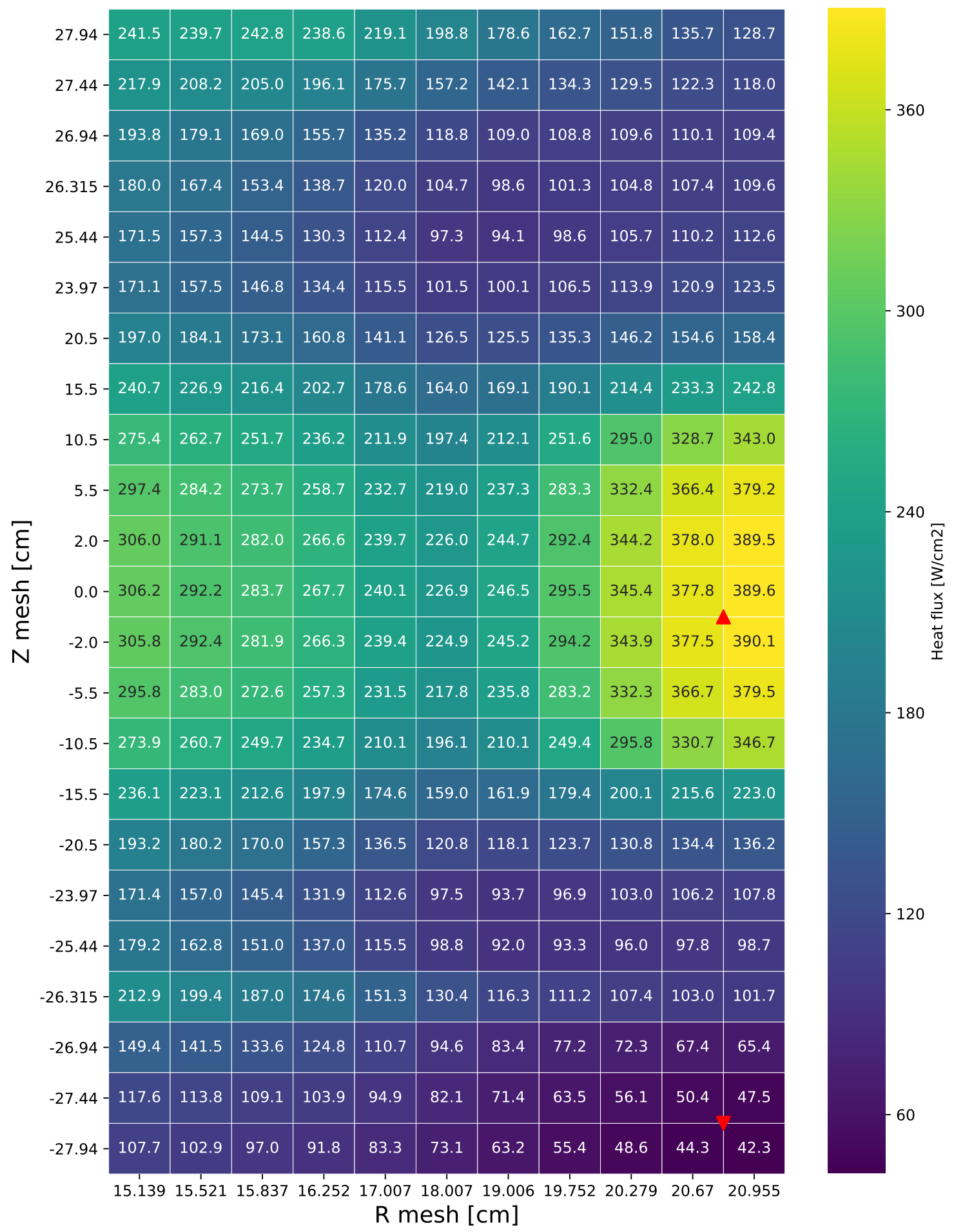

Figure 63. Heat flux distribution for optimized design OFE region on day 15 (see Section 7.1.4). 


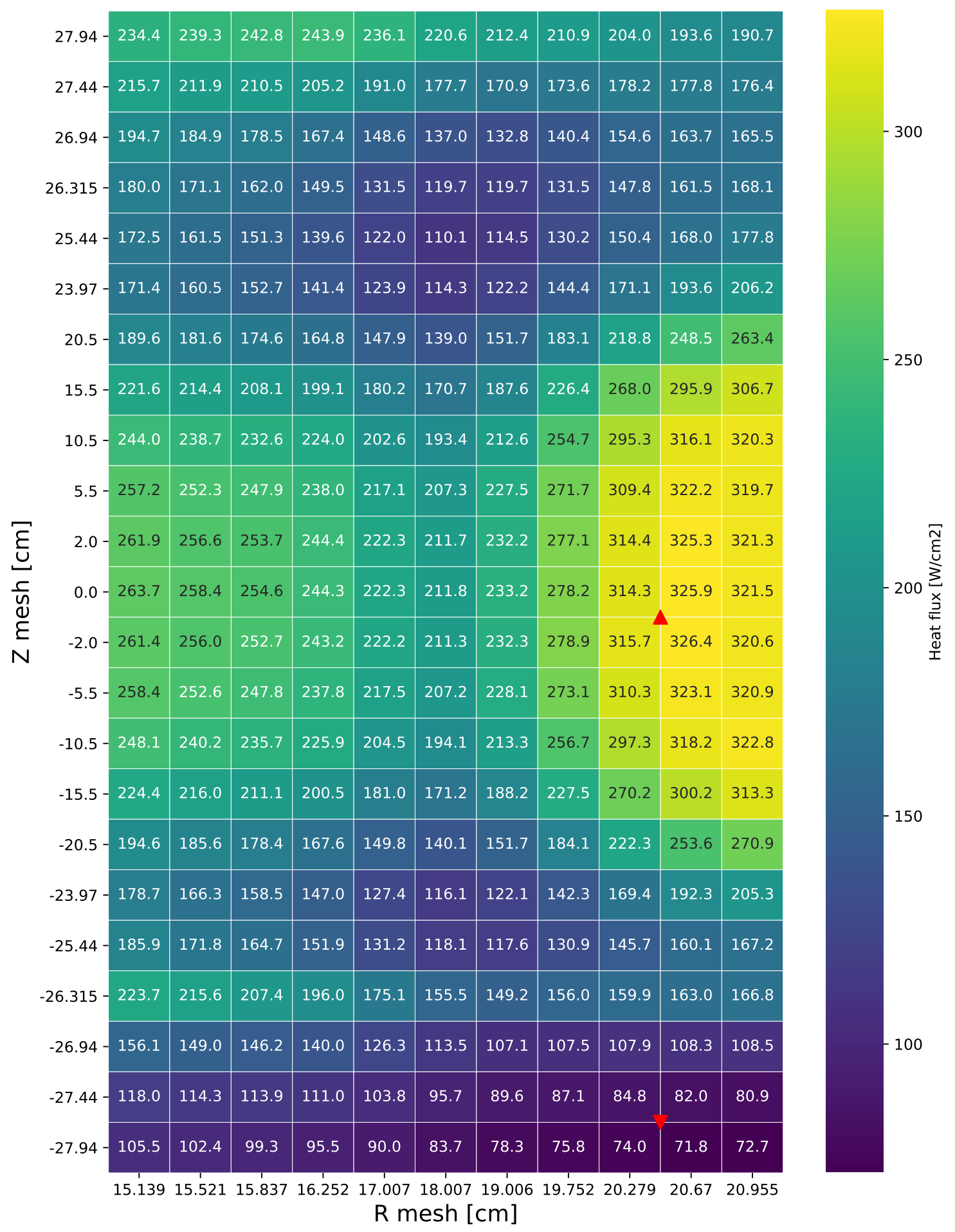

Figure 64. Heat flux distribution for optimized design OFE region on day 27 (see Section 7.1.4). 


\section{APPENDIX B. DISTRIBUTIONS FOR ALTERNATE 1 DESIGN}

\section{APPENDIX B-1. FISSION RATE DENSITY DISTRIBUTIONS FOR ALTERNATE 1 DESIGN}
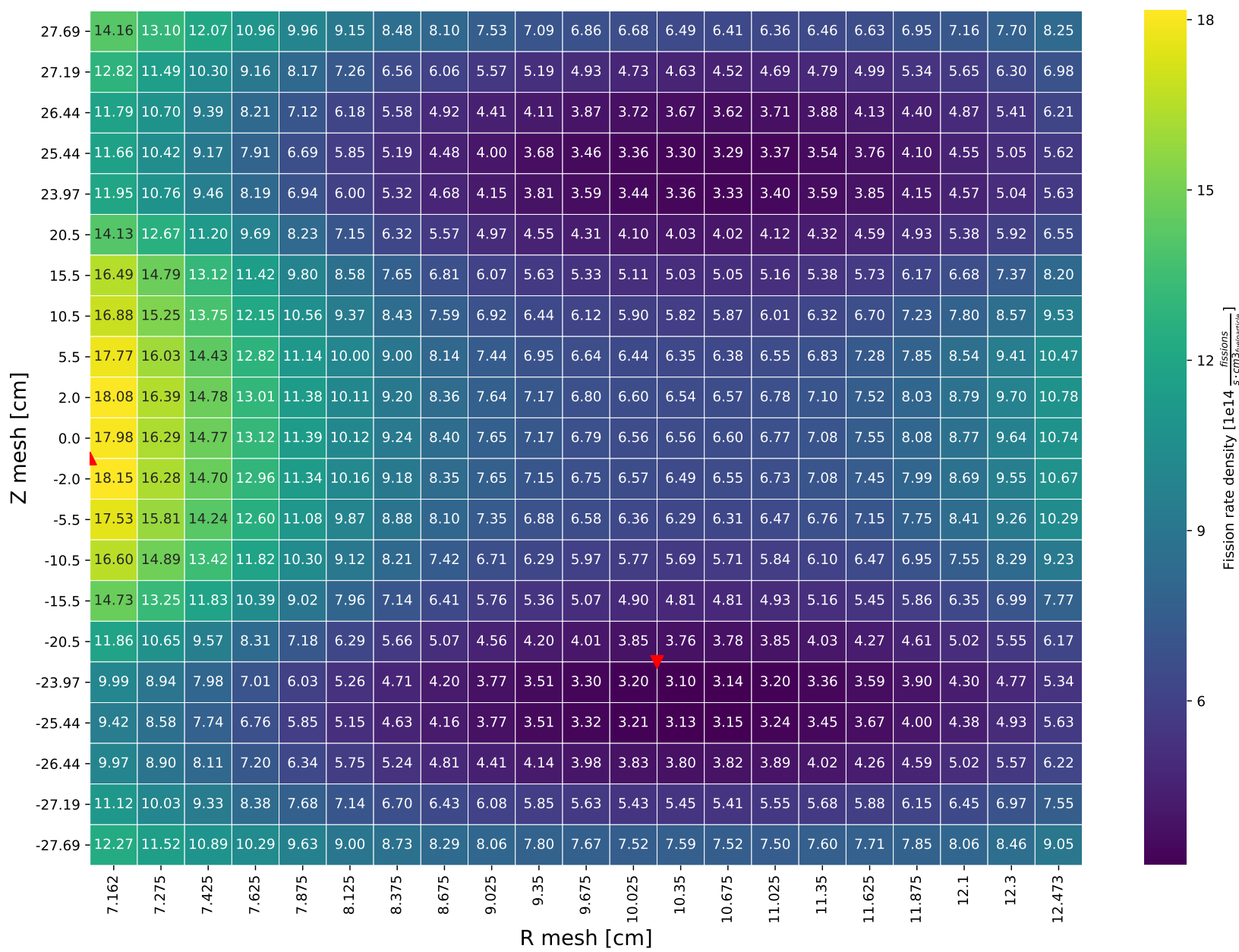

Figure 65. Fission rate density distribution for alternate 1 design IFE region on day 0 (see Section 7.2.2). 


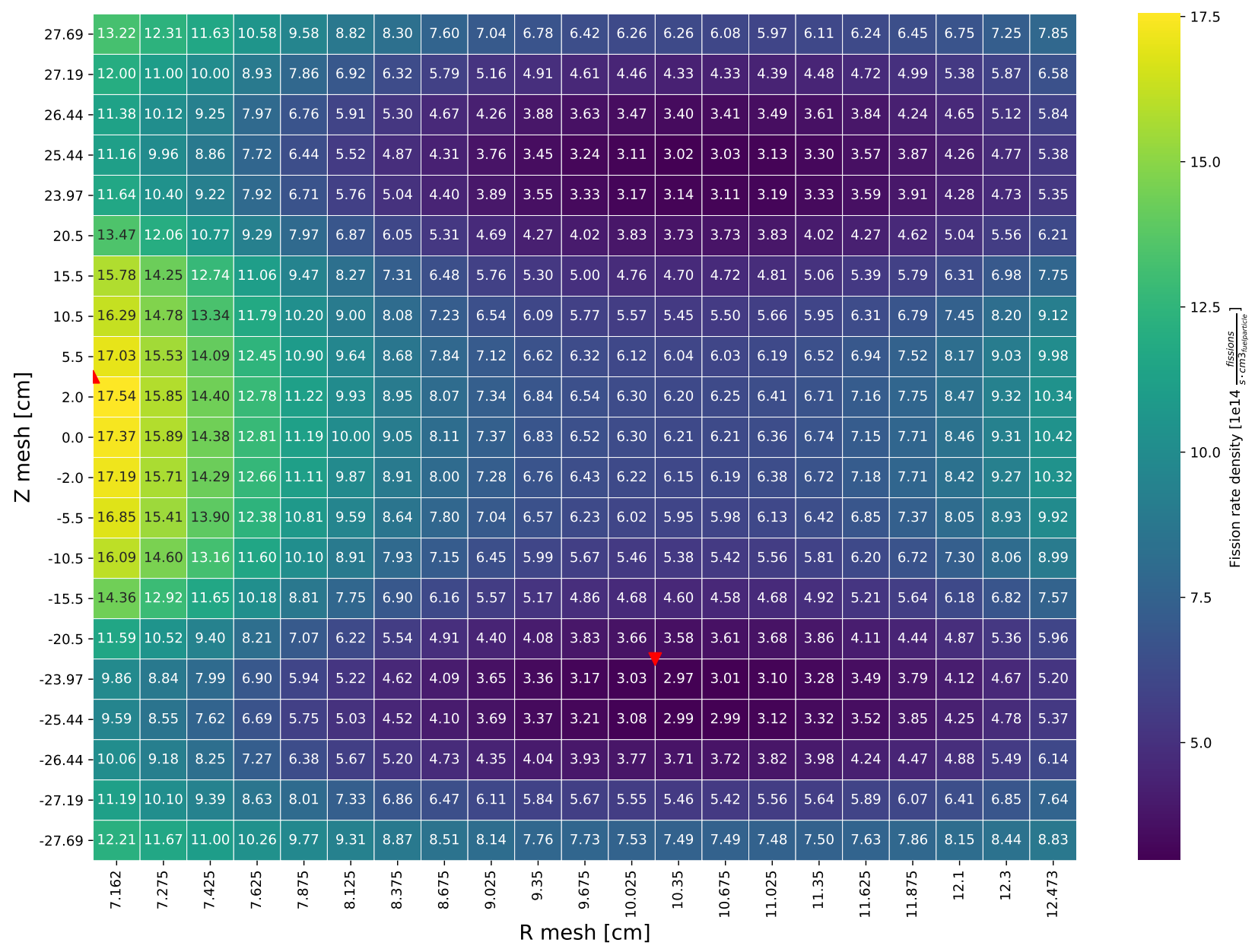

Figure 66. Fission rate density distribution for alternate 1 design IFE region on day 1 (see Section 7.2.2). 


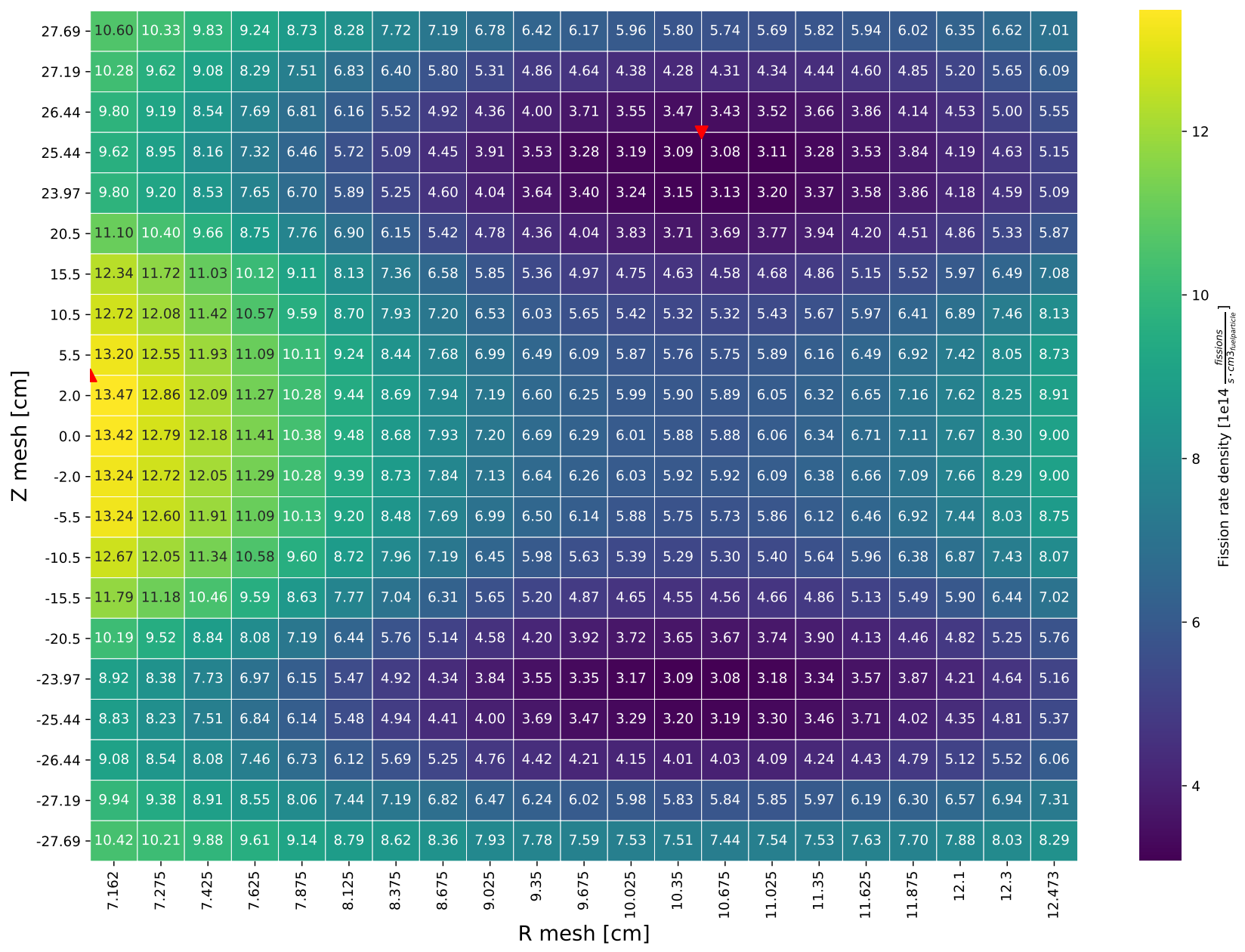

Figure 67. Fission rate density distribution for alternate 1 design IFE region on day 15 (see Section 7.2.2). 


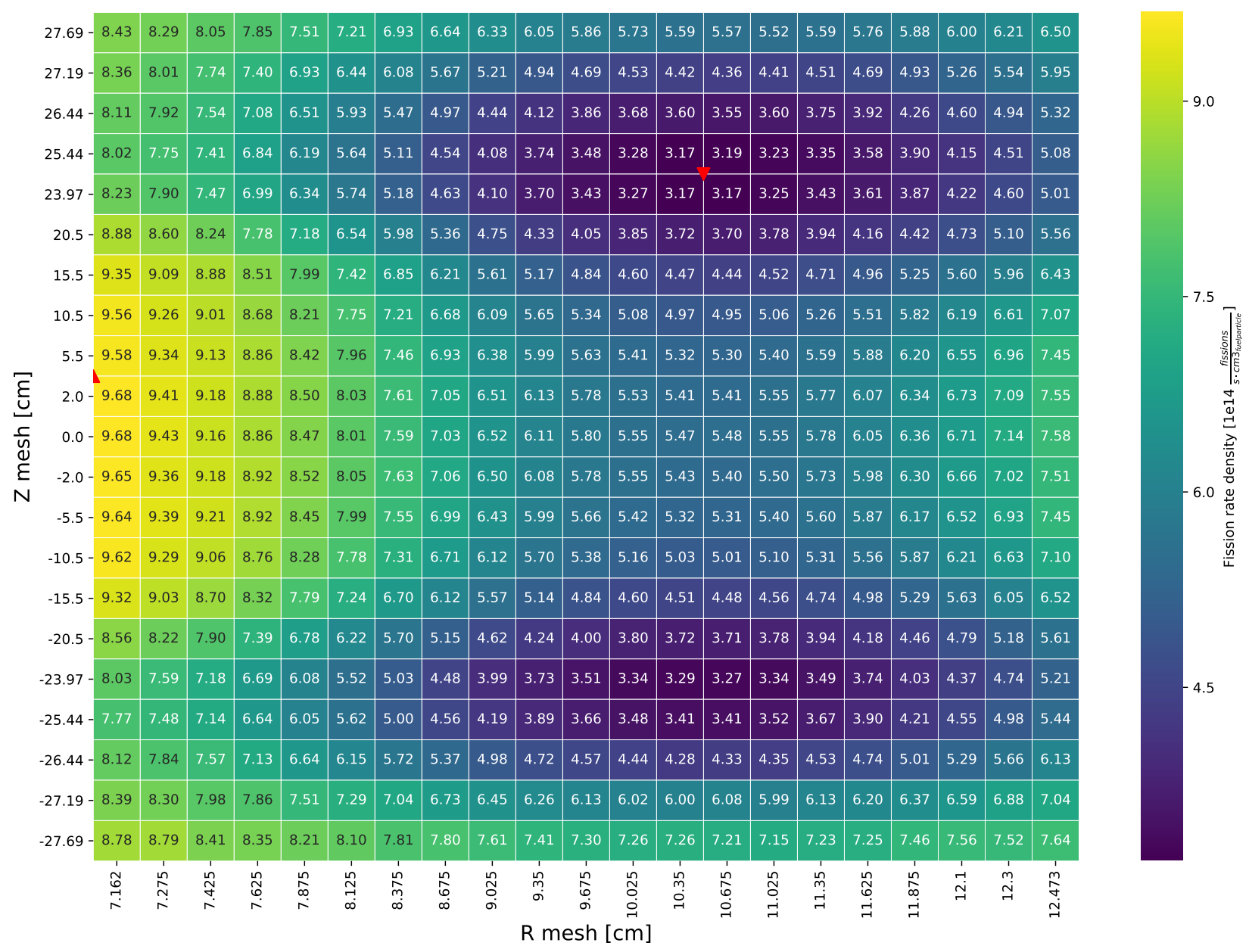

Figure 68. Fission rate density distribution for alternate 1 design IFE region on day 27 (see Section 7.2.2). 


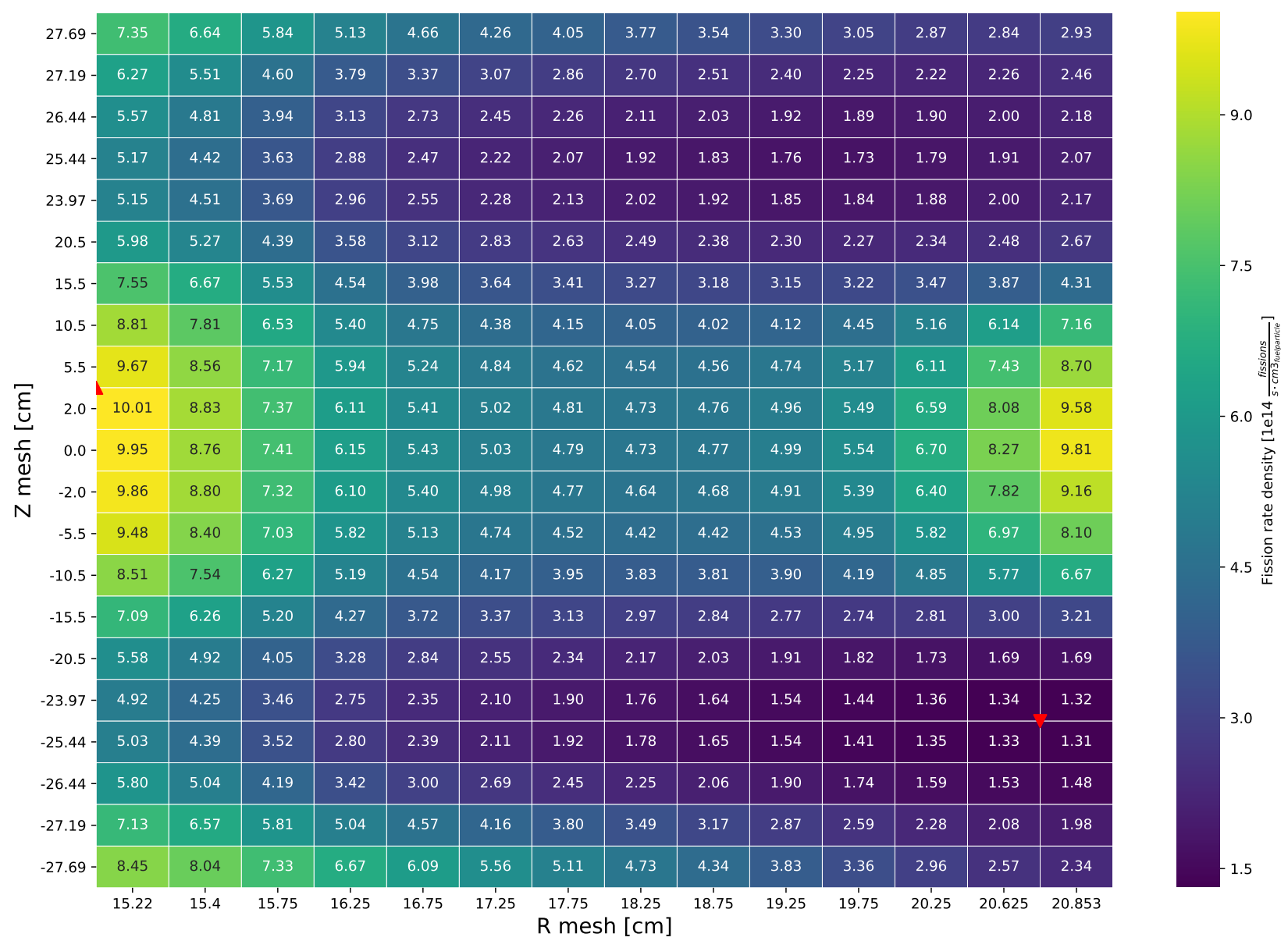

Figure 69. Fission rate density distribution for alternate 1 design OFE region on day 0 (see Section 7.2.2). 


\begin{tabular}{|c|c|c|c|c|c|c|c|c|c|c|c|c|c|c|}
\hline 27.69 & 6.99 & 6.31 & 5.48 & 4.83 & 4.42 & 4.09 & 3.84 & 3.60 & 3.36 & 3.13 & 2.96 & 2.81 & 2.78 & 2.83 \\
\hline 27.19 & 6.08 & 5.24 & 4.34 & 3.59 & 3.13 & 2.88 & 2.69 & 2.54 & 2.37 & 2.25 & 2.15 & 2.17 & 2.25 & 2.42 \\
\hline 26.44 & 5.33 & 4.53 & 3.69 & 2.96 & 2.53 & 2.29 & 2.12 & 2.01 & 1.89 & 1.83 & 1.79 & 1.85 & 2.00 & 2.17 \\
\hline 25.44 & 4.89 & 4.24 & 3.41 & 2.71 & 2.33 & 2.09 & 1.94 & 1.81 & 1.75 & 1.70 & 1.68 & 1.77 & 1.91 & 2.11 \\
\hline 23.97 & 4.91 & 4.24 & 3.48 & 2.79 & 2.41 & 2.17 & 2.04 & 1.92 & 1.83 & 1.80 & 1.81 & 1.89 & 2.06 & 2.26 \\
\hline 20.5 & 5.71 & 5.00 & 4.15 & 3.40 & 2.98 & 2.72 & 2.56 & 2.46 & 2.39 & 2.39 & 2.48 & 2.74 & 3.13 & 3.56 \\
\hline 15.5 & 7.15 & 6.31 & 5.27 & 4.33 & 3.80 & 3.51 & 3.33 & 3.25 & 3.23 & 3.31 & 3.58 & 4.15 & 4.97 & 5.79 \\
\hline 10.5 & 8.40 & 7.43 & 6.20 & 5.12 & 4.52 & 4.18 & 3.99 & 3.91 & 3.94 & 4.11 & 4.50 & 5.34 & 6.50 & 7.67 \\
\hline 5.5 & 9.24 & 8.17 & 6.86 & 5.68 & 5.04 & 4.70 & 4.51 & 4.48 & 4.56 & 4.89 & 5.54 & 6.88 & 8.70 & 10.50 \\
\hline 2.0 & 9.59 & 8.48 & 7.06 & 5.88 & 5.22 & 4.89 & 4.74 & 4.72 & 4.84 & 5.20 & 5.96 & 7.52 & 9.64 & 11.68 \\
\hline 0.0 & 9.64 & 8.47 & 7.14 & 5.91 & 5.26 & 4.92 & 4.75 & 4.74 & 4.88 & 5.24 & 6.02 & 7.62 & 9.76 & 11.82 \\
\hline-2.0 & 9.55 & 8.44 & 7.06 & 5.86 & 5.23 & 4.89 & 4.72 & 4.72 & 4.84 & 5.19 & 5.95 & 7.50 & 9.64 & 11.72 \\
\hline-5.5 & 9.16 & 8.09 & 6.79 & 5.64 & 4.99 & 4.64 & 4.47 & 4.42 & 4.53 & 4.83 & 5.48 & 6.82 & 8.63 & 10.40 \\
\hline-10.5 & 8.24 & 7.26 & 6.04 & 4.99 & 4.40 & 4.06 & 3.87 & 3.77 & 3.78 & 3.90 & 4.25 & 5.00 & 6.02 & 6.97 \\
\hline-15.5 & 6.92 & 6.10 & 5.07 & 4.18 & 3.65 & 3.36 & 3.18 & 3.08 & 3.05 & 3.13 & 3.35 & 3.85 & 4.58 & 5.30 \\
\hline-20.5 & 5.44 & 4.79 & 3.94 & 3.20 & 2.77 & 2.53 & 2.36 & 2.25 & 2.18 & 2.14 & 2.17 & 2.32 & 2.57 & 2.84 \\
\hline-23.97 & 4.75 & 4.14 & 3.35 & 2.66 & 2.26 & 2.03 & 1.86 & 1.74 & 1.64 & 1.55 & 1.47 & 1.42 & 1.42 & 1.46 \\
\hline-25.44 & 4.90 & 4.24 & 3.40 & 2.68 & 2.29 & 2.03 & 1.88 & 1.72 & 1.61 & 1.50 & 1.42 & 1.36 & 1.36 & 1.38 \\
\hline-26.44 & 5.64 & 4.92 & 4.04 & 3.30 & 2.89 & 2.59 & 2.38 & 2.17 & 2.01 & 1.85 & 1.72 & 1.59 & 1.55 & 1.56 \\
\hline-27.19 & 7.01 & 6.50 & 5.67 & 4.86 & 4.38 & 4.03 & 3.72 & 3.37 & 3.11 & 2.77 & 2.54 & 2.27 & 2.05 & 1.95 \\
\hline \multirow[t]{2}{*}{-27.69} & 8.27 & 7.83 & 7.12 & 6.41 & 5.93 & 5.41 & 5.03 & 4.59 & 4.19 & 3.73 & 3.31 & 2.89 & 2.54 & 2.33 \\
\hline & 15.22 & 15.4 & 15.75 & 16.25 & 16.75 & 17.25 & $\begin{array}{r}17.75 \\
\mathrm{R}\end{array}$ & $\begin{array}{l}18.25 \\
{[\mathrm{~cm}]}\end{array}$ & 18.75 & 19.25 & 19.75 & 20.25 & 20.625 & 20.853 \\
\hline
\end{tabular}

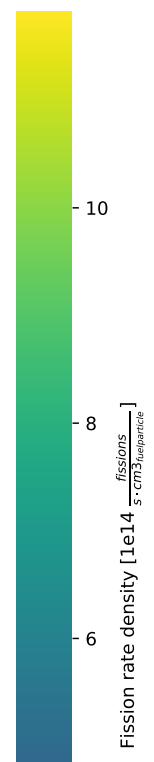

Figure 70. Fission rate density distribution for alternate 1 design OFE region on day 1 (see Section 7.2.2). 


\begin{tabular}{|c|c|c|c|c|c|c|c|c|c|c|c|c|c|c|}
\hline 27.69 & 6.89 & 6.24 & 5.53 & 4.79 & 4.35 & 4.02 & 3.83 & 3.59 & 3.30 & 3.11 & 2.91 & 2.81 & 2.79 & 2.85 \\
\hline 27.19 & 5.94 & 5.18 & 4.32 & 3.58 & 3.14 & 2.85 & 2.69 & 2.51 & 2.38 & 2.27 & 2.13 & 2.13 & 2.23 & 2.44 \\
\hline 26.44 & 5.17 & 4.48 & 3.63 & 2.91 & 2.51 & 2.27 & 2.11 & 1.98 & 1.90 & 1.81 & 1.78 & 1.85 & 2.00 & 2.17 \\
\hline 25.44 & 4.87 & 4.20 & 3.43 & 2.72 & 2.32 & 2.08 & 1.93 & 1.83 & 1.75 & 1.70 & 1.69 & 1.80 & 1.96 & 2.16 \\
\hline 23.97 & 4.85 & 4.24 & 3.43 & 2.77 & 2.40 & 2.17 & 2.04 & 1.92 & 1.88 & 1.84 & 1.85 & 1.95 & 2.16 & 2.38 \\
\hline 20.5 & 5.63 & 4.95 & 4.13 & 3.38 & 2.95 & 2.71 & 2.56 & 2.46 & 2.43 & 2.44 & 2.57 & 2.88 & 3.35 & 3.83 \\
\hline 15.5 & 7.05 & 6.25 & 5.19 & 4.29 & 3.77 & 3.49 & 3.30 & 3.22 & 3.21 & 3.29 & 3.56 & 4.12 & 4.93 & 5.72 \\
\hline 10.5 & 8.29 & 7.32 & 6.12 & 5.08 & 4.49 & 4.16 & 3.98 & 3.91 & 3.94 & 4.12 & 4.54 & 5.42 & 6.64 & 7.85 \\
\hline 5.5 & 9.16 & 8.13 & 6.78 & 5.64 & 5.02 & 4.68 & 4.53 & 4.49 & 4.60 & 4.94 & 5.63 & 7.02 & 8.94 & 10.79 \\
\hline 2.0 & 9.39 & 8.31 & 7.01 & 5.82 & 5.18 & 4.85 & 4.69 & 4.67 & 4.88 & 5.24 & 5.99 & 7.58 & 9.65 & 11.73 \\
\hline 0.0 & 9.49 & 8.40 & 7.02 & 5.88 & 5.22 & 4.84 & 4.73 & 4.71 & 4.86 & 5.26 & 6.05 & 7.62 & 9.75 & 11.82 \\
\hline-2.0 & 9.36 & 8.36 & 7.00 & 5.79 & 5.17 & 4.85 & 4.65 & 4.67 & 4.82 & 5.17 & 5.97 & 7.56 & 9.66 & 11.74 \\
\hline-5.5 & 9.03 & 7.98 & 6.72 & 5.57 & 4.94 & 4.61 & 4.44 & 4.42 & 4.54 & 4.88 & 5.58 & 6.99 & 8.90 & 10.79 \\
\hline-10.5 & 8.16 & 7.20 & 6.02 & 4.97 & 4.39 & 4.06 & 3.87 & 3.80 & 3.81 & 3.94 & 4.32 & 5.10 & 6.18 & 7.24 \\
\hline-15.5 & 6.87 & 6.06 & 5.02 & 4.12 & 3.62 & 3.34 & 3.16 & 3.08 & 3.05 & 3.10 & 3.32 & 3.79 & 4.48 & 5.15 \\
\hline-20.5 & 5.43 & 4.75 & 3.93 & 3.21 & 2.79 & 2.55 & 2.39 & 2.28 & 2.22 & 2.22 & 2.31 & 2.54 & 2.90 & 3.26 \\
\hline-23.97 & 4.70 & 4.08 & 3.35 & 2.69 & 2.29 & 2.05 & 1.88 & 1.77 & 1.68 & 1.59 & 1.52 & 1.50 & 1.52 & 1.57 \\
\hline-25.44 & 4.85 & 4.21 & 3.41 & 2.70 & 2.30 & 2.04 & 1.86 & 1.74 & 1.62 & 1.52 & 1.44 & 1.40 & 1.38 & 1.40 \\
\hline-26.44 & 5.60 & 4.88 & 4.02 & 3.30 & 2.85 & 2.57 & 2.39 & 2.21 & 2.03 & 1.85 & 1.72 & 1.61 & 1.55 & 1.56 \\
\hline-27.19 & 7.07 & 6.39 & 5.54 & 4.89 & 4.39 & 4.02 & 3.70 & 3.43 & 3.13 & 2.83 & 2.55 & 2.29 & 2.08 & 2.00 \\
\hline \multirow[t]{2}{*}{$-27.69-$} & 8.24 & 7.74 & 7.11 & 6.43 & 5.92 & 5.44 & 4.99 & 4.60 & 4.26 & 3.80 & 3.40 & 2.93 & 2.57 & 2.34 \\
\hline & 15.22 & 15.4 & 15.75 & 16.25 & 16.75 & 17.25 & $\begin{array}{r}17.75 \\
\mathrm{R} \text { me }\end{array}$ & $\begin{array}{l}18.25 \\
{[\mathrm{~cm}]}\end{array}$ & 18.75 & 19.25 & 19.75 & 20.25 & 20.625 & 20.853 \\
\hline
\end{tabular}

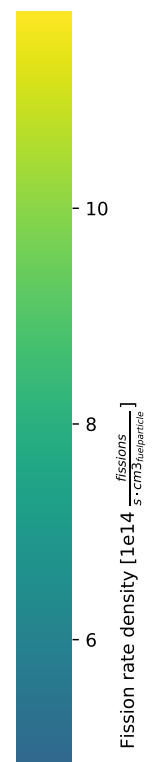

Figure 71. Fission rate density distribution for alternate 1 design OFE region on day 2 (see Section 7.2.2). 


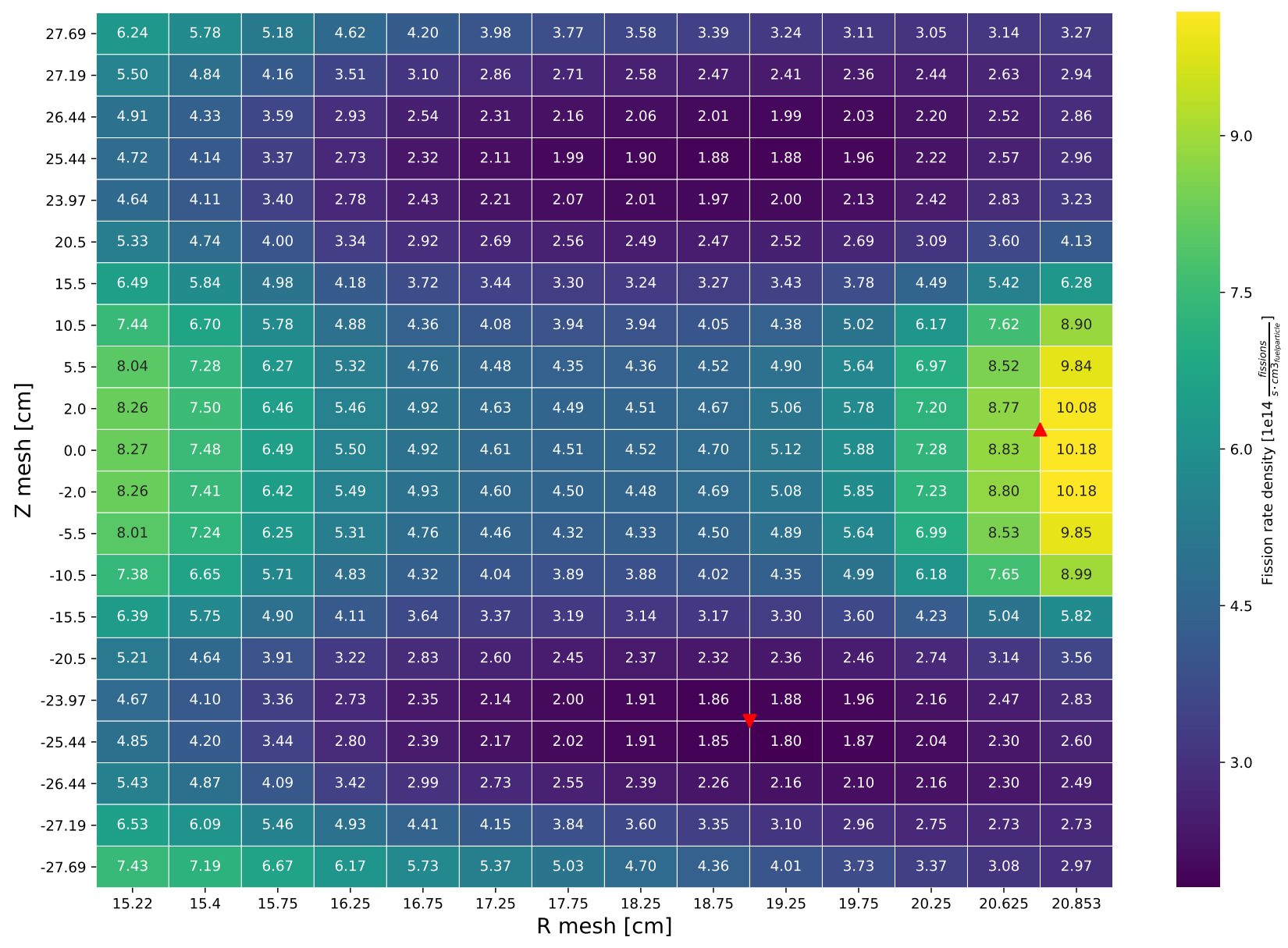

Figure 72. Fission rate density distribution for alternate 1 design OFE region on day 15 (see Section 7.2.2). 


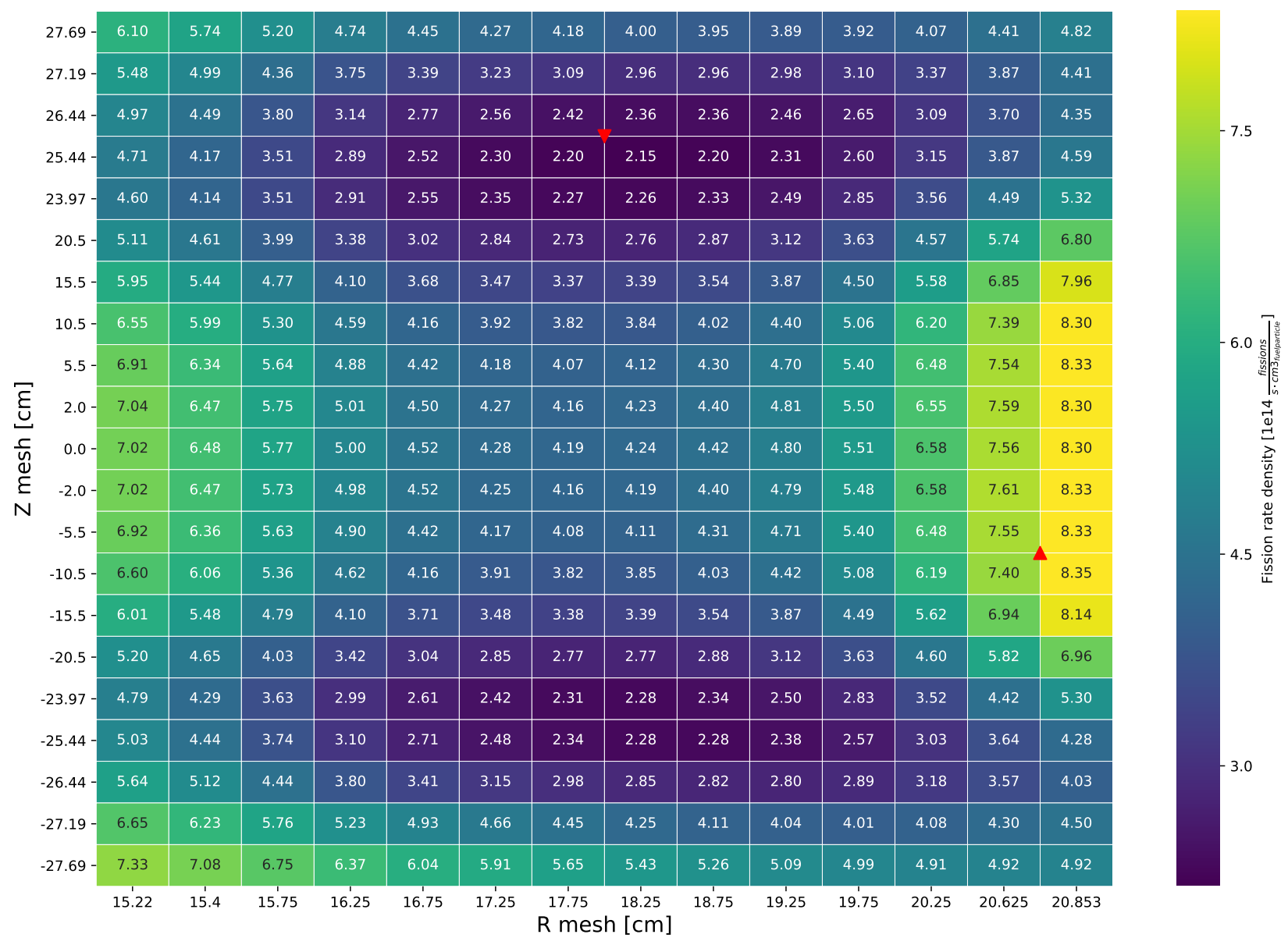

Figure 73. Fission rate density distribution for alternate 1 design OFE region on day 27 (see Section 7.2.2). 


\section{APPENDIX B-2. CUMULATIVE FISSION DENSITY DISTRIBUTIONS FOR ALTERNATE 1 DESIGN}

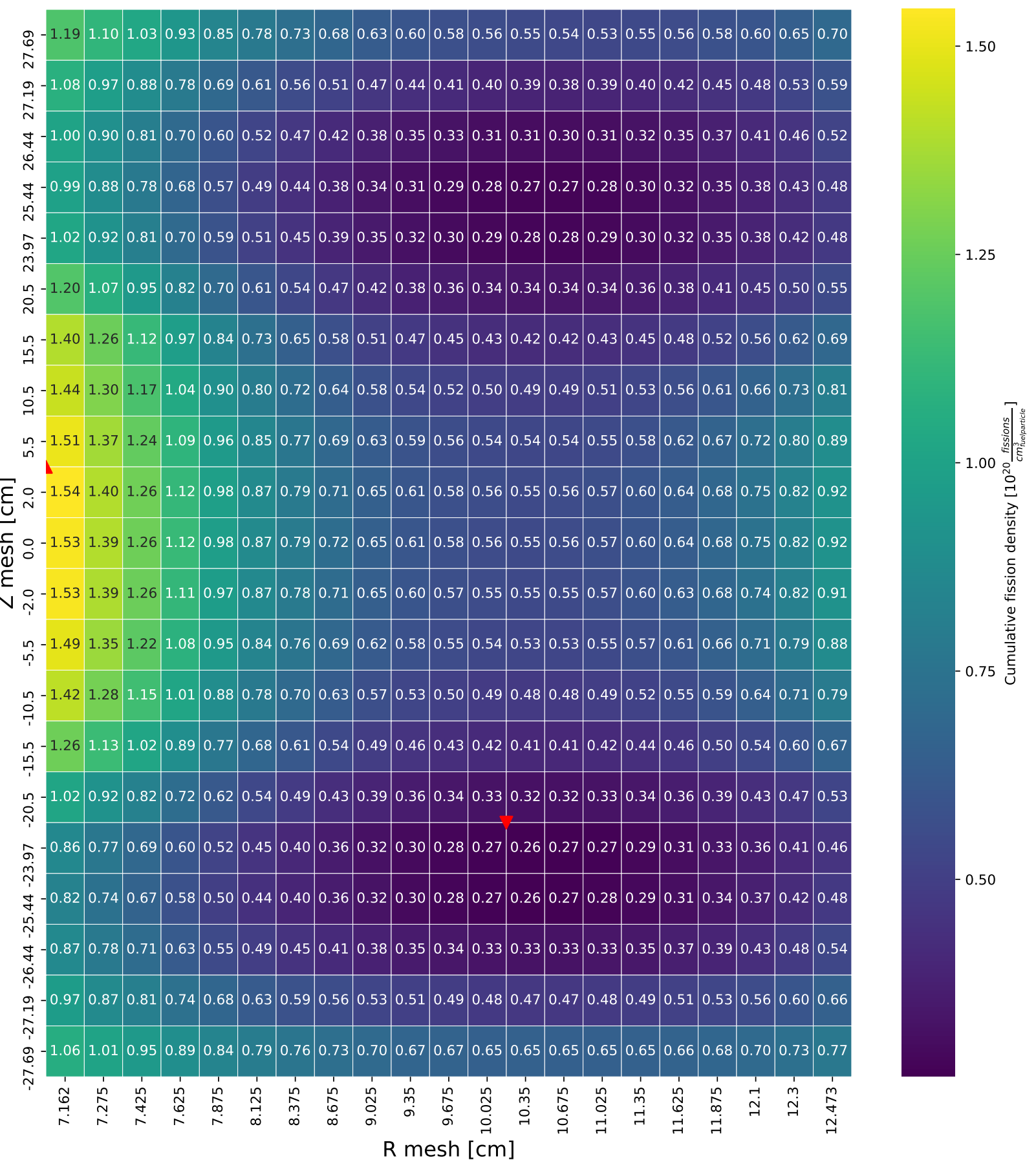

Figure 74. Cumulative fission density distribution for alternate 1 design IFE region on day 1 (see Section 7.2.5). 
๑ீ- -15.74

$\stackrel{\grave{\sim}}{\sim}$

옥-14.6013.5212.4611.2810.02 9.04 8.25 $7.506 .83 \quad 6.386 .04 \quad 5.77 \quad 5.645 .57 \quad 5.61 \quad 5.776 .016 .376 .867 .47 \quad 8.23$

กิ

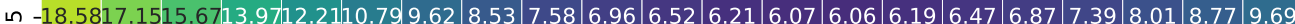
ก

นก $-19.1717 .7916 .3814 .7613 .0811 .6910 .569 .478 .537 .907 .447 .157 .017 .03 \quad 7.207 .54 \quad 8.00 \quad 8.609 .3310 .2111 .24$ 이

เก -19.9218.5517.1515.5313.8212.4111.2610.169.20 8.55 8.09 7.79 7.66 7.67 $7.878 .248 .76 \quad 9.4210 .2111 .1512 .27$

Е 우 $-20.3518 .9417 .5415 .8814 .1612 .7511 .5710 .459 .46 \quad 8.808 .348 .03 \quad 7.90 \quad 7.928 .128 .50 \quad 9.039 .7210 .5111 .4912 .62$ $\underline{\mathrm{E}} \stackrel{\mathrm{i}}{ }$

등 우 $-20.3718 .9617 .5615 .9214 .2012 .7711 .6210 .509 .508 .838 .378 .057 .92 \quad 7.938 .148 .549 .059 .7310 .5611 .5212 .68$ $\stackrel{\mathscr{w}}{\mathscr{\varepsilon}} \dot{0}$

E。 - $20.2518 .8417 .4115 .8114 .1112 .7011 .5310 .419 .448 .778 .318 .007 .87 \quad 7.898 .108 .50 \quad 9.019 .6710 .5011 .4512 .61$ $N \stackrel{\circ}{i}$

เก $-19.8718 .4917 .0715 .4813 .7812 .3811 .2310 .149 .17 \quad 8.528 .06 \quad 7.76 \quad 7.62 \quad 7.647 .83 \quad 8.208 .70 \quad 9.3410 .1411 .0812 .19$

น $-19.0117 .6416 .2414 .6412 .9811 .5910 .469 .40 \quad 8.46 \quad 7.837 .397 .096 .956 .96 \quad 7.12 \quad 7.45 \quad 7.92 \quad 8.519 .2310 .0711 .11$ 우

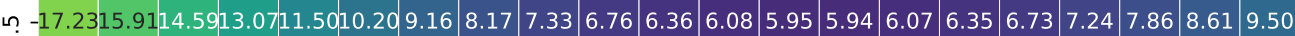
กั่

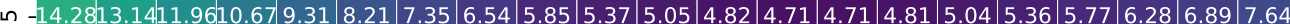

$\stackrel{\circ}{\Upsilon}$

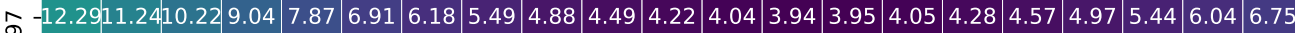

$\stackrel{\sim}{\sim}$

8

กั่

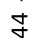

\&

국.

กิ

ตุ

N

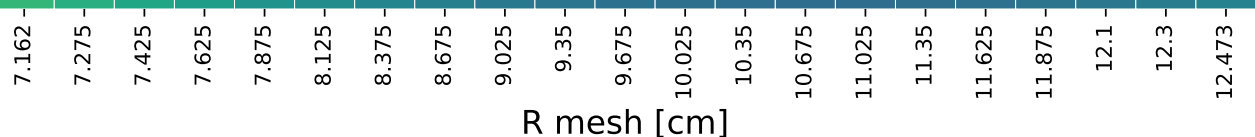

Figure 75. Cumulative fission density distribution for alternate 1 design IFE region on day 15 (see Section 7.2.5). 


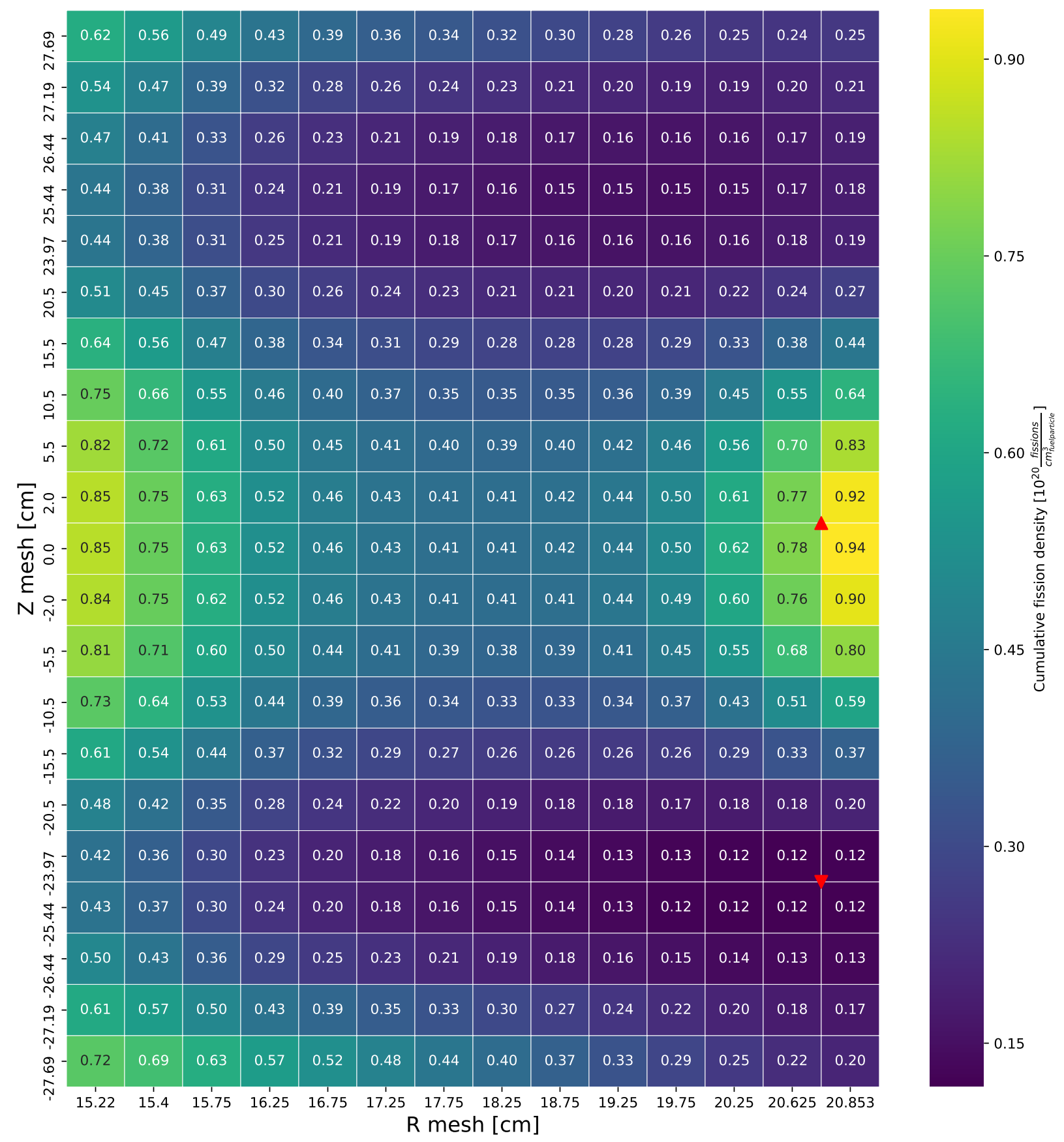

Figure 77. Cumulative fission density distribution for alternate 1 design OFE region on day 1 (see Section 7.2.5). 


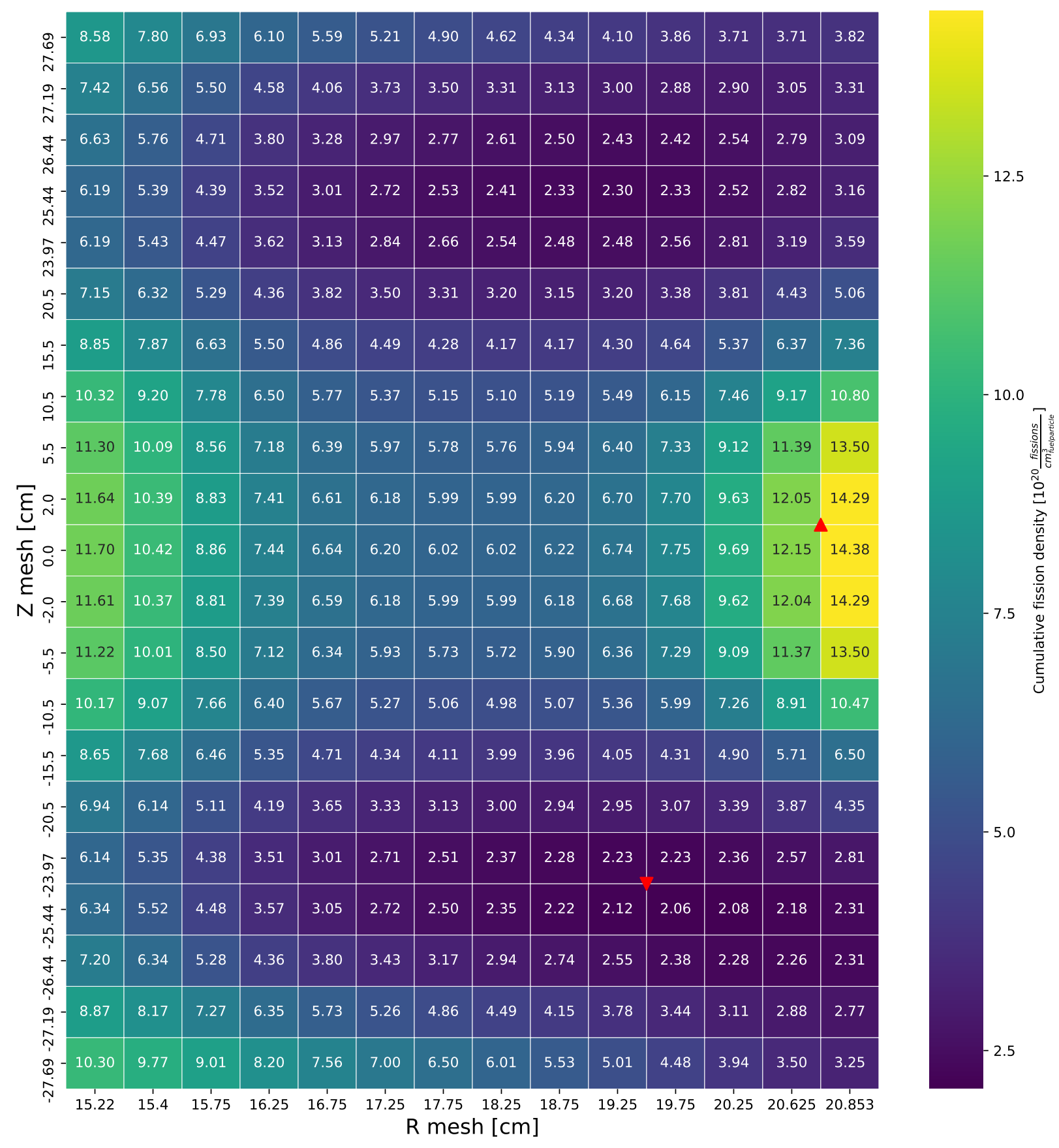

Figure 78. Cumulative fission density distribution for alternate 1 design OFE region on day 15 (see Section 7.2.5). 


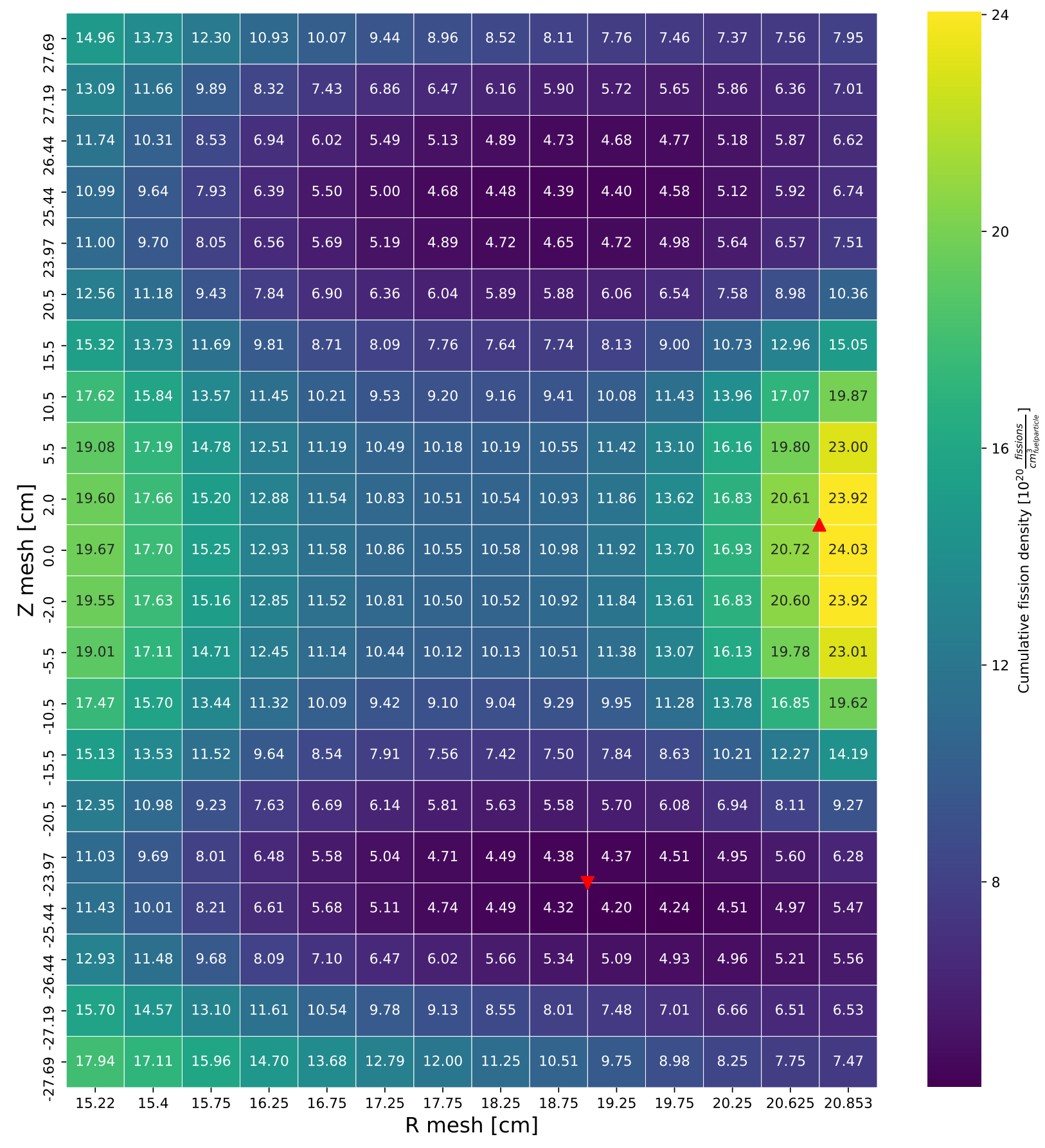

Figure 79. Cumulative fission density distribution for alternate 1 design OFE region on day 27 (see Section 7.2.5). 


\section{APPENDIX B-3. POWER DENSITY DISTRIBUTIONS FOR ALTERNATE 1 DESIGN}

ㅇํㅂ -19.3717.9216.5114.9913.6212.5111.5911.0810.309.70 9.38 9.148 .88 8.76 8.70 8.849 .069 .519 .7910 .5311 .28

ก

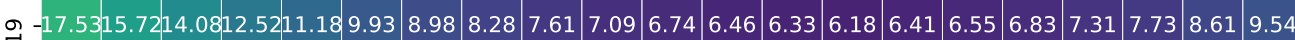

$\stackrel{\sim}{\stackrel{n}{2}}$

\&

ஸे

8

กั่

ติ

$\stackrel{\sim}{\sim}$

ํํำ

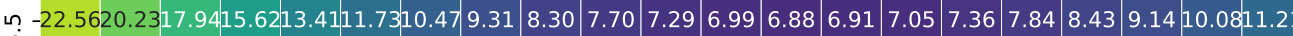
เก

เก $-23.0920 .8618 .8116 .6114 .4512 .8211 .5310 .389 .468 .818 .378 .07 \quad 7.968 .038 .228 .649 .169 .8910 .6711 .7113 .03$ 우

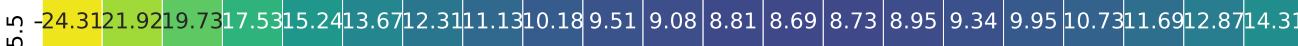
Е 울 -24.7322.4120.2117.8015.5613.8212.5911.4410.449.819.309.03 8.948 .999 .289 .71 10.2810.9812.0213.2614.75 등 웅 $-24.5922 .2820 .2017 .9515 .5713 .8312 .6411 .4810 .469 .809 .298 .96 \quad 8.969 .039 .269 .6810 .3211 .0511 .9913 .1814 .69$ $\stackrel{\text { U }}{\varepsilon} \circ$ $N \underset{i}{\circ}-24.8222 .2720 .1017 .7315 .5113 .8912 .5511 .4310 .469 .779 .248 .998 .88 \quad 8.969 .209 .6910 .1910 .9311 .8913 .0614 .60$

เก $-23.9821 .6319 .4717 .2415 .1513 .5012 .1511 .0710 .059 .408 .998 .70 \quad 8.608 .63 \quad 8.859 .25 \quad 9.78$ 10.6011.5112.6614.07 น

in $-22.7020 .3618 .3616 .1614 .0912 .4711 .2310 .159 .18 \quad 8.608 .17 \quad 7.907 .78 \quad 7.817 .98 \quad 8.348 .84 \quad 9.5110 .3311 .3312 .62$ $\stackrel{ }{\rightarrow}$

เก $-20.1418 .1116 .1814 .2012 .3310 .899 .778 .76 \quad 7.88 \quad 7.34 \quad 6.94 \quad 6.706 .586 .586 .74 \quad 7.05 \quad 7.46 \quad 8.018 .69 \quad 9.5610 .63$

เก

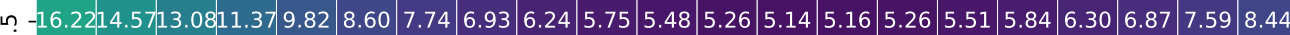
$\stackrel{\text { i }}{\circ}$

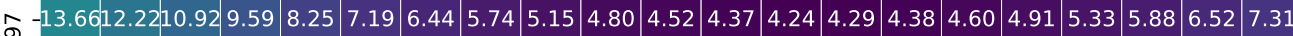

$\stackrel{m}{1}$

\&

ஸे

\&

$\stackrel{\circ}{\sim}$

- $-15.2113 .7112 .7711 .4610 .509 .779 .168 .798 .318 .007 .707 .437 .457 .397 .58 \quad 7.778 .04 \quad 8.418 .82 \quad 9.5410 .3$

ก

ตุ

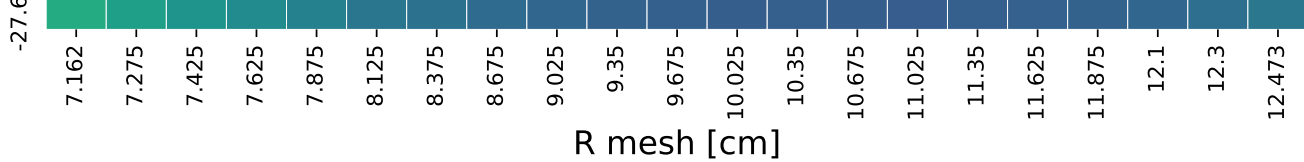

Figure 80. Power density distribution for alternate 1 design IFE region on day 0 (see Section 7.2.3). 
옥-16.4215.0413.6812.2110.75 9.46 $8.647 .927 .06 \quad 6.716 .316 .09 \quad 5.935 .926 .01 \quad 6.136 .46 \quad 6.83 \quad 7.368 .038 .99$

ì

n $-21.5819 .4817 .4315 .1212 .9611 .3110 .008 .867 .88 \quad 7.256 .836 .526 .436 .456 .586 .92 \quad 7.37 \quad 7.928 .649 .5410 .59$ $\stackrel{\sim}{\sim}$

เก $-22.2720 .2118 .2416 .1213 .9412 .3111 .069 .88 \quad 8.94 \quad 8.337 .897 .61 \quad 7.46 \quad 7.527 .74 \quad 8.14 \quad 8.63 \quad 9.2910 .1911 .2212 .48$ 宜

นก - -23.2921 .2419 .2717 .0214 .9113 .1811 .8710 .739 .749 .068 .648 .378 .268 .248 .478 .919 .4910 .2811 .1812 .3413 .65$ เก

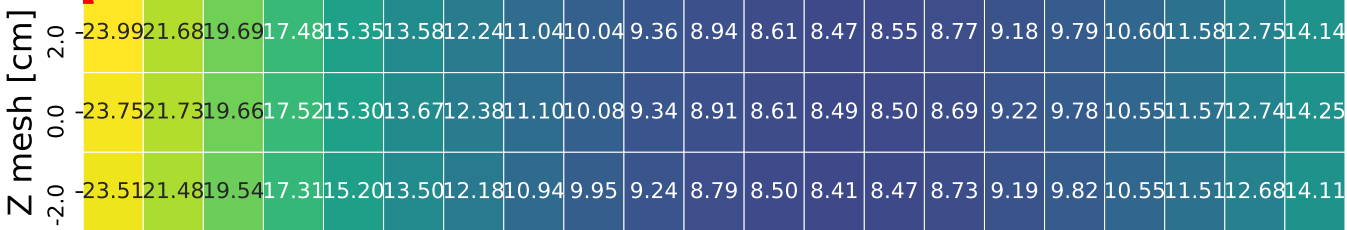

Ln $-23.0421 .0719 .0116 .9314 .7813 .1111 .8110 .679 .638 .98 \quad 8.528 .248 .13 \quad 8.18 \quad 8.398 .79 \quad 9.37 \quad 10.0811 .0012 .2213 .57$

เก $-22.0119 .9618 .0015 .8713 .8112 .1810 .859 .77 \quad 8.82 \quad 8.197 .75 \quad 7.47 \quad 7.357 .41 \quad 7.607 .95 \quad 8.48 \quad 9.199 .9811 .0312 .30$ 구

ก $-19.6417 .6815 .9313 .9212 .0510 .609 .44 \quad 8.427 .61 \quad 7.07 \quad 6.646 .406 .296 .26 \quad 6.40 \quad 6.73 \quad 7.13 \quad 7.718 .45 \quad 9.3210 .36$ กั่

in -15.8514.3912.8611.23 9.66 8.50 $7.58 \quad 6.726 .01 \quad 5.58 \quad 5.24 \quad 5.01 \quad 4.90 \quad 4.93 \quad 5.03 \quad 5.28 \quad 5.62 \quad 6.07 \quad 6.66 \quad 7.33 \quad 8.15$

ণิ

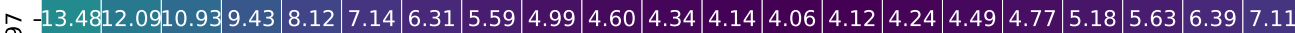

$\stackrel{\text { ì }}{\sim}$

\begin{tabular}{l}
$\dot{y}-13.1211 .7010 .42$ \\
\hline
\end{tabular}

ஸ่

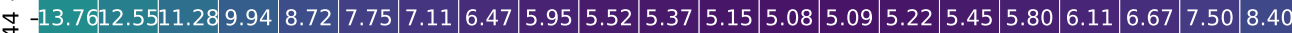

○'

$\stackrel{\sim}{\sim}$

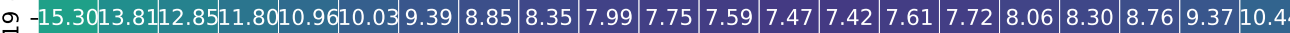

৯

ஜ.

ก

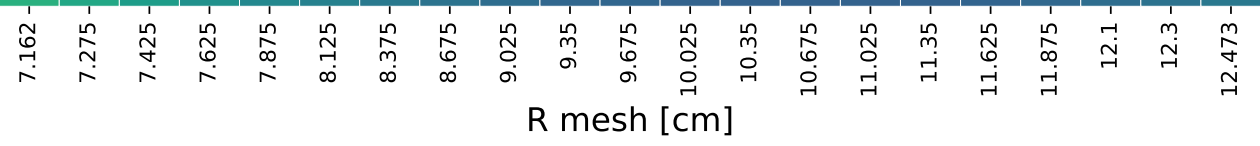

Figure 81. Power density distribution for alternate 1 design IFE region on day 1 (see Section 7.2.3). 


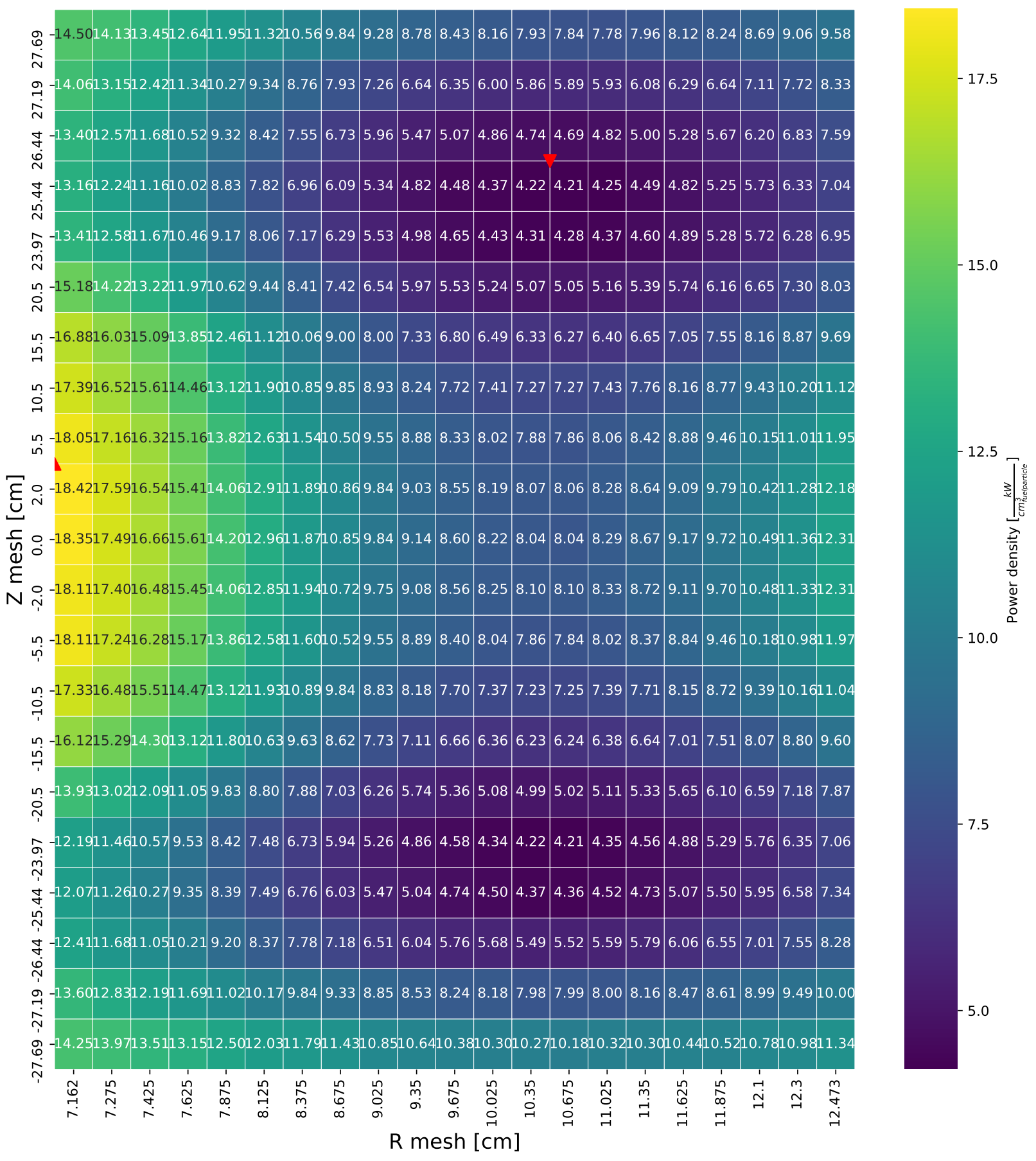

Figure 82. Power density distribution for alternate 1 design IFE region on day 15 (see Section 7.2.3). 


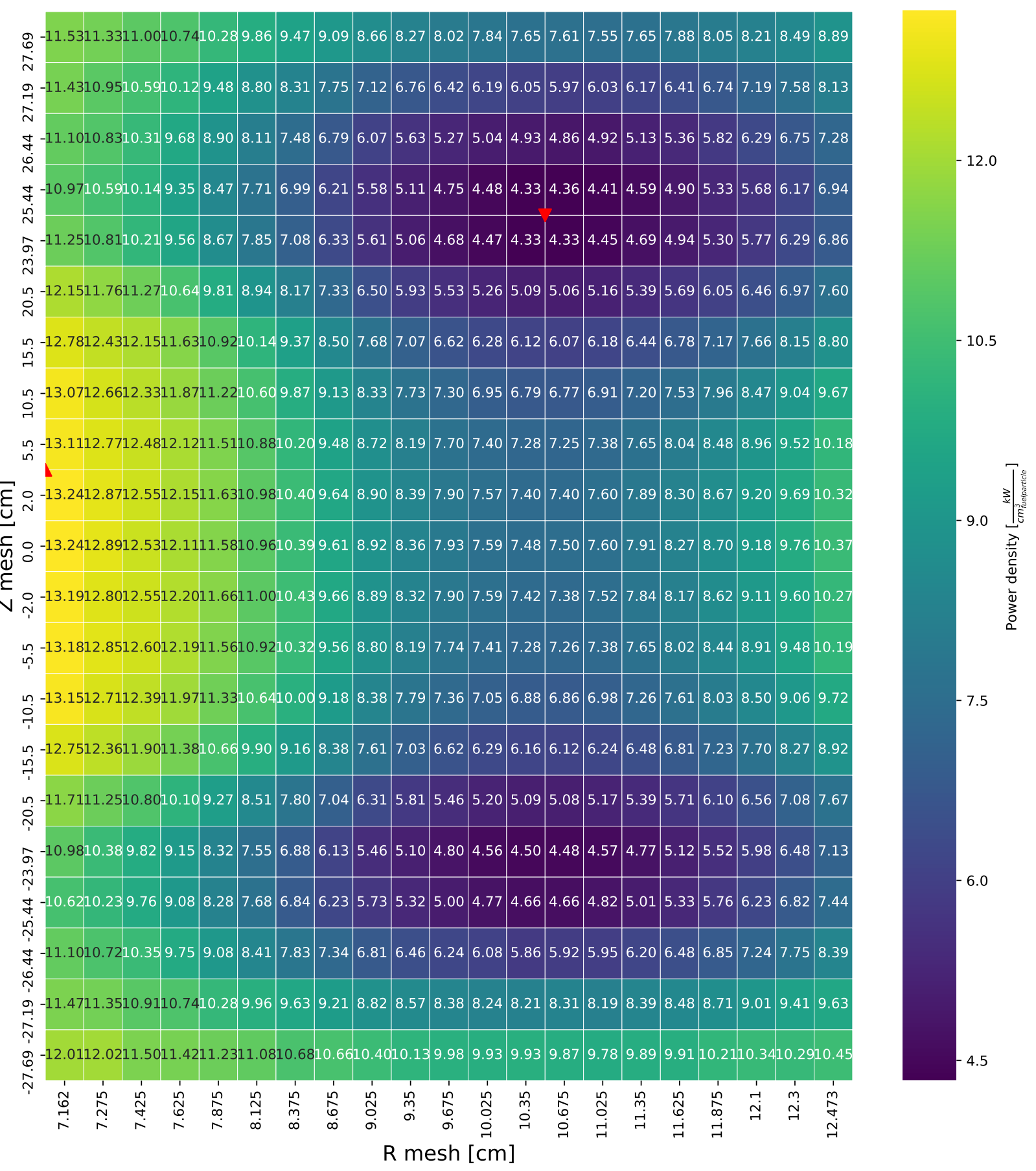

Figure 83. Power density distribution for alternate 1 design IFE region on day 27 (see Section 7.2.3). 


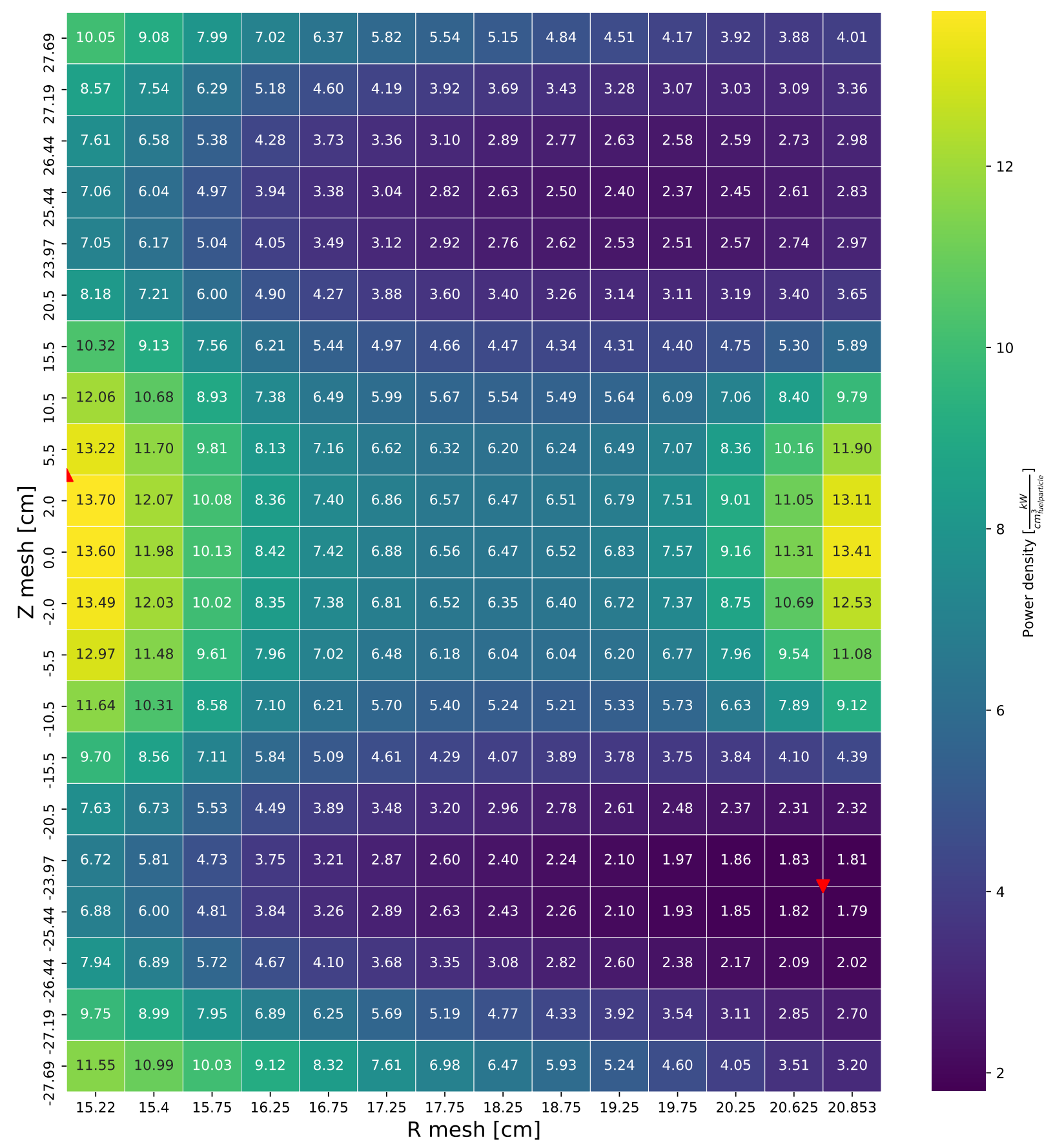

Figure 84. Power density distribution for alternate 1 design OFE region on day 0 (see Section 7.2.3). 


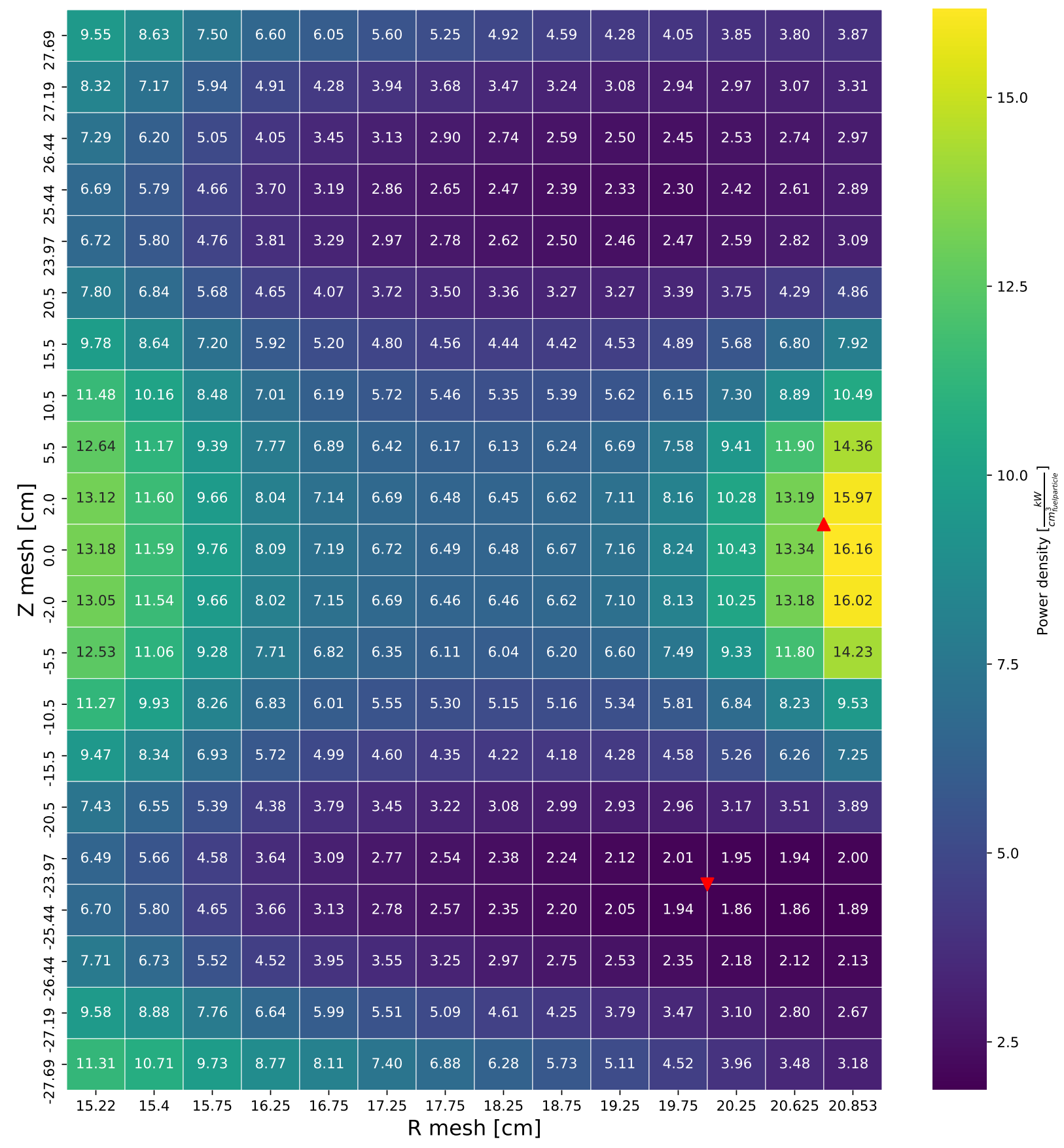

Figure 85. Power density distribution for alternate 1 design OFE region on day 1 (see Section 7.2.3). 


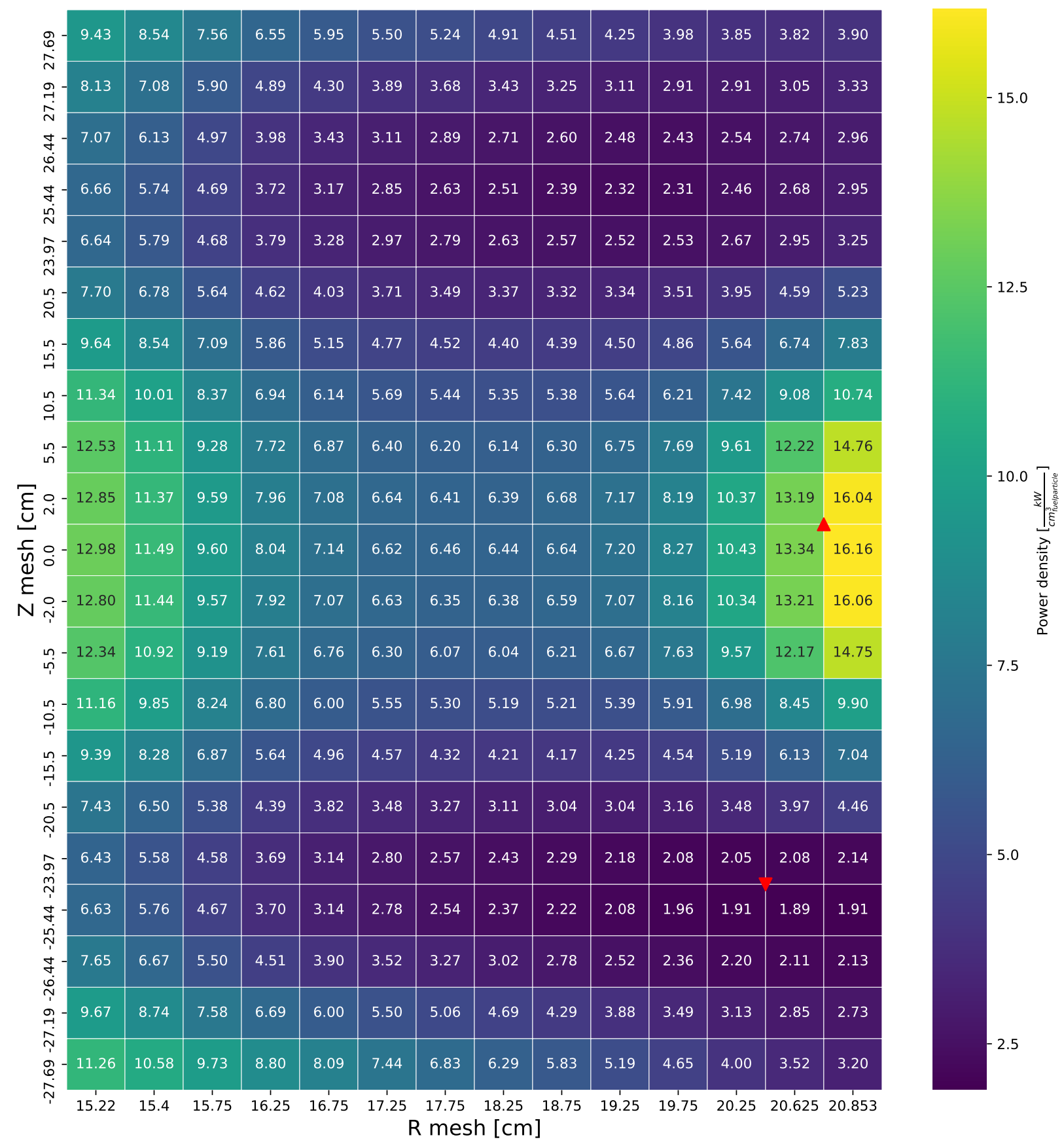

Figure 86. Power density distribution for alternate 1 design OFE region on day 2 (see Section 7.2.3). 


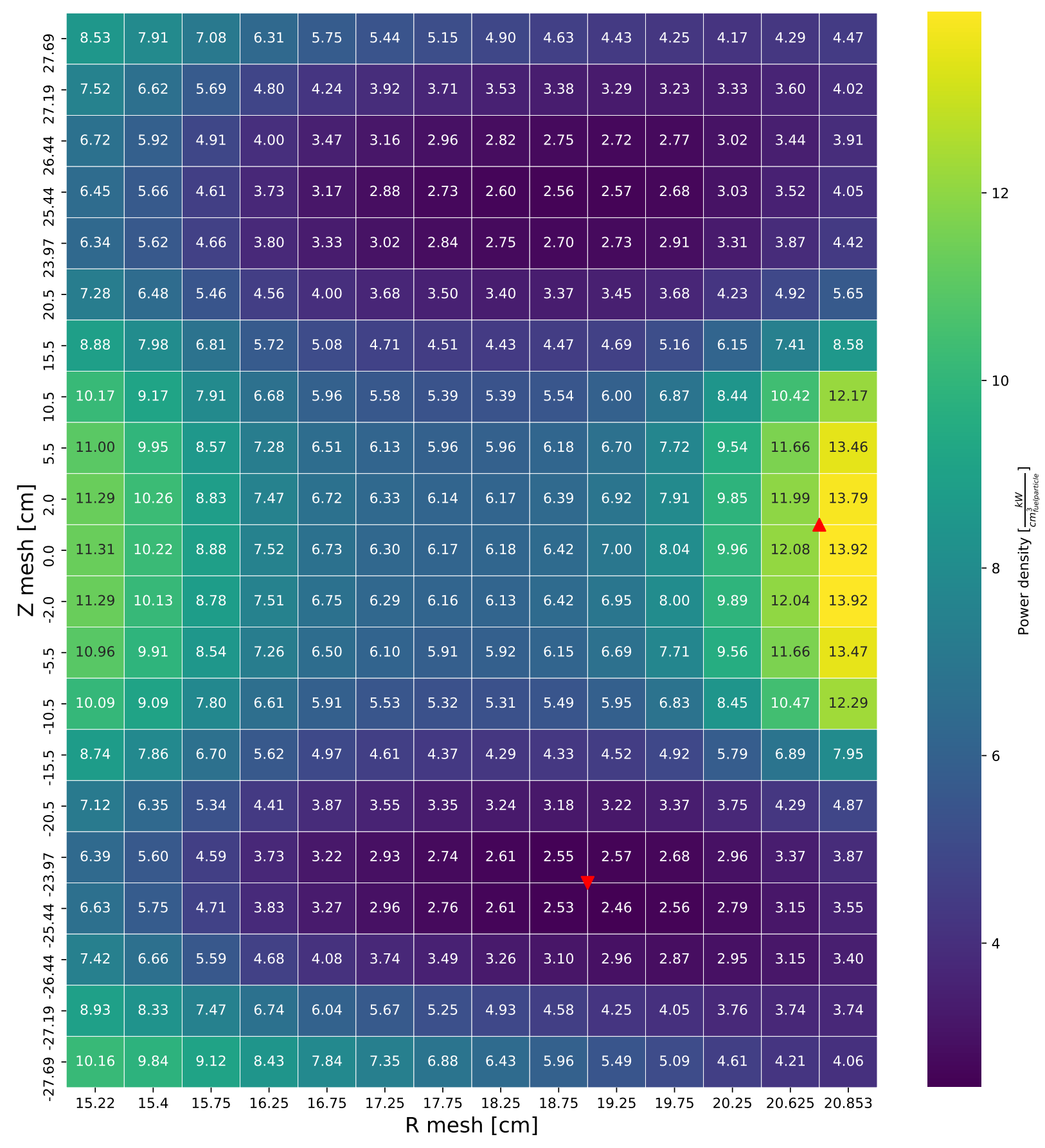

Figure 87. Power density distribution for alternate 1 design OFE region on day 15 (see Section 7.2.3). 


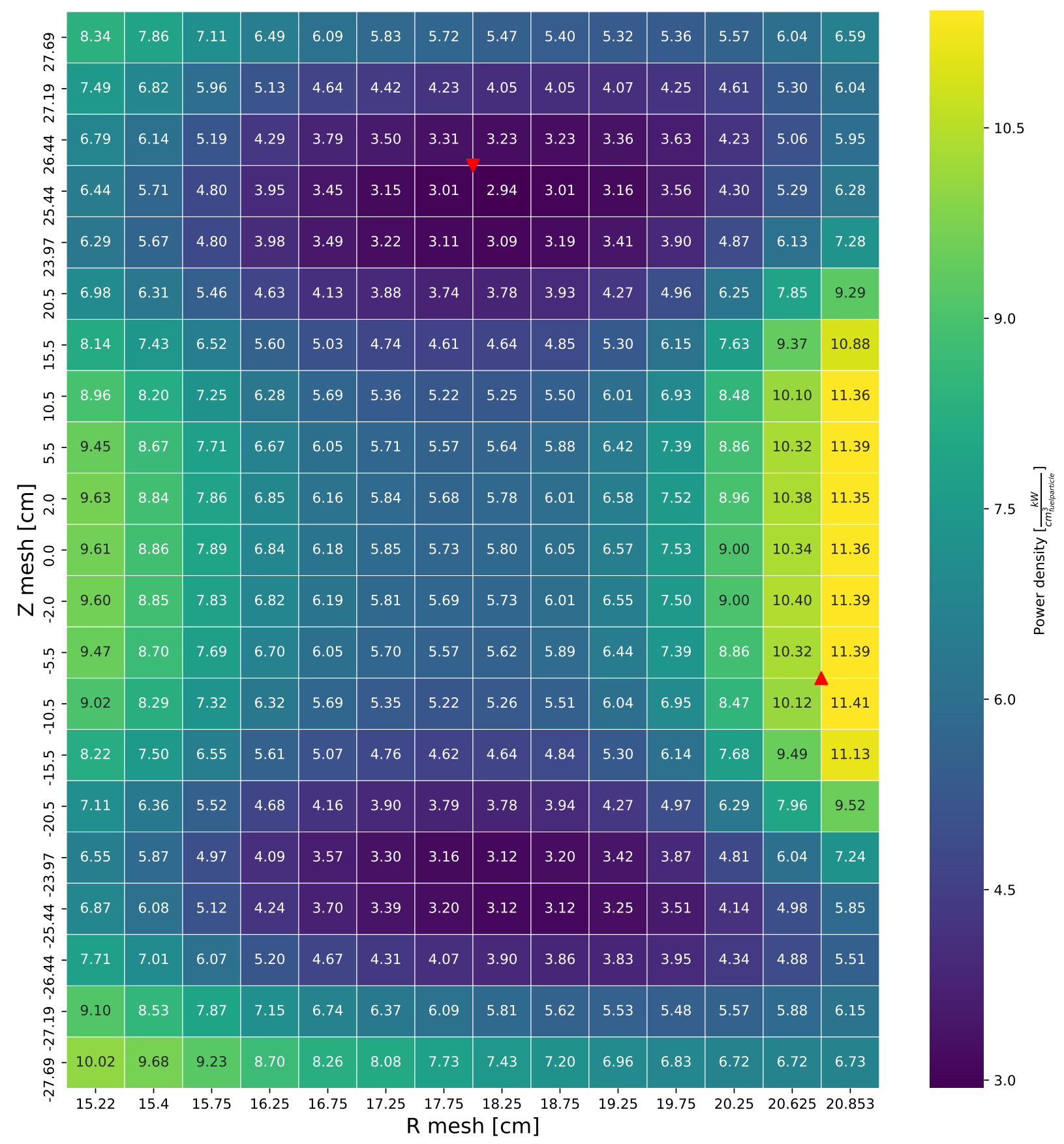

Figure 88. Power density distribution for alternate 1 design OFE region on day 27 (see Section 7.2.3). 


\section{APPENDIX B-4. HEAT FLUX DISTRIBUTIONS FOR ALTERNATE 1 DESIGN}

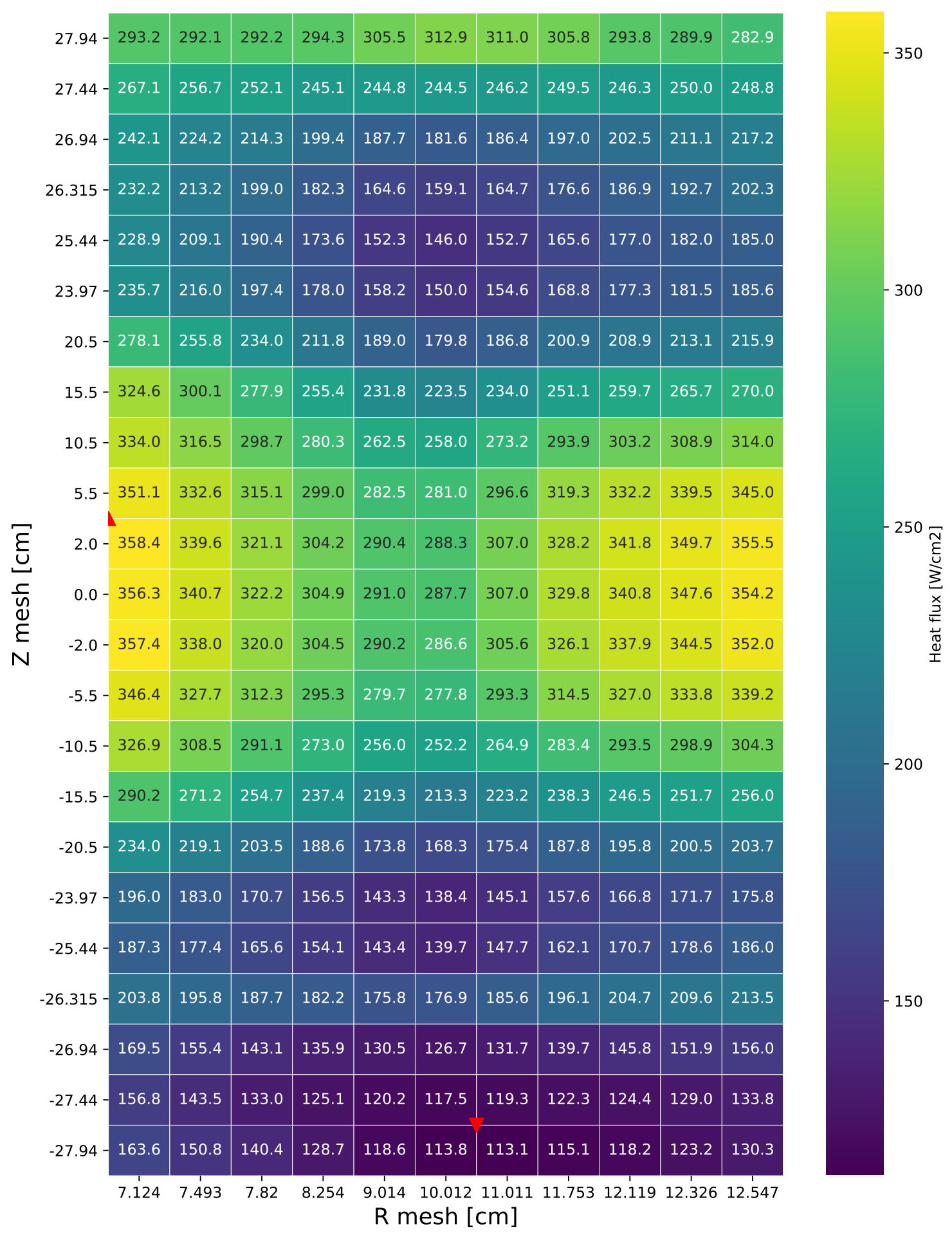

Figure 89. Heat flux distribution for alternate 1 design IFE region on day 0 (see Section 7.2.4). 


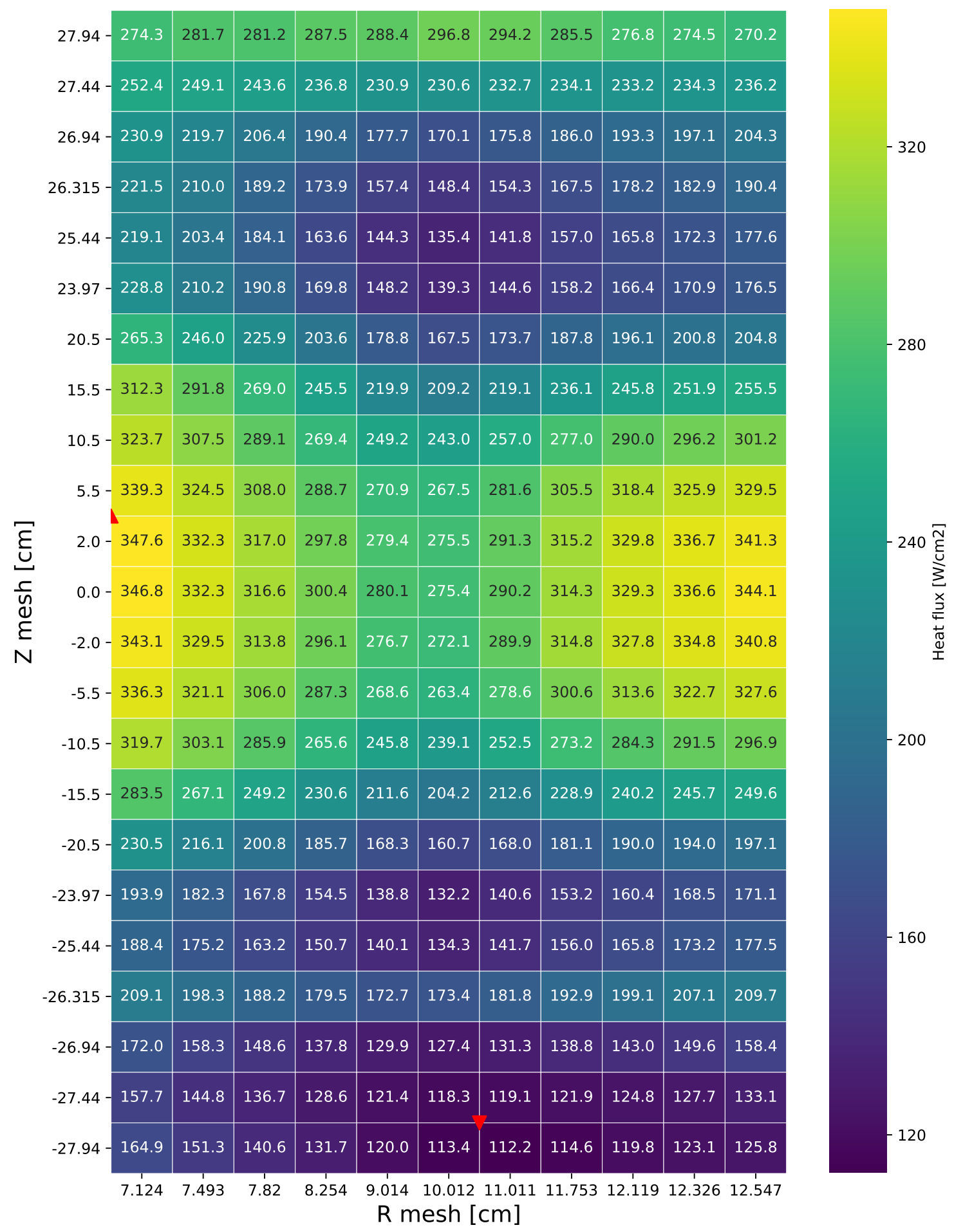

Figure 90. Heat flux distribution for alternate 1 design IFE region on day 1 (see Section 7.2.4). 


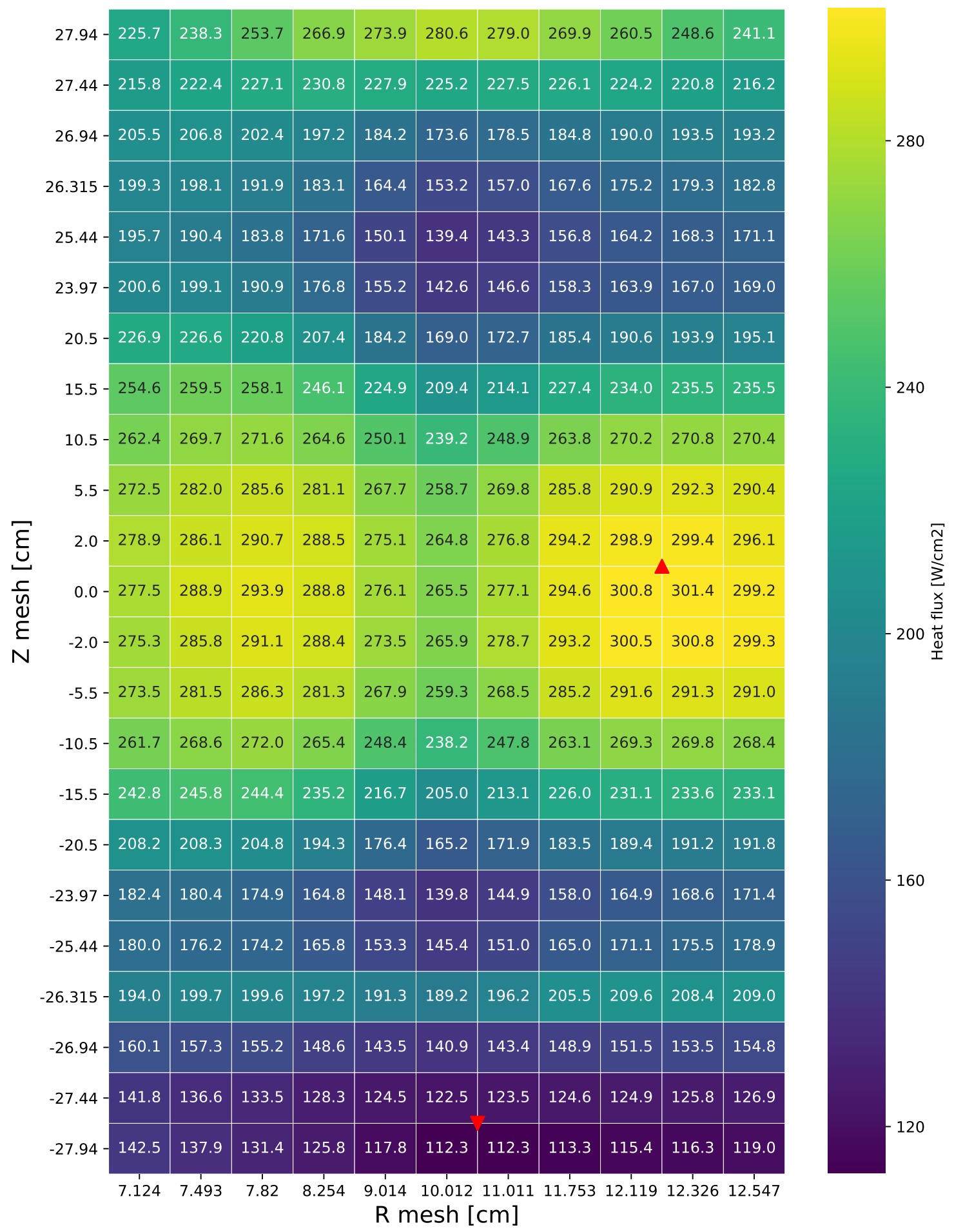

Figure 91. Heat flux distribution for alternate 1 design IFE region on day 15 (see Section 7.2.4). 


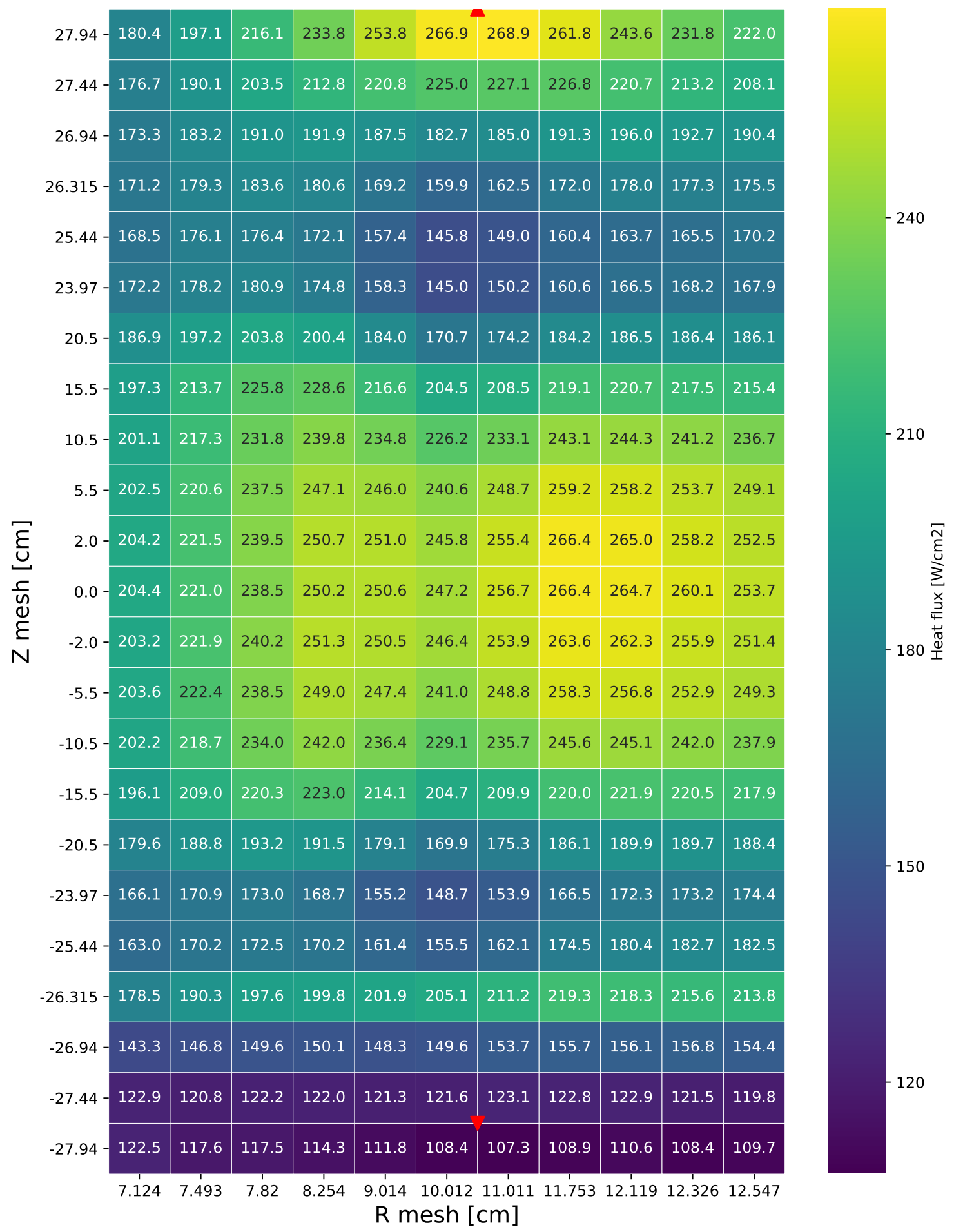

Figure 92. Heat flux distribution for alternate 1 design IFE region on day 27 (see Section 7.2.4). 


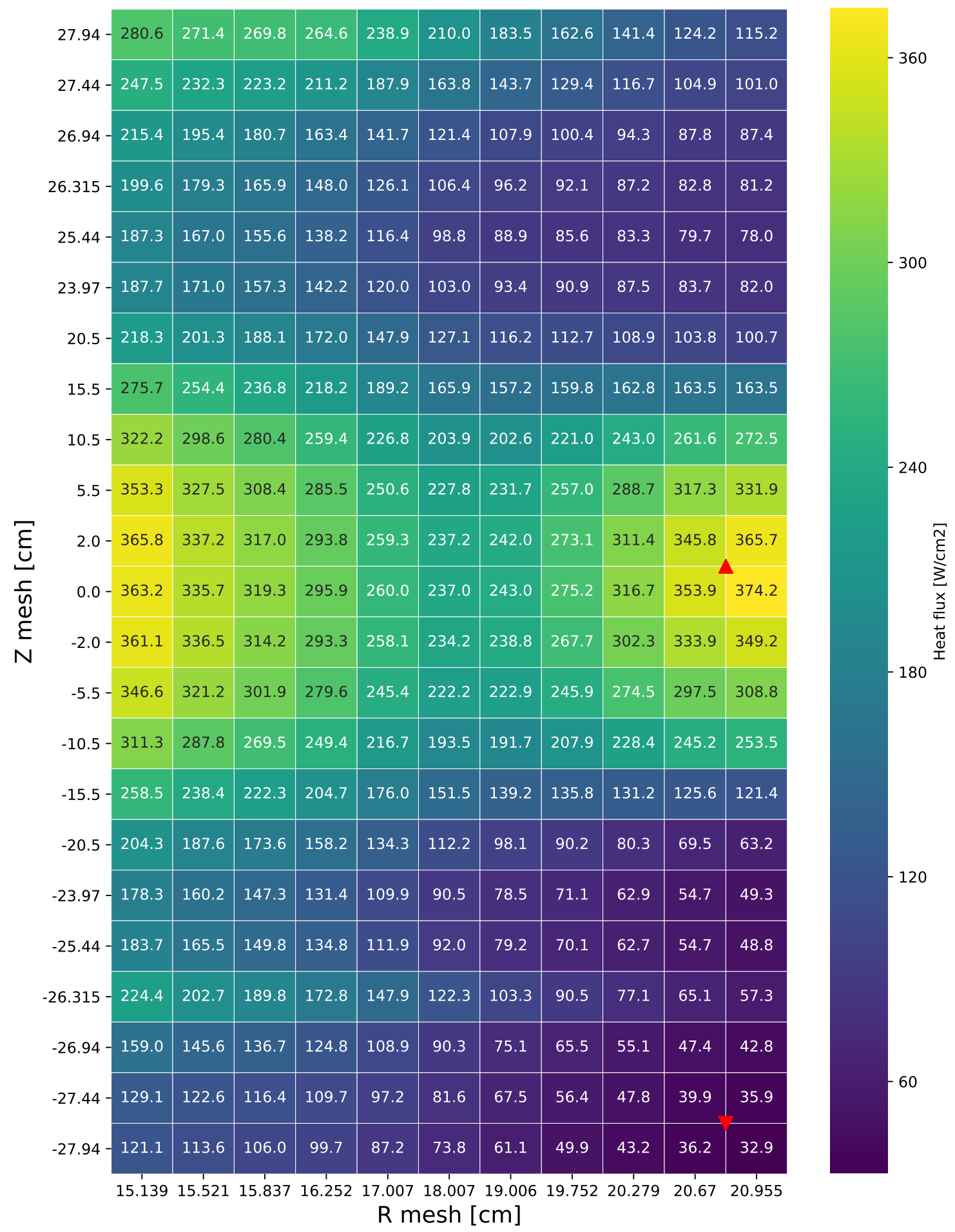

Figure 93. Heat flux distribution for alternate 1 design OFE region on day 0 (see Section 7.2.4). 


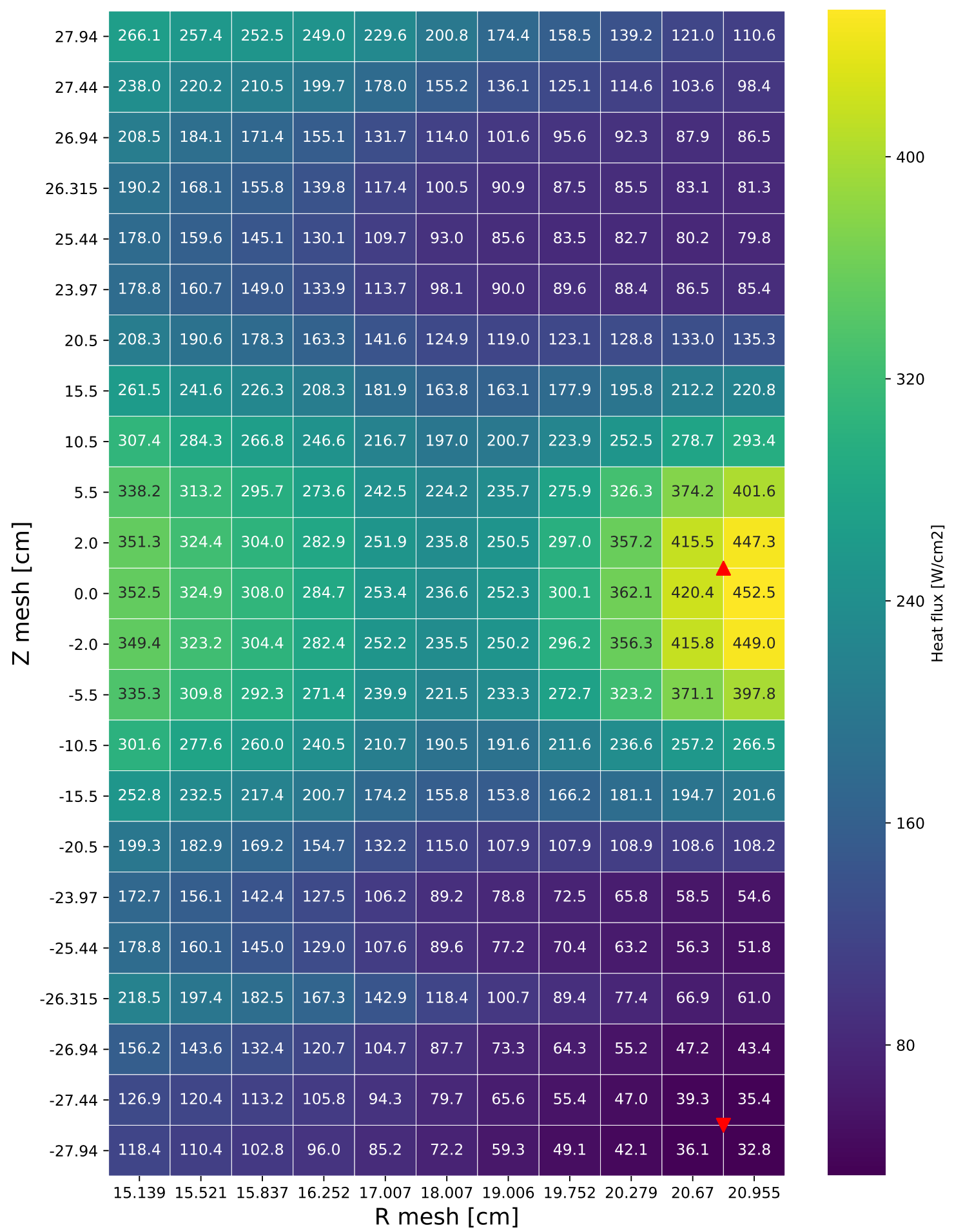

Figure 94. Heat flux distribution for alternate 1 design OFE region on day 1 (see Section 7.2.4). 


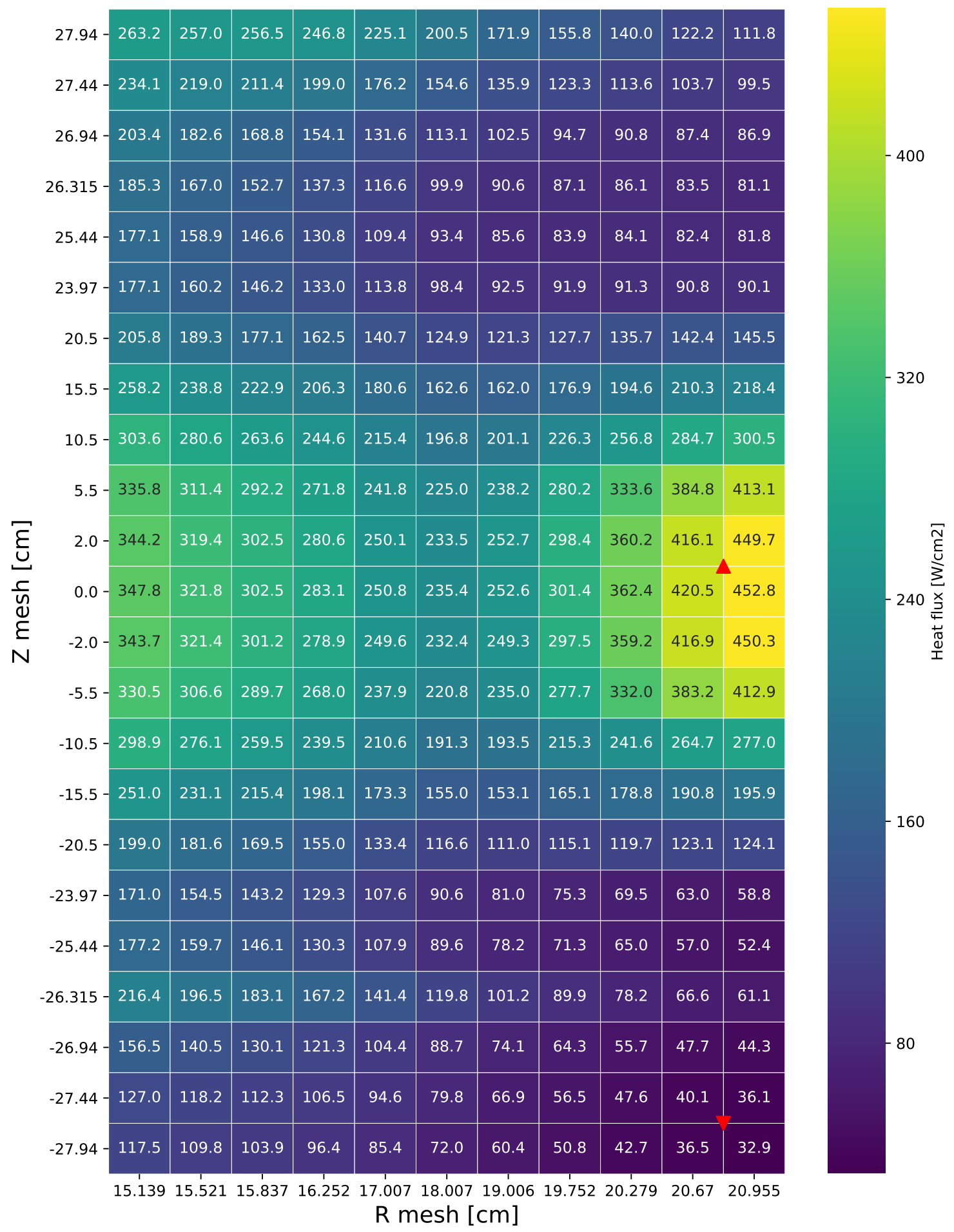

Figure 95. Heat flux distribution for alternate 1 design OFE region on day 2 (see Section 7.2.4). 


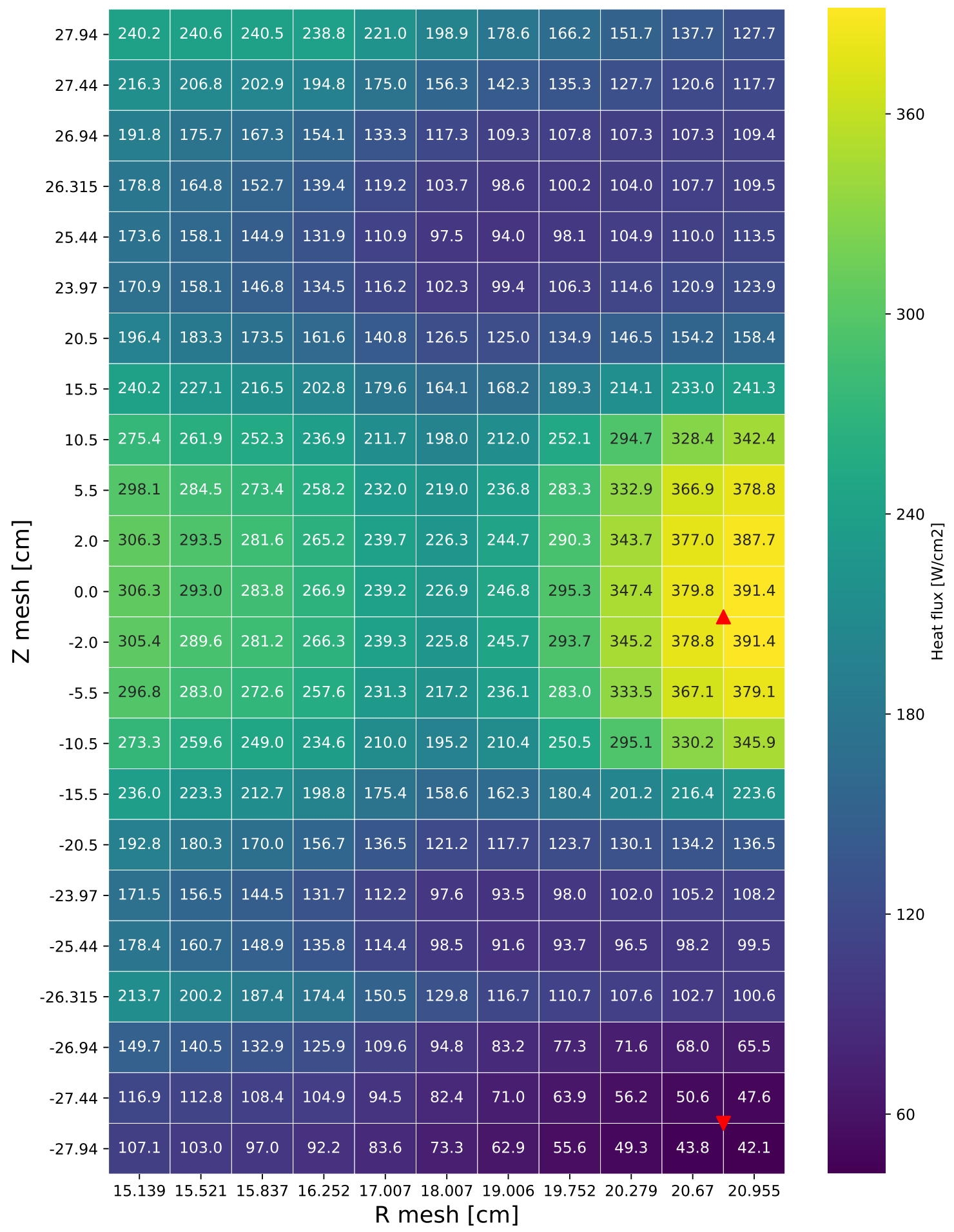

Figure 96. Heat flux distribution for alternate 1 design OFE region on day 15 (see Section 7.2.4). 


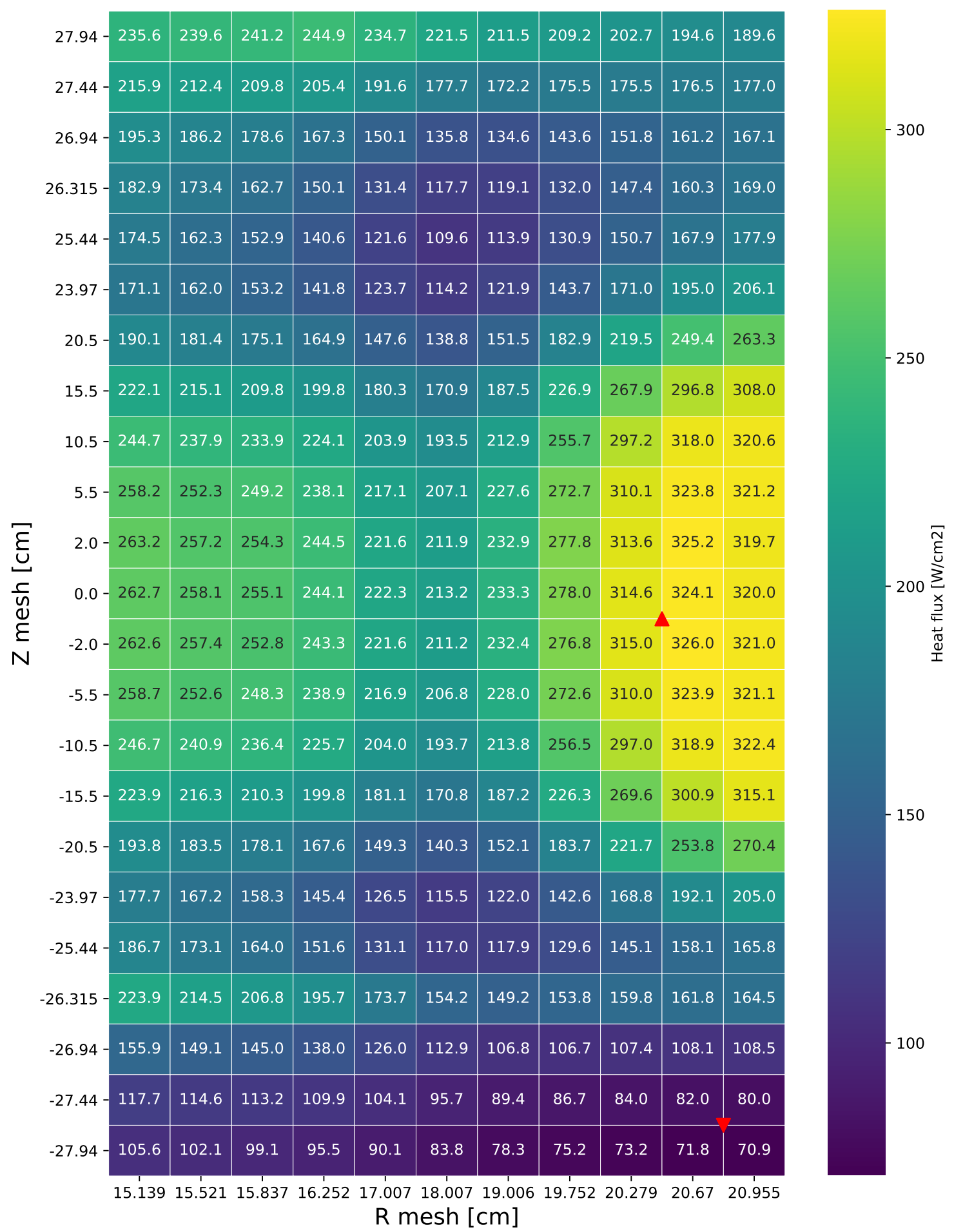

Figure 97. Heat flux distribution for alternate 1 design OFE region on day 27 (see Section 7.2.4). 


\section{APPENDIX C. DISTRIBUTIONS FOR ALTERNATE 2 DESIGN}

\section{APPENDIX C-1. FISSION RATE DENSITY DISTRIBUTIONS FOR ALTERNATE 2 DESIGN}

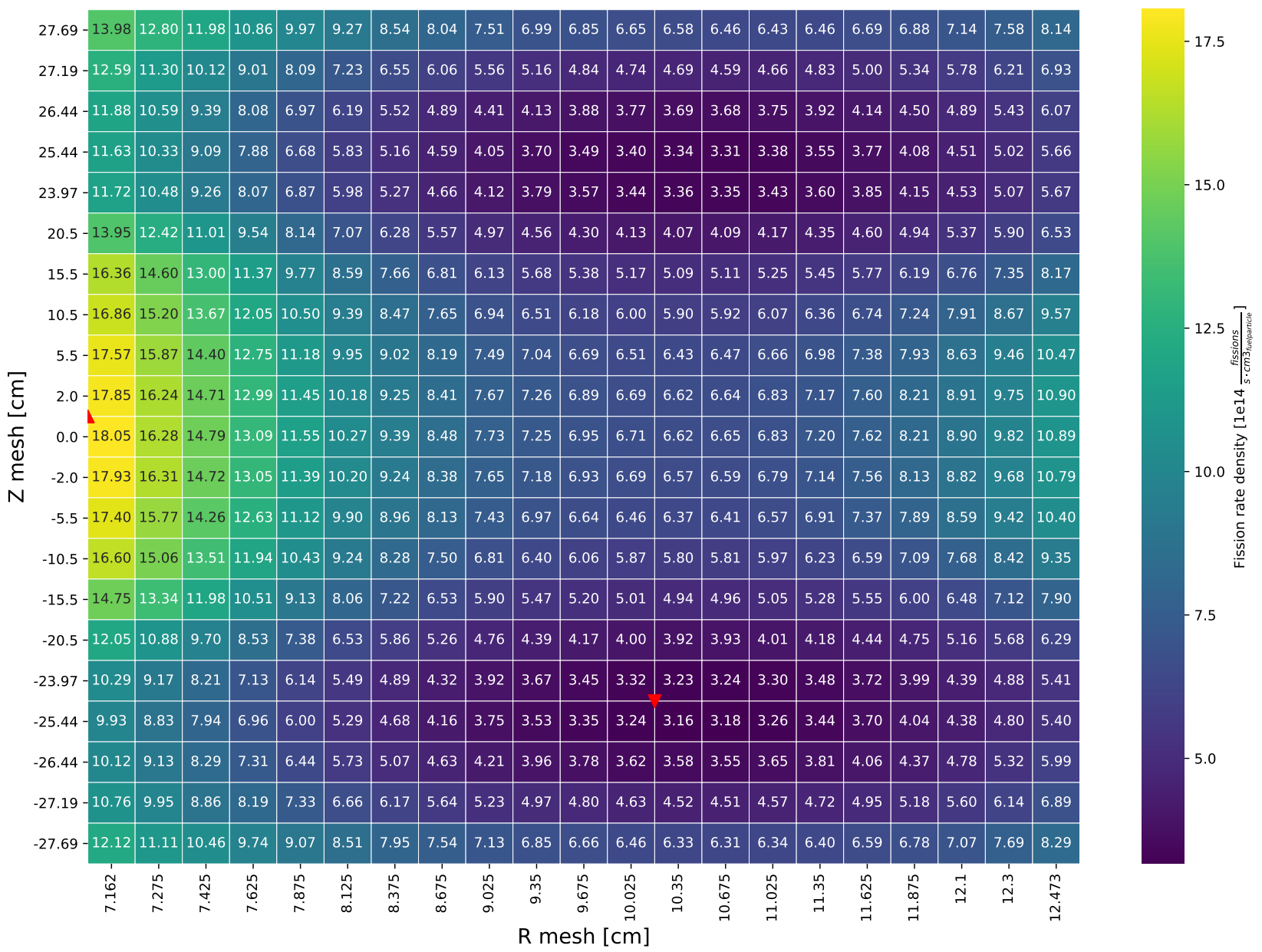

Figure 98. Fission rate density distribution for alternate 2 design IFE region on day 0 (see Section 7.3.2). 


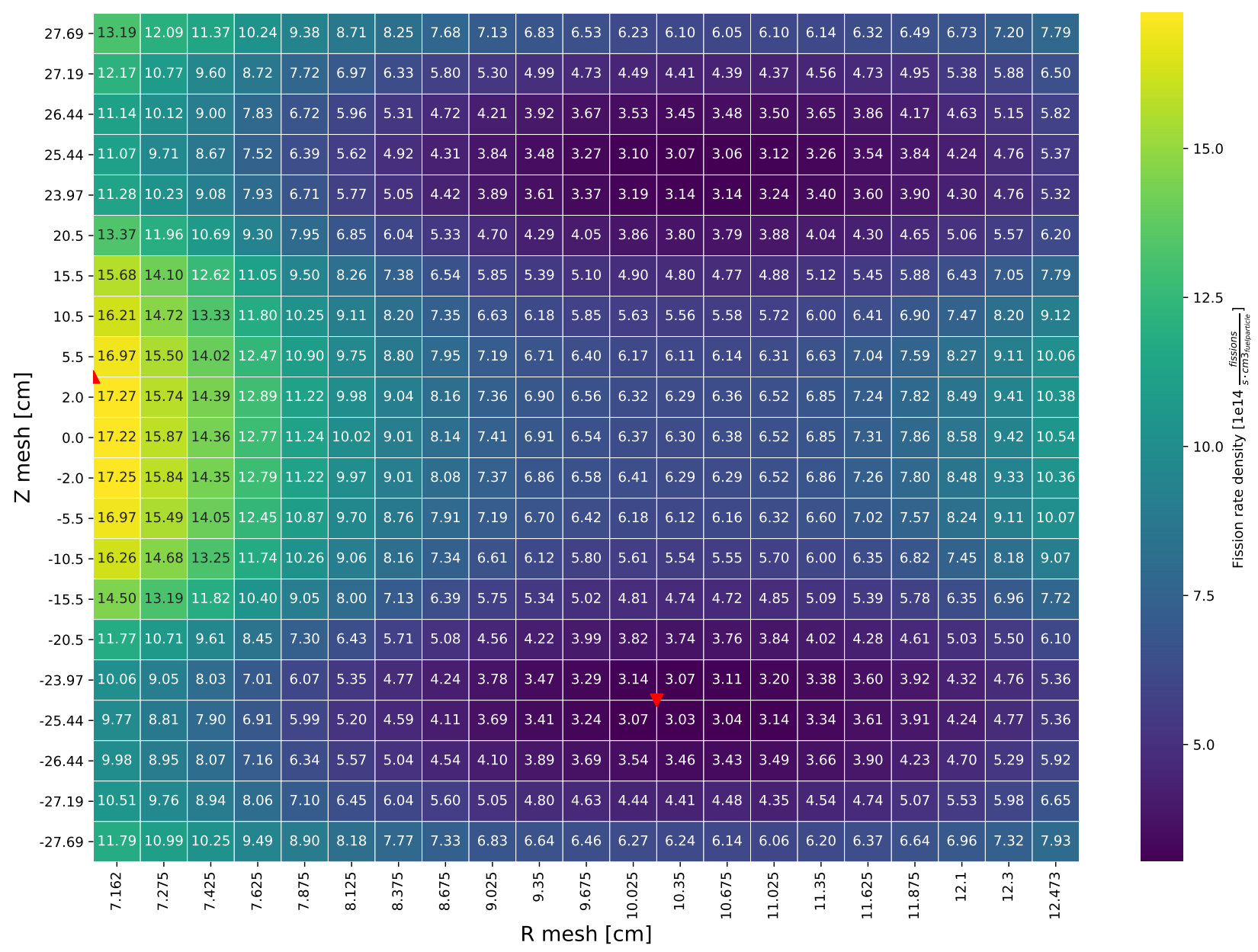

Figure 99. Fission rate density distribution for alternate 2 design IFE region on day 1 (see Section 7.3.2). 


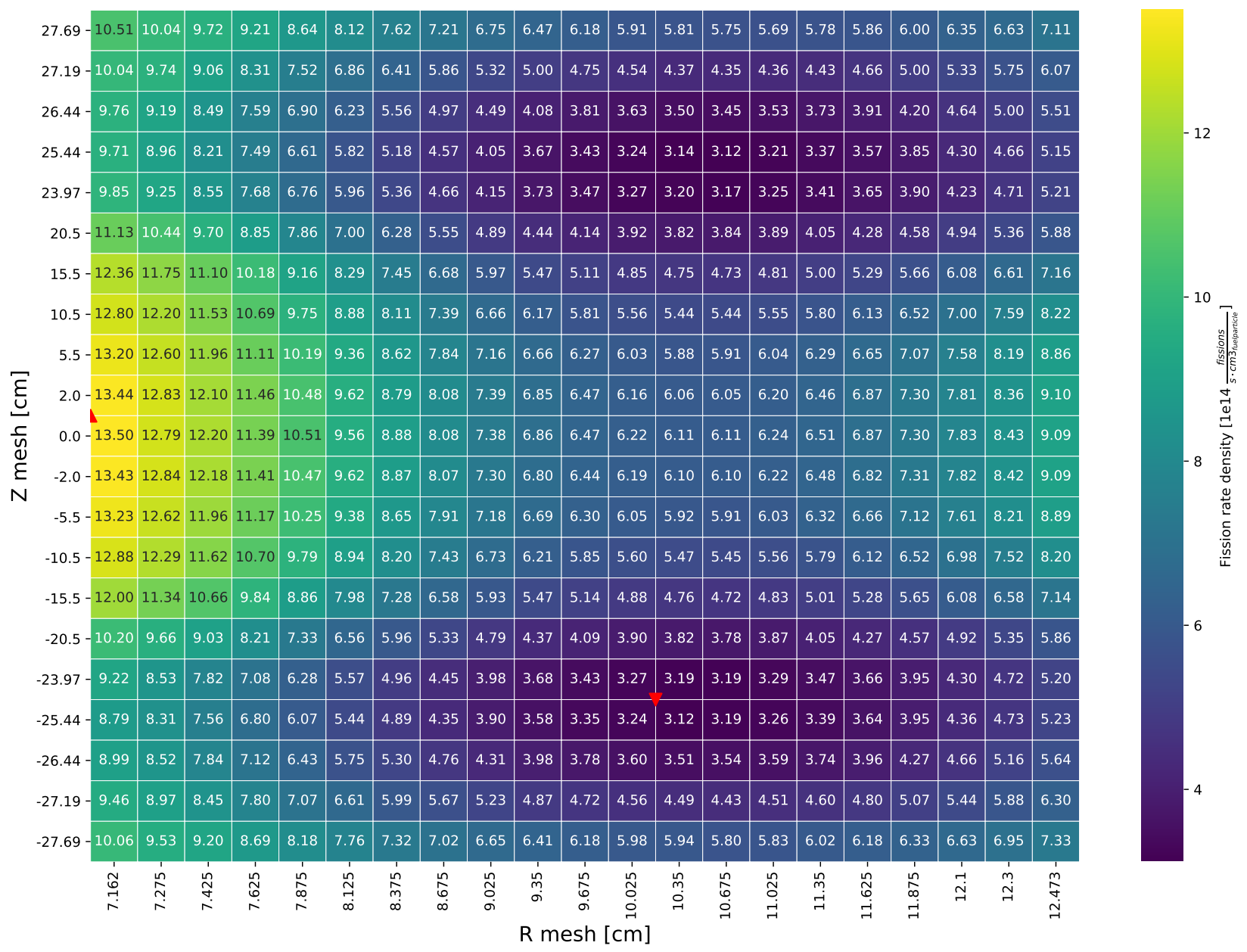

Figure 100. Fission rate density distribution for alternate 2 design IFE region on day 15 (see Section 7.3.2). 


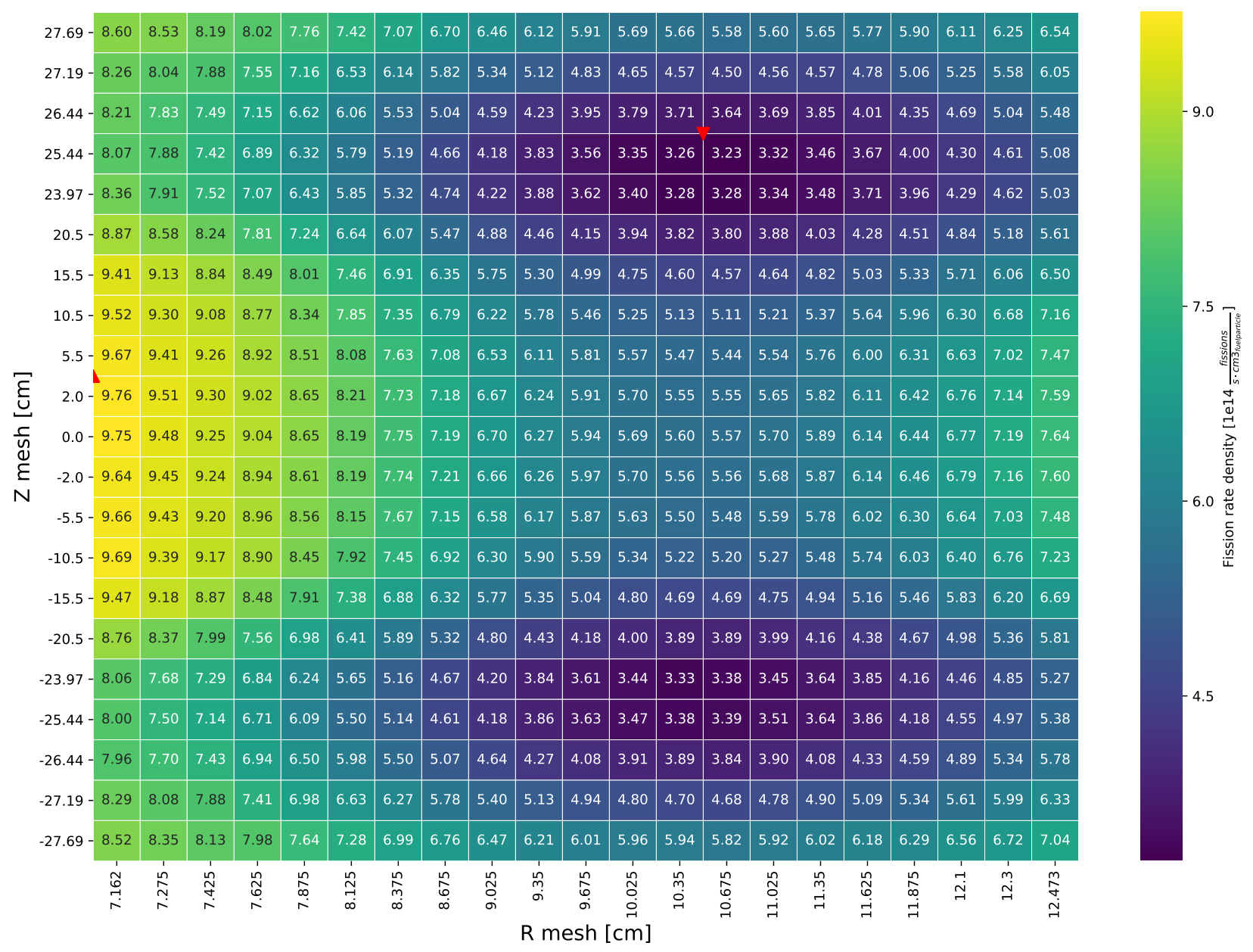

Figure 101. Fission rate density distribution for alternate 2 design IFE region on day 27 (see Section 7.3.2). 


\begin{tabular}{|c|c|c|c|c|c|c|c|c|c|c|c|c|c|c|}
\hline 27.69 & 7.27 & 6.62 & 5.74 & 5.02 & 4.54 & 4.24 & 3.96 & 3.75 & 3.46 & 3.28 & 3.05 & 2.88 & 2.82 & 2.86 \\
\hline 27.19 & 6.26 & 5.51 & 4.55 & 3.76 & 3.35 & 3.04 & 2.83 & 2.64 & 2.48 & 2.36 & 2.25 & 2.21 & 2.29 & 2.47 \\
\hline 26.44 & 5.58 & 4.77 & 3.85 & 3.11 & 2.70 & 2.40 & 2.22 & 2.09 & 1.98 & 1.89 & 1.85 & 1.89 & 2.02 & 2.19 \\
\hline 25.44 & 5.13 & 4.46 & 3.57 & 2.88 & 2.45 & 2.20 & 2.04 & 1.91 & 1.82 & 1.76 & 1.73 & 1.79 & 1.91 & 2.10 \\
\hline 23.97 & 5.14 & 4.47 & 3.66 & 2.96 & 2.53 & 2.27 & 2.11 & 1.99 & 1.89 & 1.83 & 1.81 & 1.86 & 2.02 & 2.17 \\
\hline 20.5 & 5.98 & 5.25 & 4.34 & 3.55 & 3.07 & 2.80 & 2.60 & 2.47 & 2.36 & 2.28 & 2.27 & 2.33 & 2.50 & 2.67 \\
\hline 15.5 & 7.48 & 6.61 & 5.48 & 4.51 & 3.95 & 3.60 & 3.40 & 3.27 & 3.19 & 3.17 & 3.27 & 3.60 & 4.07 & 4.56 \\
\hline 10.5 & 8.77 & 7.77 & 6.47 & 5.33 & 4.71 & 4.35 & 4.13 & 4.02 & 4.02 & 4.13 & 4.48 & 5.24 & 6.28 & 7.33 \\
\hline 5.5 & 9.68 & 8.56 & 7.16 & 5.93 & 5.24 & 4.84 & 4.63 & 4.54 & 4.58 & 4.76 & 5.20 & 6.21 & 7.59 & 8.94 \\
\hline 2.0 & 9.98 & 8.86 & 7.40 & 6.12 & 5.43 & 5.05 & 4.82 & 4.74 & 4.81 & 5.04 & 5.63 & 6.84 & 8.49 & 10.04 \\
\hline 0.0 & 9.98 & 8.82 & 7.40 & 6.13 & 5.44 & 5.04 & 4.82 & 4.76 & 4.82 & 5.09 & 5.70 & 6.95 & 8.68 & 10.34 \\
\hline-2.0 & 9.91 & 8.75 & 7.33 & 6.10 & 5.39 & 4.98 & 4.78 & 4.70 & 4.76 & 5.00 & 5.54 & 6.67 & 8.19 & 9.74 \\
\hline-5.5 & 9.51 & 8.43 & 7.03 & 5.81 & 5.13 & 4.75 & 4.53 & 4.42 & 4.45 & 4.62 & 5.04 & 5.94 & 7.17 & 8.35 \\
\hline-10.5 & 8.51 & 7.55 & 6.29 & 5.20 & 4.58 & 4.21 & 3.99 & 3.87 & 3.87 & 3.98 & 4.28 & 4.98 & 5.94 & 6.87 \\
\hline-15.5 & 7.17 & 6.34 & 5.25 & 4.29 & 3.74 & 3.41 & 3.19 & 3.04 & 2.93 & 2.87 & 2.89 & 3.06 & 3.34 & 3.66 \\
\hline-20.5 & 5.69 & 5.00 & 4.13 & 3.34 & 2.88 & 2.59 & 2.38 & 2.22 & 2.09 & 1.96 & 1.85 & 1.77 & 1.74 & 1.76 \\
\hline-23.97 & 4.95 & 4.28 & 3.47 & 2.77 & 2.34 & 2.08 & 1.91 & 1.77 & 1.64 & 1.55 & 1.45 & 1.39 & 1.37 & 1.37 \\
\hline-25.44 & 5.11 & 4.33 & 3.44 & 2.72 & 2.30 & 2.02 & 1.84 & 1.69 & 1.58 & 1.46 & 1.37 & 1.31 & 1.27 & 1.30 \\
\hline-26.44 & 5.40 & 4.64 & 3.74 & 2.97 & 2.52 & 2.23 & 2.01 & 1.85 & 1.70 & 1.59 & 1.47 & 1.38 & 1.33 & 1.35 \\
\hline-27.19 & 6.11 & 5.38 & 4.42 & 3.62 & 3.14 & 2.85 & 2.56 & 2.35 & 2.15 & 1.97 & 1.81 & 1.65 & 1.55 & 1.54 \\
\hline \multirow[t]{2}{*}{-27.69} & 7.21 & 6.50 & 5.70 & 4.85 & 4.36 & 3.98 & 3.64 & 3.31 & 3.02 & 2.72 & 2.44 & 2.16 & 1.96 & 1.91 \\
\hline & 15.22 & 15.4 & 15.75 & 16.25 & 16.75 & 17.25 & $\begin{array}{r}17.75 \\
\text { R me }\end{array}$ & $\begin{array}{l}18.25 \\
{[\mathrm{~cm}]}\end{array}$ & 18.75 & 19.25 & 19.75 & 20.25 & 20.625 & 20.853 \\
\hline
\end{tabular}

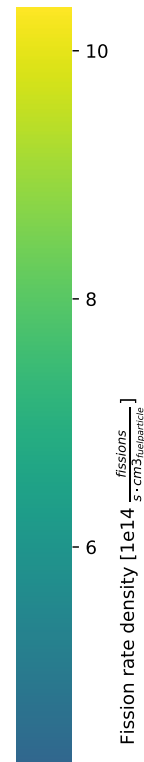

Figure 102. Fission rate density distribution for alternate 2 design OFE region on day 0 (see Section 7.3.2). 


\begin{tabular}{|c|c|c|c|c|c|c|c|c|c|c|c|c|c|c|}
\hline 27.69 & 6.79 & 6.11 & 5.42 & 4.74 & 4.33 & 4.02 & 3.79 & 3.56 & 3.29 & 3.09 & 2.90 & 2.76 & 2.75 & 2.85 \\
\hline 27.19 & 5.88 & 5.12 & 4.25 & 3.48 & 3.12 & 2.84 & 2.66 & 2.48 & 2.35 & 2.20 & 2.12 & 2.13 & 2.23 & 2.37 \\
\hline 26.44 & 5.27 & 4.52 & 3.60 & 2.88 & 2.50 & 2.28 & 2.09 & 1.96 & 1.85 & 1.80 & 1.76 & 1.83 & 1.96 & 2.15 \\
\hline 25.44 & 4.82 & 4.16 & 3.34 & 2.68 & 2.28 & 2.06 & 1.91 & 1.81 & 1.72 & 1.67 & 1.68 & 1.76 & 1.91 & 2.11 \\
\hline 23.97 & 4.87 & 4.24 & 3.43 & 2.77 & 2.39 & 2.16 & 2.01 & 1.89 & 1.83 & 1.80 & 1.79 & 1.90 & 2.08 & 2.30 \\
\hline 20.5 & 5.66 & 4.98 & 4.10 & 3.33 & 2.93 & 2.67 & 2.53 & 2.43 & 2.39 & 2.41 & 2.52 & 2.82 & 3.24 & 3.69 \\
\hline 15.5 & 7.11 & 6.26 & 5.23 & 4.27 & 3.75 & 3.47 & 3.30 & 3.22 & 3.22 & 3.31 & 3.58 & 4.17 & 5.01 & 5.84 \\
\hline 10.5 & 8.33 & 7.36 & 6.15 & 5.07 & 4.49 & 4.16 & 3.97 & 3.91 & 3.92 & 4.11 & 4.55 & 5.44 & 6.64 & 7.85 \\
\hline 5.5 & 9.28 & 8.19 & 6.80 & 5.65 & 5.00 & 4.67 & 4.51 & 4.49 & 4.57 & 4.90 & 5.58 & 6.97 & 8.85 & 10.68 \\
\hline 2.0 & 9.58 & 8.43 & 7.04 & 5.84 & 5.18 & 4.86 & 4.70 & 4.70 & 4.86 & 5.22 & 5.98 & 7.56 & 9.75 & 11.83 \\
\hline 0.0 & 9.65 & 8.51 & 7.09 & 5.86 & 5.21 & 4.89 & 4.74 & 4.71 & 4.88 & 5.27 & 6.08 & 7.65 & 9.81 & 11.97 \\
\hline-2.0 & 9.62 & 8.43 & 7.04 & 5.83 & 5.20 & 4.87 & 4.71 & 4.71 & 4.86 & 5.24 & 6.03 & 7.62 & 9.76 & 11.88 \\
\hline-5.5 & 9.20 & 8.13 & 6.77 & 5.61 & 4.98 & 4.66 & 4.48 & 4.45 & 4.56 & 4.88 & 5.58 & 6.99 & 8.88 & 10.76 \\
\hline-10.5 & 8.33 & 7.35 & 6.11 & 5.05 & 4.44 & 4.11 & 3.92 & 3.84 & 3.86 & 4.00 & 4.37 & 5.17 & 6.22 & 7.28 \\
\hline-15.5 & 7.04 & 6.19 & 5.12 & 4.22 & 3.71 & 3.40 & 3.23 & 3.13 & 3.11 & 3.19 & 3.42 & 3.96 & 4.70 & 5.46 \\
\hline-20.5 & 5.57 & 4.87 & 4.02 & 3.27 & 2.84 & 2.59 & 2.42 & 2.30 & 2.24 & 2.23 & 2.29 & 2.50 & 2.81 & 3.16 \\
\hline-23.97 & 4.79 & 4.13 & 3.36 & 2.68 & 2.31 & 2.06 & 1.90 & 1.76 & 1.67 & 1.58 & 1.51 & 1.47 & 1.47 & 1.51 \\
\hline-25.44 & 4.84 & 4.11 & 3.33 & 2.62 & 2.21 & 1.97 & 1.79 & 1.67 & 1.55 & 1.45 & 1.40 & 1.35 & 1.34 & 1.37 \\
\hline-26.44 & 5.22 & 4.50 & 3.59 & 2.85 & 2.43 & 2.12 & 1.94 & 1.80 & 1.65 & 1.56 & 1.43 & 1.36 & 1.37 & 1.40 \\
\hline-27.19 & 5.95 & 5.13 & 4.19 & 3.45 & 3.06 & 2.72 & 2.48 & 2.28 & 2.11 & 1.94 & 1.75 & 1.60 & 1.57 & 1.54 \\
\hline \multirow[t]{2}{*}{$-27.69-$} & 6.95 & 6.29 & 5.50 & 4.73 & 4.26 & 3.87 & 3.55 & 3.26 & 2.97 & 2.65 & 2.40 & 2.12 & 1.92 & 1.86 \\
\hline & 15.22 & 15.4 & 15.75 & 16.25 & 16.75 & 17.25 & $\begin{array}{r}17.75 \\
\mathrm{R}\end{array}$ & $\begin{array}{l}18.25 \\
{[\mathrm{~cm}]}\end{array}$ & 18.75 & 19.25 & 19.75 & 20.25 & 20.625 & 20.853 \\
\hline
\end{tabular}

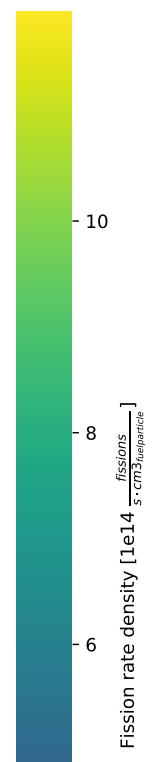

Figure 103. Fission rate density distribution for alternate 2 design OFE region on day 1 (see Section 7.3.2). 


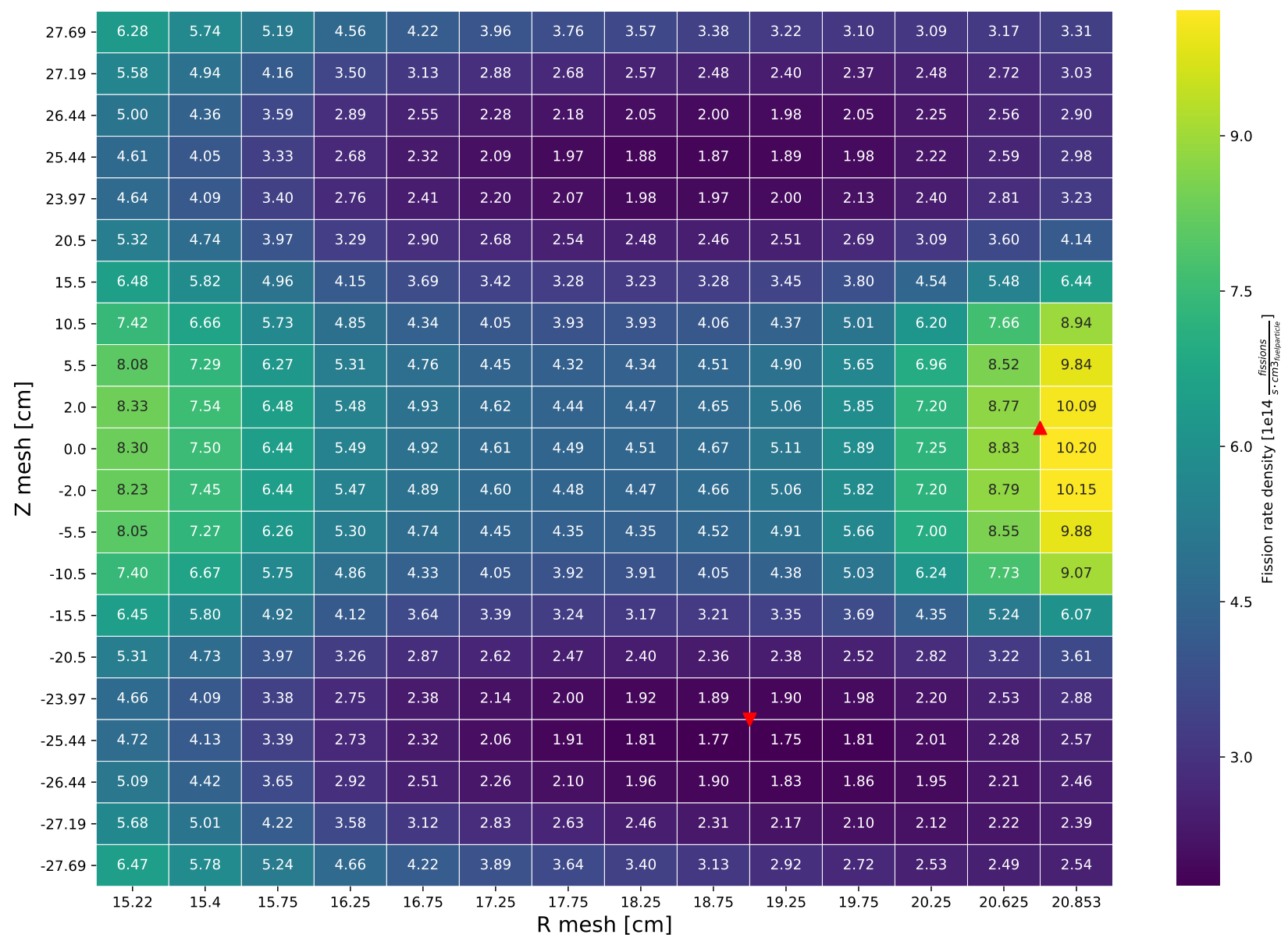

Figure 104. Fission rate density distribution for alternate 2 design OFE region on day 15 (see Section 7.3.2). 


\begin{tabular}{|c|c|c|c|c|c|c|c|c|c|c|c|c|c|c|c|}
\hline 27.69 & 6.05 & 5.70 & 5.22 & 4.75 & 4.42 & 4.23 & 4.13 & 3.99 & 3.94 & 3.90 & 3.94 & 4.15 & 4.50 & 4.91 & \multirow[b]{3}{*}{7.5} \\
\hline 27.19 & 5.47 & 5.00 & 4.38 & 3.71 & 3.39 & 3.18 & 3.04 & 2.98 & 2.91 & 2.98 & 3.08 & 3.43 & 3.93 & 4.53 & \\
\hline 26.44 & 4.98 & 4.47 & 3.77 & 3.16 & 2.77 & 2.58 & 2.46 & 2.39 & 2.37 & 2.46 & 2.67 & 3.13 & 3.79 & 4.46 & \\
\hline 25.44 & 4.70 & 4.15 & 3.49 & 2.87 & 2.51 & 2.32 & 2.22 & 2.16 & 2.20 & 2.34 & 2.62 & 3.22 & 4.02 & 4.75 & \\
\hline 23.97 & 4.61 & 4.11 & 3.49 & 2.91 & 2.57 & 2.38 & 2.29 & 2.28 & 2.34 & 2.50 & 2.89 & 3.60 & 4.54 & 5.46 & \\
\hline 20.5 & 5.15 & 4.64 & 3.97 & 3.38 & 3.02 & 2.83 & 2.74 & 2.75 & 2.86 & 3.13 & 3.63 & 4.58 & 5.74 & 6.79 & \\
\hline 15.5 & 5.98 & 5.42 & 4.75 & 4.06 & 3.65 & 3.44 & 3.35 & 3.37 & 3.53 & 3.86 & 4.46 & 5.55 & 6.80 & 7.91 & \\
\hline 10.5 & 6.57 & 6.03 & 5.27 & 4.56 & 4.10 & 3.87 & 3.79 & 3.81 & 3.97 & 4.35 & 5.01 & 6.12 & 7.27 & 8.18 & \\
\hline 5.5 & 6.89 & 6.29 & 5.56 & 4.84 & 4.40 & 4.14 & 4.06 & 4.09 & 4.29 & 4.67 & 5.36 & 6.43 & 7.47 & 8.22 & \\
\hline 2.0 & 7.03 & 6.43 & 5.70 & 4.94 & 4.49 & 4.22 & 4.13 & 4.17 & 4.36 & 4.75 & 5.47 & 6.53 & 7.55 & 8.28 & \\
\hline 0.0 & 7.07 & 6.46 & 5.72 & 4.98 & 4.50 & 4.25 & 4.14 & 4.18 & 4.38 & 4.78 & 5.49 & 6.58 & 7.58 & 8.28 & \\
\hline-2.0 & 7.00 & 6.48 & 5.71 & 5.00 & 4.50 & 4.25 & 4.14 & 4.19 & 4.37 & 4.78 & 5.47 & 6.55 & 7.57 & 8.29 & \\
\hline-5.5 & 6.94 & 6.35 & 5.64 & 4.90 & 4.42 & 4.17 & 4.06 & 4.10 & 4.30 & 4.70 & 5.37 & 6.46 & 7.52 & 8.29 & \\
\hline-10.5 & 6.65 & 6.10 & 5.35 & 4.61 & 4.16 & 3.91 & 3.83 & 3.87 & 4.03 & 4.40 & 5.08 & 6.20 & 7.37 & 8.27 & \\
\hline-15.5 & 6.13 & 5.54 & 4.83 & 4.14 & 3.72 & 3.49 & 3.40 & 3.43 & 3.58 & 3.91 & 4.54 & 5.66 & 6.97 & 8.11 & \\
\hline-20.5 & 5.30 & 4.77 & 4.09 & 3.46 & 3.08 & 2.89 & 2.81 & 2.81 & 2.92 & 3.18 & 3.69 & 4.67 & 5.92 & 7.08 & \\
\hline-23.97 & 4.81 & 4.28 & 3.60 & 2.98 & 2.63 & 2.43 & 2.32 & 2.31 & 2.35 & 2.53 & 2.92 & 3.66 & 4.63 & 5.57 & \\
\hline-25.44 & 4.94 & 4.31 & 3.63 & 2.95 & 2.57 & 2.36 & 2.25 & 2.20 & 2.20 & 2.33 & 2.57 & 3.11 & 3.79 & 4.55 & \\
\hline-26.44 & 5.27 & 4.72 & 3.96 & 3.25 & 2.84 & 2.62 & 2.46 & 2.39 & 2.35 & 2.42 & 2.59 & 2.94 & 3.50 & 3.99 & 3.0 \\
\hline$-27.19-$ & 5.83 & 5.22 & 4.63 & 3.90 & 3.52 & 3.27 & 3.12 & 2.96 & 2.91 & 2.86 & 2.91 & 3.14 & 3.52 & 3.98 & \\
\hline$-27.69-$ & 6.45 & 6.09 & 5.58 & 4.99 & 4.65 & 4.41 & 4.21 & 3.99 & 3.92 & 3.79 & 3.73 & 3.79 & 3.99 & 4.32 & \\
\hline & 15.22 & 15.4 & 15.75 & 16.25 & 16.75 & 17.25 & $\begin{array}{r}17.75 \\
\mathrm{R} \text { me }\end{array}$ & $\begin{array}{l}18.25 \\
{[\mathrm{~cm}]}\end{array}$ & 18.75 & 19.25 & 19.75 & 20.25 & 20.625 & 20.853 & \\
\hline
\end{tabular}

Figure 105. Fission rate density distribution for alternate 2 design OFE region on day 27 (see Section 7.3.2). 


\section{APPENDIX C-2. CUMULATIVE FISSION DENSITY DISTRIBUTIONS FOR ALTERNATE 2 DESIGN}

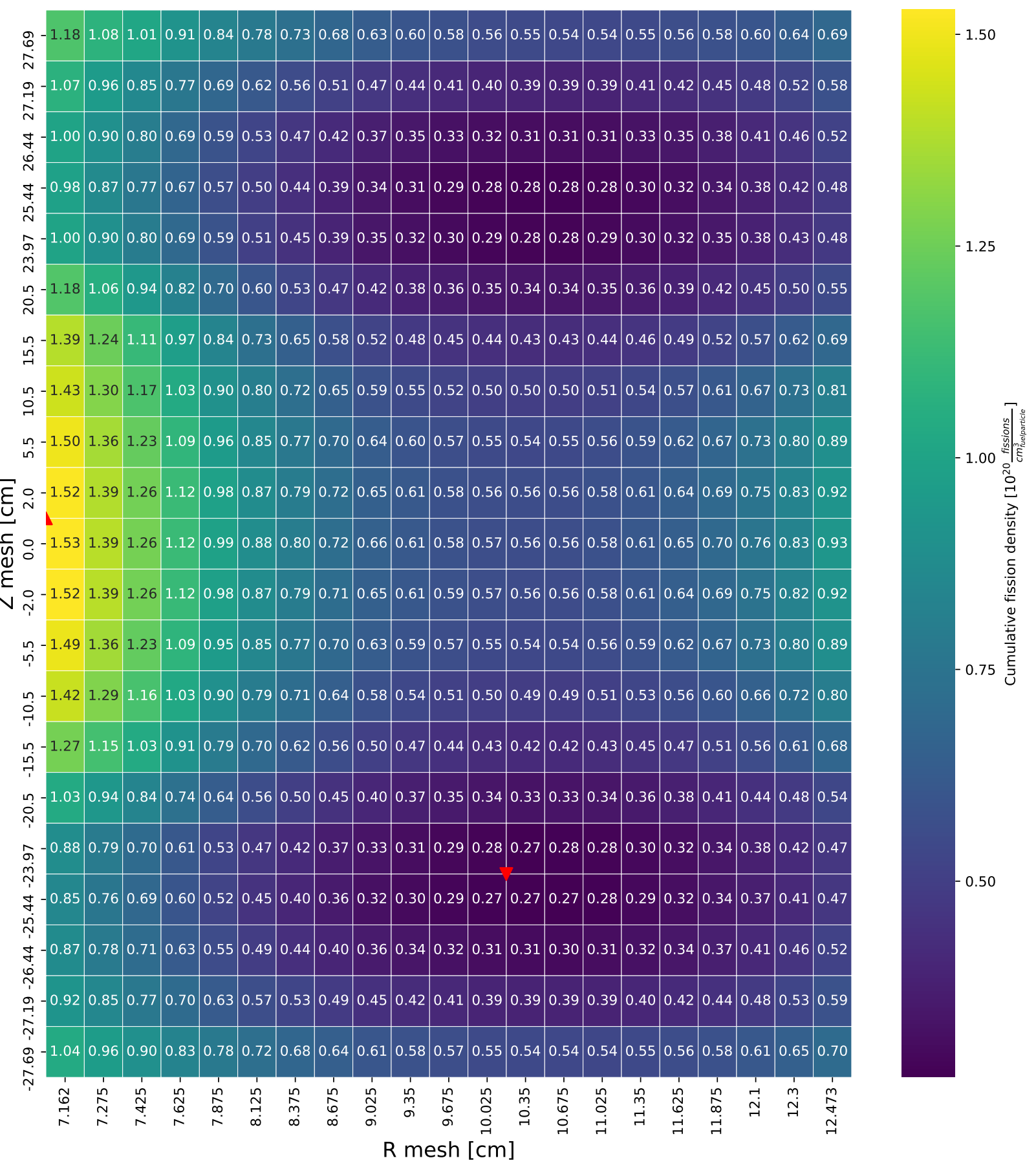

Figure 106. Cumulative fission density distribution for alternate 2 design IFE region on day 1 (see Section 7.3.5). 


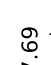

ก

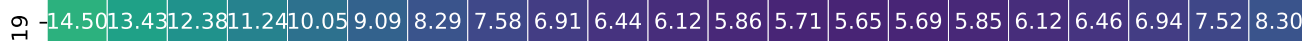

ì

$\stackrel{8}{8}$

ஸे

\&

กิ

ติ

เก -

ํำ

กุ่

นก $-19.1817 .8216 .4514 .8713 .2111 .8210 .709 .63 \quad 8.698 .05 \quad 7.61 \quad 7.31 \quad 7.17 \quad 7.17 \quad 7.35 \quad 7.70 \quad 8.16 \quad 8.75 \quad 9.4710 .3211 .33$ $\stackrel{\circ}{+1}$

in $-19.9618 .6117 .2215 .6413 .9812 .5911 .4510 .369 .398 .73 \quad 8.26 \quad 7.96 \quad 7.837 .858 .05 \quad 8.438 .93 \quad 9.5910 .3711 .2912 .37$ เก

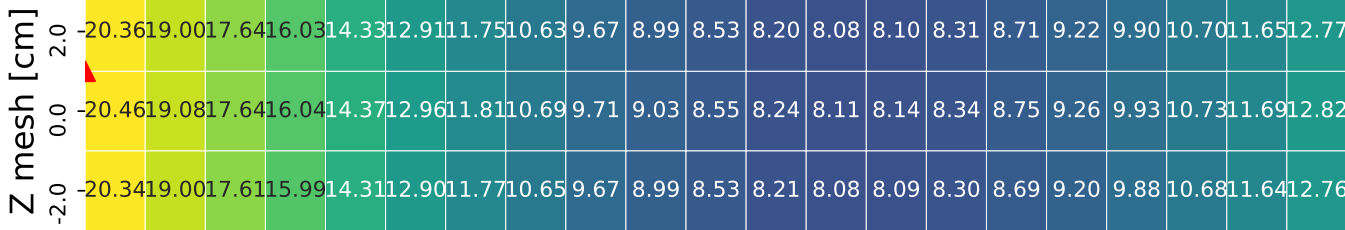

in $-19.9718 .6317 .2715 .6613 .9912 .5911 .4510 .359 .398 .72 \quad 8.27 \quad 7.96 \quad 7.83 \quad 7.84 \quad 8.05 \quad 8.42 \quad 8.92 \quad 9.5810 .3511 .2812 .37$

น $-19.1817 .8316 .4614 .8613 .2011 .8310 .719 .64 \quad 8.70 \quad 8.05 \quad 7.60 \quad 7.30 \quad 7.17 \quad 7.17 \quad 7.35 \quad 7.68 \quad 8.13 \quad 8.73 \quad 9.4310 .2811 .29$ 우

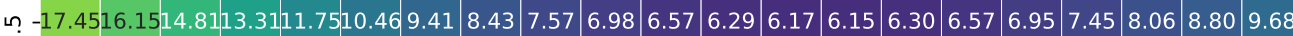
เก

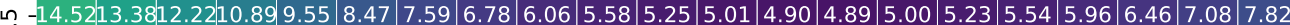

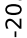

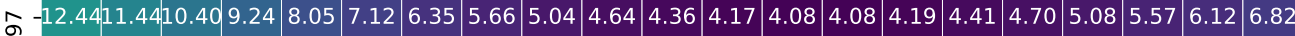

$\stackrel{m}{\sim}$

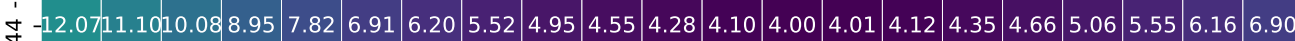

$\stackrel{\llcorner}{\sim}$

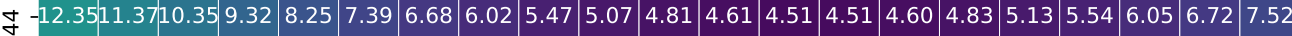

$\stackrel{\bullet}{\oplus}$

윽 -13.1212.1711.2910.309.29 $8.52 \quad 7.897 .27 \quad 6.696 .326 .07 \quad 5.835 .73 \quad 5.715 .77 \quad 5.96 \quad 6.24 \quad 6.62 \quad 7.10 \quad 7.72 \quad 8.53$

กิ

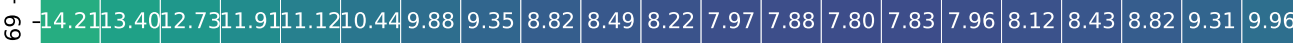

ஸิ

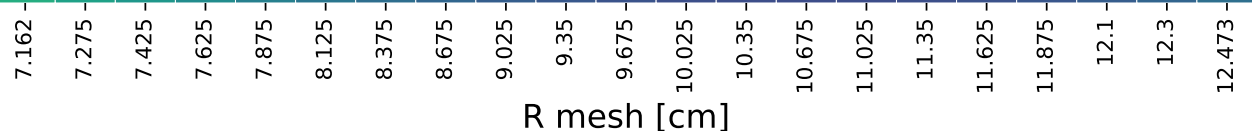

Figure 107. Cumulative fission density distribution for alternate 2 design IFE region on day 15 (see Section 7.3.5). 


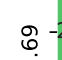

กิ

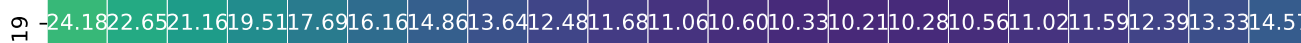

กิ

$\stackrel{n}{N}$

In -29.8428 .0126 .0823 .8021 .2919 .1217 .2615 .4513 .8212 .7011 .9011 .3411 .0711 .0411 .2611 .7312 .3913 .2414 .2615 .4516 .87$ เก

เก -30.7928 .9927 .1725 .0022 .6320 .5518 .7817 .0215 .4214 .3113 .5212 .9512 .7012 .6912 .9813 .5414 .3015 .2716 .4117 .7519 .33$ 이

เก -31.8130 .0328 .2326 .1123 .7621 .7119 .9318 .1716 .5415 .4014 .5814 .0213 .7613 .7814 .1014 .7215 .5416 .5817 .7919 .2220 .90$ เก

Е 우 -32.3730 .5728 .8026 .6724 .3022 .1920 .4118 .6217 .0015 .8315 .0114 .4114 .1714 .1814 .5215 .1816 .0017 .0818 .3119 .7621 .48$ $\underline{\varepsilon} \stackrel{i}{\sim}$

등 우 -32.4730 .6828 .8426 .6824 .3522 .2820 .5018 .7117 .0615 .9015 .0514 .4714 .2314 .2614 .5815 .2316 .0617 .1118 .3619 .8521 .58$ $\stackrel{\mathscr{v}}{\varepsilon}$

$\varepsilon$ 。 -32.3530 .5628 .7926 .6424 .2822 .1920 .4318 .6316 .9915 .8315 .0214 .4314 .1714 .1914 .5215 .1616 .0017 .0518 .3119 .7621 .48$ $N \stackrel{\circ}{\sim}$

In -31.9030 .1528 .3626 .2023 .8521 .7720 .0018 .2216 .6015 .4414 .6214 .0513 .7913 .8014 .1214 .7415 .5616 .6017 .8019 .2420 .92$

นก -30.8829 .1027 .3025 .1122 .7420 .6618 .8717 .1115 .5114 .3713 .5613 .0112 .7412 .7313 .0113 .5814 .3315 .2916 .4217 .7619 .35$ 국

in -28.6026 .8225 .0022 .8620 .5418 .5316 .8115 .1613 .6512 .5911 .8511 .3311 .0811 .0411 .2811 .7512 .4013 .2514 .2615 .4616 .88$ เก

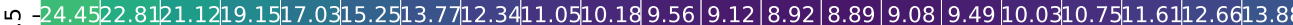

$\stackrel{\text { ì }}{\sim}$

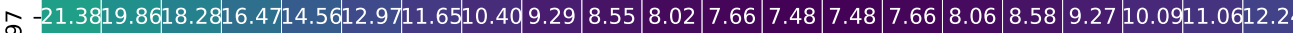

$\stackrel{m}{N}$

8

กั่

8

$\stackrel{\leftrightarrow}{\grave{1}}$

을 -22.3220 .9419 .6518 .1416 .6015 .3314 .2513 .2112 .2311 .5711 .0710 .6810 .4810 .4310 .5510 .8711 .3712 .0412 .8313 .8515 .17$

กิ

ชิ

i

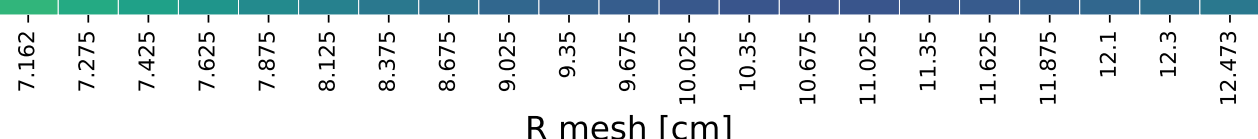

Figure 108. Cumulative fission density distribution for alternate 2 design IFE region on day 27 (see Section 7.3.5). 


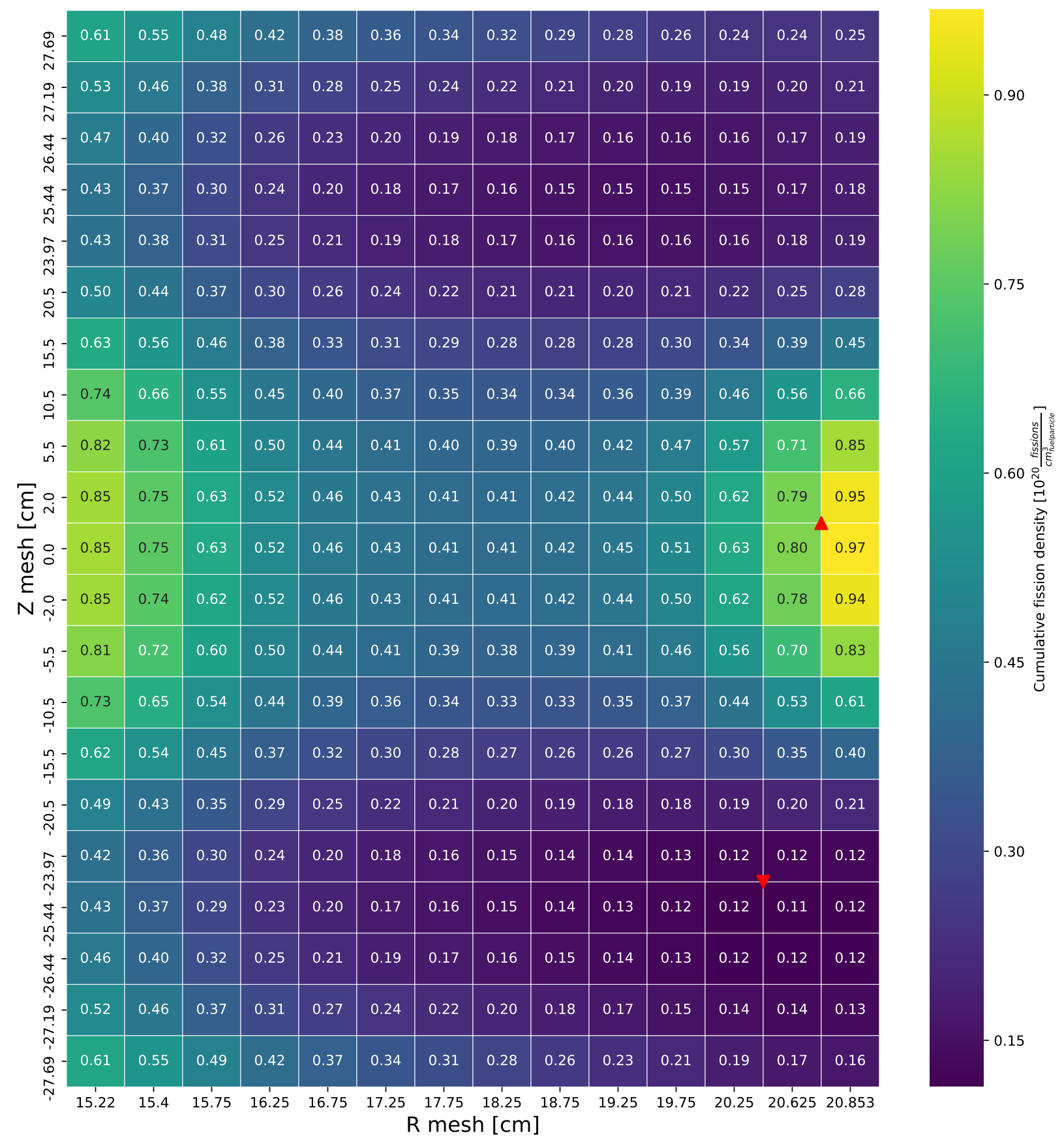

Figure 109. Cumulative fission density distribution for alternate 2 design OFE region on day 1 (see Section 7.3.5). 


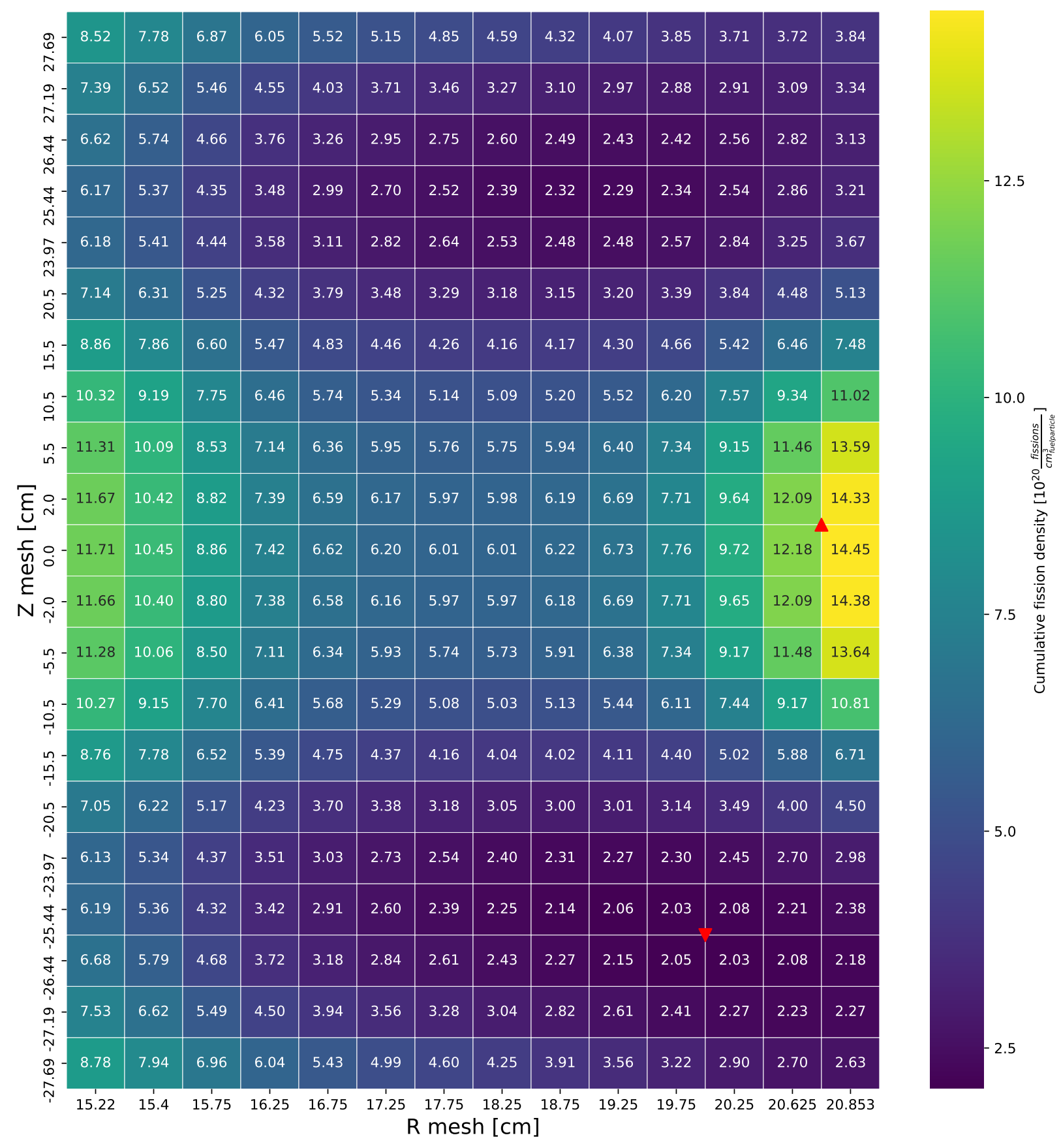

Figure 110. Cumulative fission density distribution for alternate 2 design OFE region on day 15 (see Section 7.3.5). 


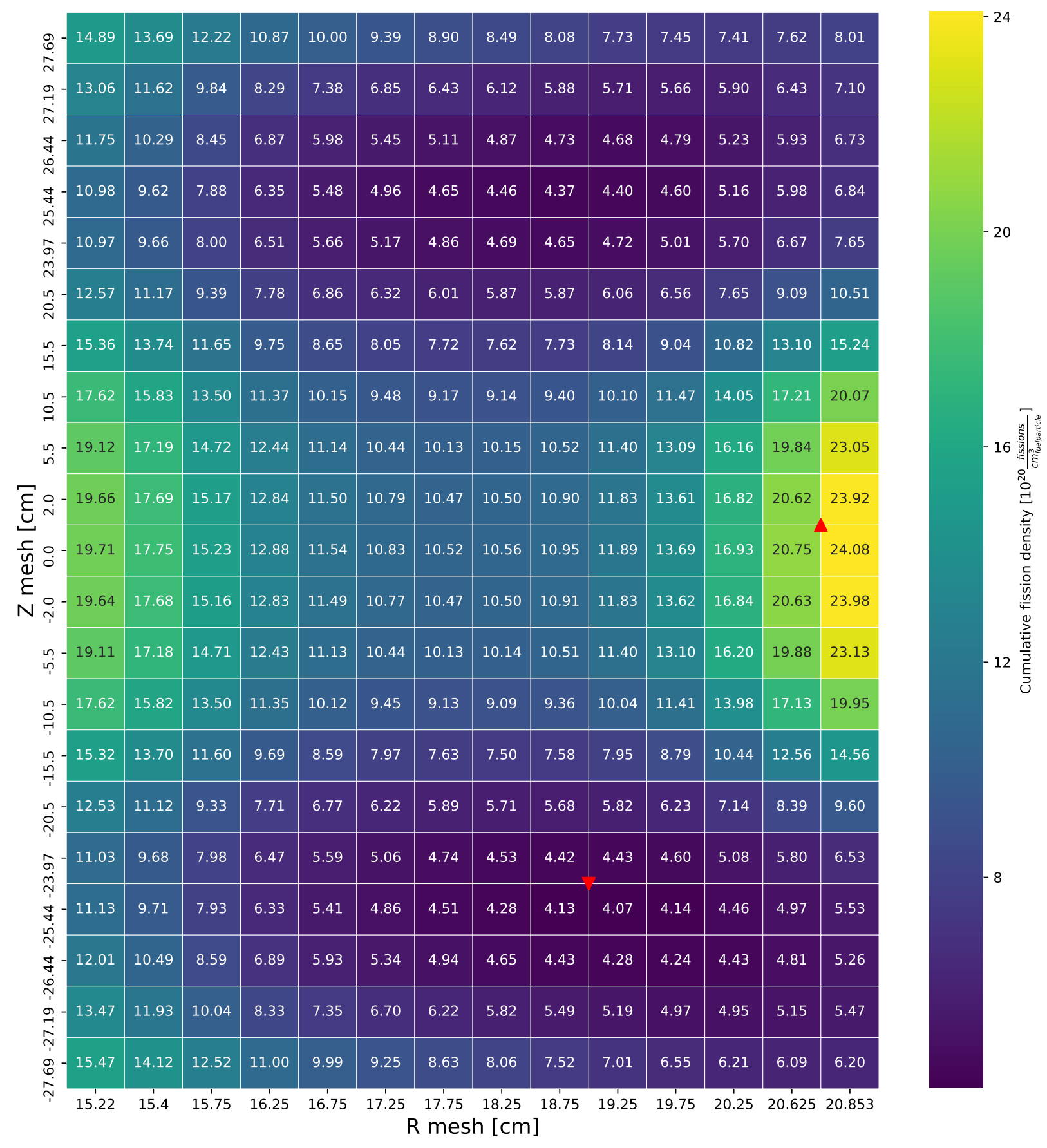

Figure 111. Cumulative fission density distribution for alternate 2 design OFE region on day 27 (see Section 7.3.5). 


\section{APPENDIX C-3. POWER DENSITY DISTRIBUTIONS FOR ALTERNATE 2 DESIGN}

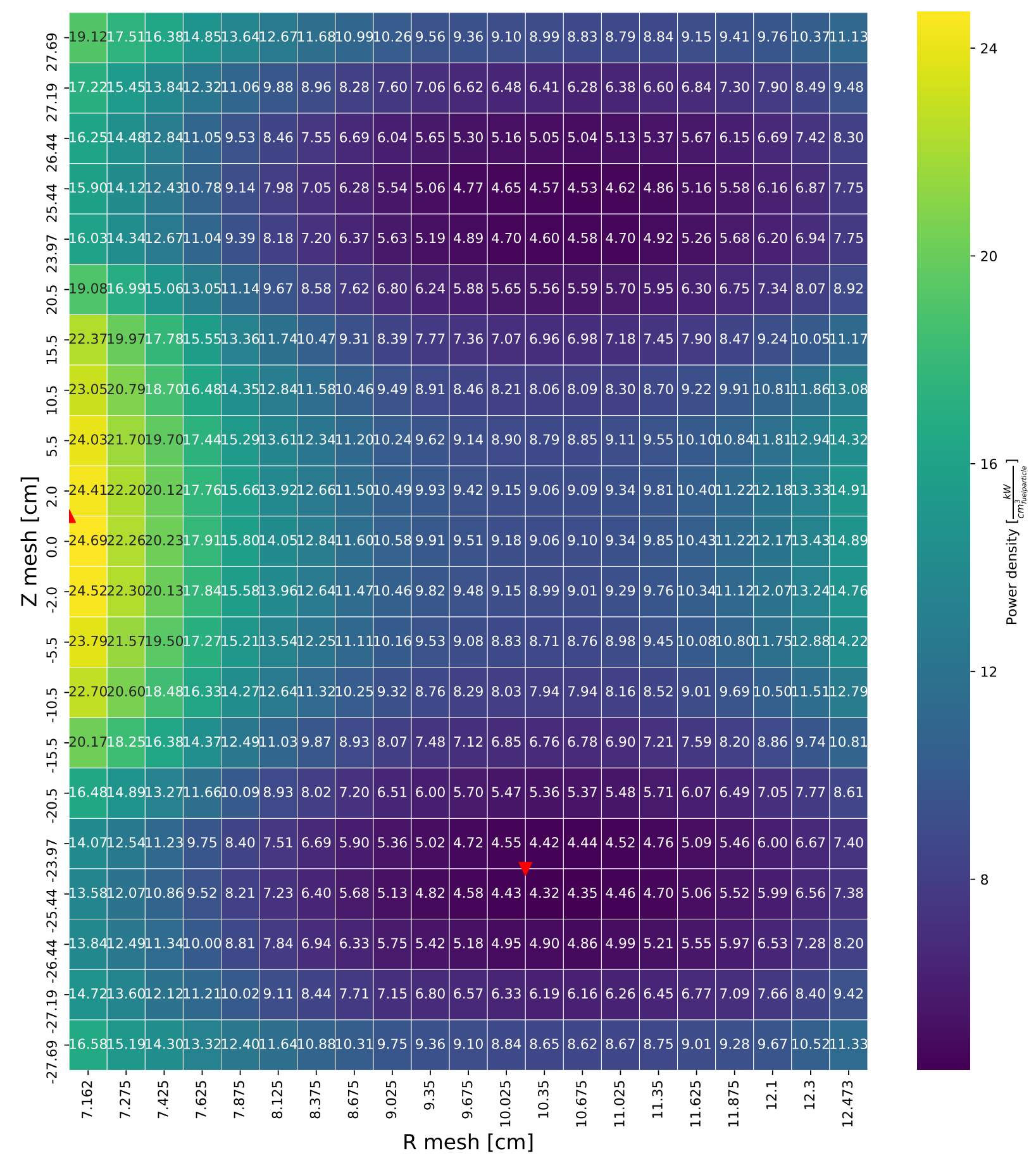

Figure 112. Power density distribution for alternate 2 design IFE region on day 0 (see Section 7.3.3). 


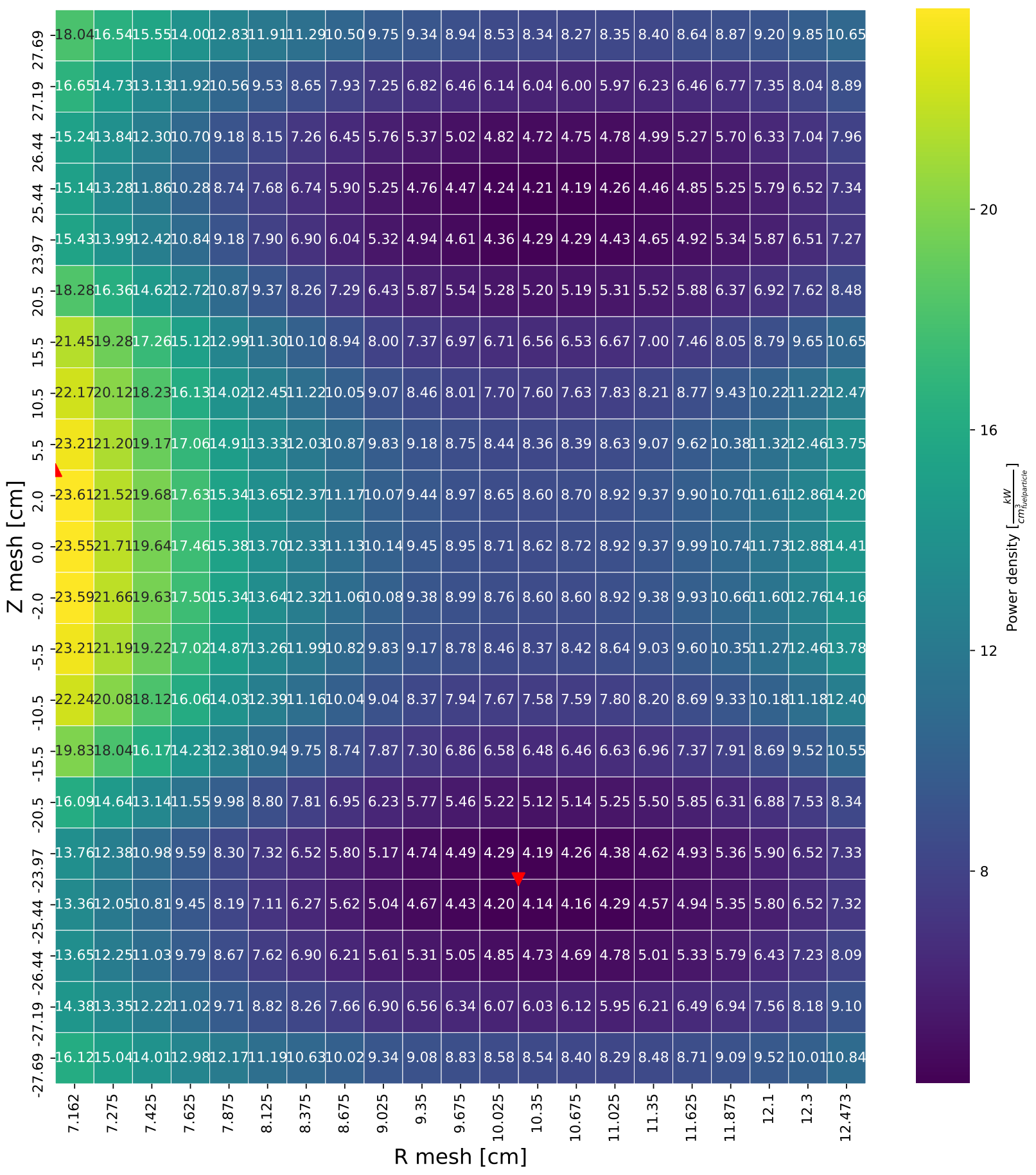

Figure 113. Power density distribution for alternate 2 design IFE region on day 1 (see Section 7.3.3). 


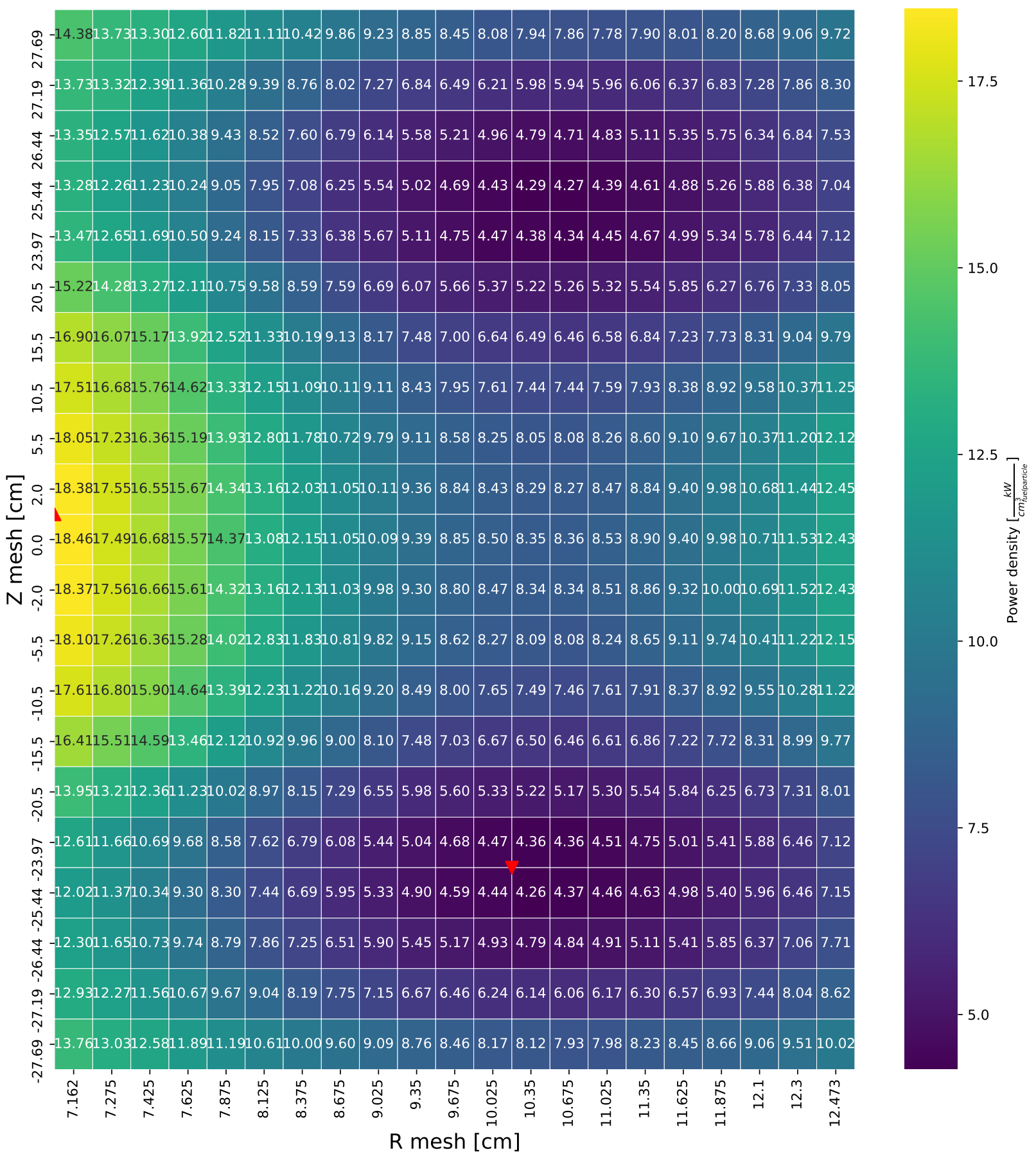

Figure 114. Power density distribution for alternate 2 design IFE region on day 15 (see Section 7.3.3). 


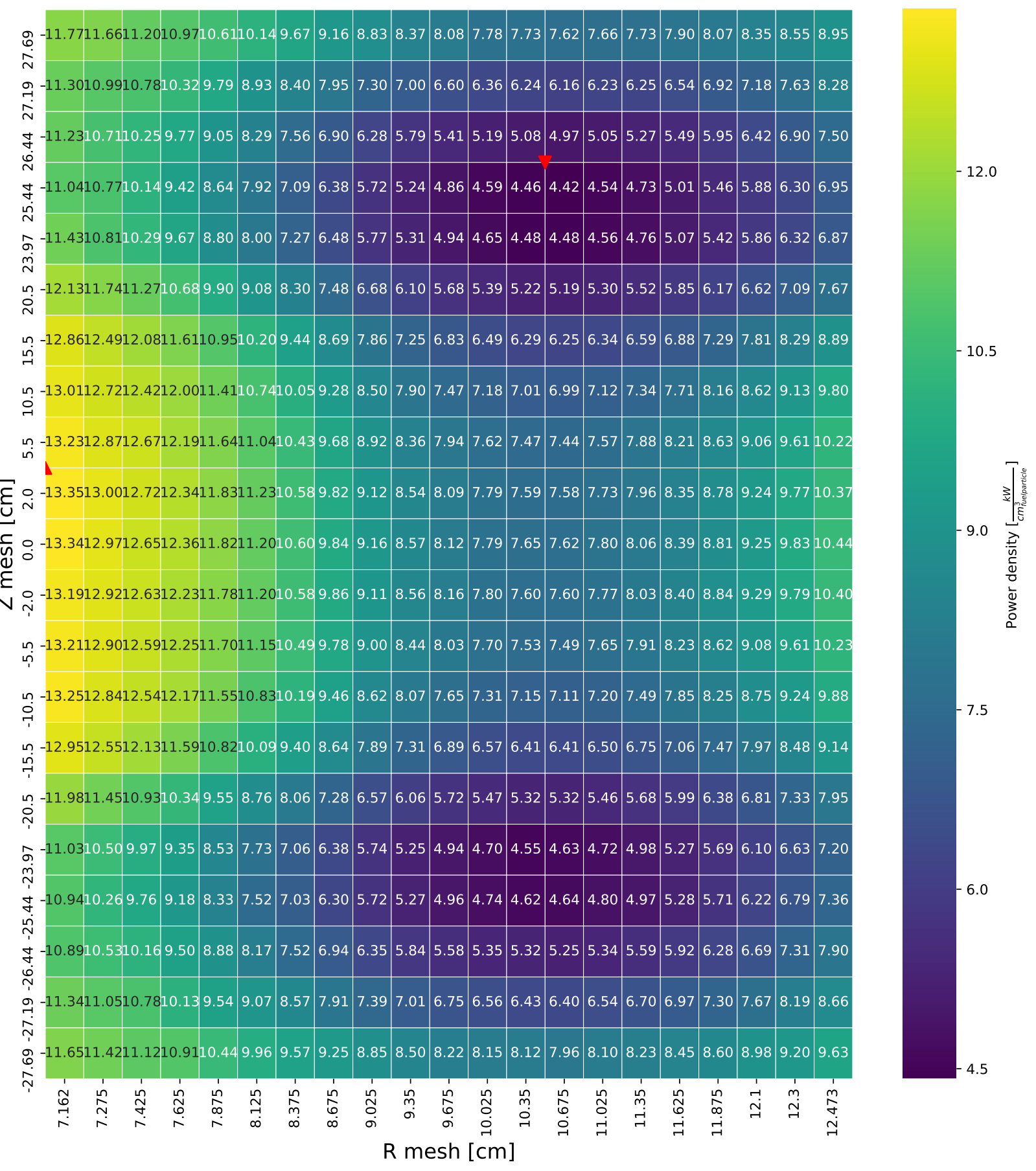

Figure 115. Power density distribution for alternate 2 design IFE region on day 27 (see Section 7.3.3). 


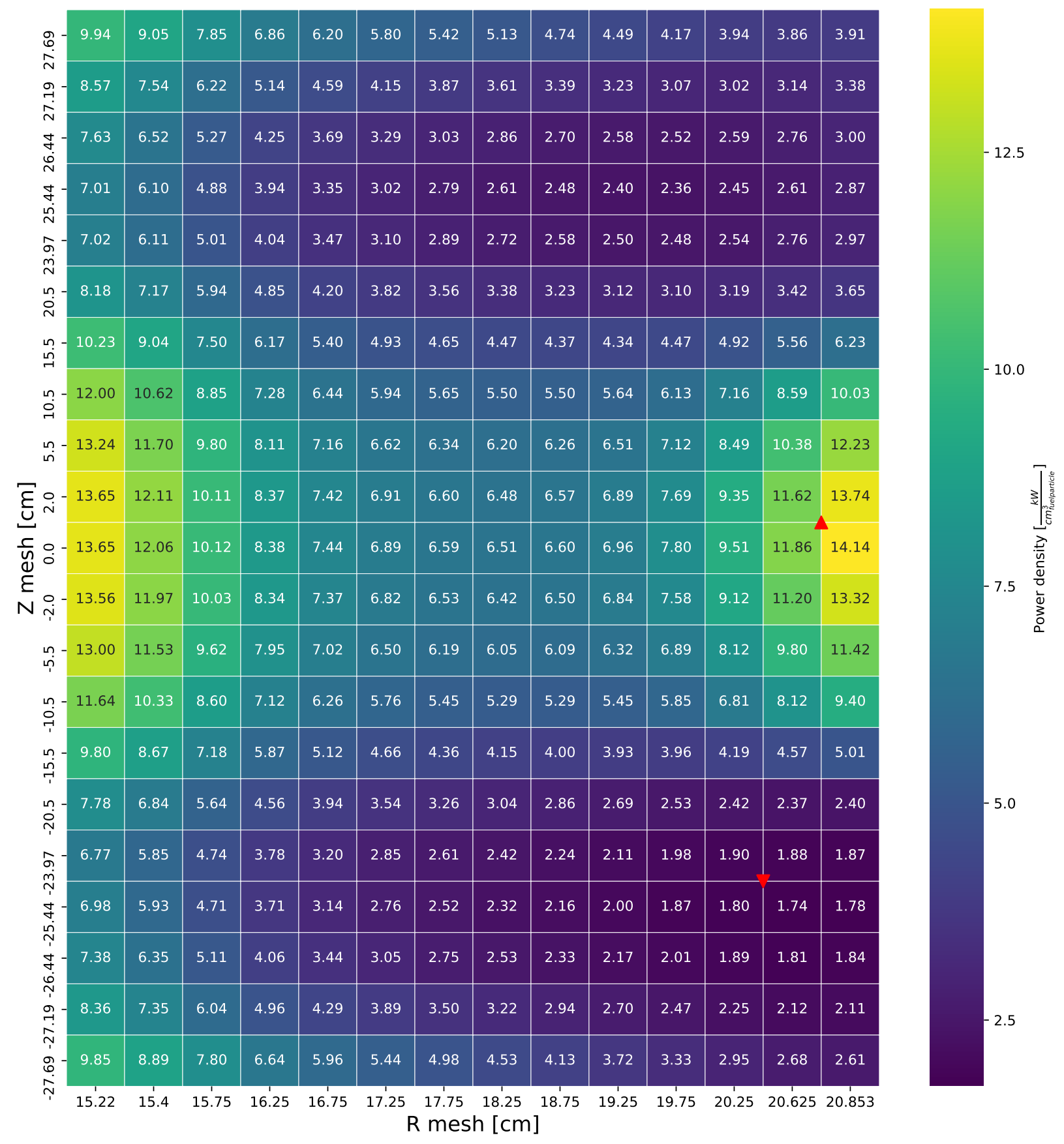

Figure 116. Power density distribution for alternate 2 design OFE region on day 0 (see Section 7.3.3). 


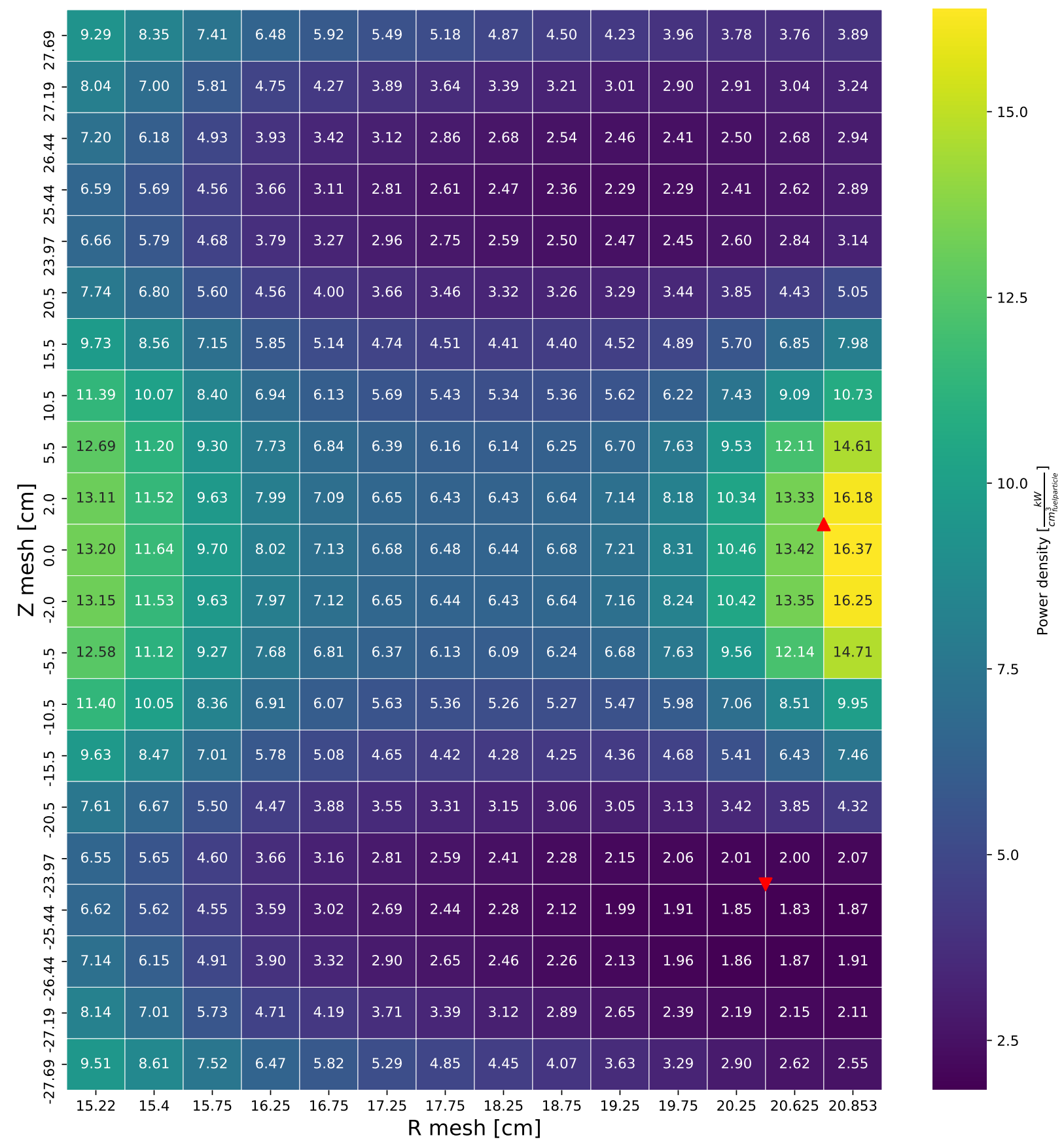

Figure 117. Power density distribution for alternate 2 design OFE region on day 1 (see Section 7.3.3). 


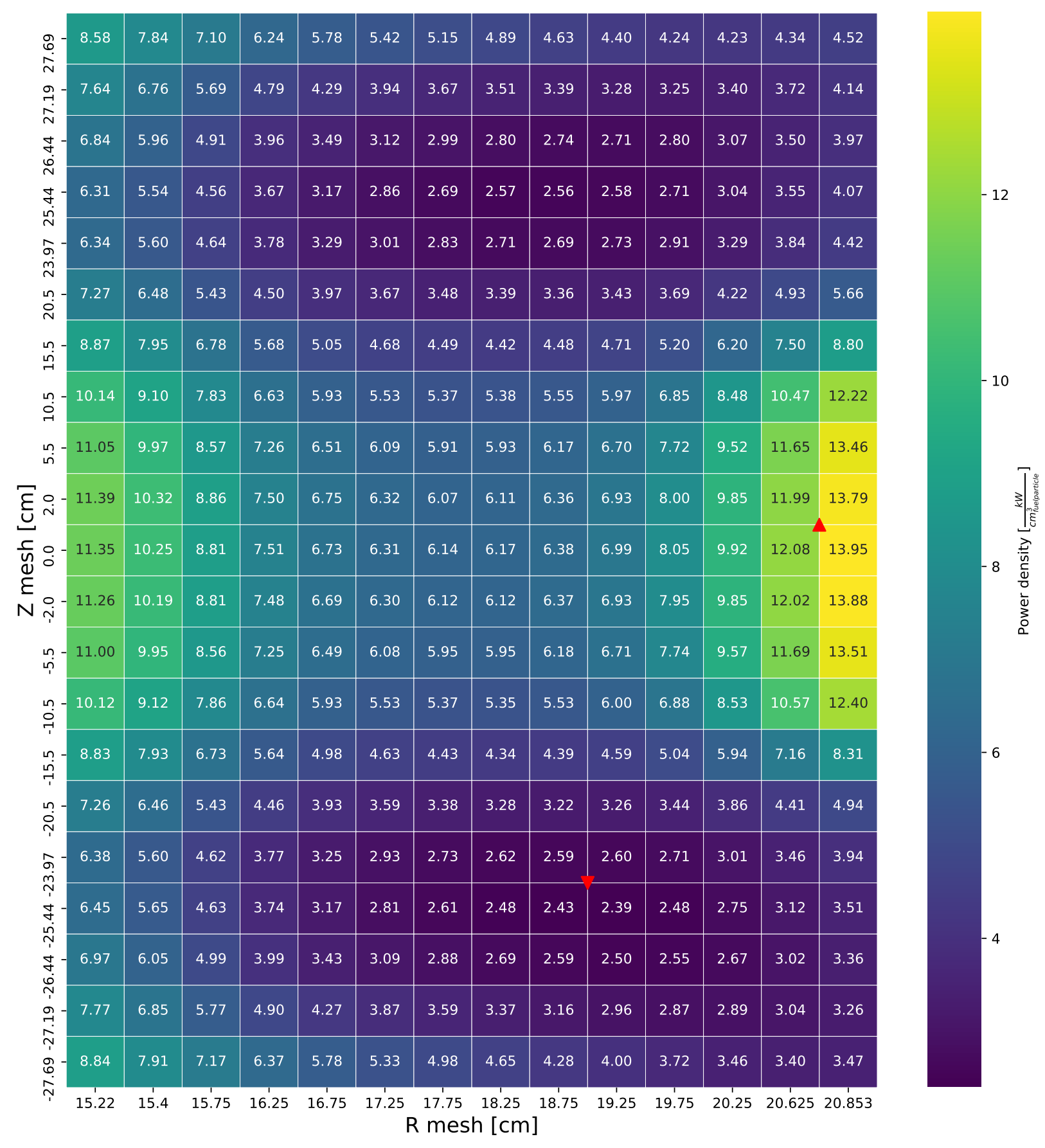

Figure 118. Power density distribution for alternate 2 design OFE region on day 15 (see Section 7.3.3). 


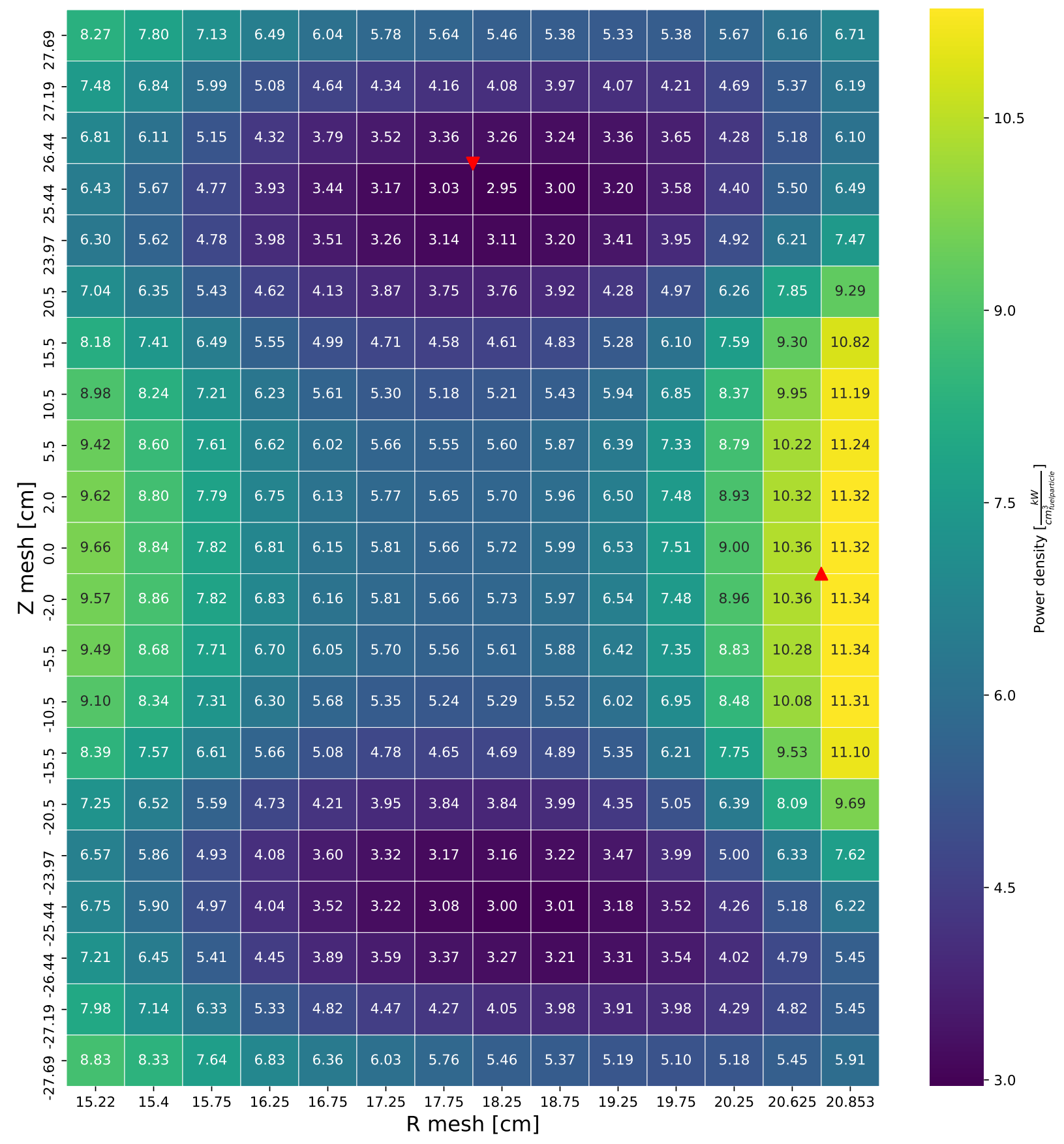

Figure 119. Power density distribution for alternate 2 design OFE region on day 27 (see Section 7.3.3). 


\section{APPENDIX C-4. HEAT FLUX DISTRIBUTIONS FOR ALTERNATE 2 DESIGN}

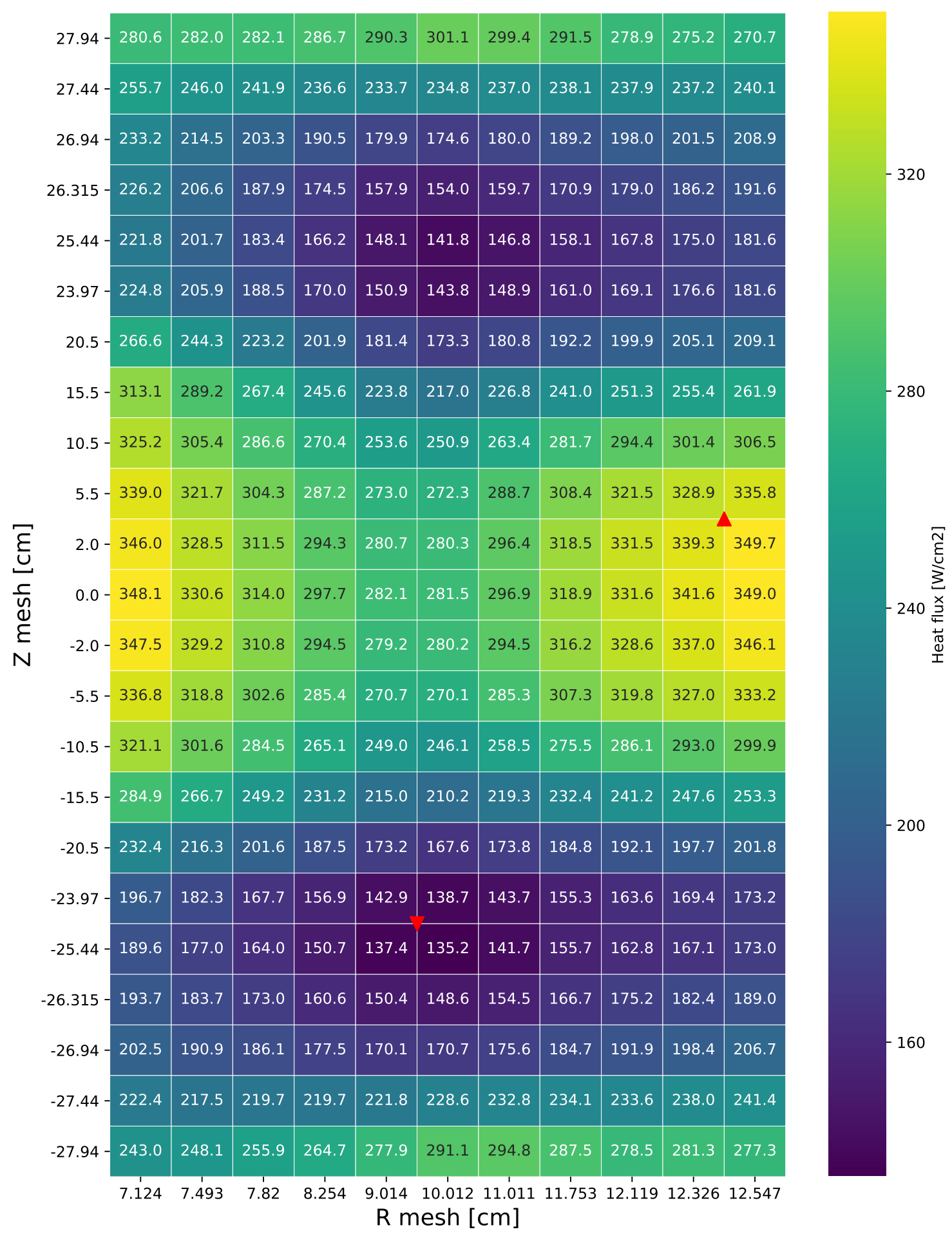

Figure 120. Heat flux distribution for alternate 2 design IFE region on day 0 (see Section 7.3.4). 


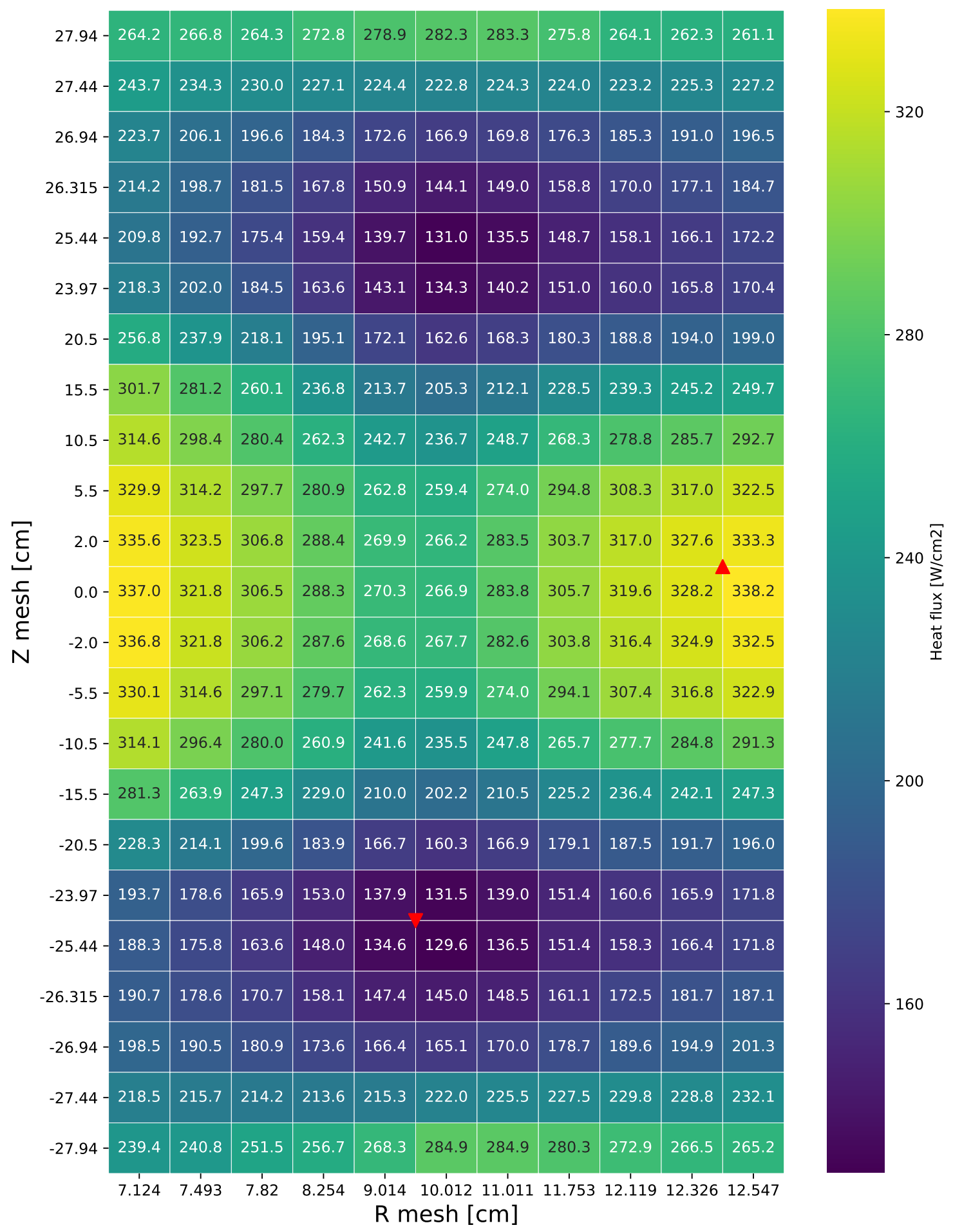

Figure 121. Heat flux distribution for alternate 2 design IFE region on day 1 (see Section 7.3.4). 


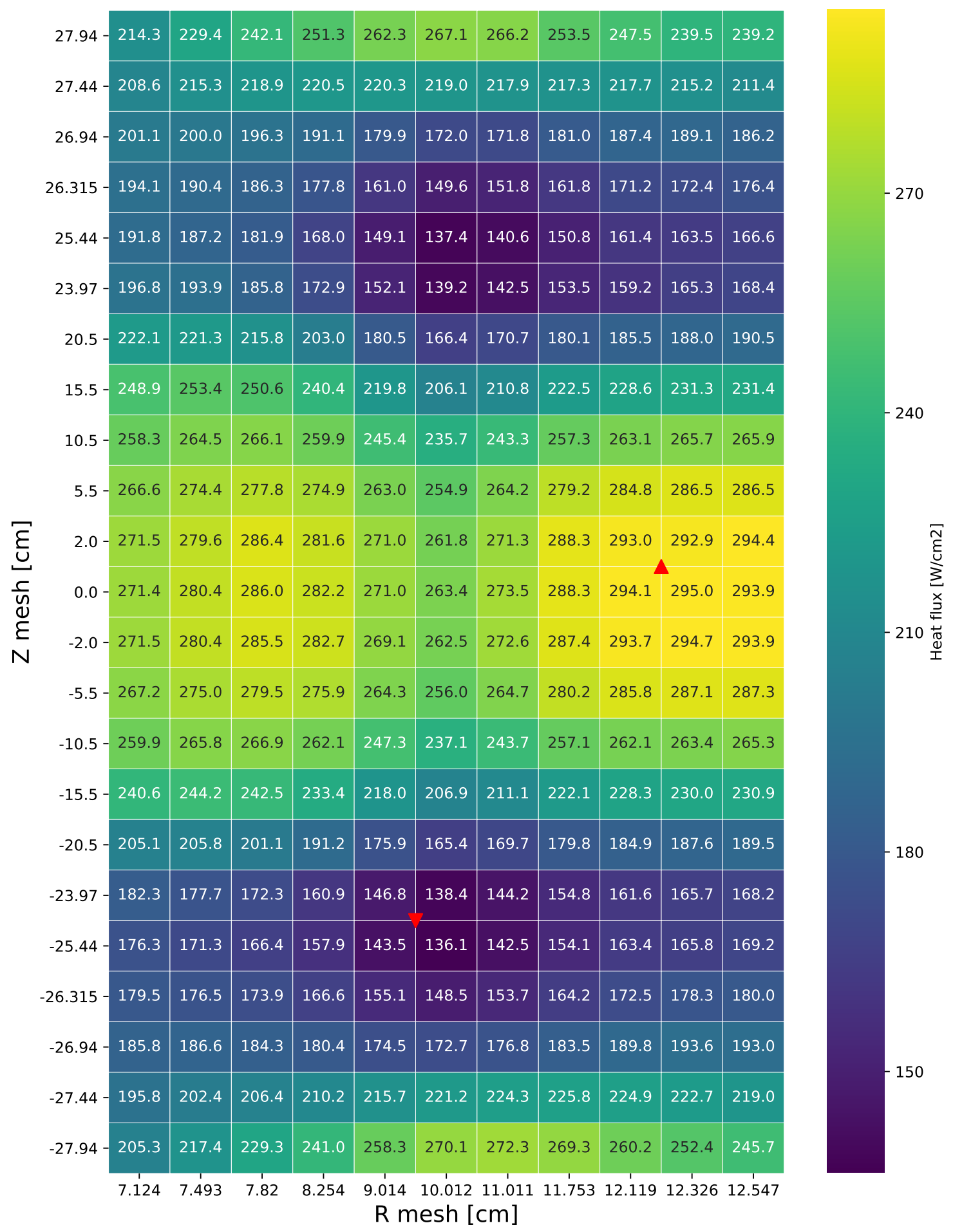

Figure 122. Heat flux distribution for alternate 2 design IFE region on day 15 (see Section 7.3.4). 


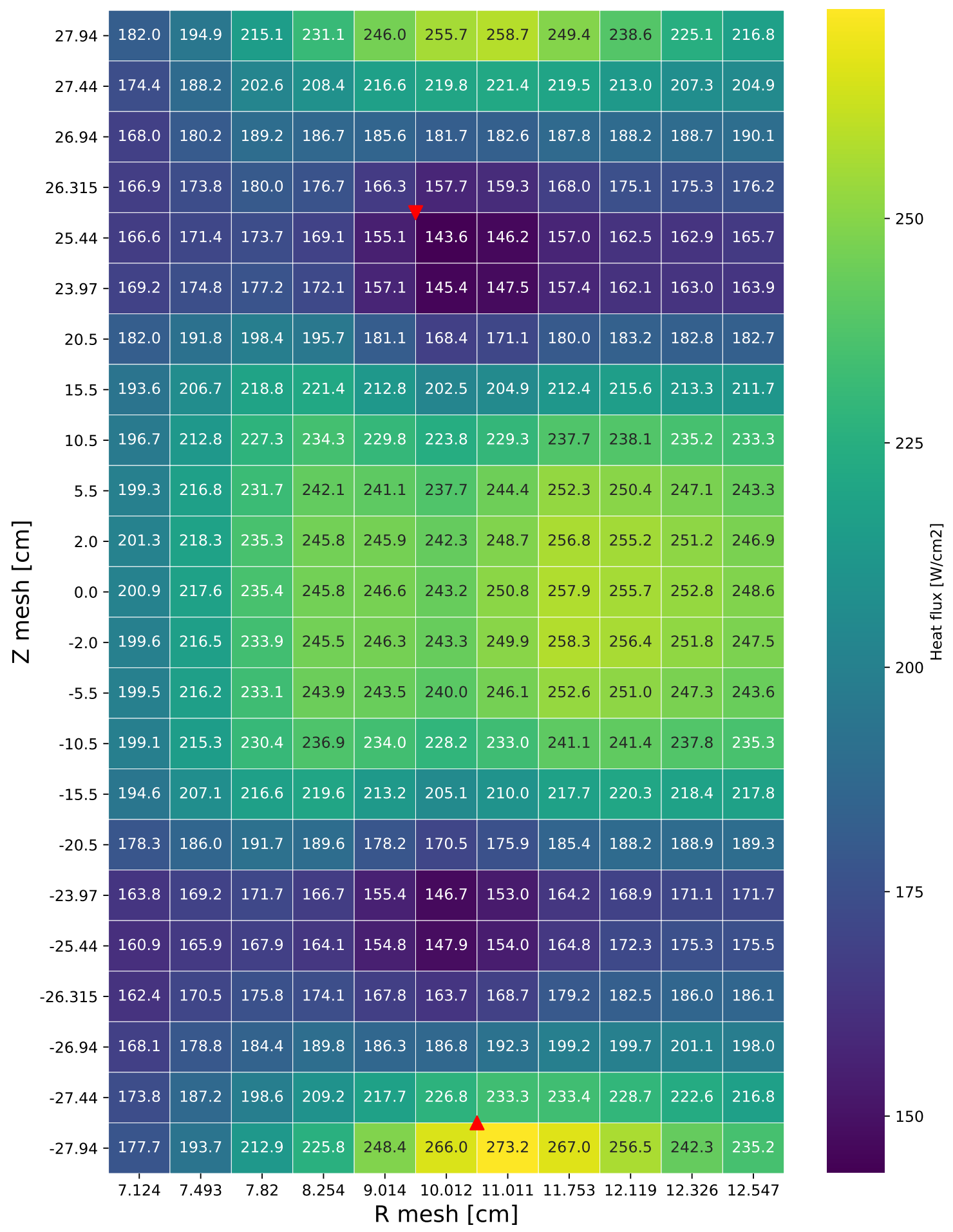

Figure 123. Heat flux distribution for alternate 2 design IFE region on day 27 (see Section 7.3.4). 


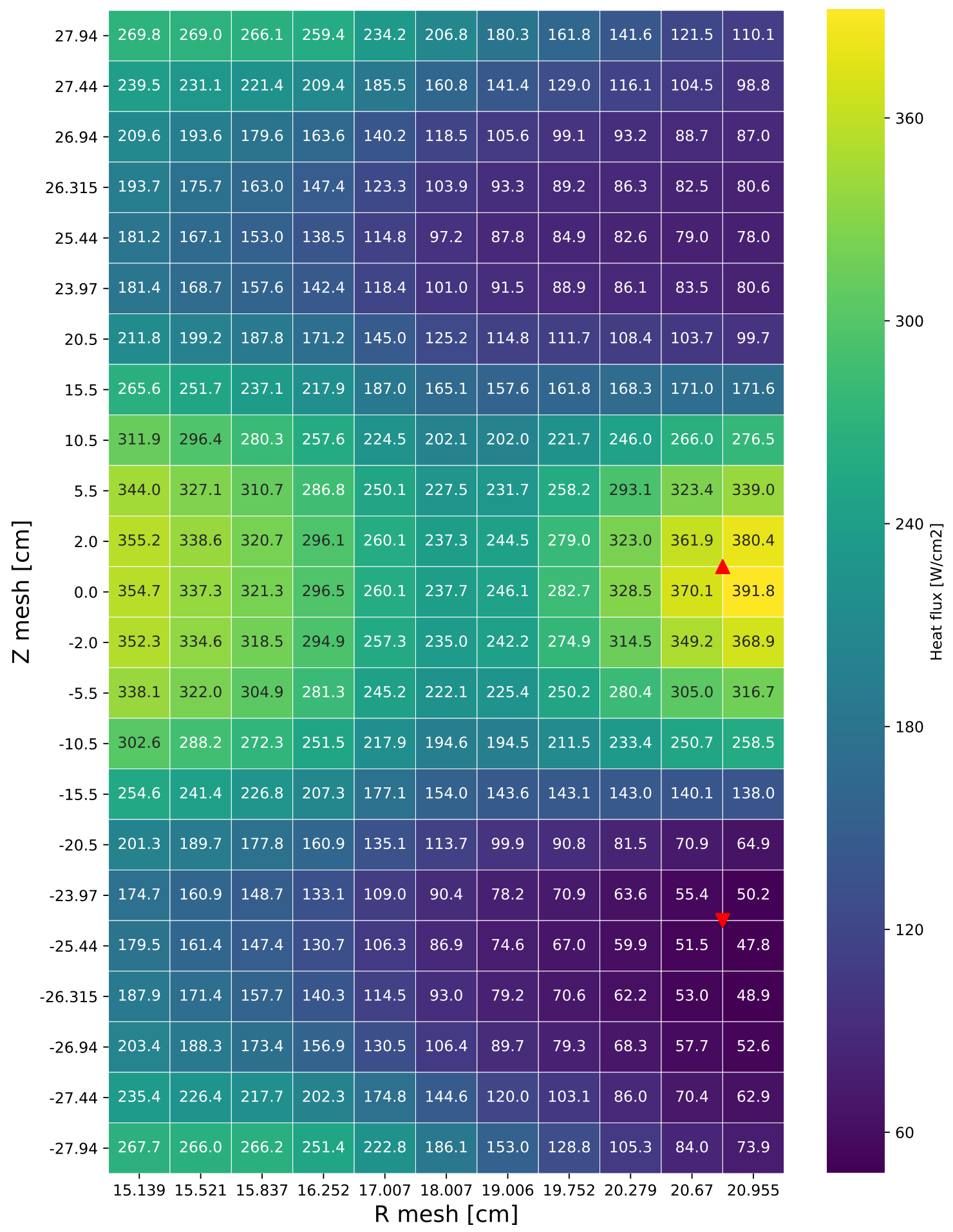

Figure 124. Heat flux distribution for alternate 2 design OFE region on day 0 (see Section 7.3.4). 


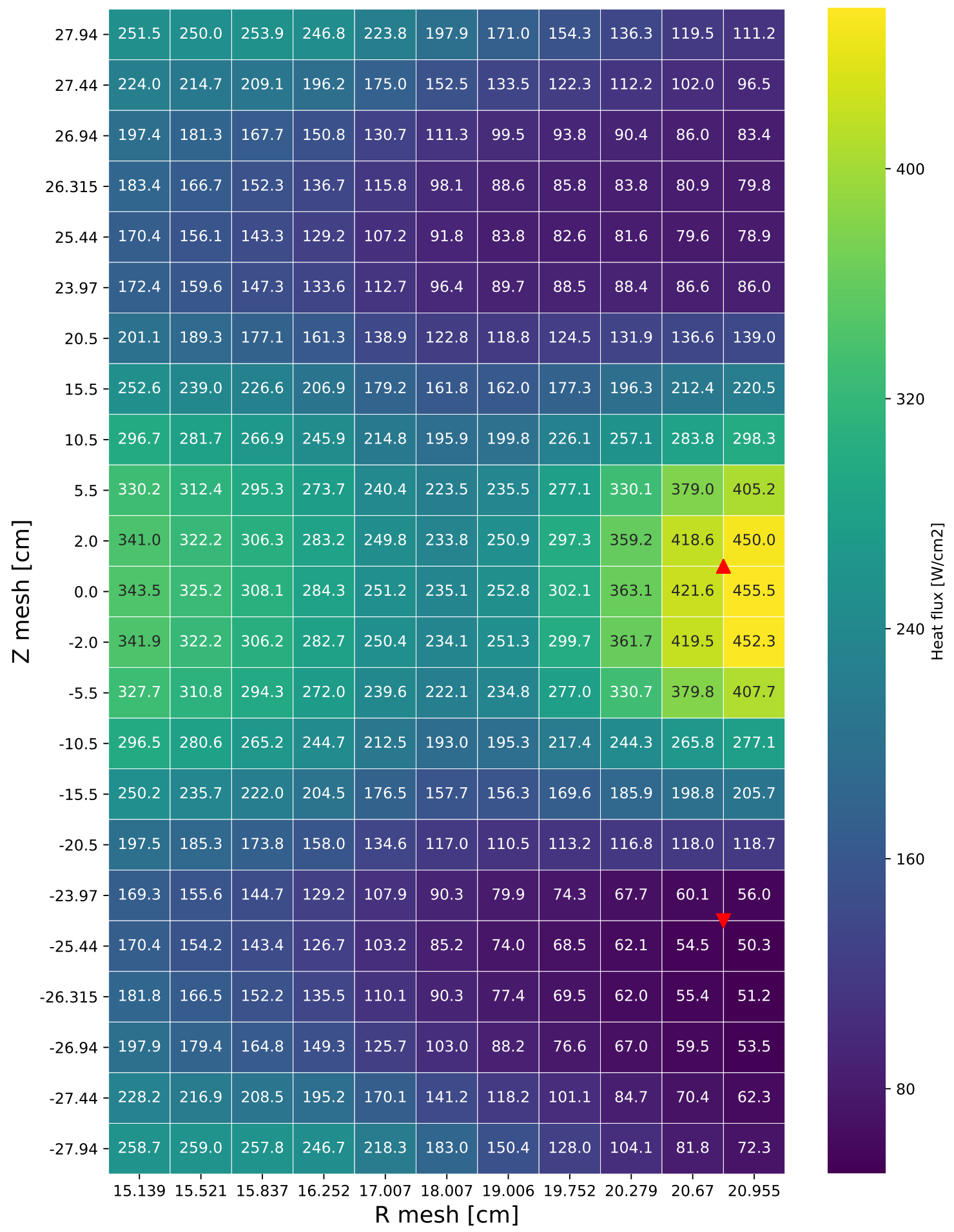

Figure 125. Heat flux distribution for alternate 2 design OFE region on day 1 (see Section 7.3.4). 


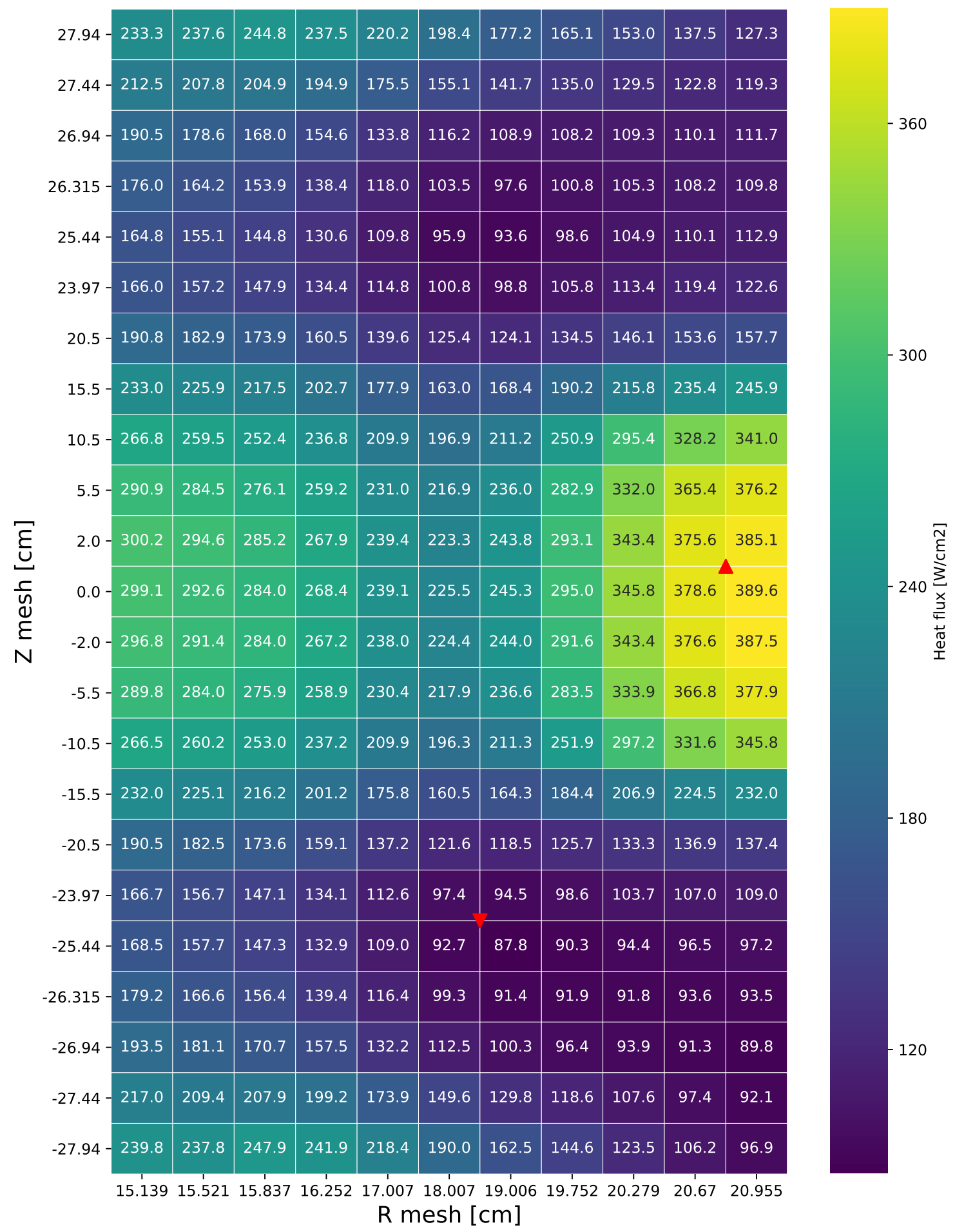

Figure 126. Heat flux distribution for alternate 2 design OFE region on day 15 (see Section 7.3.4). 


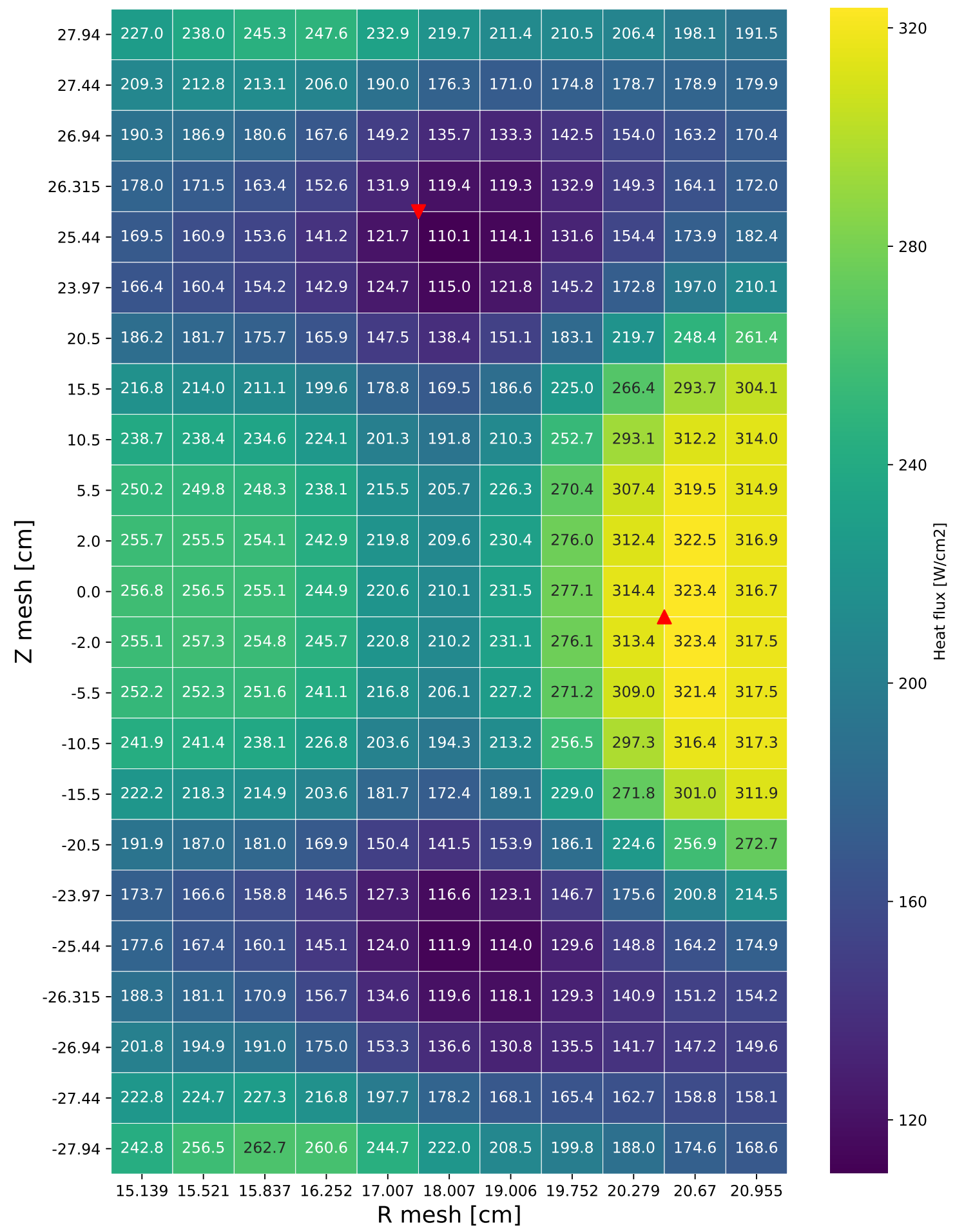

Figure 127. Heat flux distribution for alternate 2 design OFE region on day 27 (see Section 7.3.4). 


\section{APPENDIX D. DISTRIBUTIONS FOR ALTERNATE 3 DESIGN}

\section{APPENDIX D-1. FISSION RATE DENSITY DISTRIBUTIONS FOR ALTERNATE 3 DESIGN}

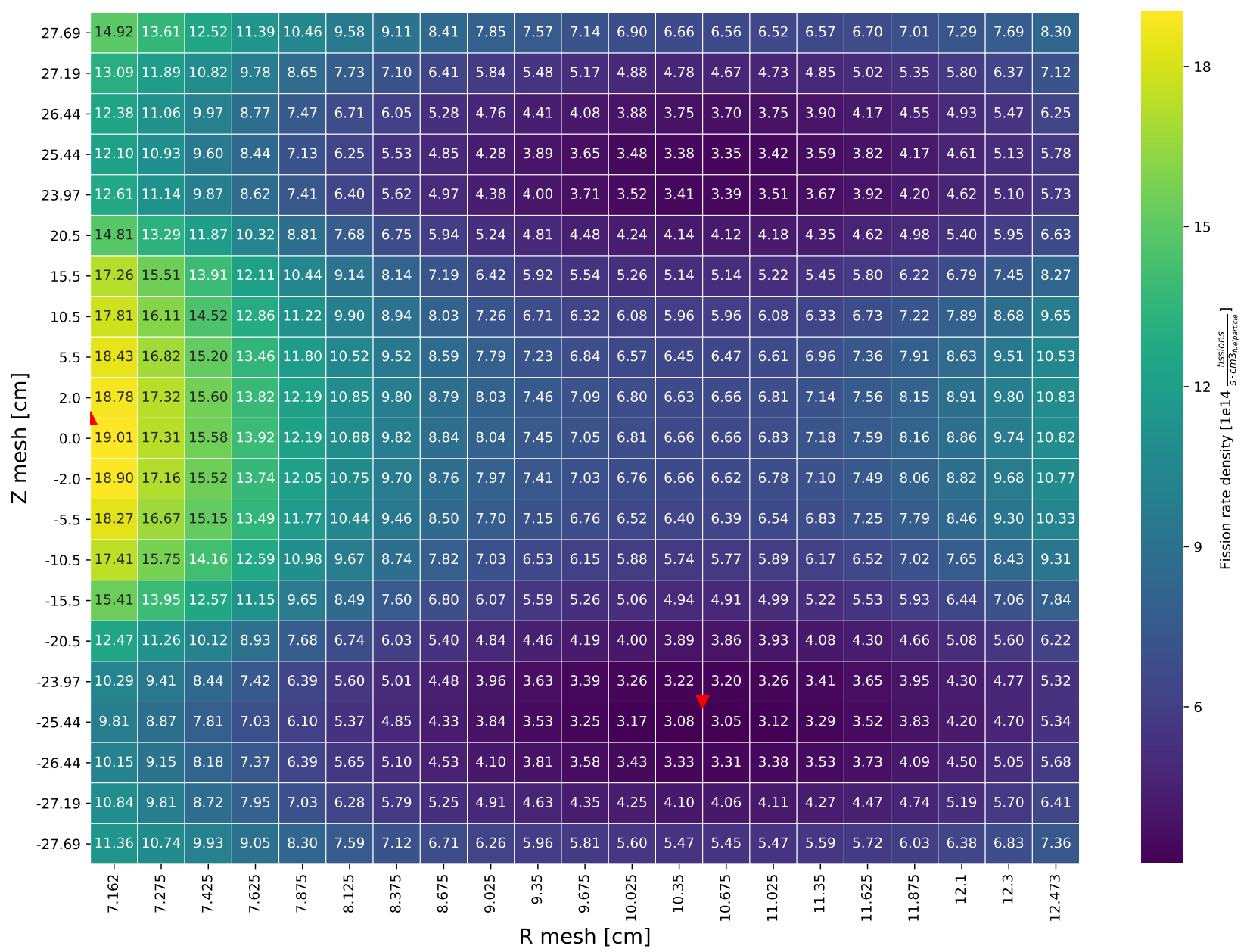

Figure 128. Fission rate density distribution for alternate 3 design IFE region on day 0 (see Section 7.4.2). 


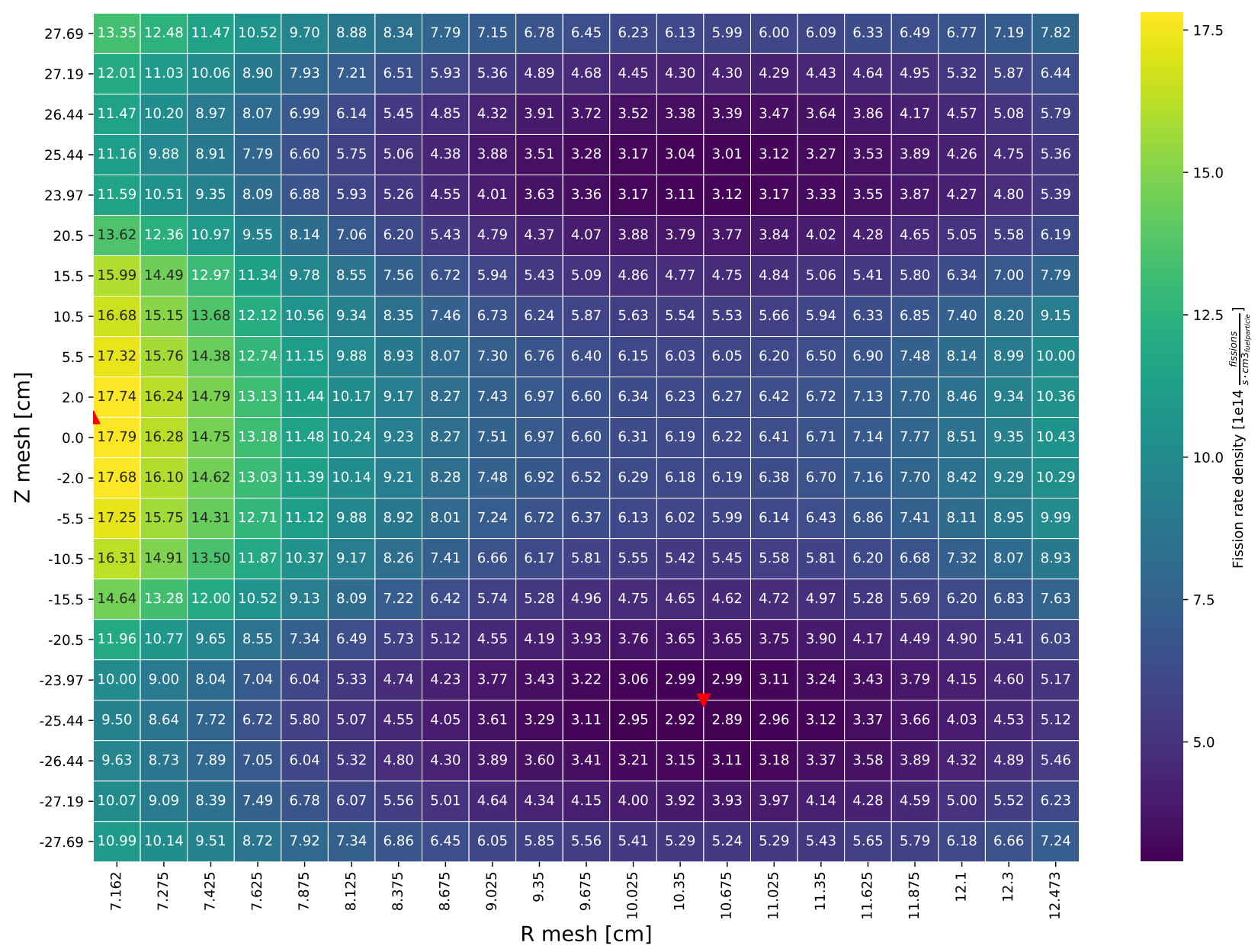

Figure 129. Fission rate density distribution for alternate 3 design IFE region on day 1 (see Section 7.4.2). 


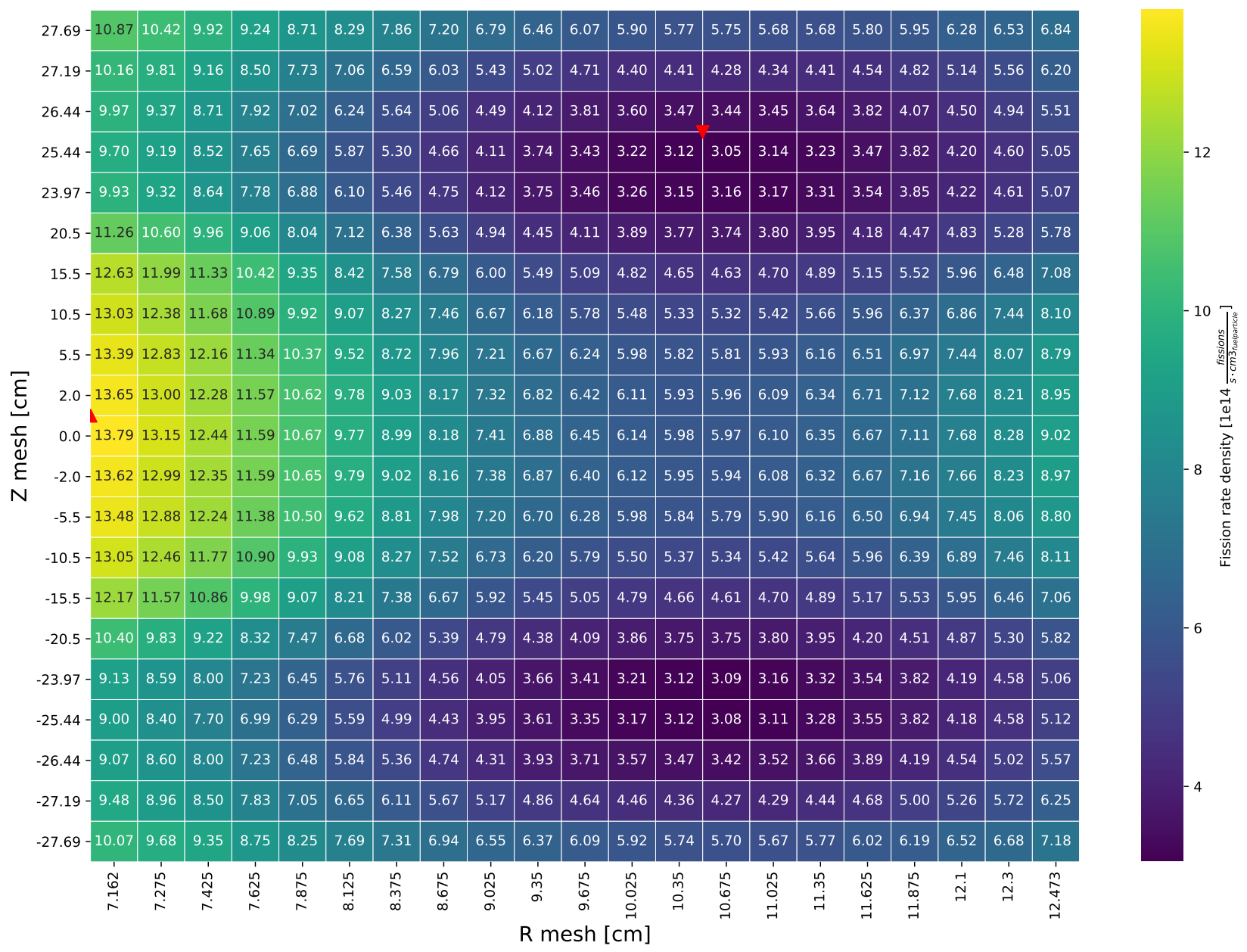

Figure 130. Fission rate density distribution for alternate 3 design IFE region on day 15 (see Section 7.4.2). 


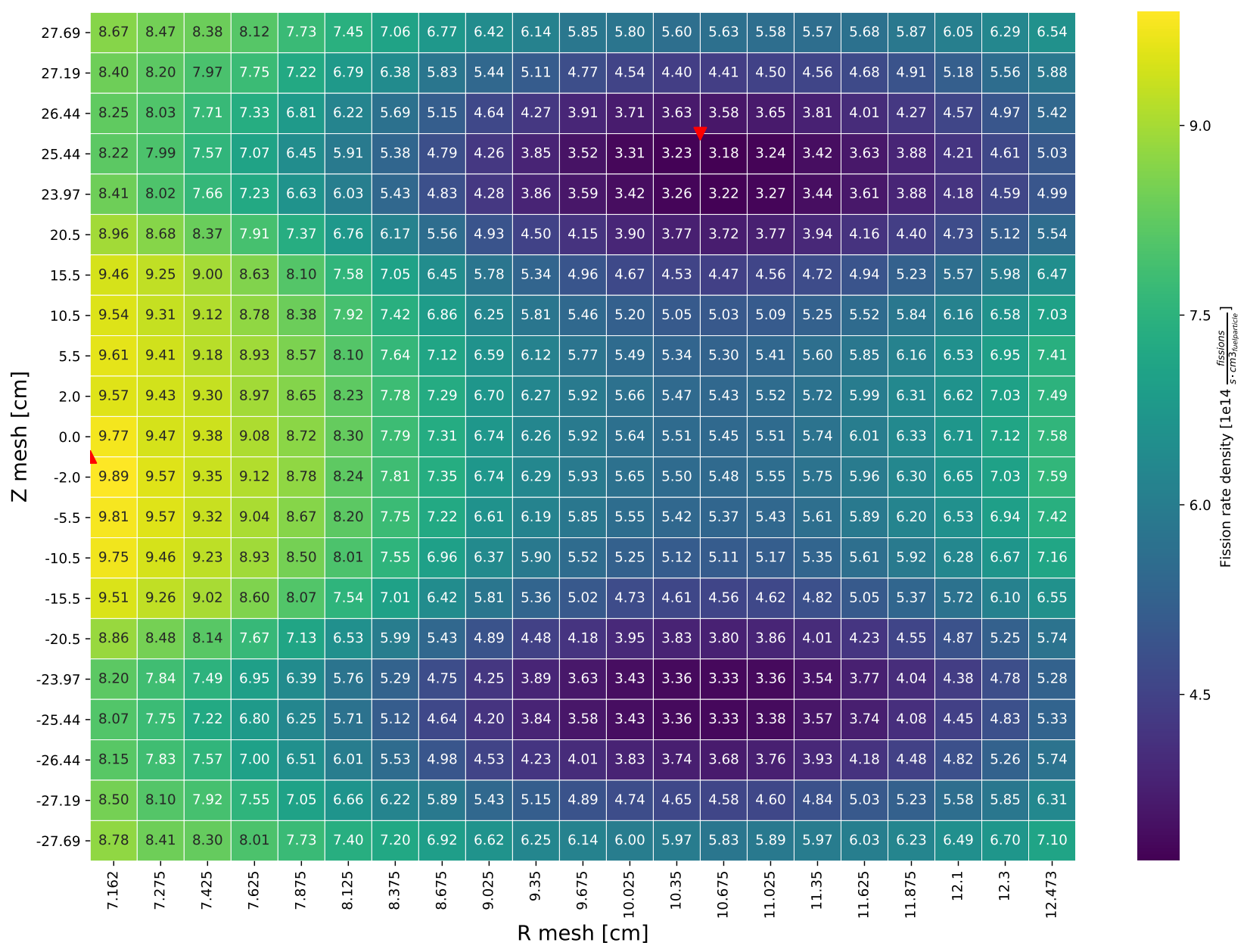

Figure 131. Fission rate density distribution for alternate 3 design IFE region on day 27 (see Section 7.4.2). 


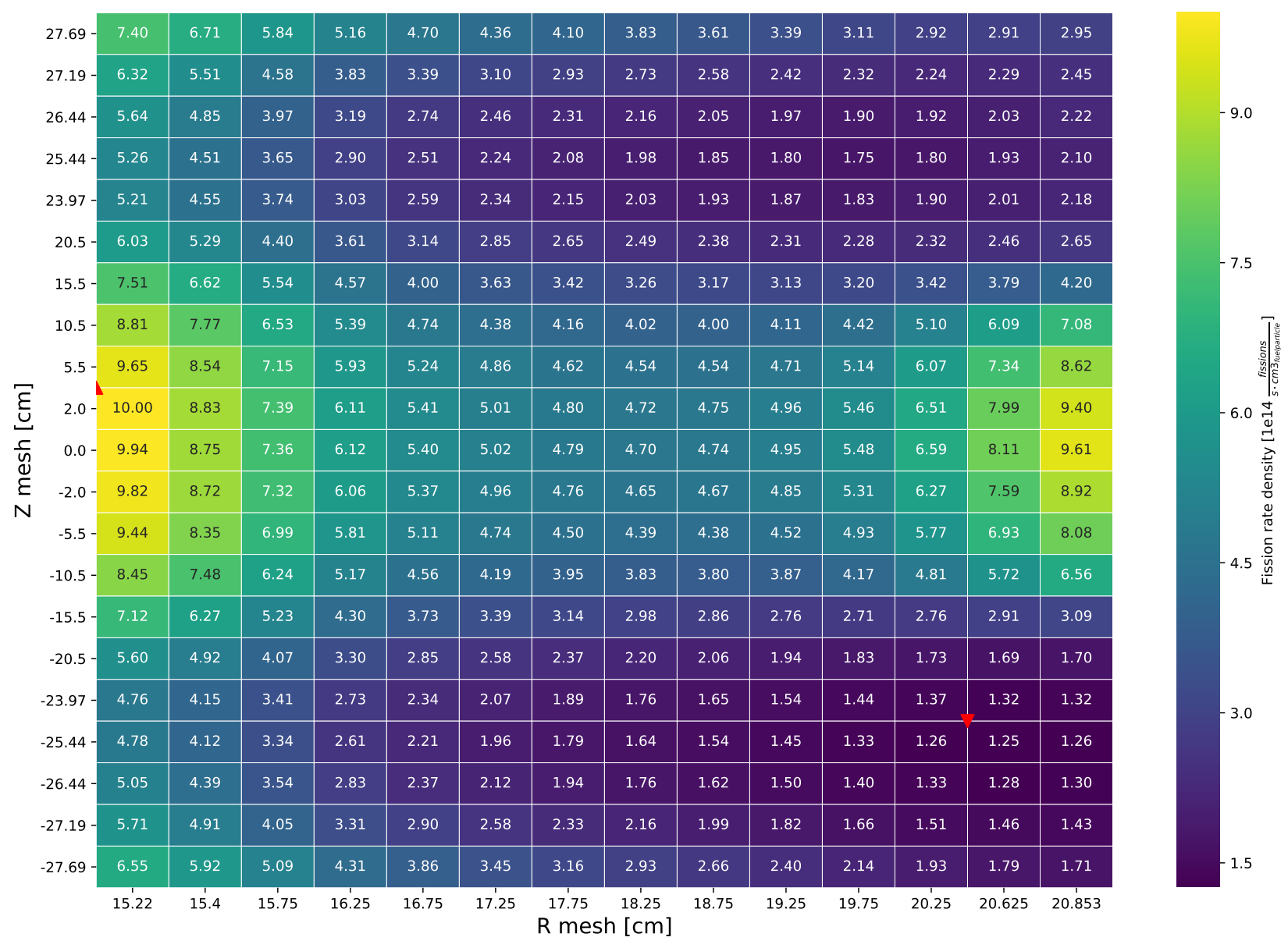

Figure 132. Fission rate density distribution for alternate 3 design OFE region on day 0 (see Section 7.4.2). 


\begin{tabular}{|c|c|c|c|c|c|c|c|c|c|c|c|c|c|c|}
\hline $27.69-$ & 6.89 & 6.28 & 5.52 & 4.77 & 4.38 & 4.07 & 3.80 & 3.56 & 3.36 & 3.16 & 2.94 & 2.82 & 2.76 & 2.86 \\
\hline $27.19-$ & 5.89 & 5.16 & 4.26 & 3.57 & 3.15 & 2.90 & 2.73 & 2.53 & 2.42 & 2.26 & 2.17 & 2.17 & 2.28 & 2.40 \\
\hline 26.44 & 5.27 & 4.52 & 3.65 & 2.96 & 2.53 & 2.31 & 2.13 & 1.99 & 1.90 & 1.83 & 1.80 & 1.85 & 2.03 & 2.20 \\
\hline 25.44 & 4.92 & 4.22 & 3.42 & 2.74 & 2.32 & 2.10 & 1.97 & 1.85 & 1.78 & 1.70 & 1.71 & 1.77 & 1.89 & 2.11 \\
\hline $23.97-$ & 4.87 & 4.28 & 3.51 & 2.81 & 2.44 & 2.19 & 2.04 & 1.94 & 1.85 & 1.81 & 1.84 & 1.92 & 2.11 & 2.31 \\
\hline 20.5 & 5.68 & 5.00 & 4.15 & 3.40 & 2.98 & 2.72 & 2.57 & 2.47 & 2.42 & 2.44 & 2.55 & 2.83 & 3.25 & 3.70 \\
\hline 15.5 & 7.10 & 6.26 & 5.23 & 4.33 & 3.80 & 3.52 & 3.34 & 3.26 & 3.24 & 3.32 & 3.59 & 4.20 & 5.04 & 5.89 \\
\hline 10.5 & 8.35 & 7.38 & 6.19 & 5.13 & 4.54 & 4.23 & 4.03 & 3.97 & 3.99 & 4.15 & 4.56 & 5.44 & 6.65 & 7.84 \\
\hline 5.5 & 9.22 & 8.14 & 6.83 & 5.70 & 5.07 & 4.73 & 4.55 & 4.53 & 4.62 & 4.95 & 5.62 & 7.00 & 8.87 & 10.71 \\
\hline $2.0-$ & 9.54 & 8.45 & 7.10 & 5.90 & 5.24 & 4.92 & 4.73 & 4.72 & 4.87 & 5.27 & 6.04 & 7.60 & 9.74 & 11.86 \\
\hline 0.0 & 9.63 & 8.51 & 7.14 & 5.93 & 5.29 & 4.94 & 4.78 & 4.77 & 4.92 & 5.32 & 6.13 & 7.70 & 9.85 & 11.95 \\
\hline$-2.0-$ & 9.51 & 8.41 & 7.03 & 5.87 & 5.24 & 4.86 & 4.74 & 4.75 & 4.88 & 5.28 & 6.06 & 7.65 & 9.77 & 11.92 \\
\hline$-5.5-$ & 9.18 & 8.08 & 6.78 & 5.64 & 5.02 & 4.68 & 4.52 & 4.48 & 4.61 & 4.92 & 5.59 & 6.97 & 8.85 & 10.72 \\
\hline-10.5 & 8.21 & 7.22 & 6.05 & 5.02 & 4.43 & 4.11 & 3.93 & 3.84 & 3.85 & 4.00 & 4.35 & 5.13 & 6.20 & 7.25 \\
\hline-15.5 & 6.93 & 6.12 & 5.09 & 4.20 & 3.68 & 3.39 & 3.22 & 3.12 & 3.10 & 3.18 & 3.41 & 3.94 & 4.68 & 5.42 \\
\hline-20.5 & 5.48 & 4.80 & 3.97 & 3.24 & 2.82 & 2.58 & 2.41 & 2.31 & 2.24 & 2.21 & 2.26 & 2.45 & 2.74 & 3.06 \\
\hline-23.97 & 4.64 & 4.03 & 3.30 & 2.64 & 2.26 & 2.03 & 1.90 & 1.75 & 1.65 & 1.54 & 1.48 & 1.44 & 1.43 & 1.47 \\
\hline-25.44 & 4.61 & 4.01 & 3.19 & 2.53 & 2.14 & 1.90 & 1.76 & 1.63 & 1.51 & 1.42 & 1.35 & 1.32 & 1.29 & 1.31 \\
\hline-26.44 & 4.94 & 4.24 & 3.43 & 2.69 & 2.27 & 2.02 & 1.87 & 1.71 & 1.58 & 1.48 & 1.37 & 1.32 & 1.30 & 1.32 \\
\hline-27.19 & 5.60 & 4.79 & 3.97 & 3.17 & 2.74 & 2.51 & 2.28 & 2.07 & 1.89 & 1.76 & 1.61 & 1.49 & 1.47 & 1.44 \\
\hline \multirow[t]{2}{*}{$-27.69-$} & 6.42 & 5.75 & 4.91 & 4.20 & 3.72 & 3.38 & 3.10 & 2.84 & 2.60 & 2.36 & 2.15 & 1.92 & 1.81 & 1.70 \\
\hline & 15.22 & 15.4 & 15.75 & 16.25 & 16.75 & 17.25 & $\begin{array}{r}17.75 \\
\mathrm{R} \text { me }\end{array}$ & $\begin{array}{l}18.25 \\
{[\mathrm{~cm}]}\end{array}$ & 18.75 & 19.25 & 19.75 & 20.25 & 20.625 & 20.853 \\
\hline
\end{tabular}

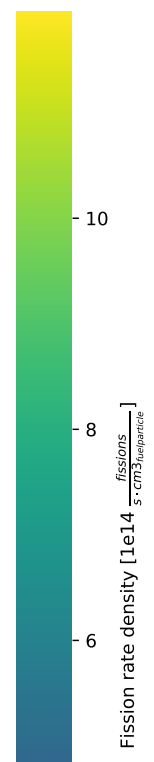

Figure 133. Fission rate density distribution for alternate 3 design OFE region on day 1 (see Section 7.4.2). 


\begin{tabular}{|c|c|c|c|c|c|c|c|c|c|c|c|c|c|c|}
\hline 27.69 & 6.81 & 6.22 & 5.39 & 4.79 & 4.34 & 4.04 & 3.78 & 3.57 & 3.32 & 3.10 & 2.93 & 2.80 & 2.79 & 2.88 \\
\hline 27.19 & 5.77 & 5.04 & 4.20 & 3.53 & 3.13 & 2.87 & 2.66 & 2.52 & 2.36 & 2.22 & 2.14 & 2.15 & 2.25 & 2.43 \\
\hline 26.44 & 5.21 & 4.47 & 3.65 & 2.92 & 2.51 & 2.27 & 2.10 & 2.00 & 1.87 & 1.84 & 1.80 & 1.84 & 2.00 & 2.22 \\
\hline 25.44 & 4.84 & 4.18 & 3.37 & 2.69 & 2.30 & 2.09 & 1.94 & 1.82 & 1.75 & 1.70 & 1.69 & 1.80 & 1.98 & 2.16 \\
\hline 23.97 & 4.82 & 4.19 & 3.44 & 2.78 & 2.40 & 2.16 & 2.03 & 1.94 & 1.87 & 1.84 & 1.88 & 1.99 & 2.21 & 2.46 \\
\hline 20.5 & 5.62 & 4.93 & 4.10 & 3.36 & 2.95 & 2.70 & 2.56 & 2.47 & 2.43 & 2.46 & 2.60 & 2.93 & 3.41 & 3.93 \\
\hline 15.5 & 7.02 & 6.19 & 5.18 & 4.28 & 3.76 & 3.48 & 3.32 & 3.24 & 3.24 & 3.32 & 3.59 & 4.17 & 4.97 & 5.76 \\
\hline 10.5 & 8.23 & 7.26 & 6.08 & 5.07 & 4.49 & 4.18 & 4.00 & 3.94 & 3.98 & 4.19 & 4.64 & 5.56 & 6.83 & 8.07 \\
\hline 5.5 & 9.13 & 8.05 & 6.76 & 5.62 & 5.00 & 4.68 & 4.51 & 4.49 & 4.63 & 4.97 & 5.69 & 7.14 & 9.06 & 10.98 \\
\hline 2.0 & 9.41 & 8.29 & 6.96 & 5.85 & 5.20 & 4.88 & 4.74 & 4.72 & 4.89 & 5.28 & 6.07 & 7.63 & 9.79 & 11.91 \\
\hline 0.0 & 9.44 & 8.37 & 7.02 & 5.85 & 5.22 & 4.88 & 4.73 & 4.73 & 4.90 & 5.30 & 6.11 & 7.72 & 9.89 & 12.01 \\
\hline-2.0 & 9.40 & 8.32 & 6.97 & 5.83 & 5.21 & 4.87 & 4.70 & 4.69 & 4.88 & 5.23 & 6.05 & 7.65 & 9.80 & 11.83 \\
\hline-5.5 & 9.05 & 8.02 & 6.73 & 5.60 & 4.99 & 4.66 & 4.51 & 4.47 & 4.60 & 4.95 & 5.67 & 7.12 & 9.08 & 11.00 \\
\hline-10.5 & 8.12 & 7.19 & 6.03 & 5.00 & 4.42 & 4.10 & 3.92 & 3.85 & 3.88 & 4.04 & 4.45 & 5.28 & 6.43 & 7.54 \\
\hline-15.5 & 6.86 & 6.04 & 5.04 & 4.15 & 3.67 & 3.36 & 3.21 & 3.11 & 3.09 & 3.15 & 3.37 & 3.87 & 4.56 & 5.24 \\
\hline-20.5 & 5.40 & 4.77 & 3.96 & 3.22 & 2.83 & 2.59 & 2.42 & 2.33 & 2.29 & 2.30 & 2.39 & 2.66 & 3.06 & 3.47 \\
\hline-23.97 & 4.64 & 4.01 & 3.28 & 2.64 & 2.27 & 2.04 & 1.89 & 1.77 & 1.68 & 1.60 & 1.55 & 1.54 & 1.57 & 1.63 \\
\hline-25.44 & 4.65 & 4.00 & 3.19 & 2.53 & 2.15 & 1.92 & 1.77 & 1.63 & 1.53 & 1.43 & 1.37 & 1.32 & 1.33 & 1.35 \\
\hline-26.44 & 4.97 & 4.23 & 3.41 & 2.70 & 2.31 & 2.04 & 1.86 & 1.74 & 1.62 & 1.51 & 1.40 & 1.34 & 1.31 & 1.36 \\
\hline-27.19 & 5.50 & 4.86 & 3.94 & 3.22 & 2.77 & 2.51 & 2.28 & 2.11 & 1.96 & 1.82 & 1.65 & 1.52 & 1.46 & 1.48 \\
\hline \multirow[t]{2}{*}{-27.69} & 6.41 & 5.69 & 4.94 & 4.22 & 3.71 & 3.40 & 3.11 & 2.90 & 2.65 & 2.41 & 2.14 & 1.93 & 1.79 & 1.77 \\
\hline & 15.22 & 15.4 & 15.75 & 16.25 & 16.75 & 17.25 & $\begin{array}{r}17.75 \\
\text { R me }\end{array}$ & $\begin{array}{l}18.25 \\
{[\mathrm{~cm}]}\end{array}$ & 18.75 & 19.25 & 19.75 & 20.25 & 20.625 & 20.853 \\
\hline
\end{tabular}

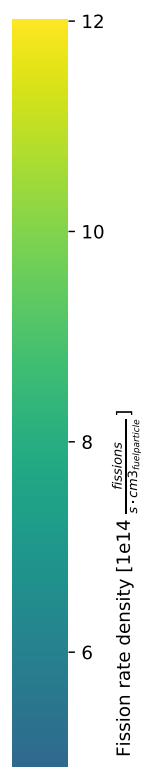

Figure 134. Fission rate density distribution for alternate 3 design OFE region on day 2 (see Section 7.4.2). 


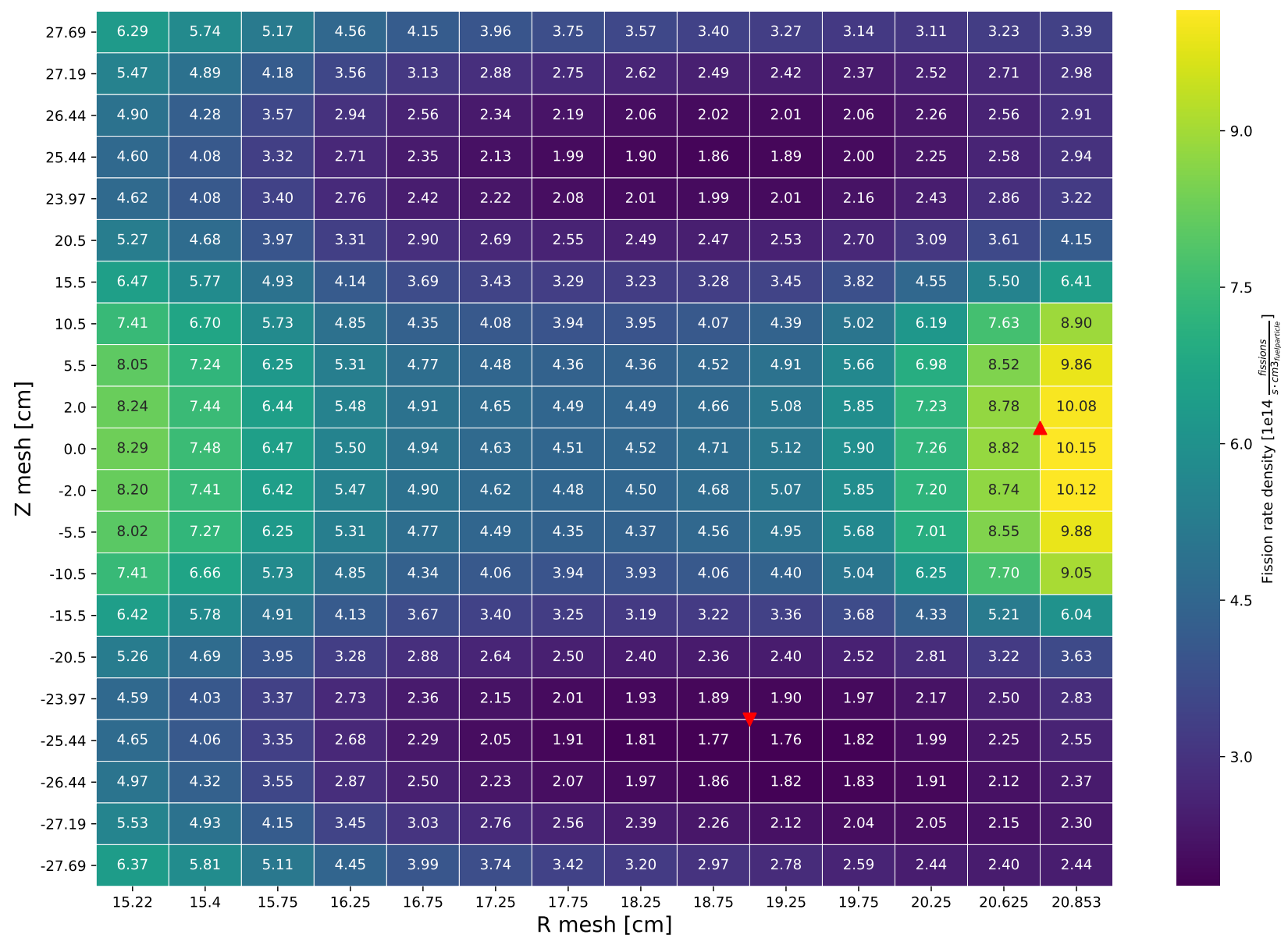

Figure 135. Fission rate density distribution for alternate 3 design OFE region on day 15 (see Section 7.4.2). 


\begin{tabular}{|c|c|c|c|c|c|c|c|c|c|c|c|c|c|c|c|}
\hline 27.69 & 6.11 & 5.67 & 5.22 & 4.75 & 4.49 & 4.27 & 4.16 & 4.01 & 3.92 & 3.86 & 3.93 & 4.14 & 4.47 & 4.88 & \multirow[b]{3}{*}{-7.5} \\
\hline 27.19 & 5.46 & 4.95 & 4.29 & 3.72 & 3.39 & 3.22 & 3.07 & 3.00 & 2.94 & 2.98 & 3.11 & 3.44 & 3.98 & 4.50 & \\
\hline 26.44 & 4.96 & 4.45 & 3.75 & 3.14 & 2.76 & 2.59 & 2.45 & 2.39 & 2.40 & 2.50 & 2.71 & 3.18 & 3.82 & 4.42 & \\
\hline 25.44 & 4.64 & 4.10 & 3.48 & 2.88 & 2.51 & 2.33 & 2.21 & 2.18 & 2.22 & 2.35 & 2.63 & 3.22 & 4.00 & 4.76 & \\
\hline 23.97 & 4.60 & 4.09 & 3.47 & 2.91 & 2.56 & 2.38 & 2.28 & 2.27 & 2.35 & 2.51 & 2.88 & 3.66 & 4.62 & 5.49 & \\
\hline 20.5 & 5.07 & 4.60 & 3.97 & 3.39 & 3.03 & 2.83 & 2.75 & 2.76 & 2.88 & 3.14 & 3.64 & 4.58 & 5.74 & 6.81 & \\
\hline 15.5 & 5.92 & 5.41 & 4.73 & 4.07 & 3.66 & 3.44 & 3.37 & 3.39 & 3.53 & 3.88 & 4.49 & 5.57 & 6.85 & 7.93 & \\
\hline 10.5 & 6.52 & 5.96 & 5.27 & 4.55 & 4.13 & 3.87 & 3.79 & 3.82 & 4.01 & 4.37 & 5.04 & 6.14 & 7.31 & 8.22 & \\
\hline 5.5 & 6.84 & 6.28 & 5.58 & 4.86 & 4.40 & 4.15 & 4.04 & 4.09 & 4.28 & 4.68 & 5.35 & 6.42 & 7.47 & 8.25 & \\
\hline 2.0 & 7.00 & 6.45 & 5.70 & 4.97 & 4.51 & 4.26 & 4.17 & 4.19 & 4.37 & 4.78 & 5.46 & 6.53 & 7.56 & 8.28 & \\
\hline 0.0 & 6.98 & 6.40 & 5.70 & 4.99 & 4.53 & 4.29 & 4.19 & 4.22 & 4.41 & 4.80 & 5.48 & 6.56 & 7.57 & 8.29 & \\
\hline-2.0 & 6.98 & 6.43 & 5.72 & 4.95 & 4.52 & 4.25 & 4.17 & 4.21 & 4.40 & 4.81 & 5.49 & 6.55 & 7.55 & 8.26 & \\
\hline-5.5 & 6.89 & 6.37 & 5.62 & 4.89 & 4.42 & 4.18 & 4.08 & 4.13 & 4.32 & 4.72 & 5.41 & 6.47 & 7.51 & 8.30 & \\
\hline-10.5 & 6.58 & 6.01 & 5.33 & 4.61 & 4.18 & 3.94 & 3.83 & 3.87 & 4.05 & 4.40 & 5.07 & 6.18 & 7.33 & 8.25 & \\
\hline-15.5 & 6.05 & 5.53 & 4.83 & 4.15 & 3.74 & 3.52 & 3.41 & 3.44 & 3.58 & 3.92 & 4.55 & 5.67 & 6.98 & 8.14 & \\
\hline-20.5 & 5.24 & 4.73 & 4.09 & 3.47 & 3.10 & 2.90 & 2.81 & 2.81 & 2.93 & 3.19 & 3.71 & 4.69 & 5.91 & 7.09 & \\
\hline-23.97 & 4.73 & 4.29 & 3.58 & 2.97 & 2.62 & 2.42 & 2.32 & 2.30 & 2.36 & 2.54 & 2.91 & 3.65 & 4.63 & 5.56 & \\
\hline-25.44 & 4.85 & 4.28 & 3.62 & 2.99 & 2.59 & 2.35 & 2.26 & 2.19 & 2.20 & 2.33 & 2.59 & 3.10 & 3.83 & 4.49 & \\
\hline-26.44 & 5.22 & 4.63 & 3.92 & 3.26 & 2.86 & 2.61 & 2.45 & 2.41 & 2.35 & 2.39 & 2.54 & 2.94 & 3.46 & 4.02 & -3.0 \\
\hline$-27.19-$ & 5.74 & 5.20 & 4.58 & 3.93 & 3.52 & 3.27 & 3.07 & 2.96 & 2.85 & 2.83 & 2.91 & 3.10 & 3.57 & 3.97 & \\
\hline$-27.69-$ & 6.44 & 6.09 & 5.49 & 4.95 & 4.58 & 4.36 & 4.16 & 4.00 & 3.83 & 3.72 & 3.69 & 3.79 & 4.00 & 4.23 & \\
\hline & 15.22 & 15.4 & 15.75 & 16.25 & 16.75 & 17.25 & $\begin{array}{r}17.75 \\
\mathrm{R} \text { me }\end{array}$ & $\begin{array}{l}18.25 \\
{[\mathrm{~cm}]}\end{array}$ & 18.75 & 19.25 & 19.75 & 20.25 & 20.625 & 20.853 & \\
\hline
\end{tabular}

Figure 136. Fission rate density distribution for alternate 3 design OFE region on day 27 (see Section 7.4.2). 


\section{APPENDIX D-2. CUMULATIVE FISSION DENSITY DISTRIBUTIONS FOR ALTERNATE 3 DESIGN}

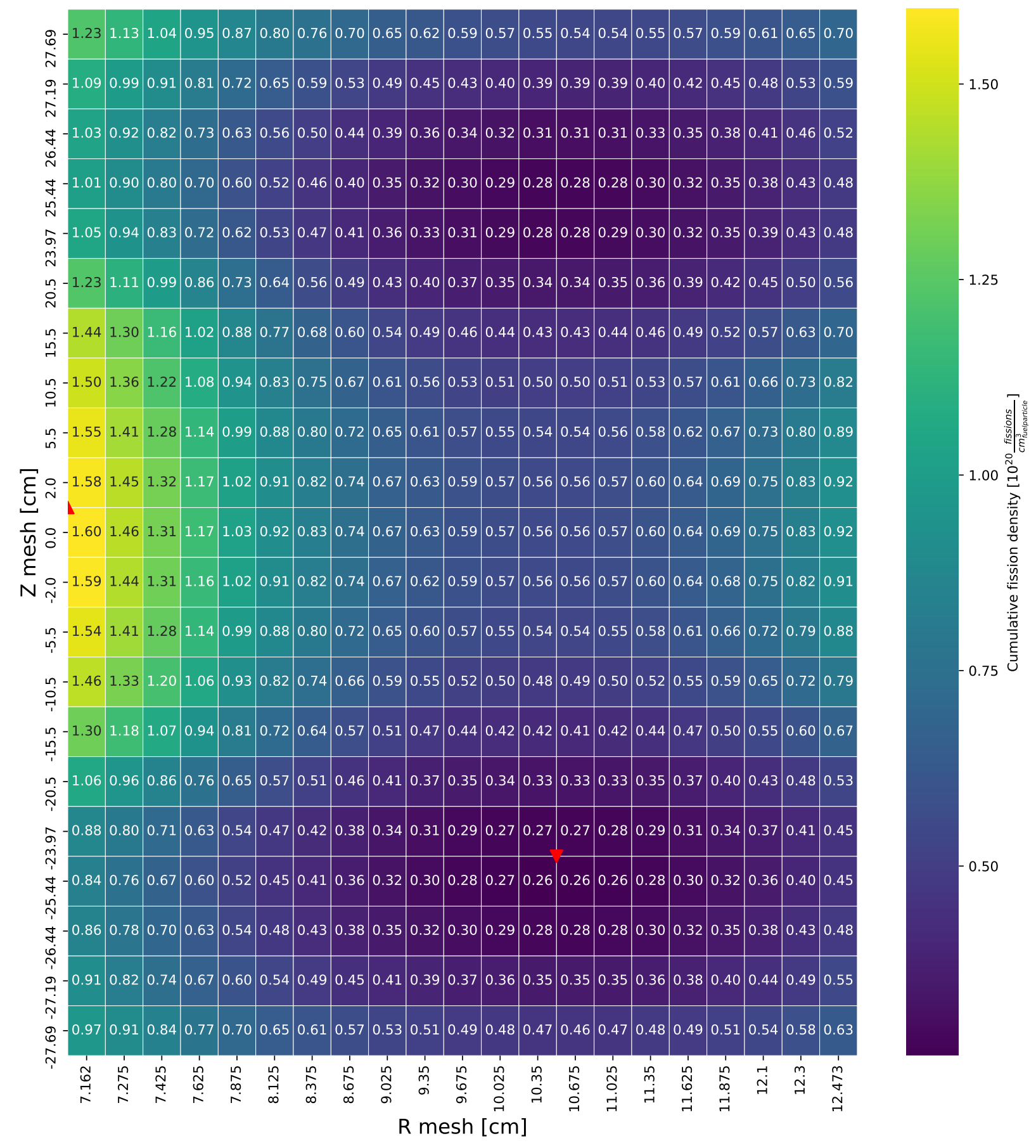

Figure 137. Cumulative fission density distribution for alternate 3 design IFE region on day 1 (see Section 7.4.5). 


\section{웅}

N

국

ก

$\checkmark$

ஸे

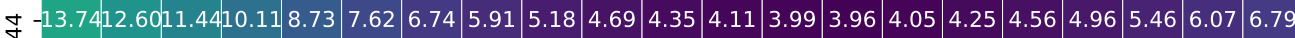

กั่

คิ

$\stackrel{\text { ஸे }}{n}$

เกำ

$\stackrel{n}{\sim}$

เก $-19.5518 .2016 .8115 .2013 .5212 .1110 .939 .818 .798 .107 .607 .25 \quad 7.08 \quad 7.067 .217 .548 .00 \quad 8.609 .3310 .2011 .24$ 이

เn -20.3218.9717.5815.9814.2612.8411.6610.519.48 $8.77 \quad 8.257 .897 .72 \quad 7.717 .898 .258 .76 \quad 9.4110 .2011 .1512 .27$

E。 - $-20.7219 .3817 .9716 .3714 .6413 .1911 .9910 .819 .759 .048 .518 .137 .95 \quad 7.968 .148 .529 .049 .7210 .5411 .5012 .65$ $\underline{\epsilon} \stackrel{i}{\sim}$

등 웅 $-20.8119 .4418 .0516 .4114 .6713 .2412 .0310 .859 .809 .08 \quad 8.558 .18 \quad 7.99 \quad 7.998 .18 \quad 8.559 .069 .7410 .5611 .5412 .68$ $\mathscr{\varepsilon}$

○ - $20.7119 .3417 .9516 .3514 .6213 .1611 .9510 .799 .75 \quad 9.048 .508 .13 \quad 7.95 \quad 7.968 .13 \quad 8.50 \quad 9.02 \quad 9.6910 .5211 .4712 .63$ $N \stackrel{\sim}{\sim}$

เn $-20.2718 .9517 .5815 .9714 .2712 .8411 .6510 .519 .47 \quad 8.76 \quad 8.25 \quad 7.88 \quad 7.71 \quad 7.69 \quad 7.86 \quad 8.22 \quad 8.73 \quad 9.3810 .1711 .1112 .22$

เก $-19.4318 .1116 .7415 .1413 .4512 .0610 .889 .76 \quad 8.75 \quad 8.07 \quad 7.57 \quad 7.21 \quad 7.04 \quad 7.02 \quad 7.17 \quad 7.50 \quad 7.94 \quad 8.539 .2710 .1311 .15$ 우

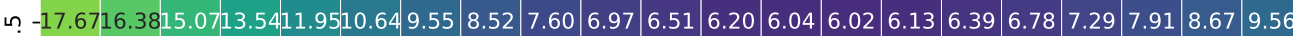
เก่

in $-14.6713 .5412 .3811 .079 .718 .58 \quad 7.68 \quad 6.83 \quad 6.07 \quad 5.56 \quad 5.194 .93 \quad 4.81 \quad 4.784 .87 \quad 5.095 .40 \quad 5.80 \quad 6.32 \quad 6.94 \quad 7.70$

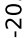

人 $-12.5411 .5210 .519 .348 .12 \quad 7.176 .405 .68 \quad 5.054 .604 .304 .08 \quad 3.99 \quad 3.964 .054 .244 .54 \quad 4.925 .38 \quad 5.946 .64$

\&

$\stackrel{\text { กั่ }}{1}$

\&

$\stackrel{\leftrightarrow}{1}$

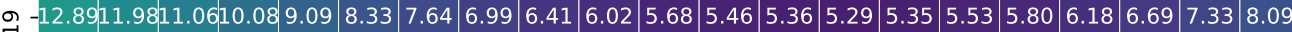

กิ

ตุ

ஸ

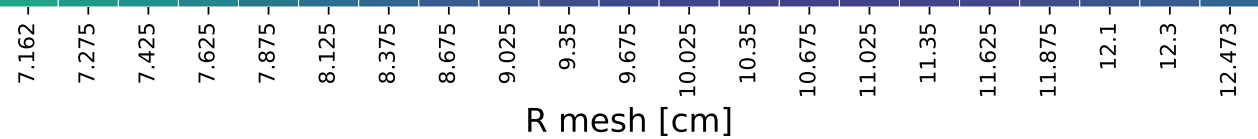

Figure 138. Cumulative fission density distribution for alternate 3 design IFE region on day 15 (see Section 7.4.5). 
ํำ-

$\stackrel{\text { v }}{ }$

$-30.2928 .4926 .6024 .2821 .7519 .5217 .6015 .7213 .9912 .7911 .8911 .2510 .9110 .8411 .0311 .4912 .1512 .9814 .0015 .2416 .71$

ก -32.2630 .5228 .7226 .5724 .1922 .0920 .2618 .4216 .6815 .4414 .5413 .8813 .5613 .5213 .8014 .3915 .2116 .2517 .4918 .9520 .68$ เ

Е 우 -32.8331 .0429 .2727 .1124 .7522 .6220 .7918 .8917 .1315 .8914 .9414 .2713 .9313 .9114 .2014 .8215 .6616 .7318 .0019 .4821 .24$ $\underline{\sim} \sim$

등 우 -32.9331 .1429 .3427 .2124 .8122 .7120 .8518 .9617 .2015 .9615 .0214 .3414 .0013 .9714 .2614 .8715 .7116 .7818 .0519 .5621 .31$ $\stackrel{\mathscr{w}}{\varepsilon} \dot{0}$

$\varepsilon$ 。 -32.8231 .0529 .2827 .1324 .7322 .5920 .7518 .8817 .1415 .8914 .9514 .2813 .9513 .9214 .2014 .8215 .6516 .7117 .9919 .4821 .24$ $N \stackrel{\circ}{i}$

In -32.3430 .5928 .8026 .6624 .2822 .1720 .3118 .4716 .7115 .4914 .5713 .9113 .5813 .5313 .8014 .3815 .2016 .2517 .4918 .9520 .68$

เก -31.2529 .5227 .7125 .5423 .1321 .0419 .1817 .3415 .6214 .4113 .5112 .8512 .5212 .4512 .7013 .2513 .9814 .9516 .1217 .4919 .11$ 국

เก -28.9627 .2025 .4023 .2420 .8918 .8317 .0715 .3313 .7212 .5911 .7711 .1710 .8710 .8110 .9911 .4512 .1012 .9613 .9915 .2216 .68$ เே่

in $-24.7223 .1021 .4319 .4517 .3215 .4913 .9512 .4711 .1110 .179 .48 \quad 8.998 .758 .698 .85 \quad 9.23 \quad 9.7710 .4911 .3712 .4213 .68$

$\stackrel{\text { ì }}{\sim}$

-21.6220.0918.5416.7014.7613.1411.7910.519.33 8.50 7.93 7.51 7.32 7.27 7.42 7.79 $8.30 \quad 8.98$ 9.81 10.8012 .00

$\stackrel{m}{\sim}$

8

กั่

8

8

กิ

국

ஸิ 웅

กิ

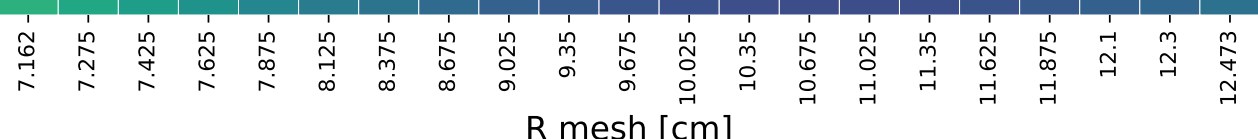

Figure 139. Cumulative fission density distribution for alternate 3 design IFE region on day 27 (see Section 7.4.5). 


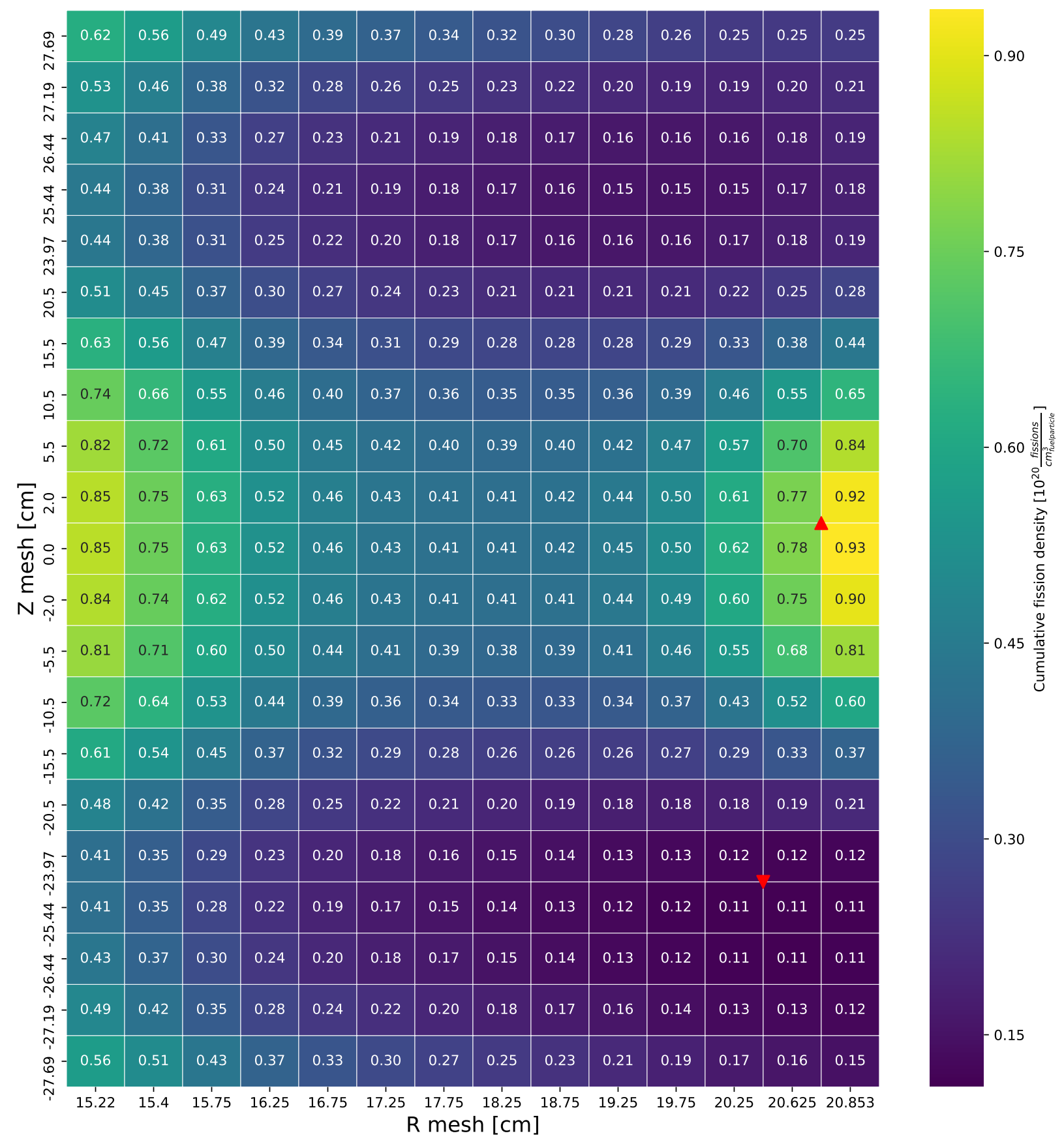

Figure 140. Cumulative fission density distribution for alternate 3 design OFE region on day 1 (see Section 7.4.5). 


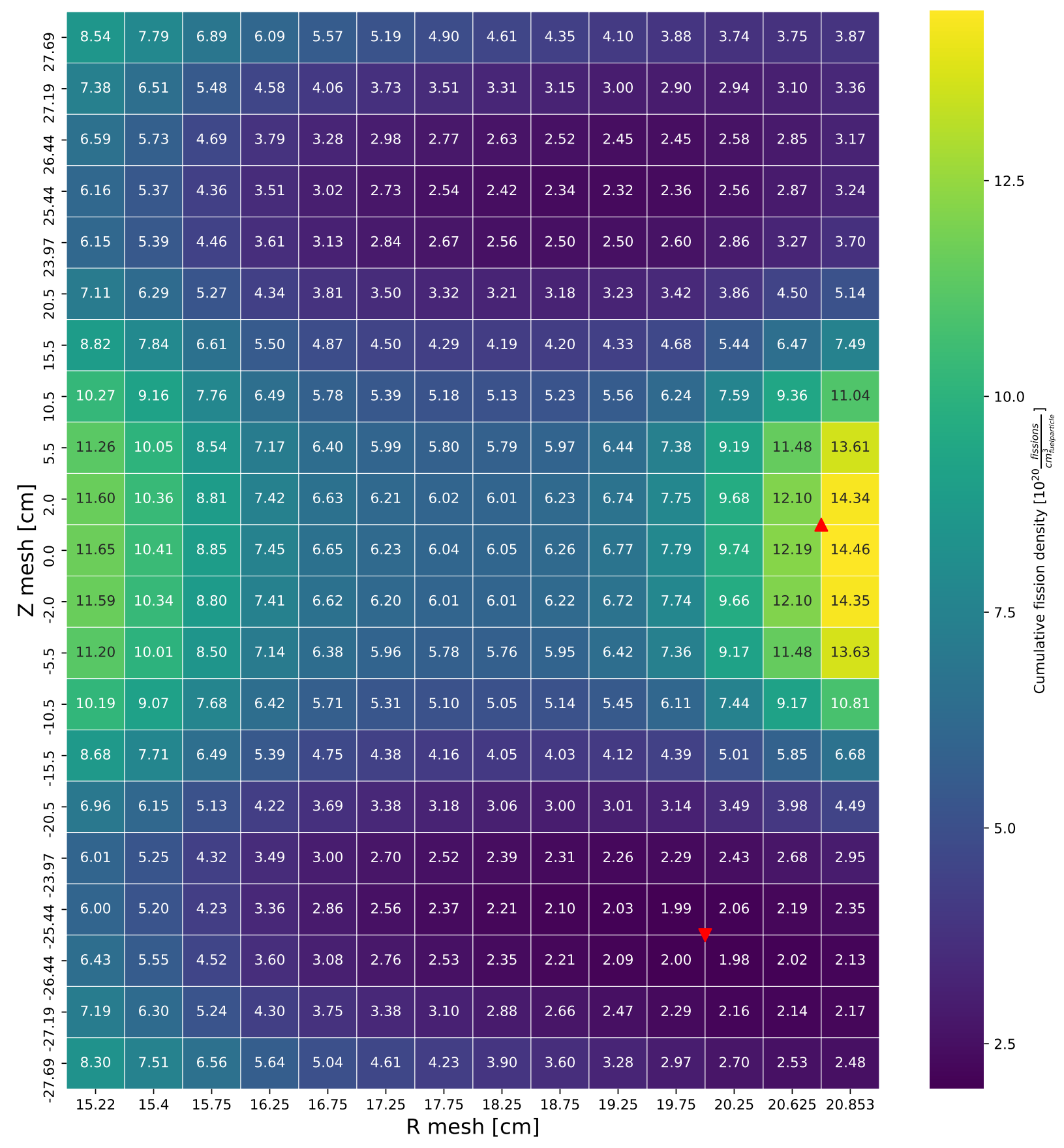

Figure 141. Cumulative fission density distribution for alternate 3 design OFE region on day 15 (see Section 7.4.5). 


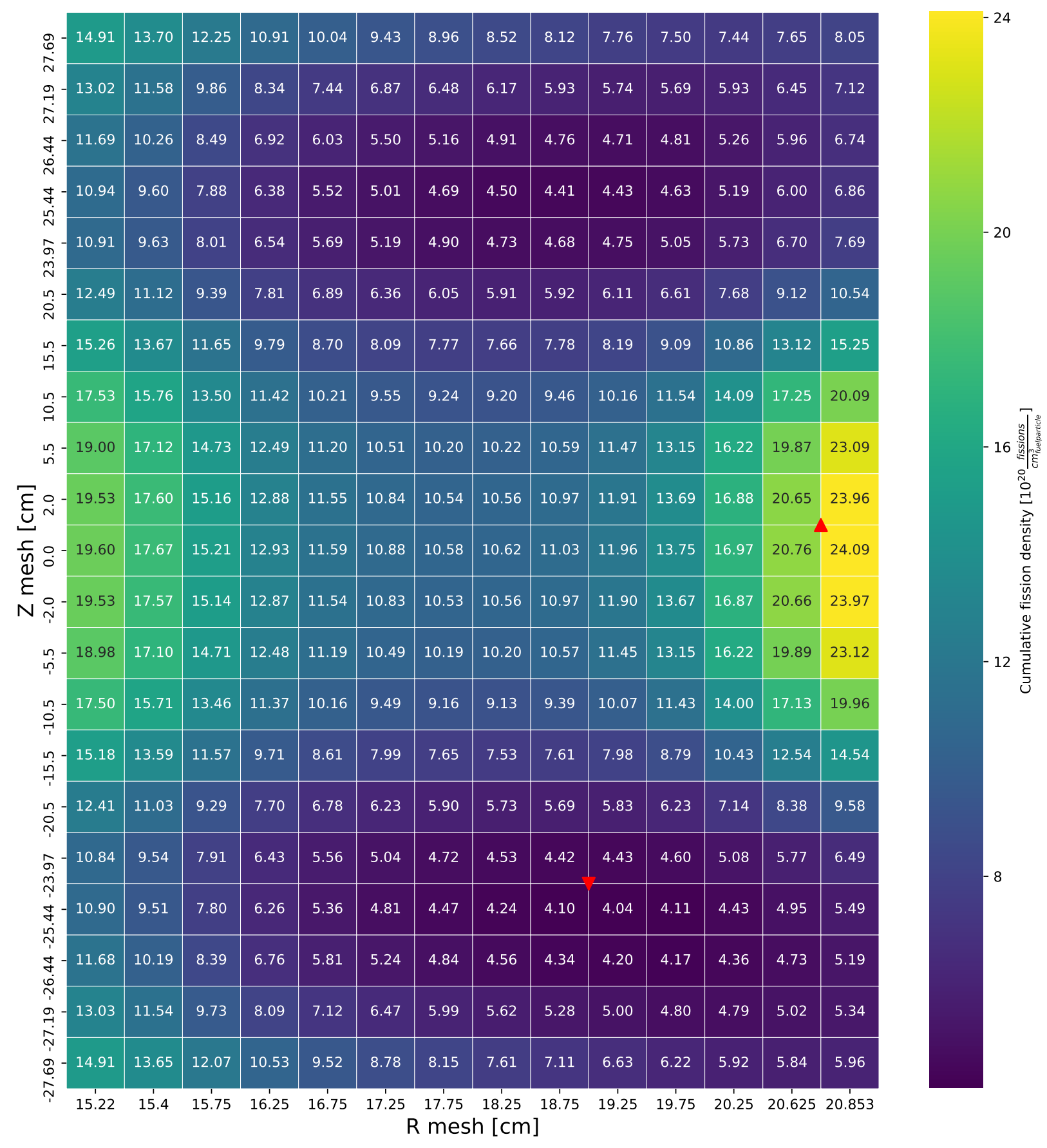

Figure 142. Cumulative fission density distribution for alternate 3 design OFE region on day 27 (see Section 7.4.5). 


\section{APPENDIX D-3. POWER DENSITY DISTRIBUTIONS FOR ALTERNATE 3 DESIGN}

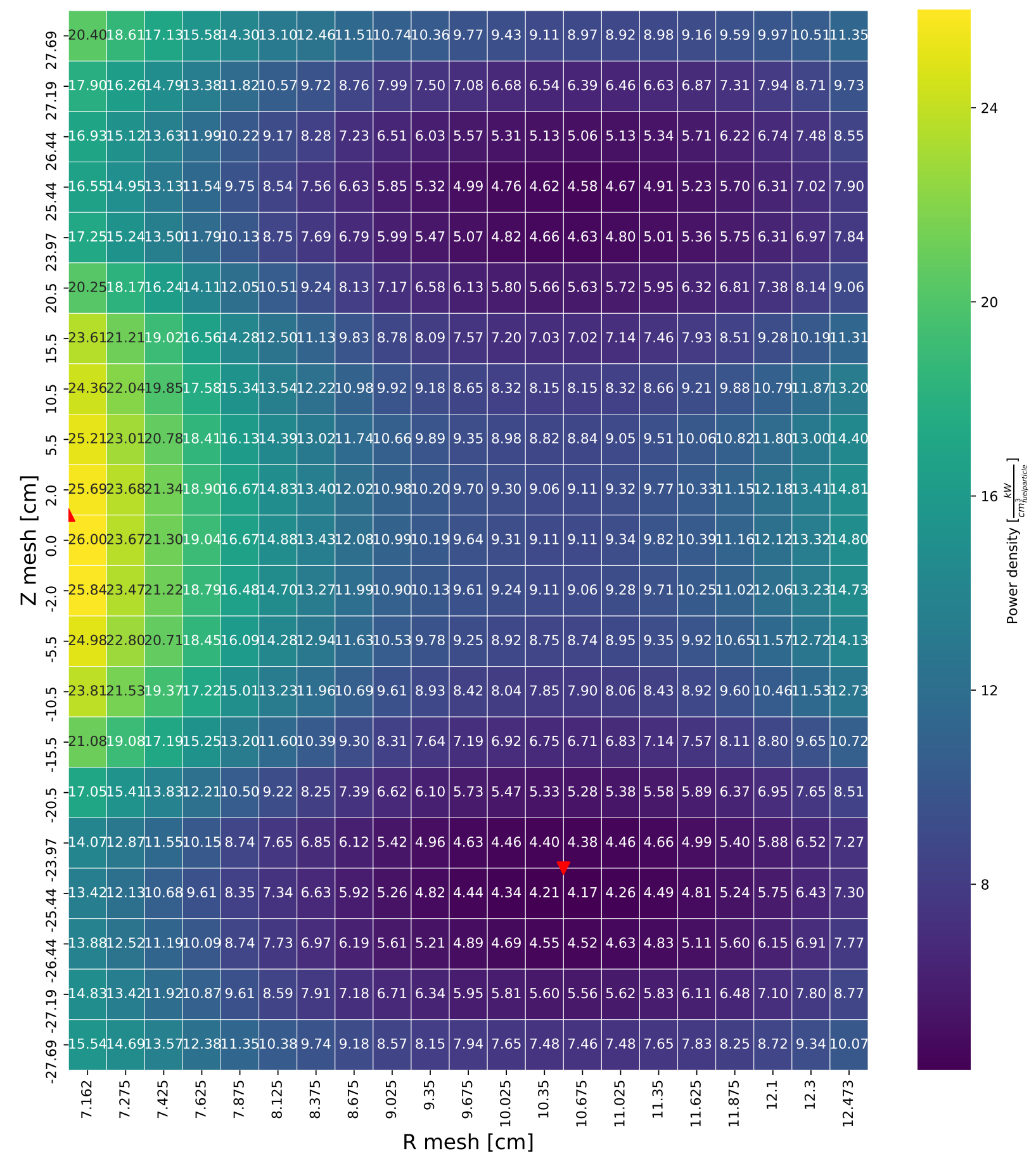

Figure 143. Power density distribution for alternate 3 design IFE region on day 0 (see Section 7.4.3). 
$-18.2517 .0715 .6814 .3913 .2612 .1411 .4110 .659 .78 \quad 9.27 \quad 8.828 .518 .398 .198 .218 .338 .668 .879 .269 .8410 .70$

เก $-22.8220 .7218 .7116 .5714 .4512 .7811 .4210 .219 .208 .548 .03 \quad 7.70 \quad 7.57 \quad 7.57 \quad 7.748 .138 .66 \quad 9.3710 .1211 .2112 .52$ 이

เก $-23.6921 .5619 .6617 .4215 .2513 .5112 .2111 .049 .999 .258 .758 .418 .258 .28 \quad 8.48 \quad 8.89 \quad 9.4310 .2211 .1412 .3013 .67$ เก

Е 우 $-24.2622 .2120 .2217 .9515 .6513 .9112 .5411 .3110 .169 .549 .038 .678 .528 .58 \quad 8.78 \quad 9.199 .7510 .5311 .5712 .7814 .17$ $\underline{\epsilon} \stackrel{\imath}{\sim}$

등 ㅇ․ -24.3422 .2620 .1818 .0215 .7014 .0012 .6311 .3110 .279 .539 .028 .648 .468 .518 .779 .179 .7610 .6311 .6312 .7914 .27$ $\stackrel{w}{\varepsilon}$

ᄃ요 $-24.1822 .0220 .0017 .8115 .5713 .8712 .5911 .3310 .229 .478 .928 .608 .458 .478 .729 .16 \quad 9.7910 .5311 .5212 .7014 .07$ $N \stackrel{\circ}{i}$

เ $-23.5921 .5319 .5717 .3815 .2013 .5112 .2010 .959 .90 \quad 9.198 .718 .38 \quad 8.238 .208 .398 .809 .3910 .1311 .0912 .2313 .66$

เก $-22.3020 .3818 .4616 .2314 .1812 .5411 .3010 .139 .11 \quad 8.447 .95 \quad 7.597 .417 .46 \quad 7.63 \quad 7.95 \quad 8.48 \quad 9.1310 .0111 .0312 .22$ 우

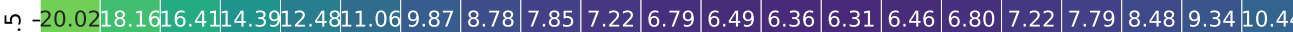
เุ

in $-16.3614 .7313 .1911 .6910 .038 .87 \quad 7.847 .006 .22 \quad 5.735 .38 \quad 5.14 \quad 5.004 .995 .13 \quad 5.33 \quad 5.70 \quad 6.14 \quad 6.707 .40 \quad 8.25$

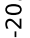

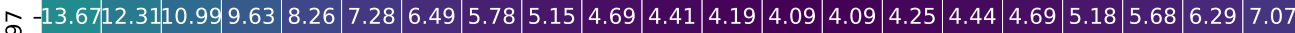
ஸ்

กั

\&

$\stackrel{\text { ำ }}{1}$

감

กิ ตุ

ஸ

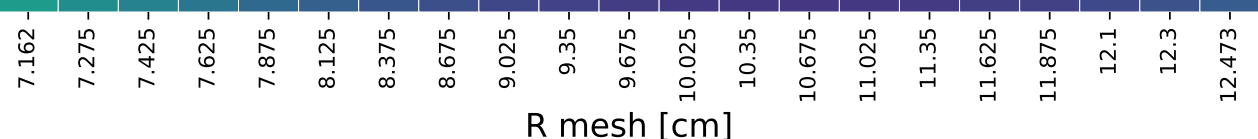

Figure 144. Power density distribution for alternate 3 design IFE region on day 1 (see Section 7.4.3). 


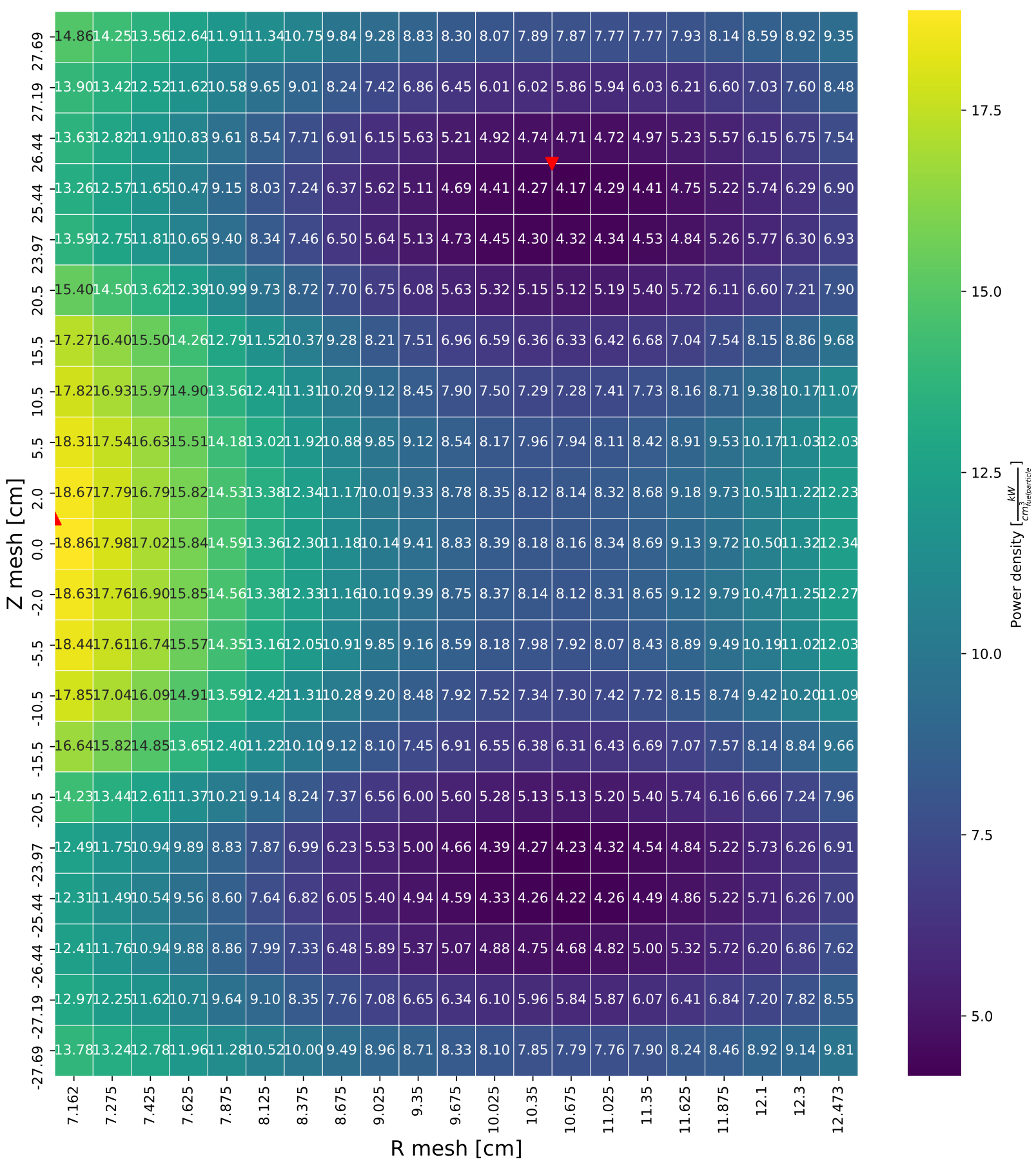

Figure 145. Power density distribution for alternate 3 design IFE region on day 15 (see Section 7.4.3). 


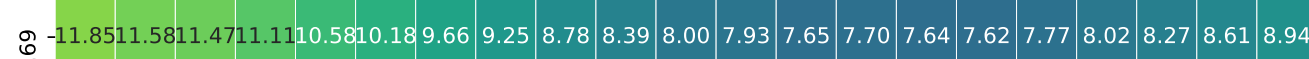
กิ

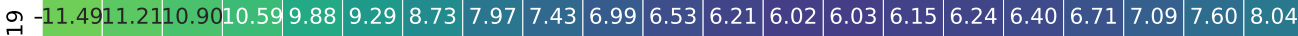
กิ

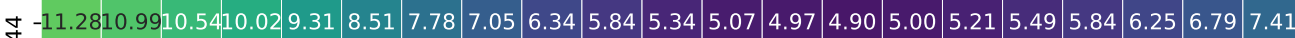
$\stackrel{\bullet}{\sim}$

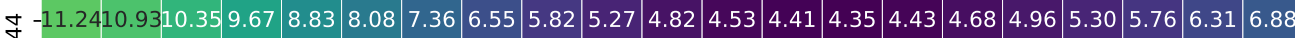

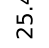

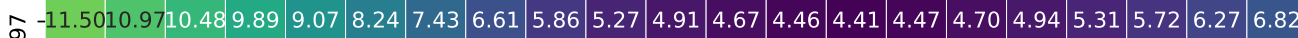
$\stackrel{\stackrel{\sim}{\sim}}{\sim}$

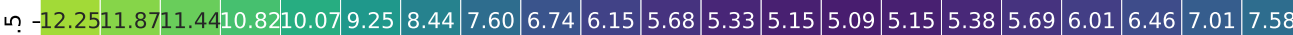
임

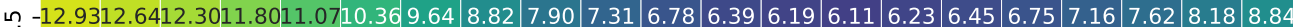
$\stackrel{\sim}{\sim}$

นก $-13.0512 .7312 .4712 .0111 .4610 .8310 .149 .38 \quad 8.55 \quad 7.947 .47 \quad 7.116 .916 .886 .967 .187 .54 \quad 7.98 \quad 8.429 .009 .61$ 이

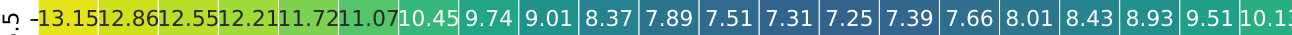
เก

Е 우 $-13.0912 .8912 .7112 .2711 .8311 .2510 .639 .979 .16 \quad 8.58 \quad 8.107 .74 \quad 7.48 \quad 7.43 \quad 7.55 \quad 7.83 \quad 8.198 .639 .059 .6110 .24$ $\underline{\varepsilon} \stackrel{\circ}{\sim}$

듬 우 $-13.3612 .9512 .8312 .4111 .9211 .3510 .6510 .009 .228 .56 \quad 8.097 .727 .54 \quad 7.467 .547 .86 \quad 8.228 .669 .189 .7410 .37$ $\stackrel{\text { 凹 }}{\varepsilon}$

○ $-13.5313 .0812 .7912 .4812 .0111 .2710 .6910 .059 .218 .618 .117 .73 \quad 7.52 \quad 7.507 .597 .86 \quad 8.158 .619 .109 .6110 .38$ $N \stackrel{\circ}{i}$

เ $-13.4213 .0812 .7512 .3611 .8611 .2210 .609 .889 .04 \quad 8.47 \quad 7.997 .59 \quad 7.42 \quad 7.347 .42 \quad 7.67 \quad 8.05 \quad 8.48 \quad 8.939 .4910 .14$

น $-13.3412 .9412 .6212 .2211 .6210 .9510 .329 .52 \quad 8.718 .087 .557 .18 \quad 7.006 .997 .07 \quad 7.317 .67 \quad 8.108 .609 .129 .79$ 우

$-13.0012 .6612 .3311 .7611 .0310 .319 .59 \quad 8.787 .957 .33 \quad 6.86 \quad 6.46 \quad 6.30 \quad 6.246 .326 .596 .91 \quad 7.34 \quad 7.82 \quad 8.358 .96$ เก่

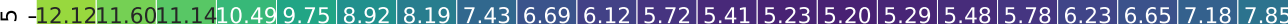
$\stackrel{\circ}{\Upsilon}$

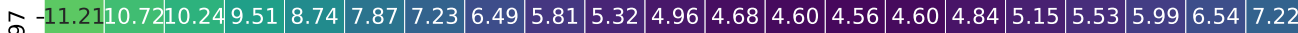
$\stackrel{\sim}{\sim}$

$\forall-11.0410 .609 .88$
$\forall$ $\stackrel{\sim}{\sim}$

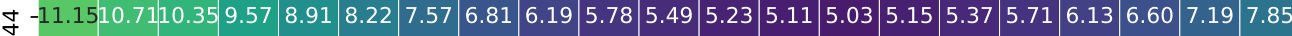
$\stackrel{\bullet}{\oplus}$

옥-11.6311.0710.8310.339.65 9.10 $8.518 .06 \quad 7.43 \quad 7.056 .696 .486 .36 \quad 6.27 \quad 6.306 .626 .88 \quad 7.15 \quad 7.64 \quad 8.00 \quad 8.62$ ヘิ

응 -12.0011.5011.3510.9510.5810.129.84 9.47 $9.06 \quad 8.558 .398 .21 \quad 8.17 \quad 7.978 .068 .178 .248 .518 .879 .169 .71$ ஸิ

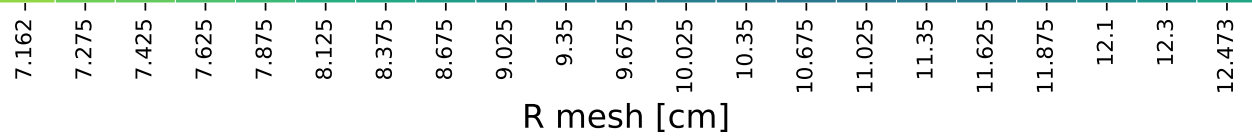

Figure 146. Power density distribution for alternate 3 design IFE region on day 27 (see Section 7.4.3). 


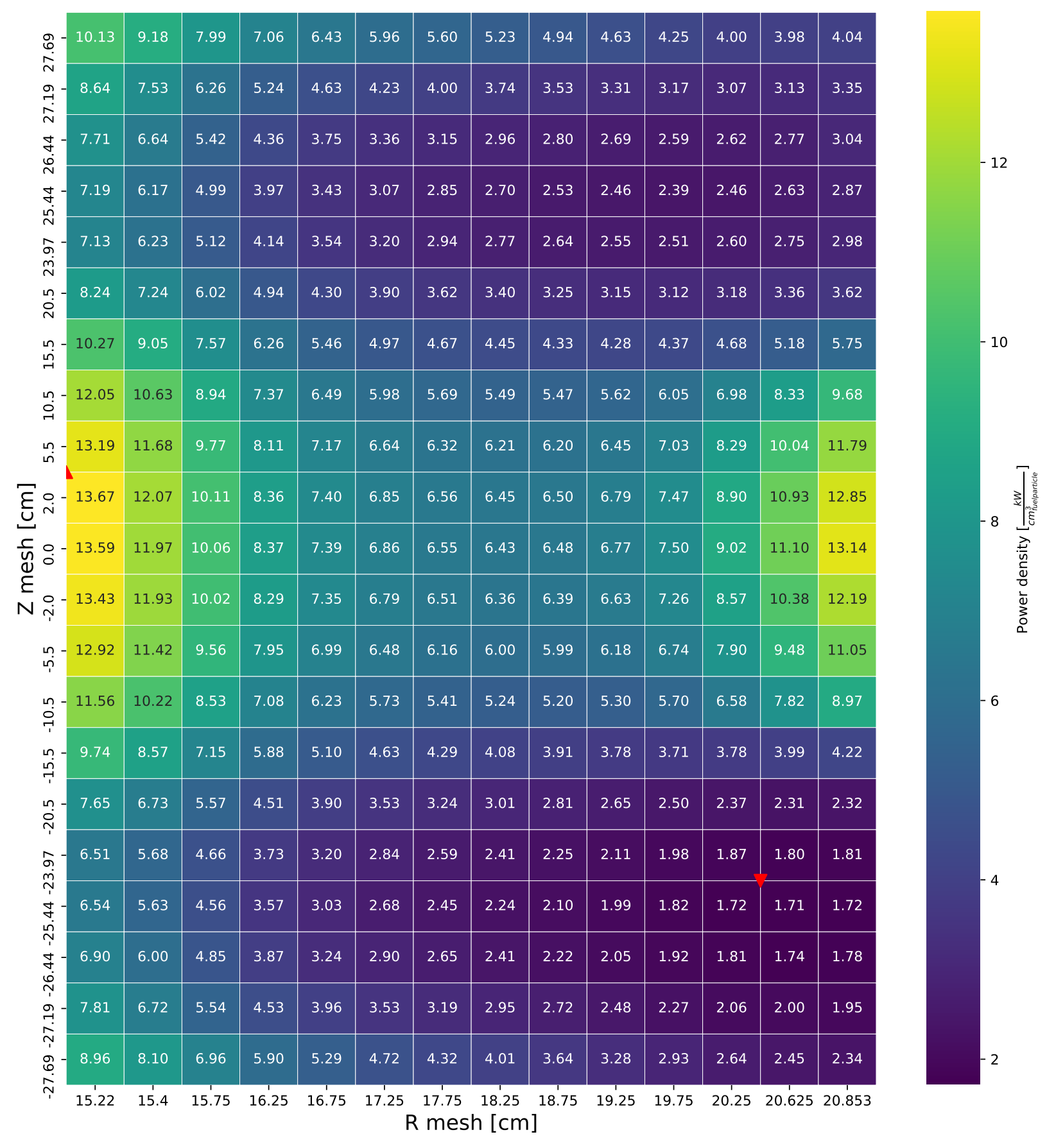

Figure 147. Power density distribution for alternate 3 design OFE region on day 0 (see Section 7.4.3). 


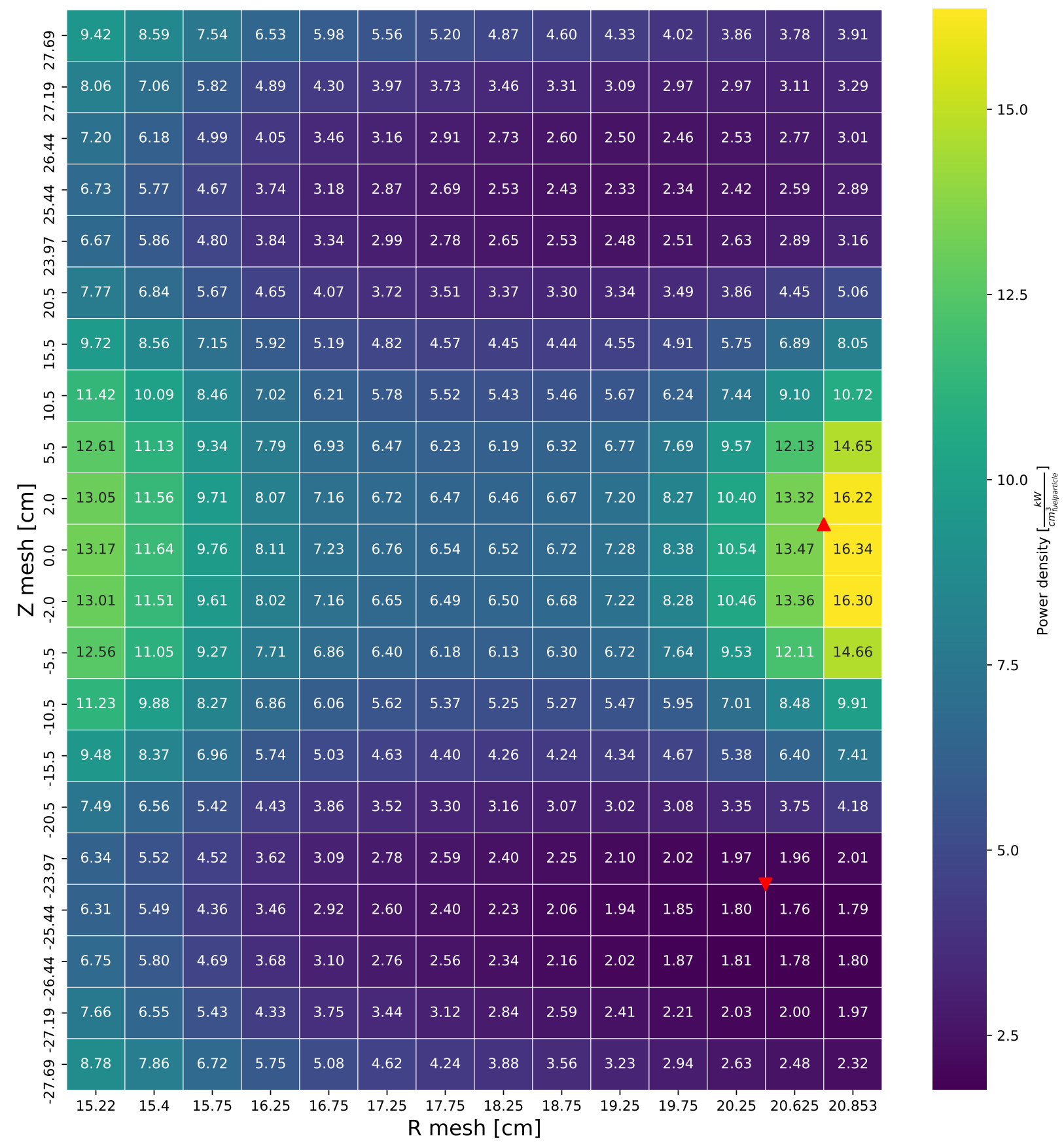

Figure 148. Power density distribution for alternate 3 design OFE region on day 1 (see Section 7.4.3). 


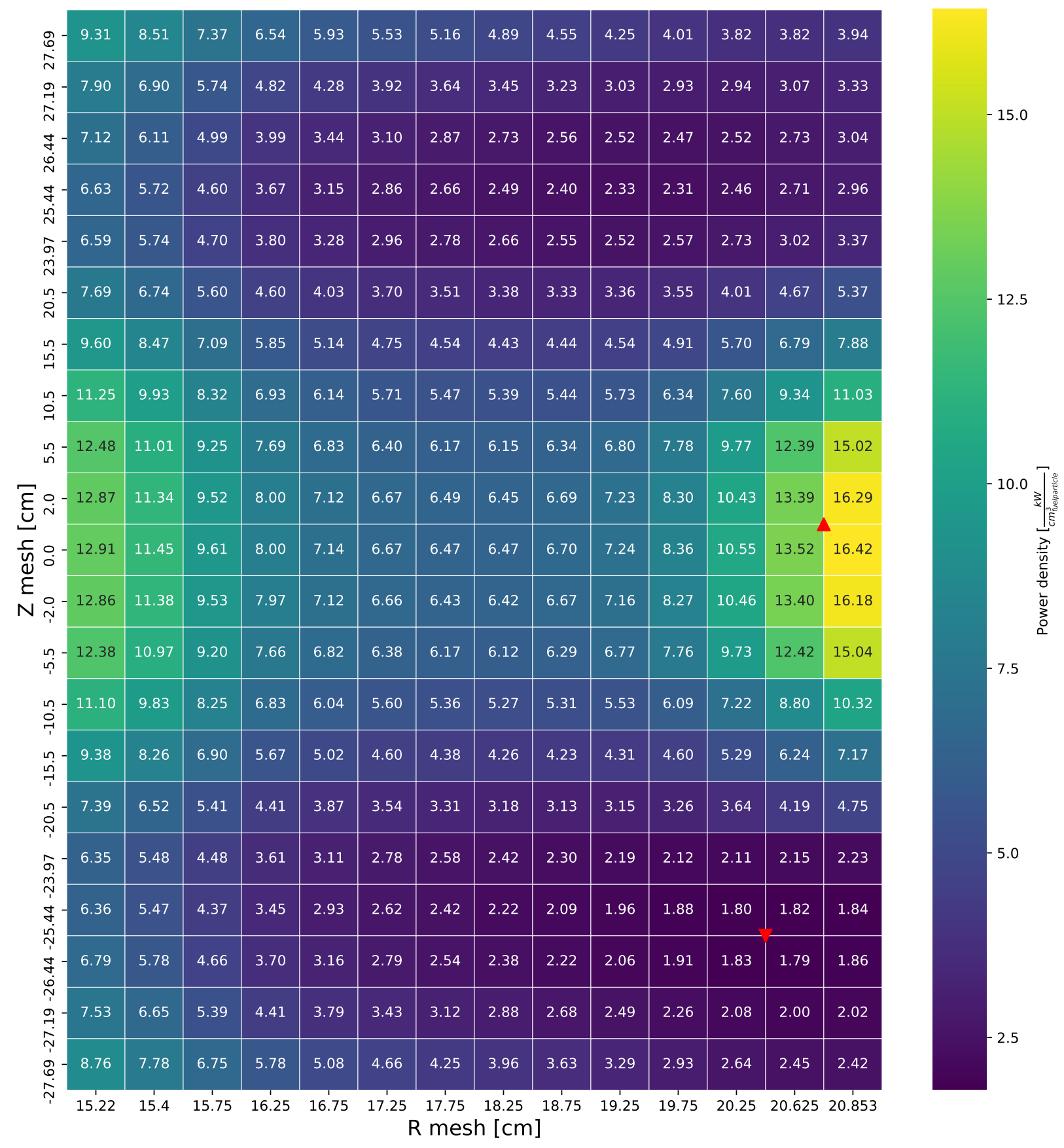

Figure 149. Power density distribution for alternate 3 design OFE region on day 2 (see Section 7.4.3). 


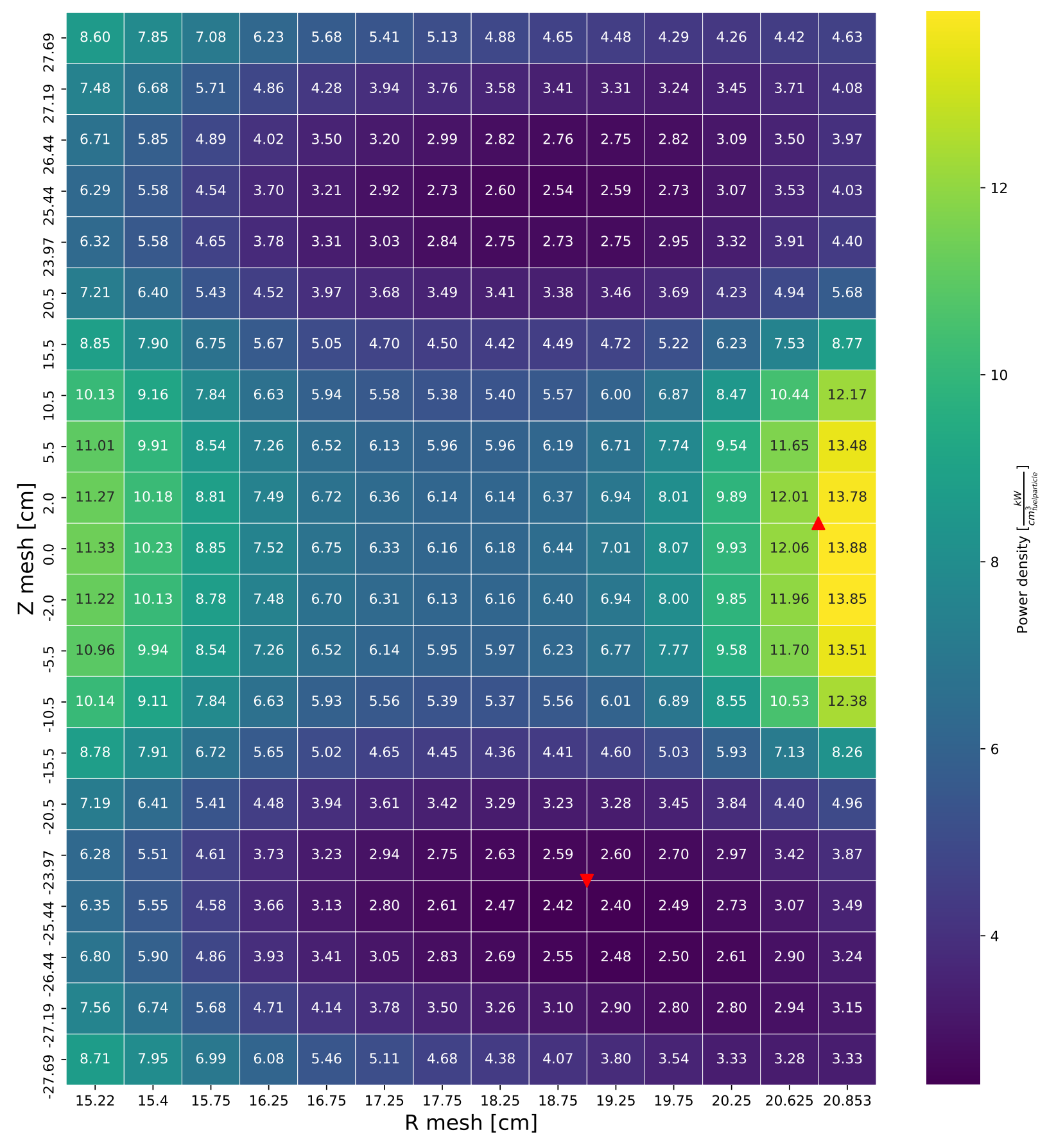

Figure 150. Power density distribution for alternate 3 design OFE region on day 15 (see Section 7.4.3). 


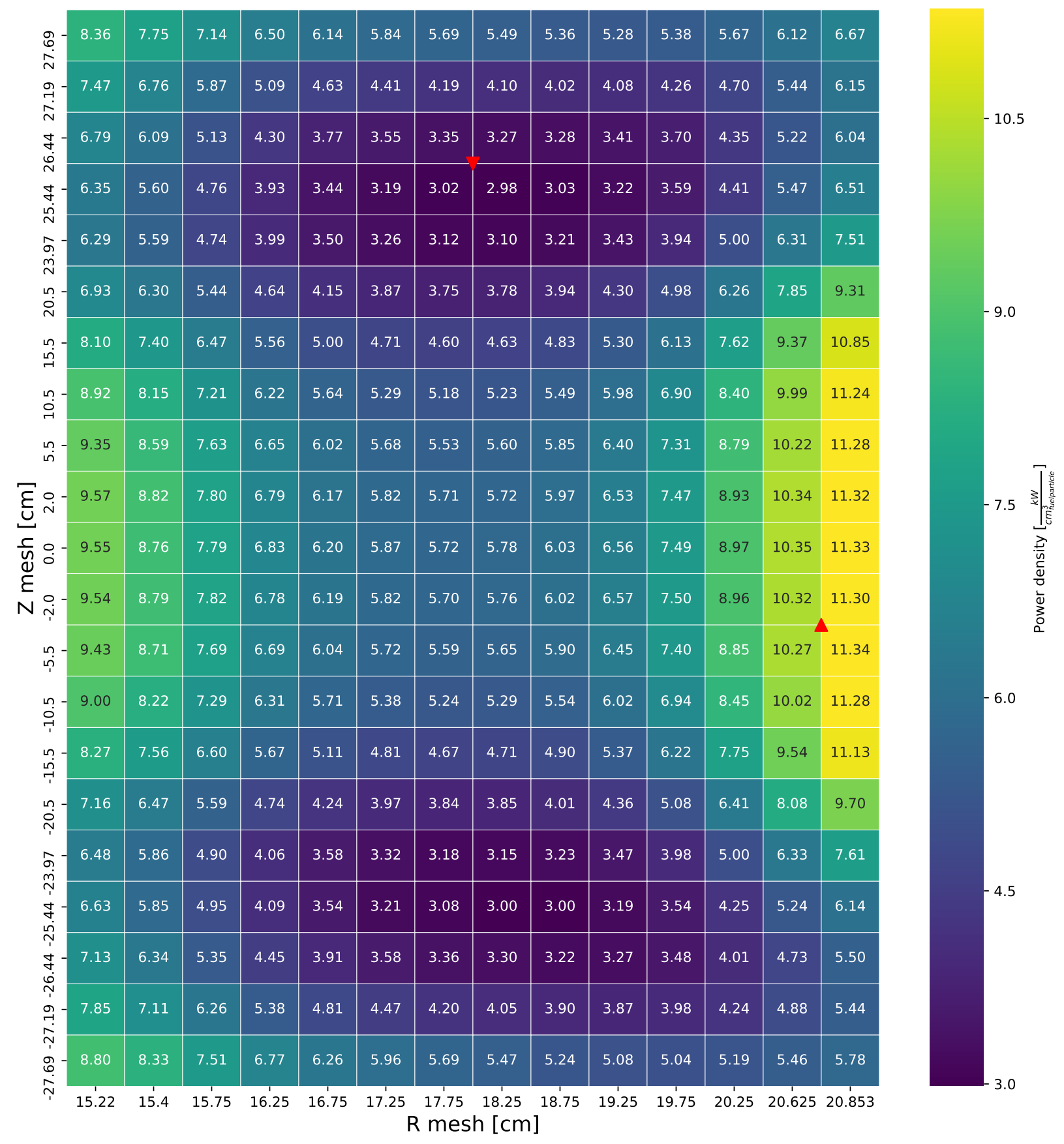

Figure 151. Power density distribution for alternate 3 design OFE region on day 27 (see Section 7.4.3). 


\section{APPENDIX D-4. HEAT FLUX DISTRIBUTIONS FOR ALTERNATE 3 DESIGN}

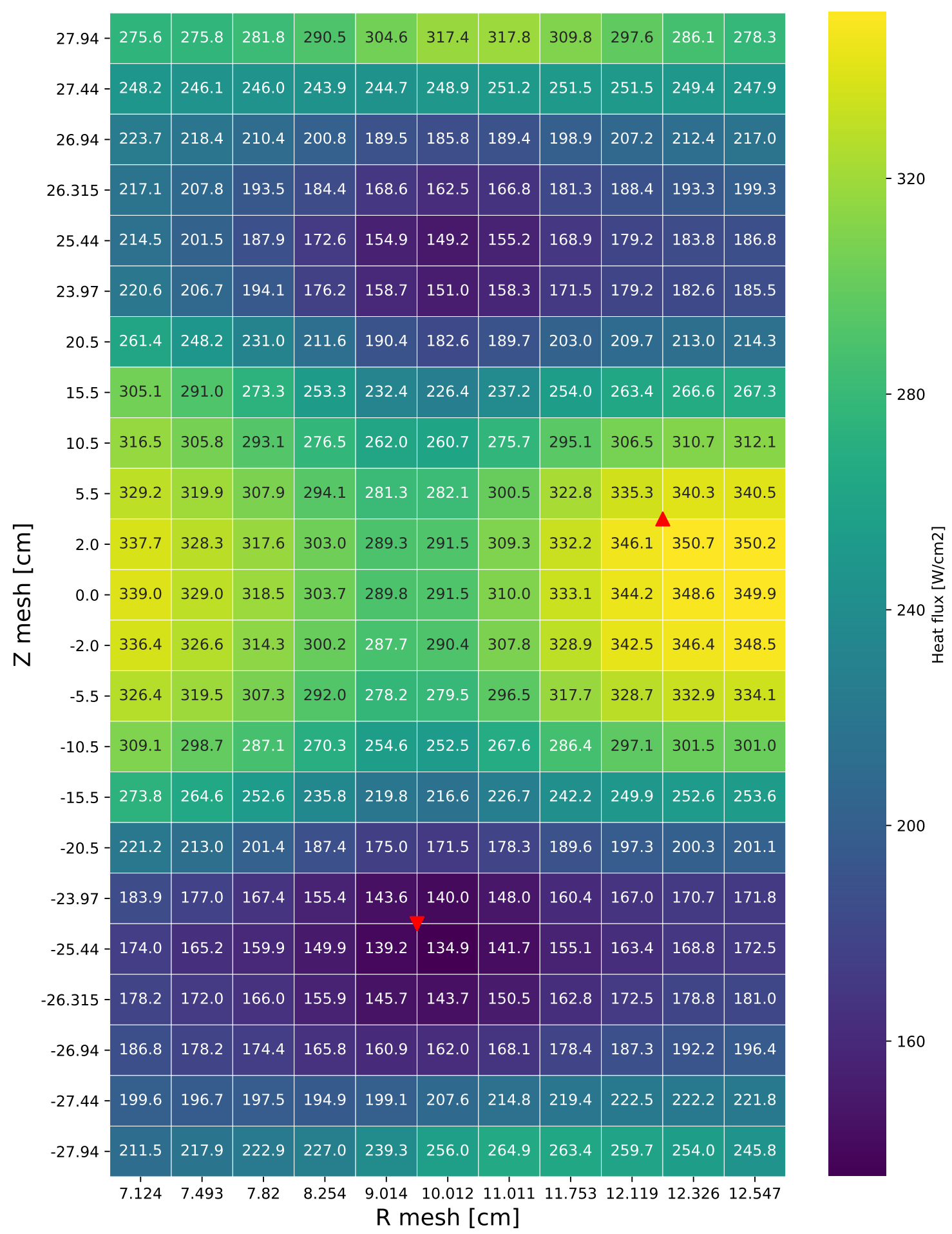

Figure 152. Heat flux distribution for alternate 3 design IFE region on day 0 (see Section 7.4.4). 


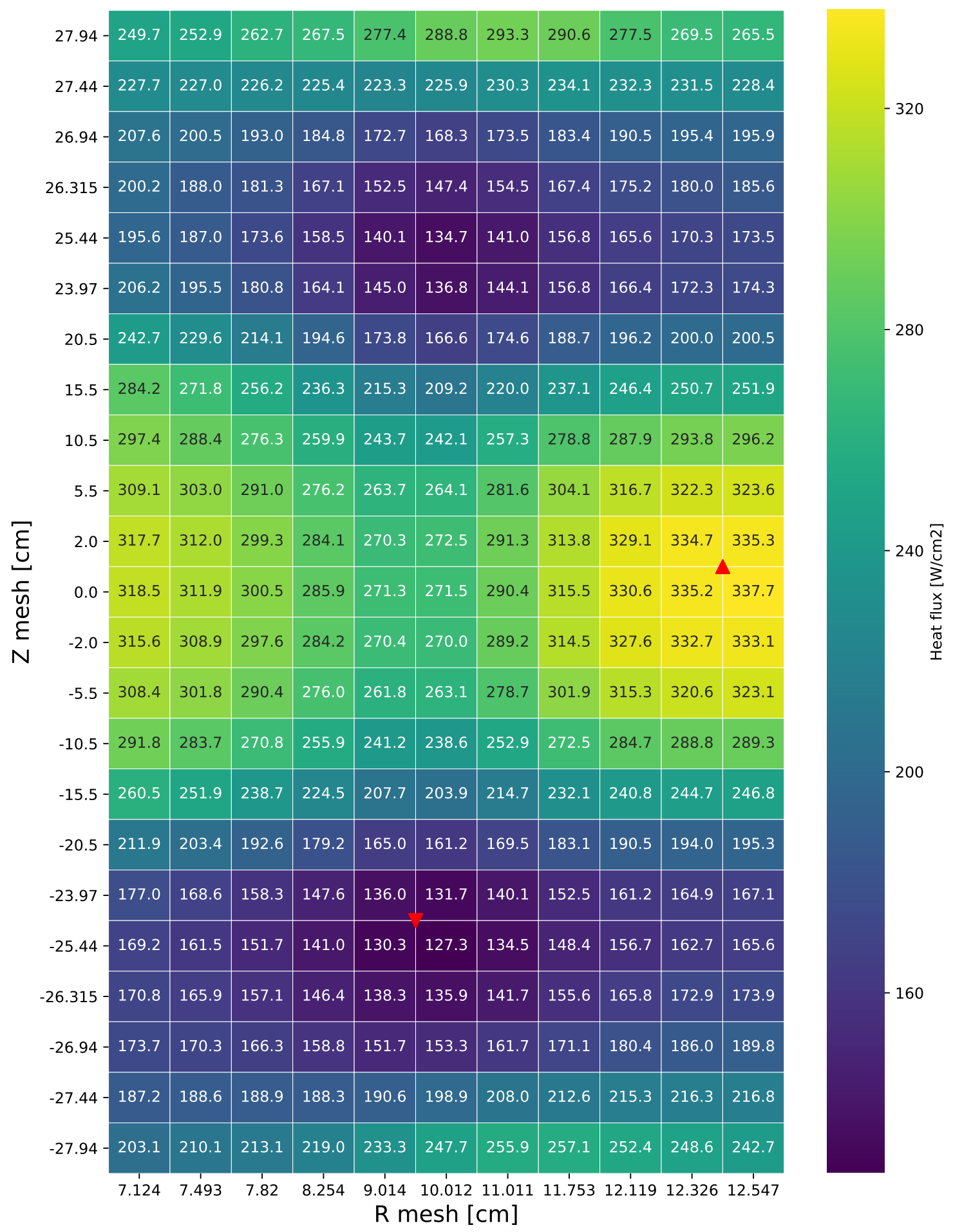

Figure 153. Heat flux distribution for alternate 3 design IFE region on day 1 (see Section 7.4.4). 


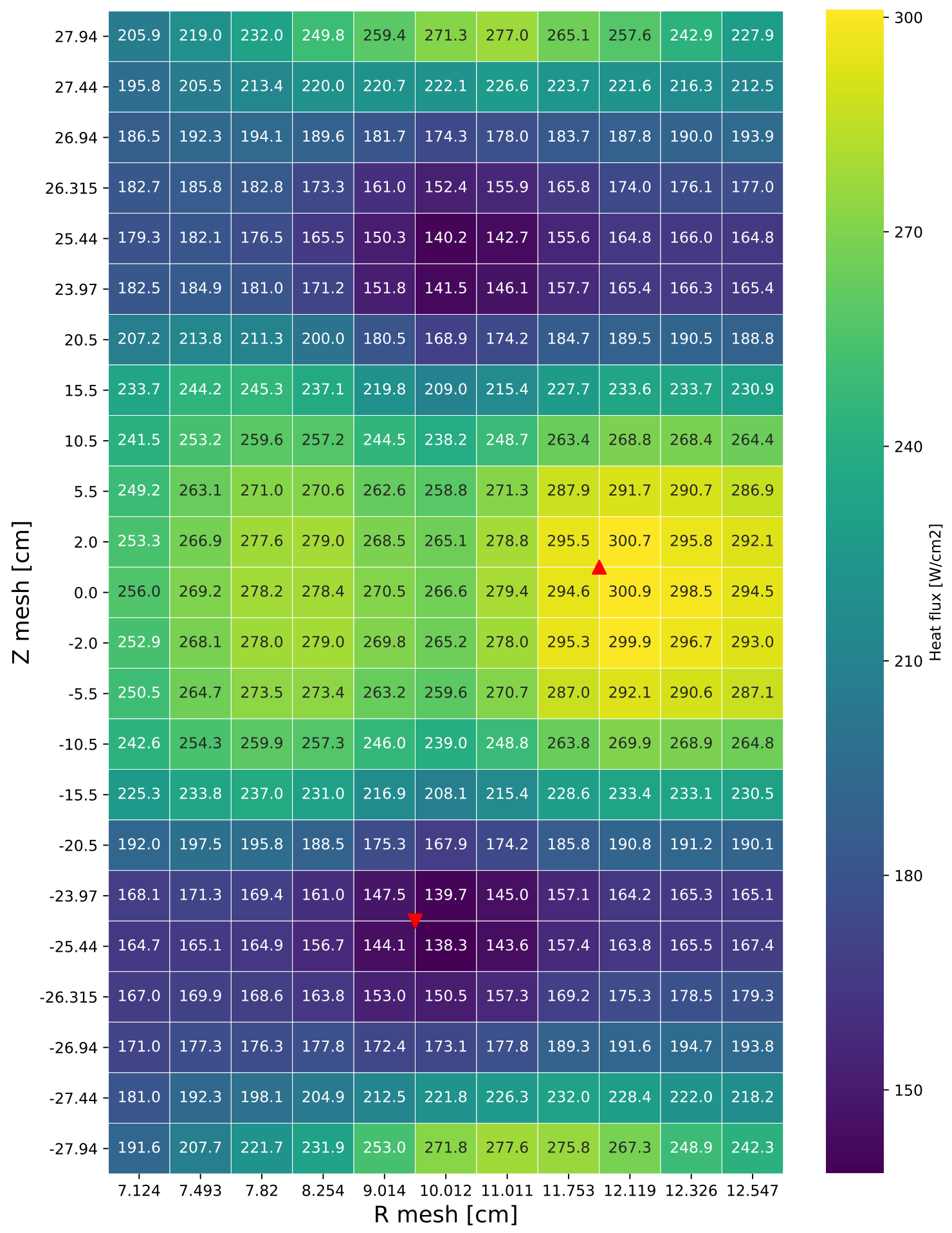

Figure 154. Heat flux distribution for alternate 3 design IFE region on day 15 (see Section 7.4.4). 


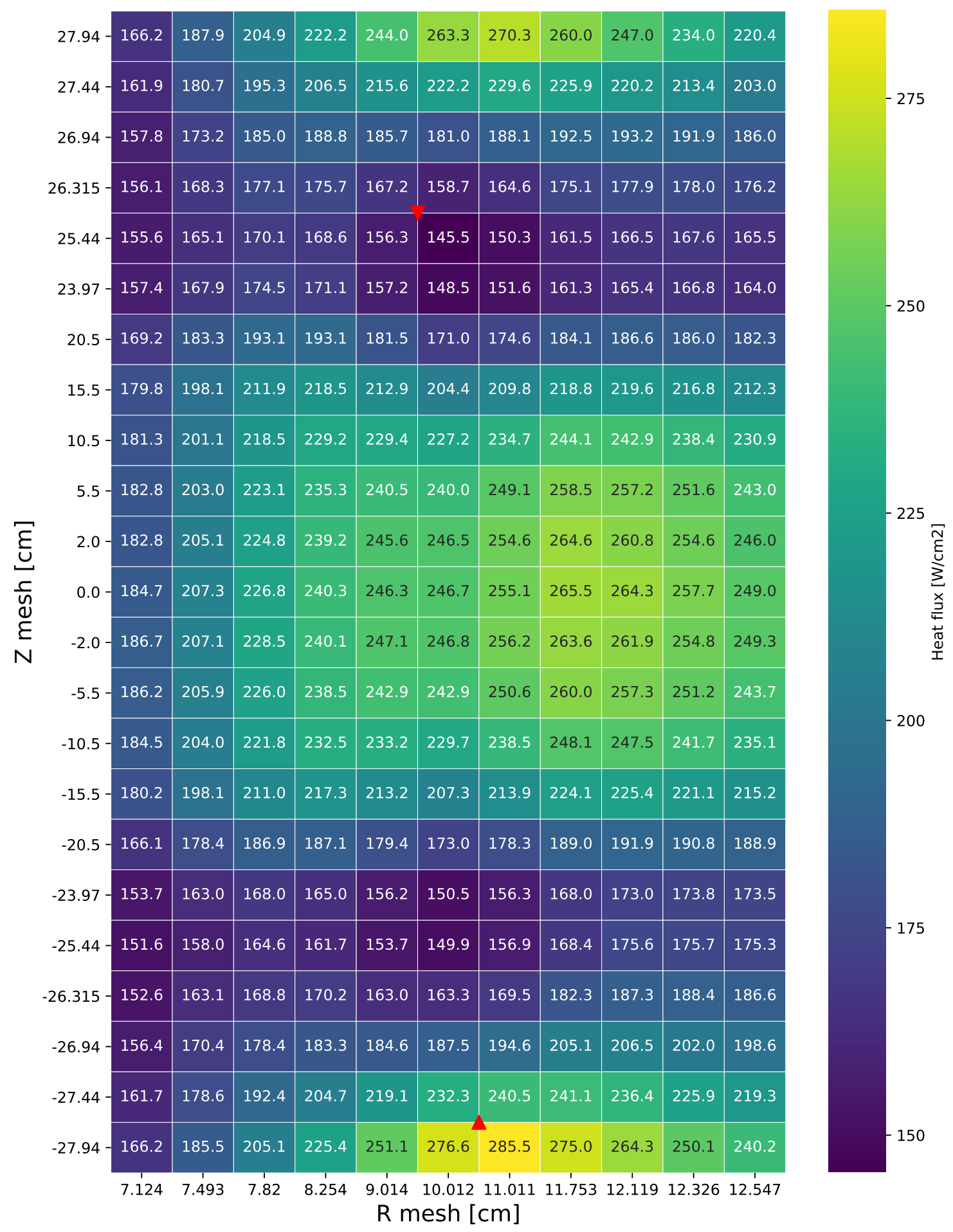

Figure 155. Heat flux distribution for alternate 3 design IFE region on day 27 (see Section 7.4.4). 


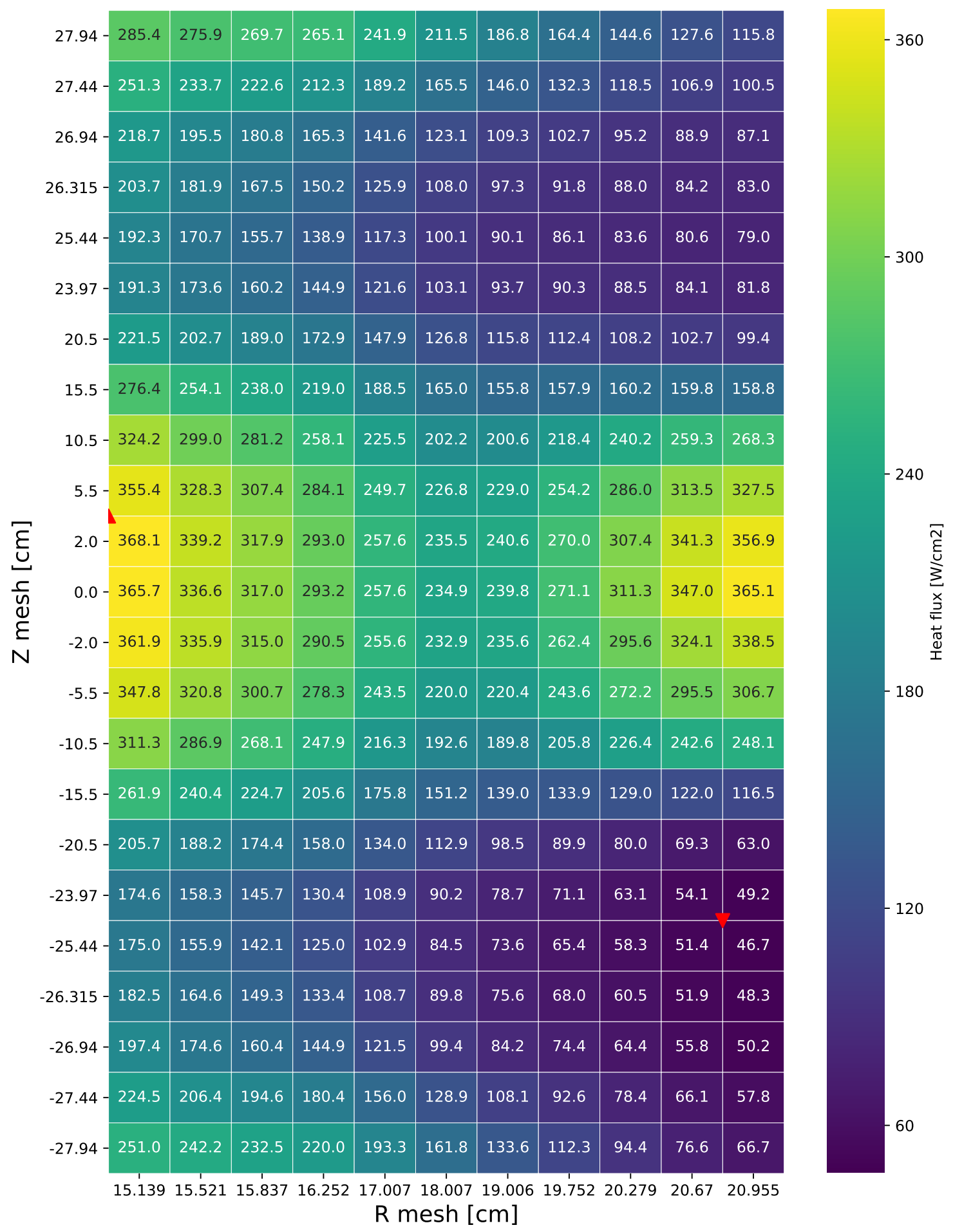

Figure 156. Heat flux distribution for alternate 3 design OFE region on day 0 (see Section 7.4.4). 


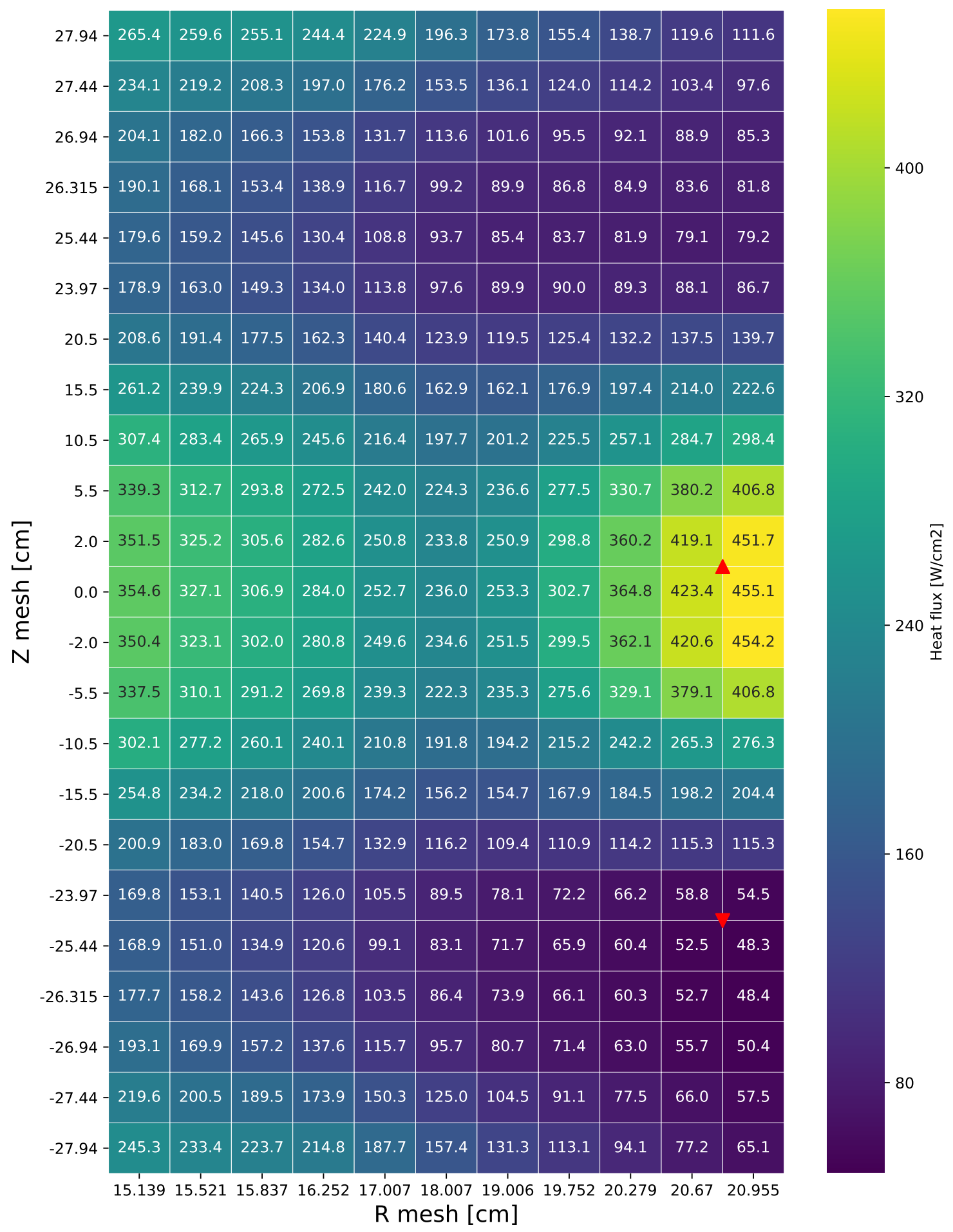

Figure 157. Heat flux distribution for alternate 3 design OFE region on day 1 (see Section 7.4.4). 


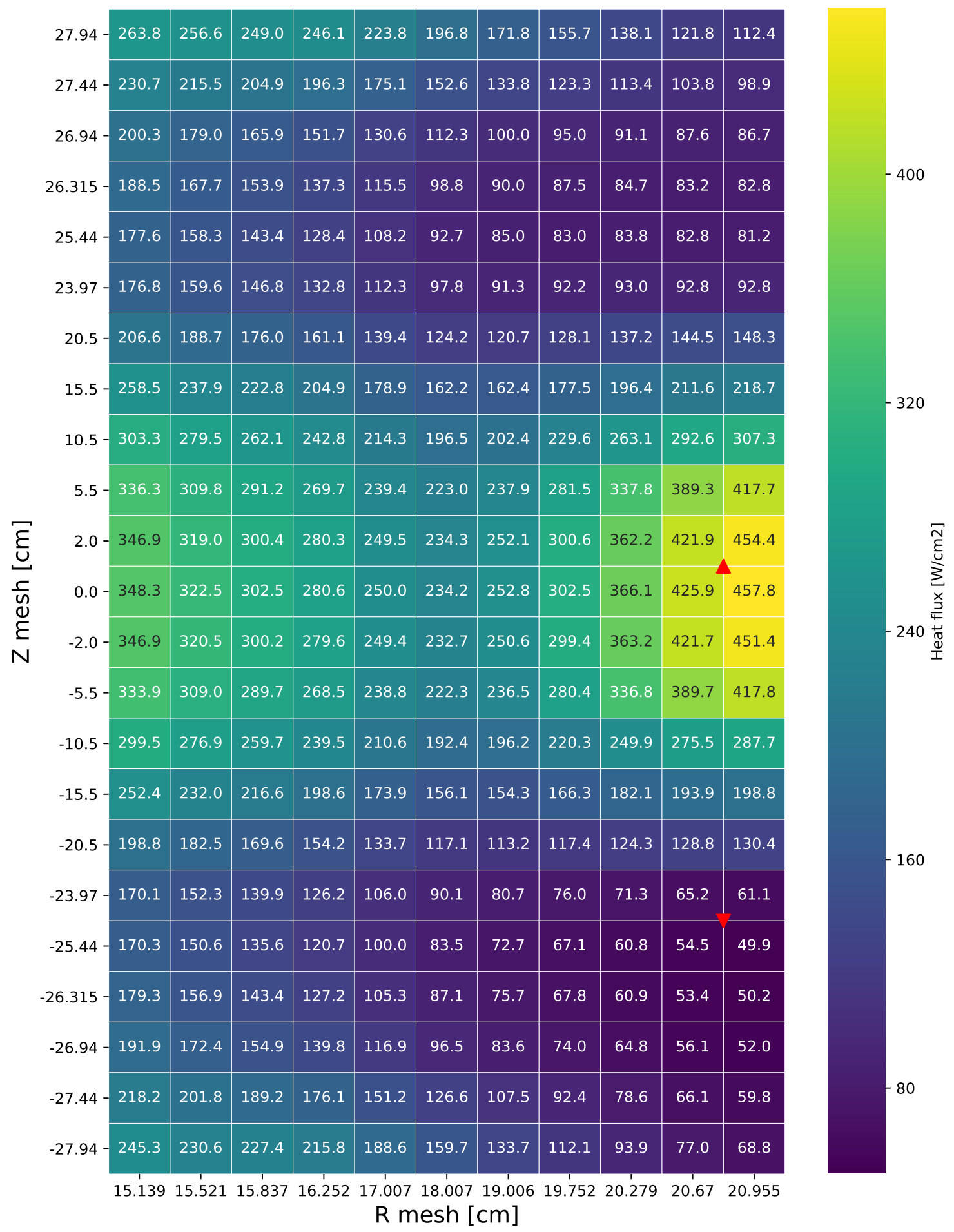

Figure 158. Heat flux distribution for alternate 3 design OFE region on day 2 (see Section 7.4.4). 


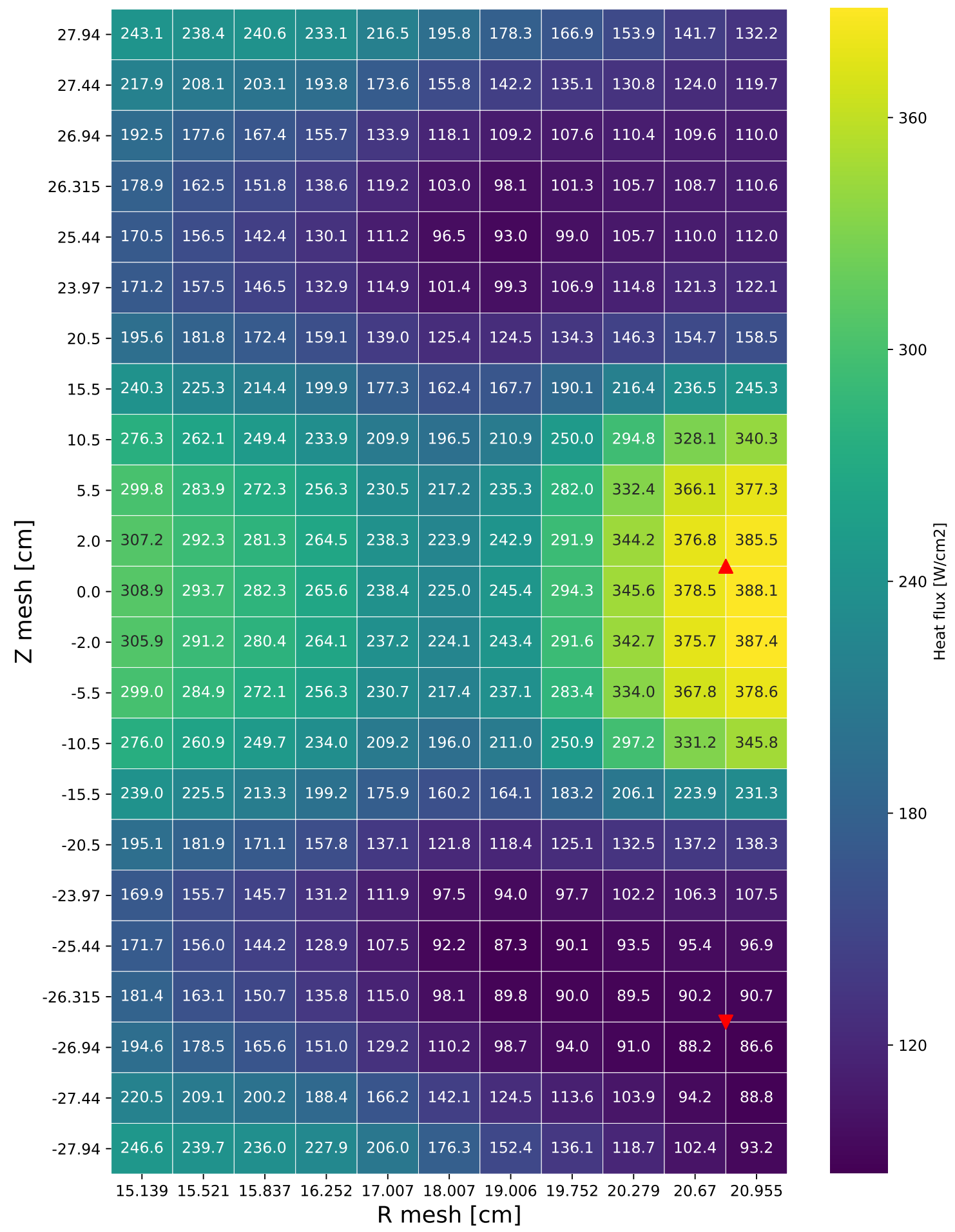

Figure 159. Heat flux distribution for alternate 3 design OFE region on day 15 (see Section 7.4.4). 


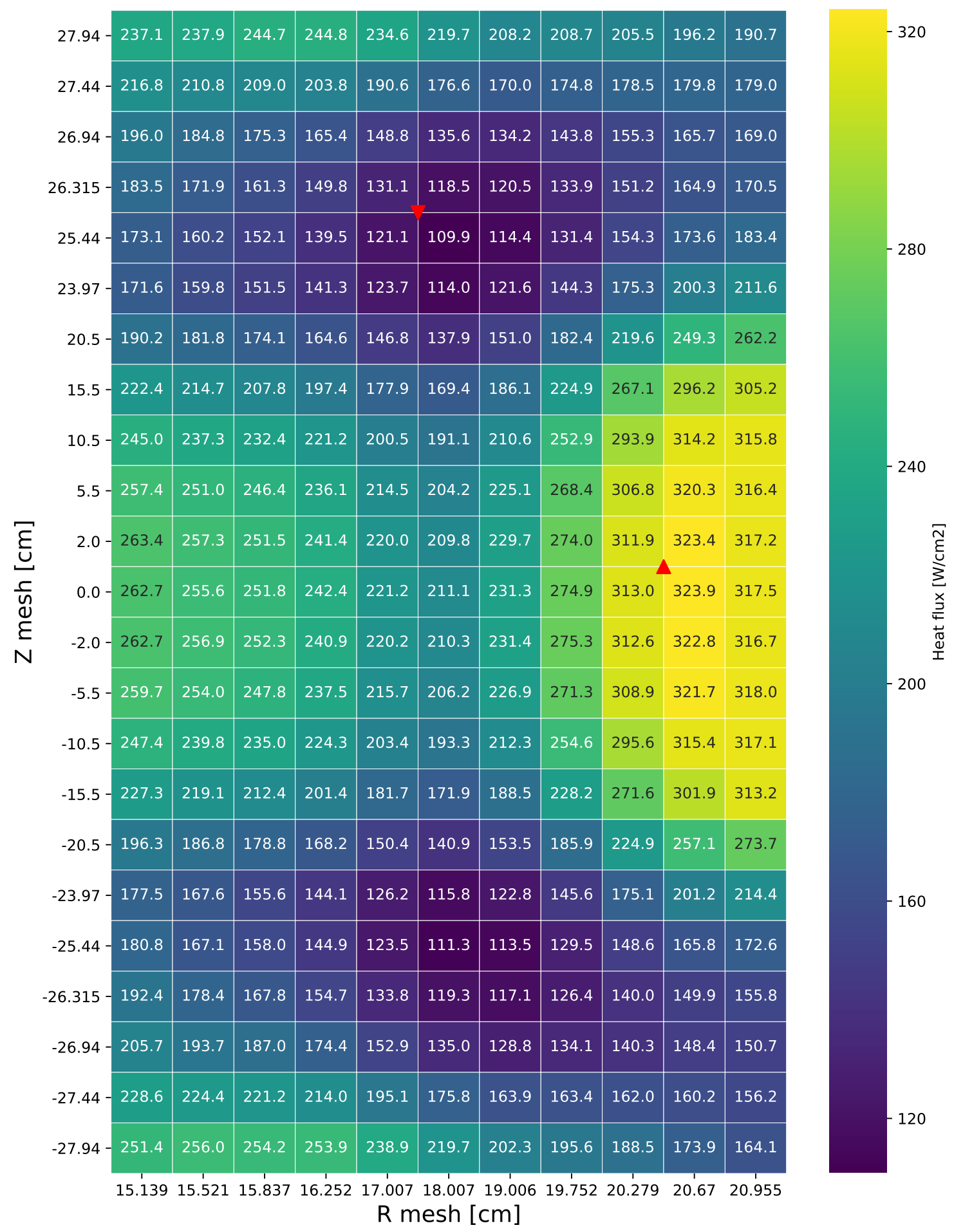

Figure 160. Heat flux distribution for alternate 3 design OFE region on day 27 (see Section 7.4.4). 